Cochrane Database of Systematic Reviews

\title{
Beta-blockers and inhibitors of the renin-angiotensin aldosterone system for chronic heart failure with preserved ejection fraction
} (Review)

Martin N, Manoharan K, Thomas J, Davies C, Lumbers RT

Martin N, Manoharan K, Thomas J, Davies C, Lumbers RT.

Beta-blockers and inhibitors of the renin-angiotensin aldosterone system for chronic heart failure with preserved ejection fraction.

Cochrane Database of Systematic Reviews 2018, Issue 6. Art. No.: CD012721.

DOI: 10.1002/14651858.CD012721.pub2.

www.cochranelibrary.com

Beta-blockers and inhibitors of the renin-angiotensin aldosterone system for chronic heart failure with preserved ejection fraction (Review) 
TABLE OF CONTENTS

HEADER

ABSTRACT

PLAIN LANGUAGE SUMMARY

SUMMARY OF FINDINGS

BACKGROUND

OBJECTIVES

METHODS

Figure 1.

RESULTS

Figure 2.

Figure 3.

DISCUSSION

AUTHORS' CONCLUSIONS

ACKNOWLEDGEMENTS

REFERENCES

CHARACTERISTICS OF STUDIES

DATA AND ANALYSES

Analysis 1.1. Comparison 1 Beta-blockers versus placebo or no treatment, Outcome 1 Cardiovascular mortality (RR). ............

Analysis 1.2. Comparison 1 Beta-blockers versus placebo or no treatment, Outcome 2 Heart failure hospitalisation (RR). .......

Analysis 1.3. Comparison 1 Beta-blockers versus placebo or no treatment, Outcome 3 All-cause mortality (RR). .....................

Analysis 1.4. Comparison 1 Beta-blockers versus placebo or no treatment, Outcome 4 Quality of life (Minnesota). ..................

Analysis 1.5. Comparison 1 Beta-blockers versus placebo or no treatment, Outcome 5 Withdrawal due to adverse event. .......

Analysis 2.1. Comparison 2 Mineralocorticoid receptor antagonists versus placebo or no treatment, Outcome 1 Cardiovascular mortality (RR).

Analysis 2.2. Comparison 2 Mineralocorticoid receptor antagonists versus placebo or no treatment, Outcome 2 Heart failure hospitalisation (RR).

Analysis 2.3. Comparison 2 Mineralocorticoid receptor antagonists versus placebo or no treatment, Outcome 3 Heart failure hospitalisation (HR).

Analysis 2.4. Comparison 2 Mineralocorticoid receptor antagonists versus placebo or no treatment, Outcome 4 Hyperkalaemia.

Analysis 2.5. Comparison 2 Mineralocorticoid receptor antagonists versus placebo or no treatment, Outcome 5 All-cause mortality (RR).

Analysis 2.6. Comparison 2 Mineralocorticoid receptor antagonists versus placebo or no treatment, Outcome 6 Quality of life. . Analysis 2.7. Comparison 2 Mineralocorticoid receptor antagonists versus placebo or no treatment, Outcome 7 Quality of life (KCCQ).

Analysis 2.8. Comparison 2 Mineralocorticoid receptor antagonists versus placebo or no treatment, Outcome 8 Quality of life (Minnesota).

Analysis 2.9. Comparison 2 Mineralocorticoid receptor antagonists versus placebo or no treatment, Outcome 9 Withdrawal due to adverse event.

Analysis 3.1. Comparison 3 Angiotensin converting enzyme inhibitors versus placebo or no treatment, Outcome 1 Cardiovascular mortality (RR).

Analysis 3.2. Comparison 3 Angiotensin converting enzyme inhibitors versus placebo or no treatment, Outcome 2 Heart failure hospitalisation (RR).

Analysis 3.3. Comparison 3 Angiotensin converting enzyme inhibitors versus placebo or no treatment, Outcome 3 Hyperkalaemia.

Analysis 3.4. Comparison 3 Angiotensin converting enzyme inhibitors versus placebo or no treatment, Outcome 4 All-cause mortality (RR).

Analysis 3.5. Comparison 3 Angiotensin converting enzyme inhibitors versus placebo or no treatment, Outcome 5 Quality of life (Minnesota).

Analysis 3.6. Comparison 3 Angiotensin converting enzyme inhibitors versus placebo or no treatment, Outcome 6 Withdrawal due to adverse event.

Analysis 4.1. Comparison 4 Angiotensin receptor blockers versus placebo or no treatment, Outcome 1 Cardiovascular mortality (RR).

Beta-blockers and inhibitors of the renin-angiotensin aldosterone system for chronic heart failure with preserved ejection fraction 
Analysis 4.2. Comparison 4 Angiotensin receptor blockers versus placebo or no treatment, Outcome 2 Cardiovascular mortality (HR).

Analysis 4.3. Comparison 4 Angiotensin receptor blockers versus placebo or no treatment, Outcome 3 Heart failure hospitalisation (RR).

Analysis 4.4. Comparison 4 Angiotensin receptor blockers versus placebo or no treatment, Outcome 4 Heart failure hospitalisation (HR).

Analysis 4.5. Comparison 4 Angiotensin receptor blockers versus placebo or no treatment, Outcome 5 Hyperkalaemia. ......... Analysis 4.6. Comparison 4 Angiotensin receptor blockers versus placebo or no treatment, Outcome 6 All-cause mortality (RR). Analysis 4.7. Comparison 4 Angiotensin receptor blockers versus placebo or no treatment, Outcome 7 All-cause mortality (HR). Analysis 4.8. Comparison 4 Angiotensin receptor blockers versus placebo or no treatment, Outcome 8 Quality of life (Minnesota).

Analysis 4.9. Comparison 4 Angiotensin receptor blockers versus placebo or no treatment, Outcome 9 Withdrawal due to adverse event.

APPENDICES

CONTRIBUTIONS OF AUTHORS 
[Intervention Review]

\section{Beta-blockers and inhibitors of the renin-angiotensin aldosterone system for chronic heart failure with preserved ejection fraction}

Nicole Martin ${ }^{1}$, Karthick Manoharan², James Thomas ${ }^{3}$, Ceri Davies ${ }^{4}$, R Thomas Lumbers ${ }^{5}$

1Farr Institute of Health Informatics Research, University College London, London, UK. 2Emergency Department, John Radcliffe Hospital, London, UK. ${ }^{3}$ EPPI-Centre, Social Science Research Unit, UCL Institute of Education, University College London, London, UK. ${ }^{4}$ Department of Cardiology, Barts Heart Centre, St Bartholomew's Hospital, London, UK. 5 Institute of Health Informatics, University College London, London, UK

Contact address: R Thomas Lumbers, Institute of Health Informatics, University College London, London, UK. t.lumbers@ucl.ac.uk.

Editorial group: Cochrane Heart Group.

Publication status and date: New, published in Issue 6, 2018.

Citation: Martin N, Manoharan K, Thomas J, Davies C, Lumbers RT. Beta-blockers and inhibitors of the renin-angiotensin aldosterone system for chronic heart failure with preserved ejection fraction. Cochrane Database of Systematic Reviews 2018, Issue 6. Art. No.:

CD012721. DOI: 10.1002/14651858.CD012721.pub2.

Copyright ( 2018 The Cochrane Collaboration. Published by John Wiley \& Sons, Ltd.

\section{A B S T R A C T}

\section{Background}

Beta-blockers and inhibitors of the renin-angiotensin aldosterone system improve survival and reduce morbidity in people with heart failure with reduced left ventricular ejection fraction. There is uncertainty whether these treatments are beneficial for people with heart failure with preserved ejection fraction and a comprehensive review of the evidence is required.

\section{Objectives}

To assess the effects of beta-blockers, angiotensin converting enzyme inhibitors, angiotensin receptor blockers, angiotensin receptor neprilysin inhibitors, and mineralocorticoid receptor antagonists in people with heart failure with preserved ejection fraction.

\section{Search methods}

We searched CENTRAL, MEDLINE, Embase and two clinical trial registries on 25 July 2017 to identify eligible studies. Reference lists from primary studies and review articles were checked for additional studies. There were no language or date restrictions.

\section{Selection criteria}

We included randomised controlled trials with a parallel group design enrolling adult participants with heart failure with preserved ejection fraction, defined by a left ventricular ejection fraction of greater than 40 percent.

\section{Data collection and analysis}

Two review authors independently selected studies for inclusion and extracted data. The outcomes assessed included cardiovascular mortality, heart failure hospitalisation, hyperkalaemia, all-cause mortality and quality of life. Risk ratios (RR) and, where possible, hazard ratios (HR) were calculated for dichotomous outcomes. For continuous data, mean difference (MD) or standardised mean difference (SMD) were calculated. We contacted trialists where neccessary to obtain missing data.

\section{Main results}

37 randomised controlled trials (207 reports) were included across all comparisons with a total of 18,311 participants.

Ten studies (3087 participants) investigating beta-blockers (BB) were included. A pooled analysis indicated a reduction in cardiovascular mortality ( $15 \%$ of participants in the intervention arm versus $19 \%$ in the control arm; RR $0.78 ; 95 \%$ confidence interval (CI) 0.62 to 0.99 ;

Beta-blockers and inhibitors of the renin-angiotensin aldosterone system for chronic heart failure with preserved ejection fraction 
number needed to treat to benefit (NNTB) 25; 1046 participants; 3 studies). However, the quality of evidence was low and no effect on cardiovascular mortality was observed when the analysis was limited to studies with a low risk of bias ( $\mathrm{RR} 0.81 ; 95 \% \mathrm{Cl} 0.50$ to $1.29 ; 643$ participants; 1 study). There was no effect on all-cause mortality, heart failure hospitalisation or quality of life measures, however there is uncertainty about these effects given the limited evidence available.

12 studies (4408 participants) investigating mineralocorticoid receptor antagonists (MRA) were included with the quality of evidence assessed as moderate. MRA treatment reduced heart failure hospitalisation ( $11 \%$ of participants in the intervention arm versus $14 \%$ in the control arm; RR 0.82; 95\% Cl 0.69 to 0.98; NNTB 41; 3714 participants; 3 studies; moderate-quality evidence) however, little or no effect on all-cause and cardiovascular mortality and quality of life measures was observed. MRA treatment was associated with a greater risk of hyperkalaemia ( $16 \%$ of participants in the intervention group versus $8 \%$ in the control group; RR $2.11 ; 95 \% \mathrm{Cl} 1.77$ to $2.51 ; 4291$ participants; 6 studies; high-quality evidence).

Eight studies (2061 participants) investigating angiotensin converting enzyme inhibitors (ACEI) were included with the overall quality of evidence assessed as moderate. The evidence suggested that ACEI treatment likely has little or no effect on cardiovascular mortality, allcause mortality, heart failure hospitalisation, or quality of life. Data for the effect of ACEI on hyperkalaemia were only available from one of the included studies.

Eight studies (8755 participants) investigating angiotensin receptor blockers (ARB) were included with the overall quality of evidence assessed as high. The evidence suggested that treatment with ARB has little or no effect on cardiovascular mortality, all-cause mortality, heart failure hospitalisation, or quality of life. ARB was associated with an increased risk of hyperkalaemia ( $0.9 \%$ of participants in the intervention group versus $0.5 \%$ in the control group; RR 1.88; $95 \% \mathrm{Cl} 1.07$ to 3.33; 7148 participants; 2 studies; high-quality evidence).

We identified a single ongoing placebo-controlled study investigating the effect of angiotensin receptor neprilysin inhibitors (ARNI) in people with heart failure with preserved ejection fraction.

\section{Authors' conclusions}

There is evidence that MRA treatment reduces heart failure hospitalisation in heart failure with preserverd ejection fraction, however the effects on mortality related outcomes and quality of life remain unclear. The available evidence for beta-blockers, ACEI, ARB and ARNI is limited and it remains uncertain whether these treatments have a role in the treatment of HFpEF in the absence of an alternative indication for their use. This comprehensive review highlights a persistent gap in the evidence that is currently being addressed through several large ongoing clinical trials.

\section{PLAIN LANGUAGE SUMMARY}

\section{Beta-blockers and inhibitors of the renin-angiotensin aldosterone system for chronic heart failure with preserved ejection fraction}

\section{Review question}

We investigated the effects of beta-blockers (BB), mineralocorticoid receptor antagonists (MRA), angiotensin converting enzyme inhibitors (ACEI), angiotensin receptor blockers (ARB) and angiotensin receptor neprilysin inhibitors (ARNI) on survival, hospital admissions for heart failure, quality of life and potassium levels in people with heart failure with preserved ejection fraction.

\section{Background}

Heart failure is a common condition that occurs when the function of the heart muscle is impaired that is associated symptoms of breathlessness and fatigue, and a reduction in survival. In around half of cases where there is reduced contraction (heart failure with reduced ejection fraction, $\mathrm{HFrEF}$ ), several treatments are known to be effective at improving survival and reducing hospitalisation. In the remaining cases where relaxation is impaired (heart failure with preserved ejection fraction, HFpEF), it is not clear whether the same drug treatments are also effective at improving outcomes.

\section{Selection criteria}

We sought to investigate whether HFrEF treatments are also effective in HFpEF. We conducted a comprehensive search for all trials investigating BB, MRA, ACEI, ARB or ARNI (evidence current to 25 July 2017).

\section{Results and conclusions}

We included 10 studies with 3087 randomised participants for BB, 12 studies with 4408 randomised participants for MRA, eight studies with 2061 randomised participants for ACEI and eight studies with 8755 randomised participants for ARB. We combined the evidence in a pooled analysis for each drug class and for each of the outcomes assessed. Not all included studies are part of each analysis.

We found that beta-blockers may improve cardiovascular mortality, however the evidence quality was low due to small trials and uncertainty about the methods used. For MRA, the results suggest a reduction in heart failure hospitalisation and have little or no effect on cardiovascular and all-cause mortality, however the evidence quality was only moderate. For ACEI, treatment probably has little or

Beta-blockers and inhibitors of the renin-angiotensin aldosterone system for chronic heart failure with preserved ejection fraction 
no effect on the outcomes of cardiovascular mortality, all-cause mortality and heart failure hospitalisation, however the evidence quality was only moderate. We found high quality evidence for ARB treatment and the results suggest little or no effect from this treatment. No completed studies were available for ARNI. Treatment with MRA and ARB was found to increase the risk of high potassium in the blood.

In conclusion, BB may improve outcomes in patients with HFpEF however this remains uncertain. MRA was found to result in a slight reduction in the risk of hospitalisation due to heart failure. Treatment with ACEI probably has no effect, however this remains uncertain. The evidence suggested that treatment with ARB is of little or no benefit in people with HFpEF.

\section{Quality of the evidence}

The quality of evidence ranged from high to low across the outcomes and drug classes studied. With the exception of ARB, there was a lack of large scale trials in HFpEF for the interventions and outcomes tested. 


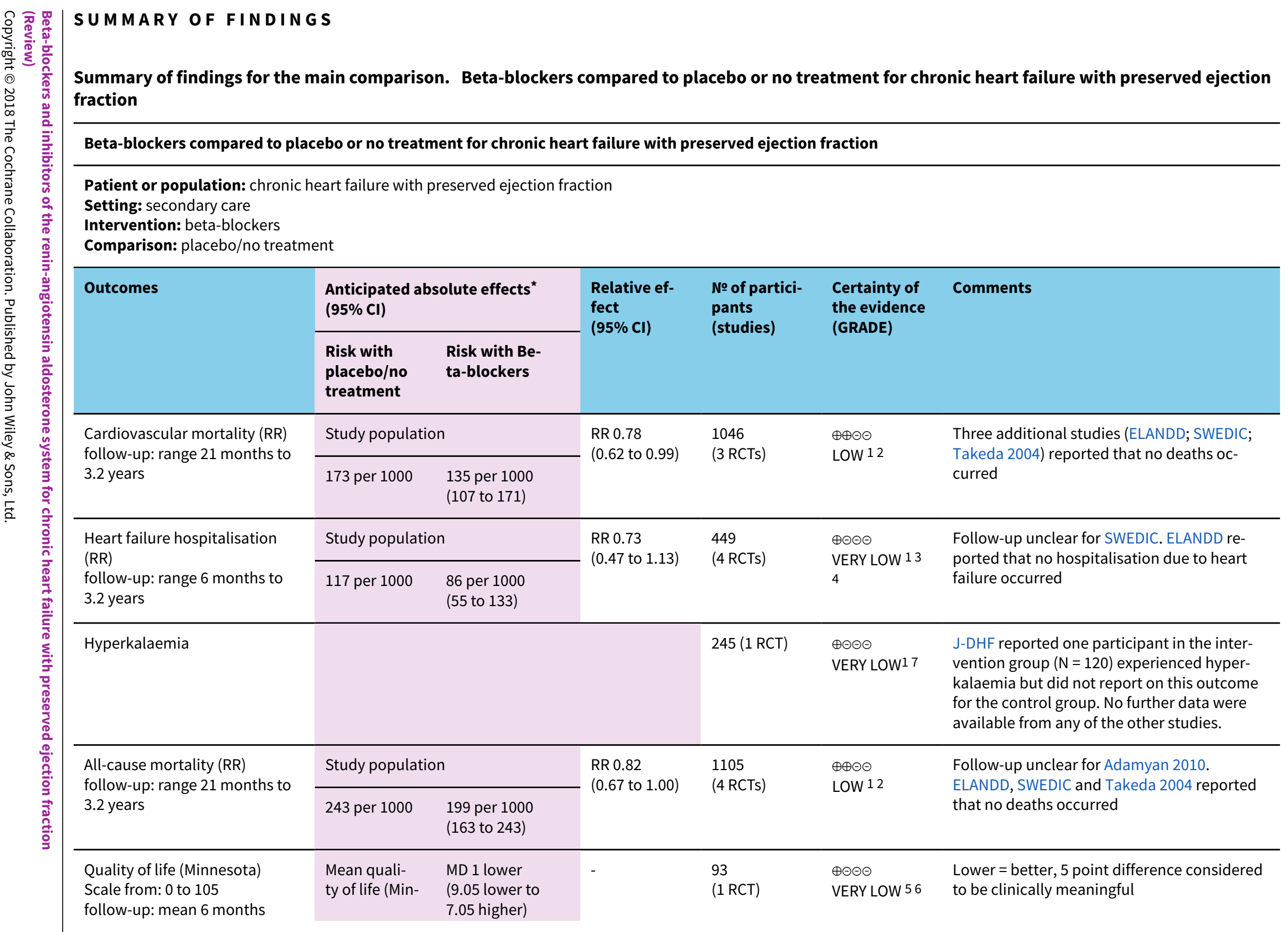

Patient or population: chronic heart failure with preserved ejection fraction

econdary care

Comparison: placebo/no treatment 


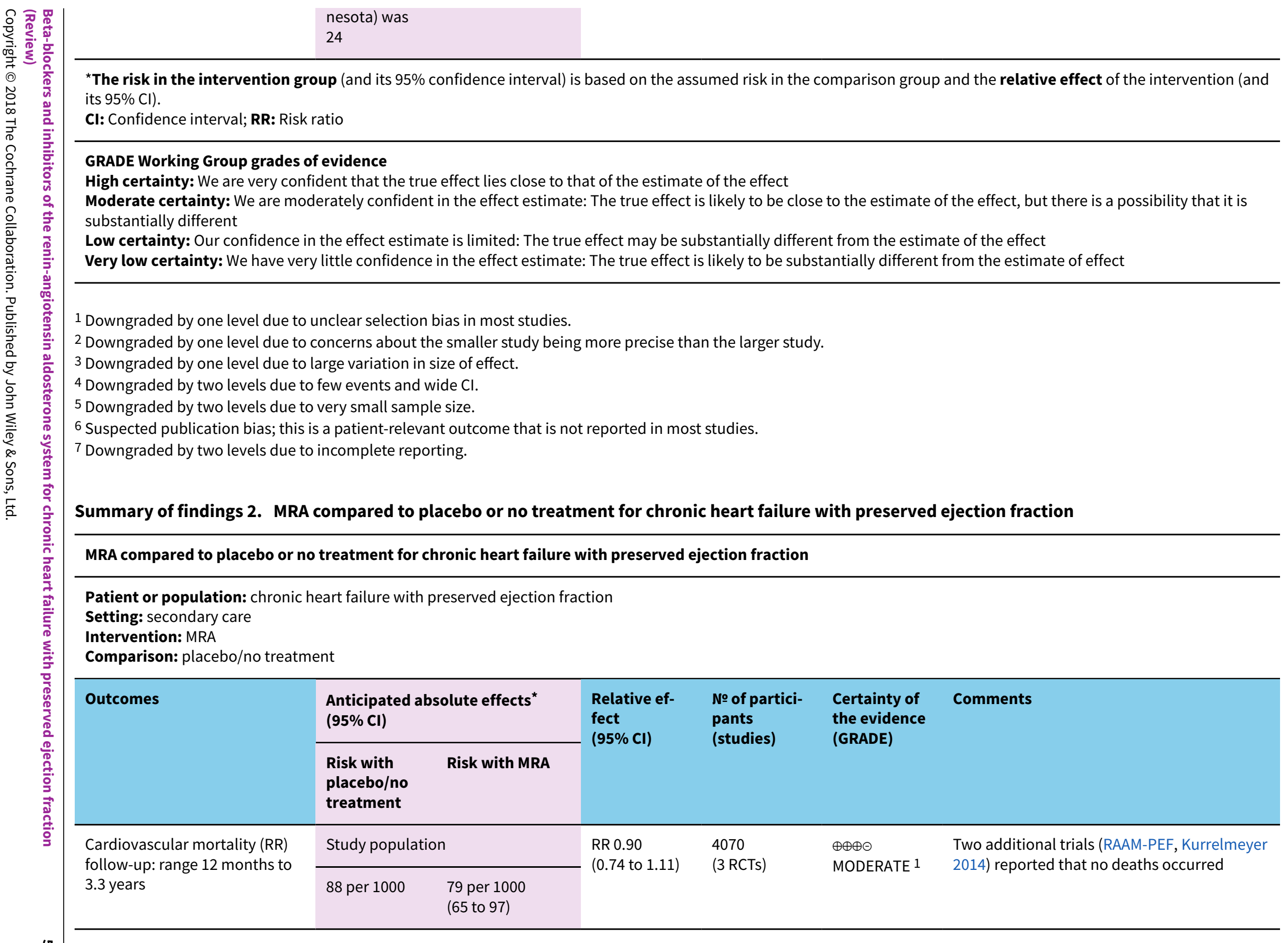

\section{GRADE Working Group grades of evidence}

High certainty: We are very confident that the true effect lies close to that of the estimate of the effect

substantially different

Low certainty: Our confidence in the effect estimate is limited: The true effect may be substantially different from the estimate of the effect

Very low certainty: We have very little confidence in the effect estimate: The true effect is likely to be substantially different from the estimate of effect

1 Downgraded by one level due to unclear selection bias in most studies.

3 Downgraded by one level due to large variation in size of effect.

4 Downgraded by two levels due to few events and wide $\mathrm{Cl}$.

in most studies.

\section{Summary of findings 2 . MRA compared to placebo or no treatment for chronic heart failure with preserved ejection fraction}

MA compared to placebo or no treatment for chronic heart failure with preserved ejection fraction 


\begin{tabular}{|c|c|c|c|c|c|c|c|c|}
\hline & Heart failure hospitalisation & Study popula & & RR 0.82 & 3714 & $\oplus \oplus \oplus \odot$ & Three additional trials (ALDO-DHF ,Kur- & \\
\hline $\begin{array}{c}=0 \\
\frac{n}{\hat{\lambda}} \\
\frac{1}{\omega} \\
0 \\
0\end{array}$ & $\begin{array}{l}\text { follow-up: range } 24 \text { weeks to } \\
3.3 \text { years }\end{array}$ & 136 per 1000 & $\begin{array}{l}112 \text { per } 1000 \\
\text { (94 to } 134 \text { ) }\end{array}$ & & & & $\begin{array}{l}\text { no hospitalisation due to heart failure oc- } \\
\text { curred }\end{array}$ & ㅌ. \\
\hline 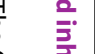 & Hyperkalaemia & Study popula & & RR 2.11 & 4291 & $\oplus \oplus \oplus \oplus$ & Two trials defined hyperkalaemia $\geq 5.5 \mathrm{mEg} / \mathrm{L}$ & \\
\hline 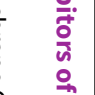 & 3.3 years & 83 per 1000 & $\begin{array}{l}175 \text { per } 1000 \\
(146 \text { to } 208)\end{array}$ & & & & & 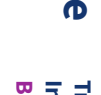 \\
\hline$\frac{\overline{0}}{0}$ & All-cause mortality & Study popula & & RR 0.91 & 4207 & $\oplus \oplus \oplus \ominus$ & Two additional trials (RAAM-PEF, Kurrelmeyer & \\
\hline 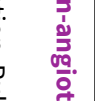 & 3.3 years & 133 per 1000 & $\begin{array}{l}121 \text { per } 1000 \\
(104 \text { to } 141)\end{array}$ & & & & & 商: \\
\hline 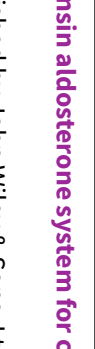 & $\begin{array}{l}\text { Quality of life (Minnesota) } \\
\text { Scale from: } 0 \text { to } 105 \\
\text { follow-up: range } 9 \text { months to } \\
12 \text { months }\end{array}$ & $\begin{array}{l}\text { Mean qual- } \\
\text { ity of life } \\
\text { (Minnesota) } \\
\text { ranged from } \\
20 \text { to } 25\end{array}$ & $\begin{array}{l}\text { MD } 0.84 \text { higher } \\
\text { (2.30 lower to } \\
3.98 \text { higher) }\end{array}$ & - & $\begin{array}{l}511 \\
\text { (3 RCTs) }\end{array}$ & $\begin{array}{l}\oplus \oplus \Theta \ominus \\
\text { LOW } 23\end{array}$ & $\begin{array}{l}\text { Lower = better, } 5 \text { points are considered a clin- } \\
\text { ically significant difference } \\
\text { We did not pre-specify which QoL scale was } \\
\text { to be reported in the 'Summary of findings' } \\
\text { table. To aid comparisons among 'Summa- } \\
\text { ry of findings' tables we chose to include the } \\
\text { Minnesota Living with Heart Failure question- } \\
\text { naire and not the SMD across two scales }\end{array}$ & \\
\hline 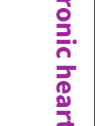 & $\begin{array}{l}{ }^{\star} \text { The risk in the intervention } \\
\text { its } 95 \% \mathrm{CI}) \text {. } \\
\text { Cl: Confidence interval; RR: Ri }\end{array}$ & $\begin{array}{l}\text { up (and its 95\% } \\
\text { atio }\end{array}$ & nfidence interv & ased on the & med risk & nparison grou & Ind the relative effect of the intervention (and & \\
\hline 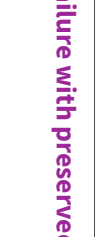 & $\begin{array}{l}\text { GRADE Working Group grade } \\
\text { High certainty: We are very cc } \\
\text { Moderate certainty: We are } \mathrm{m} \\
\text { substantially different } \\
\text { Low certainty: Our confidenc } \\
\text { Very low certainty: We have }\end{array}$ & $\begin{array}{l}\text { evidence } \\
\text { dent that the tr } \\
\text { erately confide } \\
\text { the effect estir } \\
\text { little confiden }\end{array}$ & $\begin{array}{l}\text { effect lies close } \\
\text { in the effect estir } \\
\text { te is limited: The } \\
\text { in the effect estir }\end{array}$ & $\begin{array}{l}\text { at of the estima } \\
\text { : The true effect } \\
\text { effect may be s } \\
\text { : The true effect }\end{array}$ & $\begin{array}{l}\text { of the eff } \\
\text { likely to } \\
\text { stantially } \\
\text { likely to } b\end{array}$ & $\begin{array}{l}\text { to the estimate } \\
\text { at from the estir } \\
\text { antially differer }\end{array}$ & $\begin{array}{l}f \text { the effect, but there is a possibility that it is } \\
\text { fre of the effect } \\
\text { from the estimate of effect }\end{array}$ & 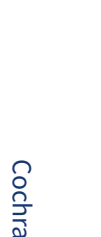 \\
\hline 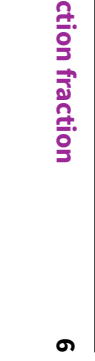 & $\begin{array}{l}1 \text { Downgraded by one level due } \\
2 \text { Downgraded by one level beca } \\
{ }^{3} \text { Downgraded by one level due }\end{array}$ & $\begin{array}{l}\text { mprecision. } \\
\text { one trial was } \\
\text { mall sample si }\end{array}$ & en label. & & & & & 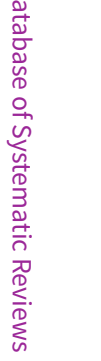 \\
\hline
\end{tabular}




\begin{tabular}{|c|c|c|c|c|c|c|}
\hline \multicolumn{7}{|c|}{ ACEI compared to placebo or no treatment for chronic heart failure with preserved ejection fraction } \\
\hline \multicolumn{7}{|c|}{$\begin{array}{l}\text { Patient or population: chronic heart failure with preserved ejection fraction } \\
\text { Setting: secondary care } \\
\text { Intervention: ACEI } \\
\text { Comparison: placebo/no treatment }\end{array}$} \\
\hline \multirow[t]{2}{*}{ Outcomes } & \multicolumn{2}{|c|}{$\begin{array}{l}\text { Anticipated absolute effects }{ }^{\star}(95 \% \\
\text { CI) }\end{array}$} & \multirow{2}{*}{$\begin{array}{l}\text { Relative ef- } \\
\text { fect } \\
(95 \% \mathrm{CI})\end{array}$} & \multirow{2}{*}{$\begin{array}{l}\text { № of partici- } \\
\text { pants } \\
\text { (studies) }\end{array}$} & \multirow{2}{*}{$\begin{array}{l}\text { Certainty of } \\
\text { the evidence } \\
\text { (GRADE) }\end{array}$} & \multirow[t]{2}{*}{ Comments } \\
\hline & $\begin{array}{l}\text { Risk with } \\
\text { placebo/no } \\
\text { treatment }\end{array}$ & Risk with ACEI & & & & \\
\hline \multirow{2}{*}{$\begin{array}{l}\text { Cardiovascular mortality (RR) } \\
\text { follow-up: range mean } 12 \text { months to } \\
\text { mean } 26.2 \text { months }\end{array}$} & \multicolumn{2}{|l|}{ Study population } & \multirow{2}{*}{$\begin{array}{l}\text { RR } 0.93 \\
\text { (0.61 to } 1.42 \text { ) }\end{array}$} & \multirow{2}{*}{$\begin{array}{l}945 \\
(2 \mathrm{RCTs})\end{array}$} & \multirow{2}{*}{$\begin{array}{l}\oplus \oplus \oplus \ominus \\
\text { MODERATE } 1\end{array}$} & \multirow{2}{*}{$\begin{array}{l}\text { One additional trial (Kitzman 2010) re- } \\
\text { ported that no deaths occurred }\end{array}$} \\
\hline & 86 per 1000 & $\begin{array}{l}81 \text { per } 1000 \\
(53 \text { to } 123)\end{array}$ & & & & \\
\hline \multirow{2}{*}{$\begin{array}{l}\text { Heart failure hospitalisation (RR) } \\
\text { follow-up: range } 6 \text { months to } 26.2 \\
\text { months }\end{array}$} & \multicolumn{2}{|l|}{ Study population } & \multirow{2}{*}{$\begin{array}{l}\text { RR } 0.86 \\
(0.64 \text { to } 1.15)\end{array}$} & \multirow{2}{*}{$\begin{array}{l}1019 \\
(3 \mathrm{RCTs})\end{array}$} & \multirow{2}{*}{$\begin{array}{l}\oplus \oplus \oplus \ominus \\
\text { MODERATE } 1\end{array}$} & \\
\hline & 13 per 1000 & $\begin{array}{l}11 \text { per } 1000 \\
(8 \text { to } 15)\end{array}$ & & & & \\
\hline Hyperkalaemia & & & & 74 (1 RCTs) & $\begin{array}{l}\oplus \odot \odot \ominus \\
\text { VERY LOW } 13 \\
4\end{array}$ & $\begin{array}{l}\text { One trial ( } Z \mathrm{i} \text { 2003) reported } 2 \text { events } \\
\text { in the intervention group }(\mathrm{N}=36), 0 \\
\text { events in the control group }(\mathrm{N}=38) \\
\text { (RR } 5.27,95 \% \mathrm{Cl} 0.26 \text { to } 106.16)\end{array}$ \\
\hline \multirow{2}{*}{$\begin{array}{l}\text { All-cause mortality (RR) } \\
\text { follow-up: range mean } 6 \text { months to } \\
\text { mean } 26.2 \text { months }\end{array}$} & \multicolumn{2}{|l|}{ Study population } & \multirow{2}{*}{$\begin{array}{l}\text { RR } 0.99 \\
\text { (0.71 to } 1.38)\end{array}$} & \multirow{2}{*}{$\begin{array}{l}1079 \\
\text { (4 RCTs) }\end{array}$} & \multirow{2}{*}{$\begin{array}{l}\oplus \oplus \oplus \ominus \\
\text { MODERATE } 1\end{array}$} & \multirow{2}{*}{$\begin{array}{l}\text { One additional trial (Kitzman 2010) re- } \\
\text { ported that no deaths occurred }\end{array}$} \\
\hline & 119 per 1000 & $\begin{array}{l}119 \text { per } 1000 \\
(84 \text { to } 166)\end{array}$ & & & & \\
\hline $\begin{array}{l}\text { Quality of life (Minnesota) } \\
\text { Scale from: } 0 \text { to } 105 \\
\text { follow-up: mean } 12 \text { months }\end{array}$ & $\begin{array}{l}\text { Mean quality of } \\
\text { life (Minneso- } \\
\text { ta) ranged from } \\
10.9 \text { to } 29\end{array}$ & $\begin{array}{l}\text { MD } 0.09 \text { lower } \\
\text { (3.66 lower to } \\
3.48 \text { higher) }\end{array}$ & - & $\begin{array}{l}154 \\
(2 \mathrm{RCTs})\end{array}$ & $\begin{array}{l}\oplus \oplus \odot \odot \\
\text { LOW } 23\end{array}$ & $\begin{array}{l}\text { Scale: } 0 \text { to } 105 \text {, lower = better, } 5 \text { point } \\
\text { difference considered clinically rele- } \\
\text { vant } \\
\text { One trial (SNEGOVIK) reported mean } \\
\text { change from baseline of - } 19.8 \text { for inter- } \\
\text { vention and }-10.7 \text { for control }\end{array}$ \\
\hline
\end{tabular}




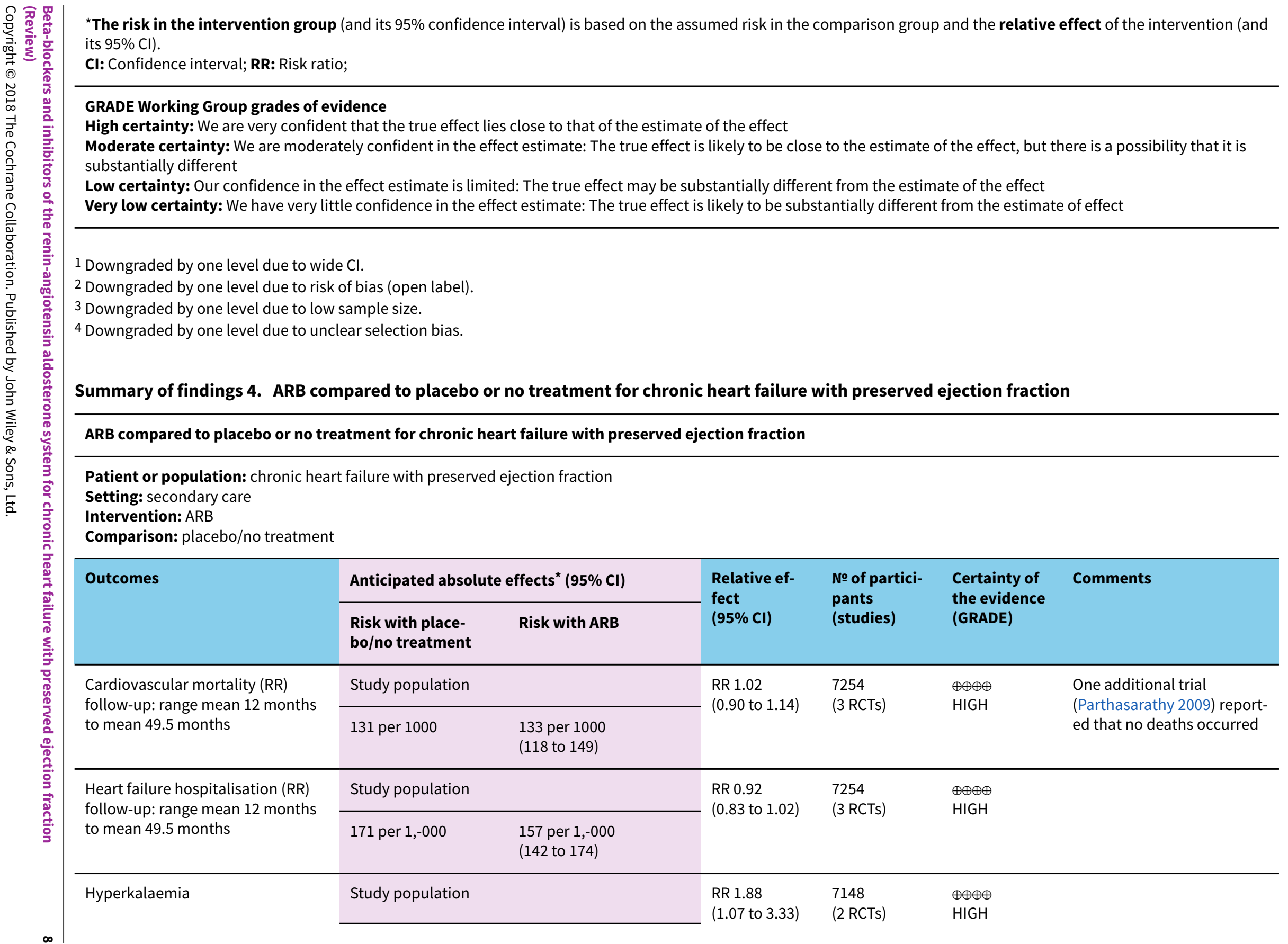




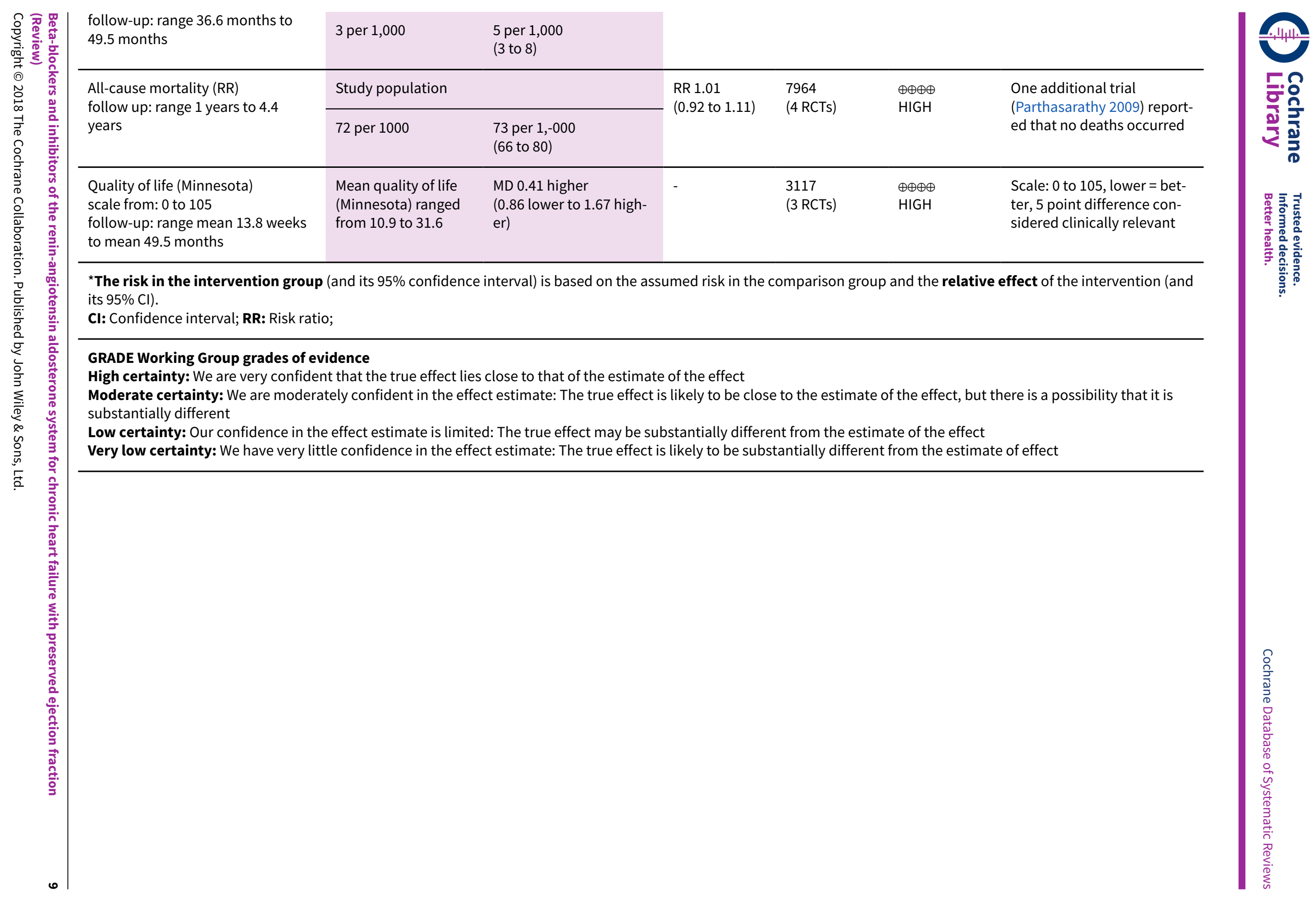




\section{B A C K G R O U N D}

\section{Description of the condition}

Heart failure is a clinical syndrome characterised by breathlessness and fatigue that results when abnormalities of cardiac structure and function lead to inadequate cardiac output, or elevated ventricular filling pressures, or both (Ponikowski 2016). Based on available data from the United States and Europe, the prevalence of heart failure is estimated from $1 \%$ to $12 \%$ of the adult population and is projected to increase with population aging and improved survival from cardiovascular disease (Roger 2013). Heart failure is a significant public health problem accounting for $5 \%$ of emergency hospital admissions in the United Kingdom, and is associated with significant mortality with five-year survival estimated at 50\% (NICE 2010). Heart failure is classified according to the left ventricular ejection fraction (LVEF) into heart failure with reduced ejection fraction (HFrEF, typically considered as LVEF $<40 \%$ ), and heart failure with preserved ejection fraction (HFpEF, typically LVEF > $40 \%$ ). Recently, an intermediate subgroup was defined by the European Society of Cardiology as heart failure with mid-range ejection fraction (HFmrEF) defined as LVEF $40 \%$ to $49 \%$ (Ponikowsk 2016). This was defined by the American College of Cardiology as borderline HFpEF, defined as LVEF $41 \%$ to $49 \%$ (Yancy 2013). In this review, we defined HFpEF as LVEF $>40 \%$ because completed and ongoing HFpEF trials have used a range of LVEF cut-offs between $40 \%$ and $50 \%$. HFpEF accounts for approximately half of all cases of heart failure; mortality outcomes are similar to those for HFrEF (Gerber 2015).

\section{Description of the intervention}

Neurohumoral inhibition with beta-blockers (BB), angiotensin converting enzyme inhibitors (ACEI), and mineralocorticoid receptor antagonists (MRAs) leads to improved survival and a reduction in hospitalisations for heart failure in people with HFrEF (CIBIS Investigators 1999; Consensus Trial Study Group 1987; Flather 2005; Hjalmarson 2000; Kotecha 2014; MERITHF Study Group 1999; Packer 1999; Packer 2002; Packer 2001; Pitt 1999; Ponikowski 2016; SOLVD Investigators 1991; SOLVD Investigators 1992; Zannad 2011). Where ACEI or MRA are contraindicated or not tolerated, angiotensin receptor antagonists (ARB) are recommended as an alternative for either, although evidence is limited (Granger 2003). Angiotensin receptor neprilysin inhibitors (ARNI) are recommended as an alternative to ACEI with superior efficacy in people with HFrEF who remain symptomatic despite optimal therapy (McMurray 2014). Although neurohumoral activation is observed in HFpEF (Hogg 2005), comparatively fewer clinical trials of neurohumoral inhibitor therapies have been performed in this population. The existing evidence from individual trials of $B B, M R A, A C E I, A R B$ or MRAs in people with HFpEF does not support a reduction in mortality with these treatments (Ponikowski 2016). However, limited evidence indicates that candesartan (an ARB) (Yusuf 2003) and spironolactone (an MRA) (Pitt 2014) may be effective in reducing numbers of people hospitalised with heart failure.

This review sought to determine whether neurohumoral inhibition with therapies that improve mortality and morbidity in those with HFrEF (BB, MRA, ACEI, ARB, and ARNI) have similar benefit in people with HFpEF.

\section{How the intervention might work}

In people with $\mathrm{HFpEF}$, inadequate cardiac function triggers compensatory neurohumoral responses similar to those observed in HFrEF (Hogg 2005). Activation of the renin-angiotensin aldosterone system (RAAS) and increased tone of the sympathetic nervous system may be adaptive in the short term; however, chronic activation is likely to be detrimental. Pre-clinical disease models of HFpEF suggest that RAAS activation leads to maladaptive hypertrophy and fibrosis (Sharma 2014). ACEls, ARBs or MRAs inhibit components of the RAAS system to counter the over activation that occurs in people with heart failure. ARNIs combine inhibition of RAAS with an ARB (valsartan) with augmentation of the natriuretic peptide system by inhibition of neprilysin (sacubitril). Neprilysin is a neutral endopeptidase that degrades a number of endogenous vasoactive peptides serving to counteract some of the effects of RAAS activation (McMurray 2014). The beneficial effects of beta-blocker therapy in people with HFrEF are likely to be mediated by a reduction in the detrimental effects of increased sympathetic tone that may include increased heart rate, adverse myocardial energetics, and stimulation of RAAS (Sackner-Bernstein 1995). These mechanisms may also be important in HFpEF and the effect of beta-blockers to increase diastolic filling time may be particularly important (Sharma 2014). The population of people with HFpEF is heterogeneous, both with respect to disease aetiology and comorbidity. However, it is possible that neurohumoral activation represents a common pathophysiological mechanism that could be successfully targeted to improve clinical outcomes in people with heart failure across the spectrum of LVEF.

\section{Why it is important to do this review}

There is uncertainty as to whether beta-blockers or RAAS inhibitors are effective at reducing mortality and heart failure hospitalisation and improving quality of life in people with HFpEF. Guidelines offer no specific treatment recommendations regarding the use of these therapies beyond the management of comorbidities, aside from a recommendation for the use of ARBs to reduce hospitalisations (Ilb recommendation, Yancy 2013) and for the use of MRAs (weak recommendation; moderate-quality evidence, Ezekowitz 2017). The UK's National Institute for Health and Care Excellence (NICE) highlighted a review of the evidence as a research priority (NICE 2010).

A recent systematic review and meta-analysis of pharmacotherapy in HFpEF included beta-blockers and RAAS inhibitors (ACEI, ARB and MRA) and suggested a reduction in cardiovascular and all-cause mortality with beta-blocker therapy (Zheng 2017). An updated review with a more comprehensive search strategy is needed to inform new guideline recommendations and to inform the conduct of further clinical trials.

\section{O B JECTIVES}

To assess the effects of beta-blockers, angiotensin converting enzyme inhibitors, angiotensin receptor blockers, angiotensin receptor neprilysin inhibitors, and mineralocorticoid receptor antagonists in people with heart failure with preserved ejection fraction. 


\section{METHODS}

\section{Criteria for considering studies for this review \\ Types of studies}

We included randomised controlled trials (RCTs) with parallel group design. We excluded cross-over trials because we considered these to be inappropriate for our review question due to the progressive nature of heart failure.

Studies published in full-text or as abstracts, or available only as unpublished data, were eligible for inclusion.

\section{Types of participants}

We included studies with adult participants (aged $\geq 18$ years) with $\mathrm{HFpEF}$ defined by a left ventricular ejection fraction of greater than 40 percent (LVEF $>40 \%$ ). It was recognised there was likely to be significant heterogeneity between study populations relating to the disease definition and a narrative summary is included in the Discussion. We contacted study authors to obtain data on the subgroup of interest for studies with mixed populations in relation to ejection fraction.

\section{Types of interventions}

We performed separate meta-analyses of studies that compared BB, MRA, ACEI, or ARB, in addition to standard care, with placebo or no treatment control. We did not perform a meta-analysis of ARNI because no trials were identified.

\section{Types of outcome measures}

\section{Primary outcomes}

1. Cardiovascular mortality.

2. Heart failure hospitalisation.

3. Hyperkalaemia.

\section{Secondary outcomes}

1. All-cause mortality.

2. Quality of life (measured using either the Minnesota Living With Heart Failure Questionnaire or Kansas City Cardiomyopathy Questionnaire).

3. Withdrawal due to adverse event (hypotension, hyperkalaemia or renal impairment).

Reporting one of more of the listed outcomes in the trial was not an inclusion criterion for the review. We assessed outcomes at the longest reported follow-up.

\section{Search methods for identification of studies}

\section{Electronic searches}

We identified trials through systematic searches of the following bibliographic databases on 25 July 2017:
1. Cochrane Central Register of Controlled Trials (CENTRAL) in the Cochrane Library (Wiley, Issue 6, June 2017);

2. MEDLINE (Ovid, 1946 to July Week 2 2017);

3. MEDLINE In-Process \& Other Non-Indexed Citations, Epub Ahead of Print (Ovid, 24 July 2017); and

4. Embase and Embase Classic (embase.com, 1974 to 25 July 2017).

The search strategies used are included in Appendix 1. We applied the Cochrane sensitivity-maximising RCT filter (Lefebvre 2011) to the main segment of MEDLINE (Ovid) (point 2 above) but did not use the filter when searching the MEDLINE Epub and In-Process database segments. We used the multi-term Embase filter with the best optimisation of sensitivity and specificity (Wong 2006) translated from Ovid to embase.com syntax.

We did not impose any restriction on language of publication.

\section{Searching other resources}

We searched ClinicalTrials.gov (https://clinicaltrials.gov/) and the World Health Organization (WHO) International Clinical Trials Registry Platform (ICTRP) Search Portal (http://apps.who.int/ trialsearch/) on 25 July 2017 to identify ongoing and unpublished trials. Search terms for the trials registers are also listed in Appendix 1 .

We checked all primary references of included studies and systematic reviews for additional references. For any studies identified as eligible from clinical trial register records, we searched for the trials registry number on PubMed for publications about this study.

We contacted study authors to clarify details or obtain additional information not included in the published reports.

\section{Data collection and analysis}

\section{Selection of studies}

Two review authors (KM and NM) independently screened titles and abstracts of all records identified in our search and coded them as 'retrieve' (eligible or potentially eligible/unclear) or 'do not retrieve'. In the event of disagreement, a third review author was asked to arbitrate (TL). We then retrieved the full-text study reports for records identified as eligible, potentially eligible or unclear. Two review authors (KM and NM) independently screened the fulltext and identified studies for inclusion. We recorded reasons for exclusion of ineligible studies. We resolved any disagreement by consensus or consulted a third review author (TL). We identified and excluded duplicates and collated multiple reports of the same study so that each study rather than each report is the unit of interest in the review. We recorded the selection process and completed a PRISMA flow diagram (Figure 1) and Characteristics of excluded studies table. 
Figure 1. Study flow diagram

7364 records identified through database searching

467 additional records identified through other sources (clinical trial registries)

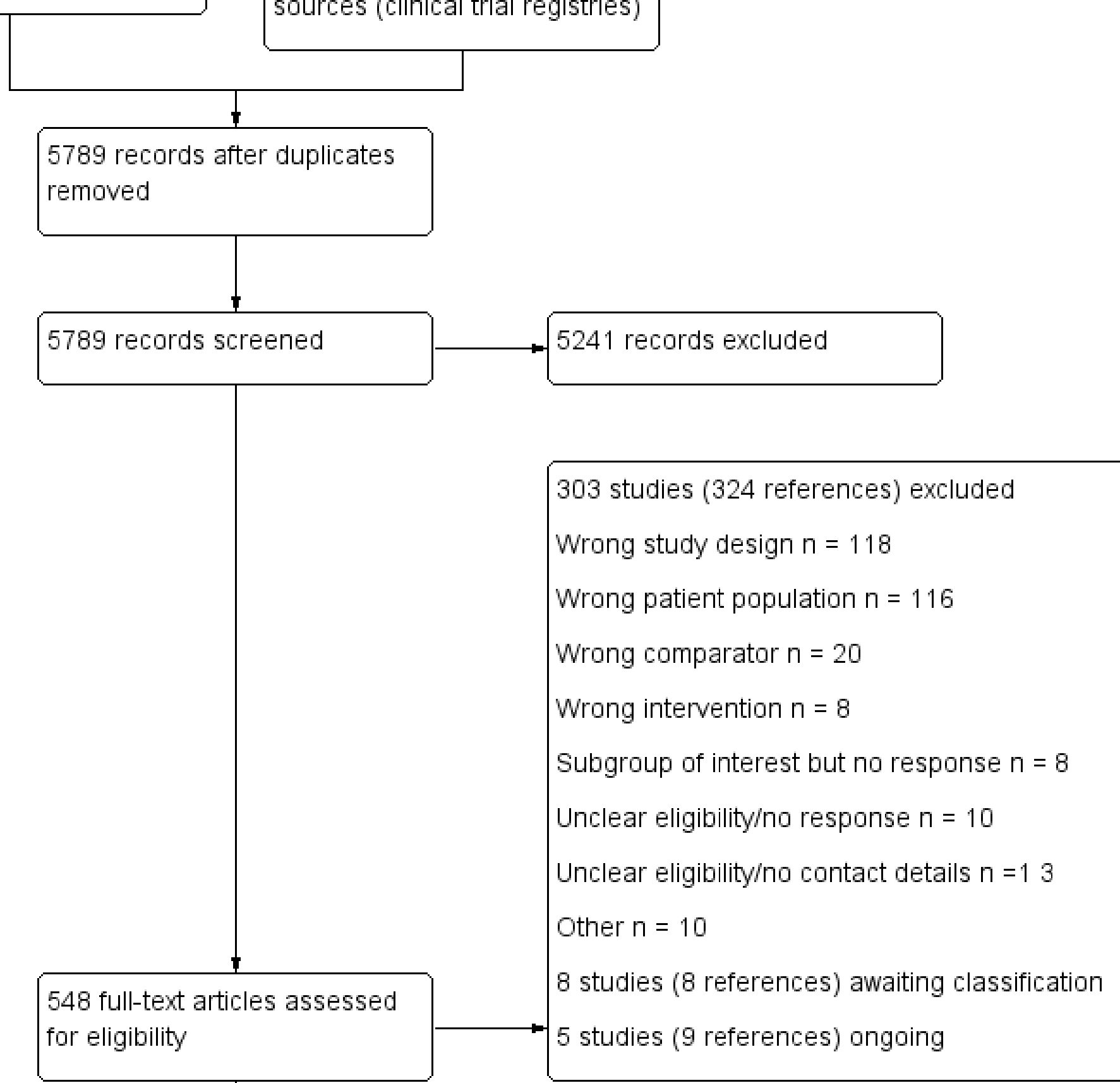




\section{Data extraction and management}

We used a data collection form to record study characteristics and outcome data from included studies, which had been piloted on two studies in the review (PEP-CHF; TOPCAT). Some modifications were made after the pilot phase. Two review authors (NM and TL) extracted study characteristics from included studies as follows:

1. Methods: study design, duration of follow-up, details of any 'run in' period, number of study centres and location, study setting, withdrawals, and start/end date of enrolment.

2. Participants: N randomised/withdrawn/lost to follow-up/ analysed, mean age/age range, \% male, inclusion criteria, exclusion criteria, systolic blood pressure, heart rate, body mass index, serum creatinine, B-type natriuretic peptide, NT pro B-type natriuretic peptide, LVEF, New York Heart Association (NYHA) class, comorbidity (hypertension, diabetes, atrial fibrillation, hospitalisation for heart failure, coronary heart disease, stroke, medications at baseline).

3. Interventions: intervention, comparison, concomitant medications (diuretic, digoxin, BB, ACEI, ARB, MRA).

4. Outcomes: planned and reported.

5. Notes: sources of funding, and notable conflicts of interest of trial authors.

Two review authors (NM and TL) independently extracted outcome data from included studies. Disagreements were resolved by consensus. One review author (NM) transferred data into the Review Manager (RevMan 2014) file. One review author (TL) doublechecked that data were entered correctly by comparing the data presented in the systematic review with the data extraction sheet.

\section{Assessment of risk of bias in included studies}

Two review authors (NM and TL) independently assessed risk of bias for each study using the criteria outlined in the Cochrane Handbook for Systematic Reviews of Interventions (Higgins 2011). Disagreements were resolved by consensus. We assessed the risk of bias according to the following domains.

1. Random sequence generation.

2. Allocation concealment.

3. Blinding of participants and personnel.

4. Blinding of outcome assessment.

5. Incomplete outcome data.

6. Selective outcome reporting.

7. Other bias.

We judged each potential source of bias as high, low or unclear and provided quotes from study reports together with justification for our judgment in the 'Risk of bias' table. We summarised the 'Risk of bias' judgements across different studies for each of the domains listed. Where information on risk of bias related to unpublished data or correspondence with a trialist, we noted this in the 'Risk of bias' table.

When considering treatment effects in the pooled analysis, we accounted for risk of bias for the studies that contributed to each outcome tested.

\section{Assessment of bias in conducting the systematic review}

We conducted the review according to the published protocol and reported protocol deviations in the Differences between protocol and review section.

\section{Measures of treatment effect}

We analysed dichotomous data as risk ratios (RR) with 95\% confidence intervals $(\mathrm{Cl})$ and continuous data as mean difference (MD) or standardised mean difference (SMD) with 95\% Cls. We analysed mortality data as hazard ratios (HR). We used SMD for one analysis when combining quality of life data reported for two different scales. We entered data presented as a scale with a consistent direction of effect.

\section{Unit of analysis issues}

We included one three-arm trial (Hong Kong DHF); because two intervention arms contributed to two separate comparisons, no unit of analysis issue arose.

\section{Dealing with missing data}

We contacted investigators or study sponsors to verify key study characteristics and obtain missing numerical outcome data where possible.

\section{Assessment of heterogeneity}

We used the $I^{2}$ statistic to measure heterogeneity among the trials in each analysis. We considered possible causes in cases of substantial heterogeneity $\left(I^{2} \geq 50 \%\right)$.

\section{Assessment of reporting biases}

We pooled fewer than 10 trials for each comparison. Therefore, we did not examine funnel plots to explore possible small-study biases for the primary outcomes.

\section{Data synthesis}

We undertook meta-analyses only where this was meaningful, that is, if the treatments, participants and the underlying clinical question were similar enough for pooling to make sense. We used a fixed-effect model in the absence of substantial heterogeneity $\left(I^{2}\right.$ $<50 \%$ ) and a random-effects model when unexplained substantial heterogeneity was present $\left(I^{2} \geq 50 \%\right)$. We applied a randomeffects model for quality of life analyses for MRA to account the high heterogeneity observed for the Kansas City Cardiomyopathy Questionnaire (KCCQ) (Analysis 2.7; $\mathrm{I}^{2}=86 \%$ ) and to permit a combined analysis with outcome data from the Minnesota Living With Heart Failure Questionnaire (MLHFQ) (Analysis 2.6; $\mathrm{I}^{2}=50 \%$ ).

We considered two relevant quality of life scales: the MLHFQ or KCCQ. The MLHFQ score has a range from 0 to 105 , lower scores indicate better quality of life. The KCCQ score has a range from 0 to 100 , higher scores indicate better quality of life. To account for the difference in the direction of the scale of the KCCQ, the mean values were multiplied by -1 (Cochrane Handbook for Systematic Reviews of Interventions, section 9.2.3.2, Deeks 2011). For the purpose of interpretation, we considered a five point difference in score as clinically significant for the MLHFQ (Rector 1995) and KCCQ (Spertus 2005). 


\section{'Summary of findings' table}

We created 'Summary of findings' tables for each of our four interventions and included the following outcomes: cardiovascular mortality, heart failure hospitalisation, all-cause mortality, quality of life (Minnesota Living with Heart Failure Questionnaire) and hyperkalaemia. We used the five GRADE considerations (study limitations, inconsistencies, imprecision, indirectness and publication bias) to assess the quality of the body of evidence as it related to the studies which contributed data to the metaanalyses for the prespecified outcomes. We used methods and recommendations described in Section 8.5 and Chapter 12 of the Cochrane Handbook for Systematic Reviews of Interventions (Higgins 2011) using GRADEpro software (GRADEpro GDT). Four review authors assessed the quality of evidence (TL, NM, KM, CD). We documented our justification for decisions to downgrade the quality of evidence using footnotes.

\section{Subgroup analysis and investigation of heterogeneity}

We planned to carry out the following subgroup analyses.

1. Age.

2. Sex.

3. Heart failure with mid-range ejection fraction (HFmrEF) LVEF $40 \%$ to $49 \%$ and preserved LVEF $\geq 50 \%$.

4. Length of follow-up $<12$ months and $\geq 12$ months.

We were only able to perform a subgroup analysis based on length of follow-up because data for the prespecified subgroups were unavailable.

We used the outcomes cardiovascular mortality and hospitalisation for heart failure in subgroup analyses.

We used the formal test for subgroup interactions in Review Manager (RevMan 2014).

\section{Sensitivity analysis}

We performed a sensitivity analysis for risk of bias by performing a pooled analysis including only studies with a low risk of bias (where at least four of the six domains for bias assessment were judged to be low risk and no domain was at high risk of bias).

\section{RE S U L T S}

\section{Description of studies}

\section{Results of the search}

The database searches retrieved 7364 records and the search of clinical trial registries retrieved 467 records. After de-duplication, 5789 records were screened by title and abstract. Of these, 5241 records did not meet the inclusion criteria and were excluded. The remaining 548 records were assessed for eligibility in full-text and 303 studies (324 references) were excluded.

\section{Included studies}

We included 37 studies (207 reports) that involved a total of 18,311 participants.

\section{Beta-blockers}

We included 10 studies (3087 participants) that investigated betablockers for HFpEF. Of these, five studies compared beta-blockers versus placebo (ELANDD; Mittal 2017; Sahoo 2016; SENIORS; SWEDIC) and five versus usual care (Adamyan 2010; Aronow 1997; JDHF; Shu 2005; Takeda 2004). Four studies investigated carvedilol: Adamyan 2010 (up to $50 \mathrm{mg}$ daily), J-DHF (up to $10 \mathrm{mg}$ twice daily), SWEDIC (up to $25 \mathrm{mg}$ twice daily or $50 \mathrm{mg}$ twice daily in people weighing over $85 \mathrm{~kg}$ ), Takeda 2004 (up to $20 \mathrm{mg}$ daily). Two studies used nebivolol: ELANDD (up to $10 \mathrm{mg}$ daily) and SENIORS (up to $10 \mathrm{mg}$ daily). One study used propranolol: Aronow 1997 (30 mg, 3 times daily); and two studies investigated metoprolol succinate: Mittal 2017; Sahoo 2016 (up to 100 mg daily). Shu 2005 investigated bisoprolol (up to $10 \mathrm{mg}$ daily).

Numbers of participants randomised ranged from 40 (Mittal 2017; Takeda 2004) to 643 (SENIORS).

Four were multicentre studies. ELANDD was conducted across 12 centres in eight countries in Europe; J-DHF was assumed to have taken place in Japan; SENIORS took place in 11 countries (Czech Republic, France, Germany, Hungary, Italy, Netherlands, Romania, Spain, Switzerland, UK and Ukraine), and SWEDIC took place in 12 centres in Sweden. Mittal 2017 and Sahoo 2016 were each conducted in one centre in India. Adamyan 2010, Aronow 1997 and Shu 2005 did not report numbers of centres or countries, but we assumed that Adamyan 2010 likely took place in Armenia. Takeda 2004 was a single centre trial in Japan.

Three studies did not report LVEF of the included participants at baseline (Adamyan 2010; Shu 2005; SWEDIC). Six studies reported LVEF at baseline with a mean ranging from $56 \%$ to $63 \%$ (Aronow 1997; ELANDD; J-DHF; Mittal 2017; Sahoo 2016; Takeda 2004). SENIORS included participants with a "clinical history of chronic HF with at least 1 of the following features: documented hospital admission within the previous 12 months with a discharge diagnosis of congestive HF or documented LVEF $\leq 35 \%$ within the previous 6 months". The SENIORS study reported a subgroup of participants with LVEF $>40 \%$ and these outcome data were used in our analysis (643 participants).

Most participants were NYHA class II (51\% to $78 \%$ ). Shu 2005 did not report participants' NYHA class at baseline. Participants' mean age ranged from 30 years to 81 years; six studies reported mean age less than 70 years (Adamyan 2010; ELANDD; Mittal 2017; Sahoo 2016; Shu 2005; SWEDIC) and four reported mean age above 70 years (Aronow 1997; J-DHF; SENIORS; Takeda 2004).

Three studies were funded by industry (ELANDD; SENIORS; SWEDIC); two studies were funded by not-for-profit organisations (J-DHF; Mittal 2017); and five did not report sources of funding (Adamyan 2010; Aronow 1997; Sahoo 2016; Shu 2005; Takeda 2004).

\section{Mineralocorticoid receptor antagonists (MRA)}

We included 12 studies that investigated MRAs for HFpEF. Of these, eight compared MRA versus placebo (ALDO-DHF; AREA IN-CHF; Kurrelmeyer 2014; Mottram 2004; RAAM-PEF; STRUCTURE; TOPCAT; Upadhya 2017) and four versus usual care (Karapysh 2015; Mak 2009; Orea-Tejeda 2007; Wang 2010). Nine studies investigated spironolactone (ALDO-DHF; Kurrelmeyer 2014; Mottram 2004; STRUCTURE; Upadhya 2017 (25 mg/d); Karapysh 2015; Orea-Tejeda 2007 ( $25 \mathrm{mg} / \mathrm{d}$ up-titrated if tolerated to $50 \mathrm{mg} / \mathrm{d}$ ); TOPCAT (15 mg/

Beta-blockers and inhibitors of the renin-angiotensin aldosterone system for chronic heart failure with preserved ejection fraction 
$\mathrm{d}$, increased to a maximum of $45 \mathrm{mg} / \mathrm{d})$; Wang $2010(50 \mathrm{mg} / \mathrm{d})$ ). Two studies used eplerenone (Mak 2009; RAAM-PEF (25 mg/d to a maximum of $50 \mathrm{mg} / \mathrm{d}$ )). AREA IN-CHF investigated canrenone at a maximum dose of $50 \mathrm{mg} / \mathrm{d}$.

Numbers of participants randomised ranged from 28 (Orea-Tejeda 2007 ) to 3445 (TOPCAT). Four were multicentre trials; ALDO-DHF included 10 centres in Germany and Austria; AREA IN-CHF was conducted in 46 centres in Italy; STRUCTURE had centres in Poland (the number is unclear but publication states "of each centre"); and TOPCAT was conducted across 233 sites in six countries (Argentina, Brazil, Canada, Georgia, Russia, USA). Two studies were singlecentre trials in USA (Kurrelmeyer 2014; RAAM-PEF). Mottram 2004 was a single centre trial in Australia. Wang 2010 was a single centre trial in Taiwan. Mak 2009 was a single-centre trial but the country was unspecified. Three trials did not report on numbers of centres or countries (Karapysh 2015; Orea-Tejeda 2007; Upadhya 2017).

Two studies (Karapysh 2015; Mottram 2004) did not report participants' LVEF at baseline. AREA IN-CHF had a mean LVEF at baseline of $39.9 \%$ (intervention) and $39.7 \%$ (control) for the overall included participants $(\mathrm{N}=467)$. However, we obtained outcome data for the subgroup of participants with LVEF $>40 \%(N=225)$. The LVEF in the remaining seven studies ranged from $62 \%$ to $72 \%$.

Most participants in five studies were NYHA class II (52\% to 88\%; ALDO-DHF; Mak 2009; RAAM-PEF; STRUCTURE; TOPCAT). Most participants in two studies were NYHA class III (58\% to 64\%; Kurrelmeyer 2014; Upadhya 2017). Three studies did not report NYHA class for participants eligible for inclusion in our review (AREA IN-CHF; Karapysh 2015; Mottram 2004). Orea-Tejeda 2007 reported that most participants in the intervention arm were NYHA class III $(57.1 \%)$ and NYHA class I (75\%) in the control arm.

Participants' mean age ranged from 54.5 years to 80 years; seven studies included participants whose mean age was less than 70 years (ALDO-DHF; AREA IN-CHF; Karapysh 2015; Mottram 2004; Orea-Tejeda 2007; STRUCTURE; TOPCAT). In four studies, participants' mean age was over 70 years (Kurrelmeyer 2014; Mak 2009; RAAM-PEF; Upadhya 2017).

AREA IN-CHF was industry funded; six studies were funded by notfor-profit organisations (ALDO-DHF; Kurrelmeyer 2014; RAAM-PEF; STRUCTURE; TOPCAT; Upadhya 2017). Five studies did not report sources of funding (Karapysh 2015; Mak 2009; Mottram 2004; OreaTejeda 2007; Wang 2010).

\section{Angiotensin converting enzyme inhibitors (ACEI)}

We included eight studies that investigated ACEls for HFpEF. Of these, three compared ACEI with placebo (Kitzman 2010; PEP-CHF; Zi 2003), and five versus usual care (Aronow 1993; Aronow 1998; Hong Kong DHF; SNEGOVIK; Yuksek 2012). Two studies investigated enalapril (Aronow 1993, up to 20 mg daily; Kitzman 2010, up to 10 $\mathrm{mg}$ daily). Aronow 1998 investigated benazepril (up to $40 \mathrm{mg} / \mathrm{d}$ ). Two studies investigated perindopril (PEP-CHF, up to $4 \mathrm{mg}$ daily; Yuksek 2012, up to $10 \mathrm{mg}$ ). Hong Kong DHF investigated ramipril in one of two active arms (maximum of $10 \mathrm{mg}$ daily). Two studies investigated quinapril (SNEGOVIK, dose not reported; Zi 2003, up to $40 \mathrm{mg}$ daily).

Numbers of participants randomised ranged from 21 (Aronow 1993) to 850 (PEP-CHF). Two studies were reportedly multicentre trials (Hong Kong DHF; PEP-CHF). Hong Kong DHF did not report details on the number of centres. PEP-CHF was conducted at 53 centres in Bulgaria (3), Czech Republic (5), Hungary (10), Ireland (1), Poland (26), Russia (1), Slovakia (2), and the UK (5). Zi 2003 took place at one hospital in the UK and Yuksek 2012 was conducted in Turkey. The countries or number of centres were not reported in four studies (Aronow 1993; Aronow 1998; Kitzman 2010; SNEGOVIK).

The mean LVEF of the included participants at baseline was not reported by two studies (SNEGOVIK; Zi 2003). LVEF ranged from $61 \%$ to 69\% in five studies (Aronow 1993; Aronow 1998; Hong Kong DHF; Kitzman 2010; PEP-CHF). Most participants were classified in NYHA class II in four studies (Hong Kong DHF; Kitzman 2010; PEP-CHF; Zi 2003) and in NYHA class III in one study (Aronow 1993). Two studies did not report participants' NYHA class at baseline (Aronow 1998; SNEGOVIK).

Participants' mean age ranged from 70 years to 82 years with all studies equal to or over a mean age of 70 years.

Four studies did not report funding sources (Aronow 1993; Aronow 1998; SNEGOVIK; Yuksek 2012). Three studies were industry funded (Hong Kong DHF; PEP-CHF; Zi 2003) and one study was funded by a not-for profit organisation (Kitzman 2010).

\section{Angiotensin receptor blockers (ARB)}

We included eight studies that investigated ARBs for HFpEF. Of these, five compared ARB versus placebo (CAN-DHF; CHARMPreserved; I-PRESERVE; Kasama 2005; Parthasarathy 2009) and three compared ARB versus usual care (CandHeart; Hong Kong DHF; SUPPORT). Four studies investigated candesartan (CAN-DHF; CandHeart; CHARM-Preserved (up to $32 \mathrm{mg}$ daily), Kasama 2005 ( $8 \mathrm{mg}$ to $12 \mathrm{mg}$ daily)). Two studies investigated irbesartan (one of the two active treatment arms in Hong Kong DHF (up to $75 \mathrm{mg}$ daily), I-PRESERVE (up to $300 \mathrm{mg}$ )). Parthasarathy 2009 investigated valsartan ( $80 \mathrm{mg}$ daily). SUPPORT investigated olmesartan (up to 40 mg daily).

Numbers of participants randomised ranged from 22 (CAN-DHF) to 4128 (I-PRESERVE). Seven were multicentre trials: CAN-DHF was conducted at eight centres in Germany; CandHeart at 70 centres in Italy; CHARM-Preserved was conducted at 618 centres in 26 countries; I-PRESERVE involved 293 centres in 25 countries; Parthasarathy 2009 was conducted at five centres each in Germany and the UK; and SUPPORT was conducted at 17 centres in Japan. Hong Kong DHF was reported to be a multicentre trial but no details were provided on numbers of centres or countries. Kasama 2005 was reported to be a single-centre trial in Japan.

The mean LVEF of the included participants at baseline was not reported by CAN-DHF and ranged from $49 \%$ to $72 \%$ in seven studies (CandHeart; CHARM-Preserved; Hong Kong DHF; IPRESERVE; Kasama 2005; Parthasarathy 2009; SUPPORT). Most participants were assessed as NYHA class II at baseline in five studies (CandHeart; CHARM-Preserved; Hong Kong DHF; Kasama 2005; SUPPORT); NYHA class III in I-PRESERVE; and was not reported by two studies (CAN-DHF; Parthasarathy 2009).

Participants' mean age ranged from 61 years to 75 years. Mean age was below 70 years in six studies (CAN-DHF; CandHeart; CHARMPreserved; Kasama 2005; Parthasarathy 2009; SUPPORT) and over 70 years in two studies (Hong Kong DHF; I-PRESERVE).

Beta-blockers and inhibitors of the renin-angiotensin aldosterone system for chronic heart failure with preserved ejection fraction 
Six studies were funded by industry (CAN-DHF; Cand Heart; CHARMPreserved; Hong Kong DHF; I-PRESERVE; Parthasarathy 2009). SUPPORT was funded by a not-for-profit organisation. Kasama 2005 did not report the source of funding.

\section{Angiotensin receptor neprilysin inhibitors (ARNI)}

We did not identify any completed trials that compared ARNI to placebo or no treatment control. However, one completed and two ongoing active controlled studies were identified investigating ARNI for HFpEF. Although people with HFpEF and co-existing hypertension are often treated with the active comparators used in these studies (ARB or ACEI), these therapies are not considered as usual care for HFpEF.

The PARAMOUNT study, which randomised participants with HFpEF defined as heart failure with LVEF $\geq 45 \%$, investigated ARNI (sacubitril/valsartan), ( $\mathrm{N}=149)$ or matching ARB (valsartan), ( $N$ = 152) (Zile 2016). The primary outcome measure was change in N-terminal pro b-type natriuretic peptide (NT-proBNP), and secondary outcomes included echocardiographic parameters, NYHA class, and quality of life (KCCQ). During the 36-week followup, one death occurred in the ARNI group and two deaths in the ARB group. Hyperkalaemia and quality of life outcomes did not differ between groups (Solomon 2012). PERSPECTIVE (NCT02884206) is an ongoing RCT to examine the effect of LCZ696 compared to valsartan on cognitive outcomes in participants with HFpEF, defined as LVEF > 40\%. NCT03066804 is a four-arm, parallel group study to compare the effects of sacubitril/valsartan, enalapril, valsartan and placebo in participants with HFpEF ( LVEF $\geq 45 \%$ ), with estimated enrolment of 2200 participants.

PARAGON-HF (NCT01920711) is a large active comparator RCT comparing sacubitril/valsartan with valsartan for a composite primary outcome of cardiovascular death and heart failure hospitalisation. The study is ongoing with 4822 participants enrolled, and an estimated study completion date of March 2019.

\section{Excluded studies}

We excluded 303 studies (324 references) based on full-text assessment. Details for the reasons for exclusion are provided in the Characteristics of excluded studies table. In summary we made exclusions based on:
- wrong population: $\mathrm{n}=116$

- wrong intervention: $\mathrm{n}=8$;

- wrong comparator: $\mathrm{n}=20$;

- wrong study design: $\mathrm{n}=118$;

- subgroup of interest but no response to our enquiry for data: $n$ $=8$;

- unclear eligibility and no response to our enquiry for details: $\mathrm{n}$ $=10$;

- unclear eligibility and no current contact details: $n=13$;

- completed status in trial registry record but no published results and no response to our enquiry for data: $\mathrm{n}=1$;

- missing data and response that no details can be provided: $n=6$;

- retraction: $\mathrm{n}=1$; and

- did not take place as planned: $\mathrm{n}=2$.

\section{Studies awaiting classification}

We identified eight studies that await classification (Anonymous 2003d; Botoni 2010; Dielievska 2015; Gao 2010; Liu 2006; Metra 1999; Rapezzi 1999; Zheng 2009; Characteristics of studies awaiting classification). We are waiting to retrieve the full-text $(n=4)$, responses from translators $(n=3)$ and response from the trialists to clarify eligibility $(n=1)$.

\section{Ongoing studies}

We identified five ongoing studies (EudraCT 2013-000867-10; IMPRESS-AF; NCT02901184; NCT03066804; Zhou 2010; Characteristics of ongoing studies). Three studies are investigating MRAs: spironolactone versus placebo (EudraCT 2013-000867-10; IMPRESS-AF); spironolactone versus usual care (NCT02901184). NCT03066804 is a four-arm trial comparing ARNI (sacubitril/ valsartan), ACEI (enalapril), ARB (valsartan) and matching placebo. Zhou 2010 is testing a beta-blocker (metoprolol succinate) versus usual care.

\section{Risk of bias in included studies}

The risk of bias assessments are detailed in the Characteristics of included studies tables, and summarised in the text below and in Figure 2 and Figure 3. 
Figure 2. Risk of bias graph: review authors' judgements about each risk of bias item presented as percentages across all included studies.

Random sequence generation (selection bias)

Allocation concealment (selection bias)

Blinding of participants and personnel (performance bias)

Blinding of outcome assessment (detection bias)

Incomplete outcome data (attrition bias)

Selective reporting (reporting bias)

Other bias

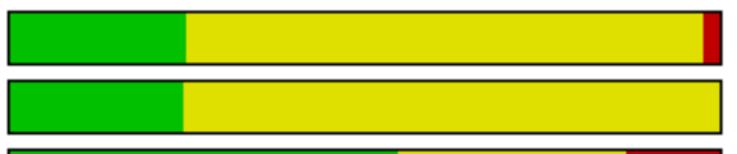

L

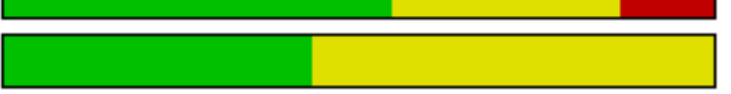

L
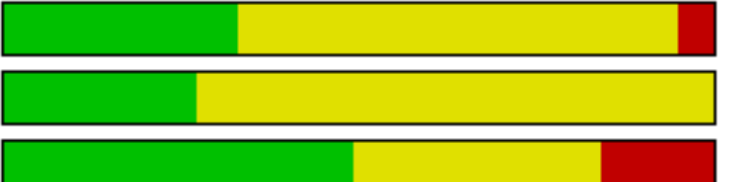

\begin{tabular}{|lllll}
\hline $0 \%$ & & 1 & 1 & \\
\hline 1 & $25 \%$ & $50 \%$ & $75 \%$ & $100 \%$
\end{tabular}

Low risk of bias

Unclear risk of bias

High risk of bias 
Figure 3. Risk of bias summary: review authors' judgements about each risk of bias item for each included study.

\begin{tabular}{|c|c|c|c|c|c|c|c|}
\hline & 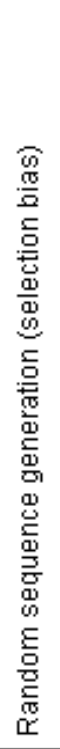 & 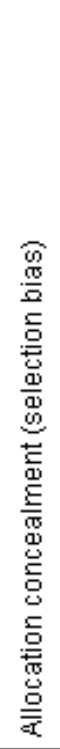 & 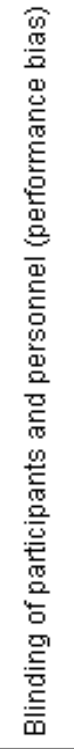 & 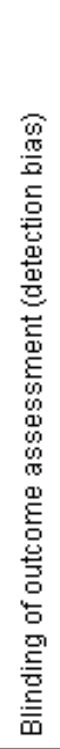 & 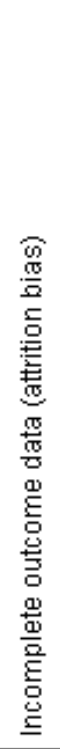 & 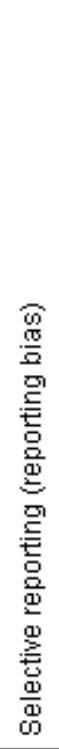 & 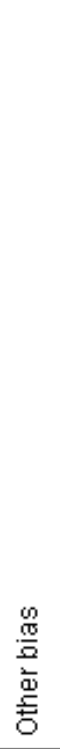 \\
\hline Adamyan 2010 & $?$ & $?$ & $?$ & $?$ & $?$ & $?$ & $\odot$ \\
\hline ALDO-DHF & $\odot$ & + & $\odot$ & $\odot$ & $\odot$ & + & $\odot$ \\
\hline AREA IN-CHF & $?$ & $?$ & + & $?$ & $?$ & $?$ & $\odot$ \\
\hline Aronow 1993 & $?$ & $?$ & $?$ & $?$ & $?$ & $?$ & $?$ \\
\hline Aronow 1997 & $?$ & $?$ & $?$ & $?$ & $?$ & $?$ & $?$ \\
\hline Aronow 1998 & ? & $?$ & $?$ & $?$ & $?$ & $?$ & $?$ \\
\hline CandHeart & $\odot$ & $?$ & 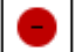 & $?$ & $?$ & $?$ & $?$ \\
\hline CAN-DHF & $?$ & $?$ & $\odot$ & $?$ & $?$ & + & $\odot$ \\
\hline CHARM-Preserved & $?$ & + & + & + & + & + & $\odot$ \\
\hline ELANDD & $\odot$ & $?$ & $\odot$ & $?$ & + & + & $\odot$ \\
\hline Hong Kong DHF & + & $?$ & $\theta$ & + & $?$ & $?$ & $?$ \\
\hline I-PRESERVE & $\oplus$ & + & 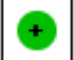 & $?$ & + & + & 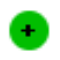 \\
\hline J-DHF & $?$ & $?$ & 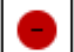 & + & + & + & $\odot$ \\
\hline Karapysh 2015 & $?$ & $?$ & $?$ & $?$ & $?$ & $?$ & $\odot$ \\
\hline Kasama 2005 & $?$ & $?$ & + & + & $\theta$ & $?$ & $?$ \\
\hline Kitman 2010 & ? & $?$ & + & + & ? & ? & $\odot$ \\
\hline Kurrelmeyer 2014 & $?$ & + & + & $?$ & $?$ & $?$ & $\boldsymbol{\theta}$ \\
\hline Mak 2009 & $?$ & $?$ & $\theta$ & $\odot$ & $?$ & ? & $\odot$ \\
\hline Mittal 2017 & $?$ & + & $\odot$ & + & $?$ & $?$ & $\odot$ \\
\hline Mottram 2004 & $?$ & $?$ & + & + & $?$ & $?$ & $?$ \\
\hline
\end{tabular}

Beta-blockers and inhibitors of the renin-angiotensin aldosterone system for chronic heart failure with preserved ejection fraction 
Figure 3. (Continued)

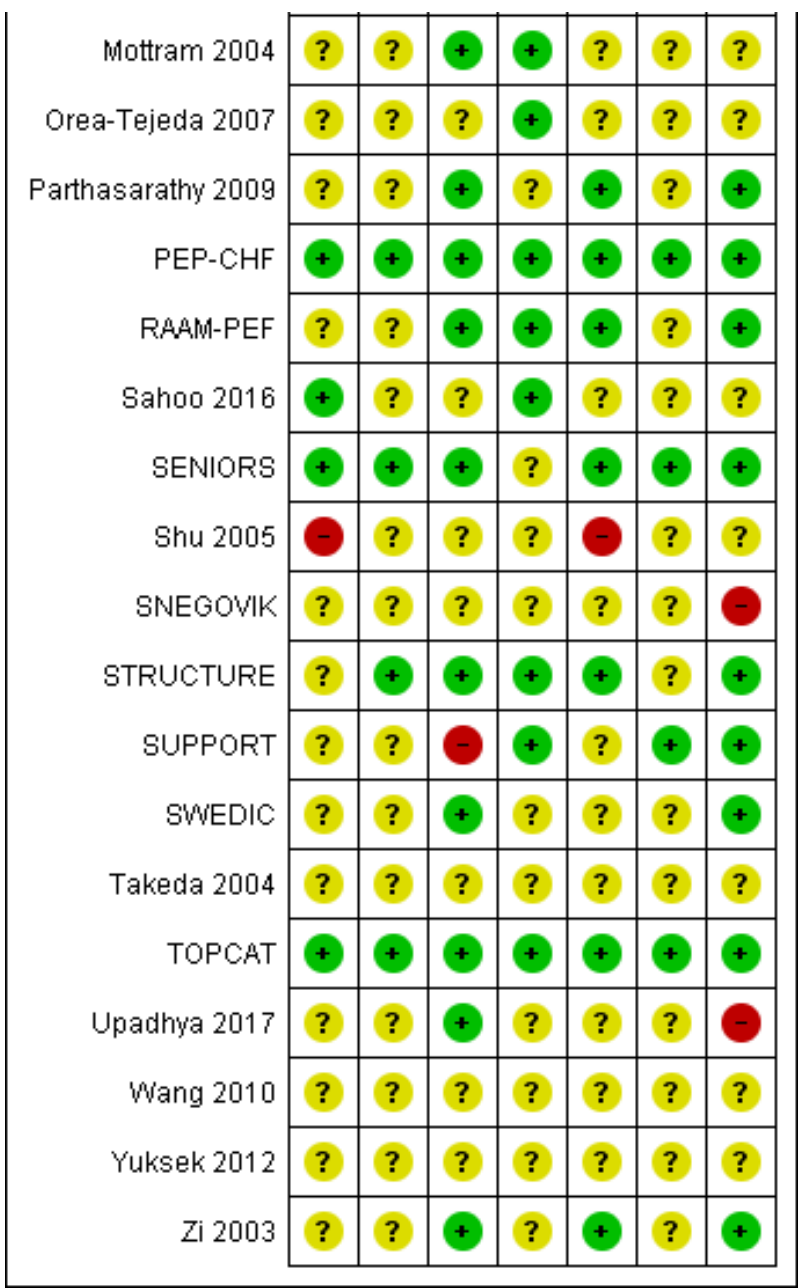

\section{Allocation}

Nine studies reported random sequence methods and were rated as low risk of bias (ALDO-DHF; CandHeart; ELANDD; Hong Kong DHF; I-PRESERVE; PEP-CHF; Sahoo 2016; SENIORS; TOPCAT). We assessed 28 studies at unclear risk of bias for this domain because no information was provided in study reports.

Nine studies used a method for allocation concealment that was judged to be of low risk of bias (ALDO-DHF; CHARM-Preserved; I-PRESERVE; Kurrelmeyer 2014; Mittal 2017; PEP-CHF; SENIORS; STRUCTURE; TOPCAT). We assessed 28 studies at unclear risk of bias for this domain because no information was provided in study reports.

\section{Blinding}

We assessed 20 studies as low risk of bias regarding blinding of participants and personnel (ALDO-DHF; AREA IN-CHF; CANDHF; CHARM-Preserved; ELANDD; I-PRESERVE; Kasama 2005; Kitzman 2010; Kurrelmeyer 2014; Mittal 2017; Mottram 2004; Parthasarathy 2009; PEP-CHF; RAAM-PEF; SENIORS; STRUCTURE; SWEDIC; TOPCAT; Upadhya 2017; Zi 2003). Five studies were openlabel designs and therefore judged to be at high risk of bias for this domain (CandHeart; Hong Kong DHF; J-DHF; Mak 2009; SUPPORT).
The remaining 12 studies were assessed at unclear risk of bias because no information was provided.

Detection bias was judged to be at low risk in 16 studies (ALDO-DHF; CHARM-Preserved; Hong Kong DHF; J-DHF; Kasama 2005; Kitzman 2010; Mak 2009; Mittal 2017; Mottram 2004; Orea-Tejeda 2007; PEPCHF; RAAM-PEF; Sahoo 2016; STRUCTURE; SUPPORT; TOPCAT). The remaining 21 studies did not provide information and were judged to be at unclear risk of detection bias.

\section{Incomplete outcome data}

Attrition bias was judged to be at low risk in 12 studies (ALDO-DHF; CHARM-Preserved; ELANDD; I-PRESERVE; J-DHF; Parthasarathy 2009; PEP-CHF; RAAM-PEF; SENIORS; STRUCTURE; TOPCAT; Zi 2003). We judged Kasama 2005 to be at high risk of bias for this domain because the study report did not indicate if losses to followup or withdrawals occurred. All other 25 studies were assessed as unclear risk of bias for attrition bias as no information was reported to allow judgement.

\section{Selective reporting}

We assessed 10 studies to be at low risk of reporting bias (ALDODHF; CAN-DHF; CHARM-Preserved; ELANDD; I-PRESERVE; J-DHF; PEP-CHF; SENIORS; SUPPORT; TOPCAT). These 10 studies reported 
planned outcomes in either published protocols or clinical trial registers before enrolment started. We were unable to assess reporting bias in 27 studies because either no information was available in the form of protocols or clinical trial registry entries, or they were published/entered after enrolment was completed.

\section{Other potential sources of bias}

We judged 18 studies to be at low risk of other biases (mainly based on providing details on funding and declaring any conflict of interest by the authors) (ALDO-DHF; AREA IN-CHF; CHARMPreserved; ELANDD; I-PRESERVE; J-DHF; Kitzman 2010; Mak 2009; Mittal 2017; Parthasarathy 2009; PEP-CHF; RAAM-PEF; SENIORS; STRUCTURE; SUPPORT; SWEDIC; TOPCAT; Zi 2003).

We judged six studies to be at high risk of other bias. Kurrelmeyer 2014 was originally registered as an observational study and this detail was changed after completion of the trial but before the results were published. Five studies (Adamyan 2010; CANDHF; Karapysh 2015; SNEGOVIK; Upadhya 2017) were published as conference abstracts only; withholding the full results from publication may present a form of bias. The remaining 26 studies were judged to be at unclear risk of bias.

\section{Effects of interventions}

See: Summary of findings for the main comparison Beta-blockers compared to placebo or no treatment for chronic heart failure with preserved ejection fraction; Summary of findings 2 MRA compared to placebo or no treatment for chronic heart failure with preserved ejection fraction; Summary of findings $3 \mathrm{ACEl}$ compared to placebo or no treatment for chronic heart failure with preserved ejection fraction; Summary of findings 4 ARB compared to placebo or no treatment for chronic heart failure with preserved ejection fraction

\section{Beta-blockers versus placebo or no treatment}

We included 10 studies that involved a total of 3087 participants that assessed beta-blockers versus placebo or no treatment. The main outcomes for this comparison are included in Summary of findings for the main comparison.

\section{Cardiovascular mortality}

Six studies reported cardiovascular mortality (Aronow 1997; ELANDD; J-DHF; SENIORS; SWEDIC; Takeda 2004). Three studies reported that no deaths occurred (ELANDD; SWEDIC; Takeda 2004). We included three studies in the meta-analysis (Aronow 1997; JDHF; SENIORS) (15\% of participants in the intervention arm versus $19 \%$ in the control arm; RR 0.78; $95 \% \mathrm{Cl} 0.62$ to 0.99 ; NNTB 25; 1046 participants; $I^{2}=0 \%$; low-quality evidence; Analysis 1.1 ).

J-DHF reported cardiovascular mortality but with different numbers for events within the same table (Table 2 in the primary reference). We contacted the study authors to seek clarification but are yet to receive a response; we used the higher numbers in the analysis.

SENIORS reported a hazard ratio (HR 0.80; 95\% $\mathrm{Cl} 0.49$ to $1.32 ; 643$ participants).

\section{Heart failure hospitalisation}

We included five studies that reported heart failure hospitalisation (ELANDD; J-DHF; Shu 2005; SWEDIC; Takeda 2004). ELANDD reported that no hospitalisation occurred due to heart failure. Data from four studies (J-DHF; Shu 2005; SWEDIC; Takeda 2004) contributed to the meta-analysis (RR $0.73 ; 95 \% \mathrm{Cl} 0.47$ to $1.13 ; 449$ participants; $\left.\right|^{2}=22 \%$; very low-quality evidence; Analysis 1.2 ).

\section{Hyperkalaemia}

J-DHF reported that one participant in the intervention group $(\mathrm{N}=$ 120) experienced hyperkalaemia but did not report on this outcome for the control group (very low-quality evidence). No further data were available from any other studies.

\section{All-cause mortality}

We included seven studies that reported all-cause mortality (Adamyan 2010; Aronow 1997; ELANDD; J-DHF; SENIORS; SWEDIC; Takeda 2004). Of these, three studies reported that no deaths occurred (ELANDD; SWEDIC; Takeda 2004). We included data from four studies in the meta-analysis (Adamyan 2010; Aronow 1997; JDHF; SENIORS) (RR 0.82; 95\% Cl 0.67 to $1.00 ; 1105$ participants; $I^{2}=$ $0 \%$; low-quality evidence; Analysis 1.3).

J-DHF reported all-cause mortality but with different numbers for events within the same table (Table 2 in the primary reference). We contacted the study authors to seek clarification but are yet to receive a response. We used the higher number of deaths in the analysis.

SENIORS reported a hazard ratio ( $\mathrm{HR} 0.92 ; 95 \% \mathrm{Cl} 0.61$ to $1.36 ; 643$ participants).

\section{Quality of life}

We included two studies that reported quality of life (ELANDD; Mittal 2017). Mittal 2017 reported quality of life using SF-36, which was not a scale we considered for our analysis. ELANDD reported end scores for the Minnesota Living with Heart Failure Questionnaire (MLHFQ) total score and showed MD -1.00 between the treatment arms, favouring the intervention $(95 \% \mathrm{Cl}-9.05$ to 7.05; 93 participants; very low-quality evidence).

\section{Withdrawal due to adverse event}

We included five studies that reported withdrawals due to adverse events (Aronow 1997; ELANDD; J-DHF; Mittal 2017; Sahoo 2016). Mittal 2017 and Sahoo 2016 reported no withdrawals due to adverse events. Aronow 1997 reported 11 withdrawals due to "worsening $\mathrm{CHF}$ [chronic heart failure] in 7 patients and hypotension in 4 patients" but did not provide this information by intervention arm. Only two studies (ELANDD; J-DHF) contributed data for metaanalysis (9\% of participants in the intervention arm versus $0 \%$ in the control arm, RR $18.07 ; 95 \% \mathrm{Cl} 2.45$ to $133.04 ; 338$ participants; $1^{2}=0 \%$; Analysis 1.5; number needed to harm (NNTH) 11 ).

\section{Mineralocorticoid receptor antagonists (MRA) versus placebo or no treatment}

We included 12 studies (4408 participants) that assessed MRA versus placebo or no treatment. The main outcomes for this comparison are included in Summary of findings 2. The findings for this comparison were driven by one trial (TOPCAT). Four trials (Karapysh 2015; Mottram 2004; Orea-Tejeda 2007; Wang 2010) did not contribute any outcome data of interest for this review.

Beta-blockers and inhibitors of the renin-angiotensin aldosterone system for chronic heart failure with preserved ejection fraction (Review)

Copyright (c) 2018 The Cochrane Collaboration. Published by John Wiley \& Sons, Ltd. 


\section{Cardiovascular mortality}

We included five studies that reported cardiovascular mortality (ALDO-DHF; AREA IN-CHF; Kurrelmeyer 2014; RAAM-PEF; TOPCAT). Of these, two studies reported that no deaths occurred (Kurrelmeyer 2014; RAAM-PEF). We included data from three studies in the meta-analysis (ALDO-DHF; AREA IN-CHF; TOPCAT) (RR $0.90 ; 95 \% \mathrm{Cl} 0.74$ to $1.11 ; 4070$ participants; $\mathrm{I}^{2}=0 \%$; moderatequality evidence; Analysis 2.1).

TOPCAT also reported a hazard ratio (HR 0.90; $95 \% \mathrm{Cl} 0.73$ to 1.12 ; 3445 participants).

\section{Heart failure hospitalisation}

We included six studies that reported heart failure hospitalisation (ALDO-DHF; AREA IN-CHF; Kurrelmeyer 2014; RAAM-PEF; TOPCAT; Upadhya 2017). Of these, three studies reported no hospitalisations due to heart failure (ALDO-DHF; Kurrelmeyer 2014; Upadhya 2017). We included data from three studies in the meta-analysis (AREA INCHF; RAAM-PEF; TOPCAT) (11\% of participants in the intervention arm versus $14 \%$ in the control arm, RR $0.82 ; 95 \% \mathrm{Cl} 0.69$ to 0.98 ; 3714 participants; NNTB $41 ; I^{2}=22 \%$; moderate-quality evidence; Analysis 2.2).

Hazard ratios for time to first heart failure hospitalisation were reported for two studies (AREA IN-CHF; TOPCAT) (HR 0.82; 95\% $\mathrm{Cl} 0.69$ to $0.98 ; 3670$ participants; $\left.\right|^{2}=59 \%$; Analysis 2.3). The substantial heterogeneity was explained by differences in population characteristics (TOPCAT, LVEF $\geq 45 \%$; AREA IN-CHF subgroup, LVEF $40 \%$ to $45 \%$ ).

\section{Hyperkalaemia}

We included six studies that reported hyperkalaemia (ALDO-DHF; AREA IN-CHF; Kurrelmeyer 2014; RAAM-PEF; STRUCTURE; TOPCAT) (16\% of participants in the intervention arm versus $8 \%$ in the control arm, RR $2.11 ; 95 \% \mathrm{Cl} 1.77$ to $2.51 ; 4291$ participants; I $^{2}=0 \%$; high-quality evidence; Analysis 2.4).

\section{All-cause mortality}

We included eight studies that reported all-cause mortality (ALDODHF; AREA IN-CHF; Kurrelmeyer 2014; Mak 2009; RAAM-PEF; STRUCTURE; TOPCAT; Upadhya 2017). Of these, three studies reported that no deaths occurred (Kurrelmeyer 2014; RAAM-PEF; STRUCTURE). The meta-analysis included data from five studies (ALDO-DHF; AREA IN-CHF; Mak 2009; TOPCAT; Upadhya 2017) (RR $0.91 ; 95 \% \mathrm{Cl} 0.78$ to $1.06 ; 4207$ participants; $I^{2}=0 \%$; moderatequality evidence; Analysis 2.5).

TOPCAT also reported a hazard ratio (HR 0.91; $95 \% \mathrm{Cl} 0.77$ to 1.08 ; 3445 participants).

\section{Quality of life}

We included six studies that reported quality of life (ALDO-DHF; Kurrelmeyer 2014; Mak 2009; RAAM-PEF; TOPCAT; Upadhya 2017). TOPCAT reported quality of life in a report by Lewis 2016 , but the end scores per treatment arm were not provided. We contacted the investigators and await details.

Three studies (ALDO-DHF; Mak 2009; Upadhya 2017) reported total MLFHQ scores and were pooled for analysis (MD 0.84; $95 \% \mathrm{Cl}$ -2.30 to $3.98 ; 511$ participants; $I^{2}=0 \%$; low-quality evidence; Analysis 2.8). Kurrelmeyer 2014 and RAAM-PEF reported Kansas City
Cardiomyopathy Questionnaire (KCCQ) results and were pooled (MD $-0.78 ; 95 \% \mathrm{Cl}-28.02$ to $26.46 ; 92$ participants; $\left.\right|^{2}=86 \%$; Analysis 2.7). The substantial heterogeneity could not be explained.

All five studies that used MLHFQ and KCCQ were pooled (SMD 0.05; $95 \% \mathrm{Cl}-0.23$ to $0.34 ; 603$ participants; $I^{2}=50 \%$; Analysis 2.6 ). The substantial heterogeneity could not be explained.

\section{Withdrawal due to adverse event}

Four studies reported this outcome (ALDO-DHF; Kurrelmeyer 2014; TOPCAT; Upadhya 2017) and contributed to the meta-analysis (RR $1.10 ; 95 \% \mathrm{Cl} 1.00$ to $1.21 ; 3986$ participants; $I^{2}=0 \%$; Analysis 2.9 ).

\section{Angiotensin converting enzyme inhibitors (ACEI) versus placebo or no treatment}

We included eight studies that involved a total of 2061 participants that assessed ACEI versus placebo or no treatment. The main outcomes for this comparison are presented in Summary of findings 3 . The findings for this comparison were driven by PEPCHF. Two studies (Aronow 1993; Yuksek 2012) did not contribute any outcome data of interest for this review.

\section{Cardiovascular mortality}

Three studies reported cardiovascular mortality (Hong Kong DHF; Kitzman 2010; PEP-CHF). Kitzman 2010 reported that no deaths occurred. Hong Kong DHF and PEP-CHF contributed data to the meta-analysis (RR $0.93 ; 95 \% \mathrm{Cl} 0.61$ to $1.42 ; 945$ participants; $I^{2}=$ $0 \%$; moderate-quality evidence; Analysis 3.1 ).

PEP-CHF also reported a hazard ratio (HR 0.98; $95 \% \mathrm{Cl} 0.63$ to 1.52 ; 850 participants).

\section{Heart failure hospitalisation}

Three studies (Hong Kong DHF; PEP-CHF; Zi 2003) reported heart failure hospitalisation and were pooled for analysis (RR $0.86,95 \% \mathrm{Cl}$ 0.64 to $1.15 ; 1019$ participants; $I^{2}=0 \%$; moderate-quality evidence; Analysis 3.2).

PEP-CHF also reported a hazard ratio (HR 0.86, 95\% Cl 0.61 to 1.20 ; 850 participants).

\section{Hyperkalaemia}

Zi 2003 reported hyperkalaemia (RR 5.27; 95\% Cl 0.26 to 106.16; 74 participants; very low-quality evidence; Analysis 3.3).

\section{All-cause mortality}

We included five studies that reported all-cause mortality (Aronow 1998; Hong Kong DHF; Kitzman 2010; PEP-CHF; Zi 2003). Kitzman 2010 reported that no deaths occurred. Four studies (Aronow 1998; Hong Kong DHF; PEP-CHF; Zi 2003) contributed to the metaanalysis (RR 0.99; 95\% Cl 0.71 to $1.38 ; 1079$ participants; $I^{2}=0 \%$; moderate-quality evidence; Analysis 3.4).

PEP-CHF also reported a hazard ratio (HR 1.09; $95 \% \mathrm{Cl} 0.75$ to 1.58 ; 850 participants)

\section{Quality of life}

Three studies reported quality of life assessed using the MLHFQ scale (Hong Kong DHF; Kitzman 2010; SNEGOVIK). SNEGOVIK reported quality of life assessment based on the MLHFQ scale as

Beta-blockers and inhibitors of the renin-angiotensin aldosterone system for chronic heart failure with preserved ejection fraction 
change from baseline per treatment arm (-18.9 for intervention, -10.7 for control). We were unsuccessful in our attempts to contact study authors to obtain scores at the end of follow-up. Two studies (Hong Kong DHF; Kitzman 2010) contributed to the meta-analysis (MD $-0.09 ; 95 \% \mathrm{Cl}-3.66$ to $3.48 ; 154$ participants; $\left.\right|^{2}=4 \%$; low-quality evidence; Analysis 3.5).

Zi 2003 assessed quality of life using the McMaster quality of life questionnaire and reported end scores at six months and reported $12.9 \pm 3.1$ for the intervention and $13.1 \pm 4.7$ for the control arm.

\section{Withdrawal due to adverse event}

Three studies (Hong Kong DHF; PEP-CHF; Zi 2003) reported this outcome and were pooled for analysis (RR $1.53 ; 95 \% \mathrm{Cl} 0.26$ to 9.00; 1019 participants; $\left.\right|^{2}=59 \%$; Analysis 3.6).

\section{Angiotensin receptor blockers (ARB) versus placebo or no treatment}

We included eight studies that involved a total of 8755 participants that assessed ARB versus placebo or no treatment. The main outcomes for this comparison are included in Summary of findings 4 . The findings for this comparison were driven by two studies (CHARM-Preserved; I-PRESERVE). Three trials (CAN-DHF; CandHeart; Kasama 2005) did not contribute any outcome data of interest for this review.

\section{Cardiovascular mortality}

Four studies reported this outcome (CHARM-Preserved; Hong Kong DHF; I-PRESERVE; Parthasarathy 2009). Parthasarathy 2009 reported that no deaths occurred. Three studies (CHARMPreserved; Hong Kong DHF; I-PRESERVE) contributed to the metaanalysis (RR 1.02; 95\% Cl 0.90 to 1.14; 7254 participants; $I^{2}=0 \%$; high-quality evidence; Analysis 4.1).

Two studies (CHARM-Preserved; I-PRESERVE) were also pooled for analysis (HR 1.00; 95\% Cl 0.89 to 1.13; 5087 participants; Analysis 4.2).

\section{Heart failure hospitalisation}

Three studies (CHARM-Preserved; Hong Kong DHF; I-PRESERVE) reported this outcome and were pooled for analysis (RR 0.92; 95\% $\mathrm{Cl} 0.83$ to $1.02 ; 7254$ participants; $I^{2}=0 \%$; high-quality evidence; Analysis 4.3).

Two studies (CHARM-Preserved; I-PRESERVE) were also pooled for analysis (HR 0.90; 95\% Cl 0.80 to 1.01; 7148 participants; Analysis 4.4).

\section{Hyperkalaemia}

Two studies reported this outcome and were pooled for analysis (CHARM-Preserved; I-PRESERVE) (0.9\% of participants in the intervention group and $0.5 \%$ in the control group; RR 1.88; $95 \%$ $\mathrm{Cl} 1.07$ to 3.33; participants $=7148$; high-quality evidence; Analysis 4.5).

\section{All-cause mortality}

Five studies reported this outcome (CHARM-Preserved; Hong Kong DHF; I-PRESERVE; Parthasarathy 2009; SUPPORT). Parthasarathy 2009 reported that no deaths occurred. Four studies (CHARMPreserved; Hong Kong DHF; I-PRESERVE; SUPPORT) contributed to the meta-analysis (RR 1.01; 95\% Cl 0.92 to $1.11 ; 7964$ participants; $1^{2}=0 \%$; high-quality evidence; Analysis 4.6). For the SUPPORT trial, data for participants with LVEF $\geq 50 \%$ were analysed according to the definition of HFpEF used in this trial.

Two studies (I-PRESERVE; SUPPORT) were also pooled for analysis (HR 0.99; $95 \% \mathrm{Cl} 0.88$ to $1.12 ; 4838$ participants; Analysis 4.7).

\section{Quality of life}

Four studies reported this outcome (CHARM-Preserved; Hong Kong DHF; I-PRESERVE; Parthasarathy 2009). CHARM-Preserved reported quality of life (MLHF) in a study report (Lewis 2007): however, end scores per treatment arm were not provided. Three studies (Hong Kong DHF; I-PRESERVE; Parthasarathy 2009) contributed to the meta-analysis for MLHF (MD $0.41 ; 95 \% \mathrm{Cl}-0.86$ to $1.67 ; 3117$ participants; $\left.\right|^{2}$ = 19\%; high-quality evidence; Analysis 4.8).

\section{Withdrawal due to adverse event}

Four studies (CHARM-Preserved; Hong Kong DHF; I-PRESERVE; Parthasarathy 2009) reported this outcome and contributed to the meta-analysis (16\% of participants in the intervention arm versus $13 \%$ in the control arm; RR $1.22 ; 95 \% \mathrm{Cl} 1.09$ to $1.36 ; 7406$ participants; $I^{2}=0 \%$; Analysis 4.9; NNTH 33).

\section{Angiotensin receptor neprilysin inhibitors (ARNI) versus placebo or no treatment}

We did not identify any completed trials that assessed ARNI.

\section{Subgroup analyses}

We were unable to perform a subgroup analysis for length of follow up for cardiovascular mortality as all included studies fell into one category of follow-up ( $\geq 12$ months: Analysis 1.1; Analysis 2.1; Analysis 3.1; Analysis 4.1). Similarly, we were unable to perform a subgroup analysis for ARB and heart failure hospitalisation (Analysis 4.3).

Heart failure hospitalisation for the comparison of beta-blockers versus control (Analysis 1.2) showed no difference among the subgroups (< 12 months: RR $0.31 ; 95 \% \mathrm{Cl} 0.09$ to $1.02 ; 67$ participants; 1 study; versus $\geq 12$ months: RR $0.79 ; 95 \% \mathrm{Cl} 0.48$ to $1.31 ; 285$ participants; studies $=2$ ). SWEDIC did not report length of follow-up.

Heart failure hospitalisation for the comparison of MRA versus control (Analysis 2.2) showed a confirmation of the overall effect estimate (RR $0.82 ; 95 \% \mathrm{Cl} 0.69$ to $0.98 ; 3714$ participants; 3 studies) only in the subgroup for follow-up $\geq 12$ months (RR $0.82 ; 95 \% \mathrm{Cl} 0.69$ to $0.98 ; 3670$ participants; 2 studies) while the much smaller study of shorter duration (< 12 months) showed RR $0.55 ; 95 \% \mathrm{Cl} 0.05$ to $5.61 ; 44$ participants.

Heart failure hospitalisation for the comparison of ACEI versus control (Analysis 3.2) showed no difference between subgroups (< 12 months: RR $0.42 ; 95 \% \mathrm{Cl} 0.09$ to $2.04 ; 74$ participants; 1 study; versus $\geq 12$ months: RR $0.88 ; 95 \% \mathrm{Cl} 0.66$ to 1.19 ; 945 participants; 2 studies).

\section{Sensitivity analyses}

We conducted a sensitivity analysis by only including studies assessed at low risk of bias. Across comparisons, the estimates were not significantly changed with the exception of beta-blockers where

Beta-blockers and inhibitors of the renin-angiotensin aldosterone system for chronic heart failure with preserved ejection fraction 
no effect on cardiovascular mortality was observed (1 low risk of bias study (SENIORS): RR $0.81 ; 95 \% \mathrm{CI} 0.50$ to 1.29 versus overall analysis of 3 studies: RR $0.78 ; 95 \% \mathrm{Cl} 0.62$ to 0.99 ).

\section{DISCUSSION}

\section{Summary of main results}

We examined the evidence for the effects of $B B$ and RAAS inhibitors for the treatment of HFpEF. We included 37 trials, reported in 207 publications that involved a total of 18,311 participants. We identified five ongoing trials with treatment arms that include interventions assessed in this review. A further eight studies await assessment.

We performed a pooled analysis for the outcomes of cardiovascular and all-cause mortality, heart failure hospitalisation, quality of life and hyperkalaemia. We used data from the Minnesota Living with Heart Failure (MLHF) questionnaire for quality of life outcomes because this was most frequently reported instrument.

Withdrawals due to adverse events were inconsistently reported; these data could not be included in 'Summary of findings' tables.

We conducted a sensitivity analysis by including only studies assessed with overall low risk of bias. The effect estimates were not significantly changed except for beta-blockers.

\section{Beta-blockers}

A total of 10 included studies (3087 participants) assessed betablockers compared with placebo or no intervention. We performed meta-analyses including up to four studies and 1105 participants. The results suggested that treatment may improve cardiovascular mortality, however the quality of evidence was low due to imprecision and risk of bias. When we performed a sensitivity analysis by including only studies at low overall risk of bias, the effects on cardiovascular mortality did not persist. The two largest studies (J-DHF; SENIORS) reported high rates of study drug discontinuation due to intolerance rather than adverse events, which may have attenuated any true treatment effects. There is uncertainty about the effects of beta-blocker pharmacotherapy in people with HFpEF. A large, randomised, controlled, open label, clinical outcomes trial of metoprolol for HFpEF is ongoing (Zhou 2010, beta-PRESERVE).

\section{Mineralocorticoid receptor antagonists (MRA)}

A total of 12 studies (4408 participants) assessed MRA compared with placebo or no intervention. We combined evidence from up to six trials and 4291 participants in meta-analyses. We found that treatment with MRA reduces the risk of heart failure hospitalisation but found little or no effect on cardiovascular and all-cause mortality; however the quality of evidence was moderate and uncertainty remains over these treatment effects. As expected, MRA treatment was associated with an increased risk of hyperkalaemia; potassium monitoring is therefore required in people being treated using MRA. A large, registry-randomised clinical outcomes trial of spironolactone for HFpEF is ongoing and due to complete in 2022 (NCT02901184: Spironolactone Initiation Registry Randomized Interventional Trial in Heart Failure with Preserved Ejection Fraction, SPIRRIT).

\section{Angiotensin converting enzyme inhibitors (ACEI)}

A total of eight included studies (2062 participants) assessed ACEI versus placebo or no intervention. We conducted a meta-analysis of data from four trials and 1079 participants. We found that there was probably little or no effect on cardiovascular mortality, all-cause mortality, heart failure hospitalisation or quality of life and data on hyperkalaemia were limited. No large clinical trials (>1000 participants) were available and the quality of evidence was assessed as moderate due to imprecision. The effectiveness of ACEI therapy in the treatment of people with HFpEF remains unclear.

\section{Angiotensin receptor antagonists (ARB)}

A total of eight included studies (8755 participants) assessed ARB therapy for people with HFpEF with the evidence quality assessed as high. We combined evidence from up to four trials and 7964 participants for meta-analysis and found little or no overall difference on the outcomes of cardiovascular mortality, allcause mortality, heart failure hospitalisation or quality of life. The CHARM study found an effect on heart failure hospitalisation based on a time to event analysis, and the strength of this association was increased in a subsequent analysis based on recurrent events (Rogers 2014). As expected, ARB treatment was associated with an increased risk of hyperkalaemia; potassium monitoring is therefore required.

\section{Overall completeness and applicability of evidence}

This review provides the most comprehensive appraisal of the evidence to date. We included 37 studies (207 reports) that involved 18,311 participants. The included trials assessed beta-blockers (10 studies, 3087 participants), MRA (12 studies, 4408 participants), ACEI (8 studies, 2061 participants) and ARB (8 studies, 8755 participants).

We searched clinical trials registries and identified five ongoing clinical trials, several of which have potential to influence the review findings. We also identified eight studies that were classified as Studies awaiting classification, for which there was insufficient information to determine whether these studies met our inclusion criteria. These studies were mostly small and it is therefore unlikely that they would influence the results of this review. In total, we identified 207 reports of 37 trials, 8 studies awaiting classification, and 5 ongoing trials, compared with a total of 22 identified by Zheng 2017 for the same comparisons.

The LVEF threshold for defining the HFpEF trial populations varied among the included studies and may contribute to indirectness with implications for the applicability of the evidence. Nine studies included participants with an ejection fraction cut-off of $40 \%, 10$ used $45 \%, 14$ used $50 \%$, and one used $55 \%$. Adamyan 2010 included participants with preserved ejection fraction but did not specify the cut-off. SENIORS reported a subgroup of participants with LVEF > $40 \%$ and we obtained outcomes for a subgroup with LVEF $>40 \%$ for AREA IN-CHF. No trials reported outcomes for the subgroup in the $40 \%$ to $49 \%$ mid-range so we were unable to investigate this subgroup.

The included studies had enrolment start dates from 1997 to 2011. In more recent studies, B-type natriuretic peptides have been used as a key inclusion criterion to improve the specificity of the HFpEF population and enrich the trial populations for people at higher risk for clinical outcomes (e.g. CAN-DHF; Mak 2009; RAAM-PEF). 
Similarly, new measures of diastolic function have been included in more recent studies to increase the specificity (e.g. ELANDD; J-DHF; PEP-CHF). We noted considerable clinical heterogeneity between study populations with respect to comorbidities and cardiovascular therapies at baseline, which may influence the applicability of the evidence.

\section{Quality of the evidence}

We used the GRADE method to assess evidence quality for the outcomes of cardiovascular mortality, all-cause mortality, heart failure hospitalisation, quality of life (assessed using the Minnesota Living with Heart Failure questionnaire), and hyperkalaemia. For beta-blockers, evidence quality for clinical outcomes (cardiovascular mortality, all-cause mortality and heart failure hospitalisation) ranged from low to very low. In the combined analysis, most participants were from a subgroup of a single large trial; the other included studies were small with high or unclear risk of bias.

For MRA, the TOPCAT study contributed the majority of participants to the meta-analysis for which the overall evidence quality for clinical outcomes was assessed as moderate. We noted differences in participant populations among the included studies (TOPCAT, LVEF > 40\%; RAAM-PEF, LVEF $\geq 50 \%$; AREA IN-CHF LVEF $40 \%$ to $45 \%$ ) and it is reported that ejection fraction is a modifier of treatment effect for MRA (Solomon 2016). Notably, a post hoc analysis of the TOPCAT study reported important differences in the placebo event rates among participants enrolled from the Americas (Argentina, Brazil, Canada, USA) and participants enrolled from Russia and Georgia (Pfeffer 2015). Furthermore, a pharmacology substudy of participants at 12 months (206 participants from USA and Canada; 160 participants from Russia) found that drug metabolites were undetectable in a greater proportion of participants from Russia compared with participants from the USA and Canada (30\% versus $3 \%, \mathrm{P}<0.001$ ) (de Denus 2017). A geographical subgroup analysis suggested possible clinical benefit from spironolactone in HFpEF in participants who were enrolled in the Americas (United States, Canada, Brazil, Argentina; cardiovascular mortality HR 0.74, 95\% $\mathrm{Cl} 0.57$ to 0.97 ; all-cause mortality $\mathrm{HR} 0.83,95 \% \mathrm{Cl} 0.68$ to 1.02 ; heart failure hospitalisation HR $0.82,95 \% \mathrm{Cl} 0.67$ to 0.99 ). These findings will be investigated further in the ongoing SPIRRIT study (NCT02901184).

For ARB, several large trials contributed a large number of events to the meta-analysis for the clinical outcomes of mortality and heart failure hospitalisation, and the evidence quality was high. For ACEI, fewer trials were included in the combined analysis, event numbers were low and the evidence quality was assessed as moderate. For beta-blockers, the quality of evidence was low due to small study

\section{Potential biases in the review process}

Although we conducted a comprehensive search of major databases, it is possible we missed studies on clinical trials registers, had not been reported, or both. Where information on relevant subgroups or outcomes were not reported, we attempted to contact the study authors however only a limited number of responses were received. Given the small number of included studies per analysis, we were unable to formally assess for the existence of publication bias. sizes and risk of bias.

\section{Agreements and disagreements with other studies or reviews}

Our results were largely consistent with those from the most recent comprehensive review of evidence for beta-blockers and RAAS inhibitors in people with HFpEF (Zheng 2017). However, important differences were noted. Our analysis included more studies for each comparison, but the additional studies were small and did not significantly alter the overall effect estimates. A further distinction is that we used a fixed-effect model rather than a randomeffects model for meta-analysis given the low heterogeneity among studies for all comparisons. We found a reduction in cardiovascular mortality for beta-blocker therapy but this was not robust to a sensitivity analysis that included only studies assessed at low risk of bias. In contrast to Zheng 2017, we did not find an effect of betablocker treatment on all-cause mortality that achieved statistical significance.

\section{AUTHORS' CONCLUSIONS}

\section{Implications for practice}

The available evidence for the effects of treatment with betablockers, MRA, ACEI, ARNI for HFpEF was limited. Beta-blockers may improve cardiovascular mortality however the quality of evidence was low. The evidence for MRA suggests that treatment reduces the risk of $\mathrm{HF}$ hospitalisation; there was little or no effect on cardiovascular and all-cause mortality however the quality of evidence was only moderate due to imprecision. Treatment with ACEI probably has little or no effect on the outcomes of cardiovascular and all-cause mortality and heart failure hospitalisation, however evidence was limited. There is high quality evidence that ARB treatment has no beneficial effect on these outcomes. For all comparisons, no effect on quality of life was observed however the quality of evidence was low. The mainstay of pharmacological therapy in HFpEF remains the treatment of comorbid conditions such as hypertension that are implicated in aetiology and as triggers for decompensation.

\section{Implications for research}

This review highlights a persistent gap in the evidence for the role of beta-blockers, MRA, ACEI, ARNI in HFpEF. Large trials powered for clinical outcomes are under way for these interventions and these should provide greater certainty for the estimates of treatment effect. Substantial heterogeneity of study populations with respect to baseline LVEF, co-morbidity and medication was observed that may contribute to heterogeneity of treatment effects. Ultimately, a redefinition of HFpEF disease subtypes based on underlying disease mechanisms will likely be needed to enable the development of more effective therapeutic approaches. A stratified analysis of individual participant data from trials would enable the investigation of subgroups that may benefit most from beta-blockers or RAAS inhibition or both, and provide important insights to guide the design of future clinical trial. In addition, improved outcome measures that quantify the burden of disease, such as recurrent hospitalisations, may increase the power to detect any treatment effect.

\section{ACKNOWLEDGEMENTS}

T.L was supported by an NIHR Clinical Lectureship and, subsequently, a UKRI Health Data Research Fellowship. We are grateful to Marta Battle Lopez, Derya Senturk, Hatoko Sasaki, Lu

Beta-blockers and inhibitors of the renin-angiotensin aldosterone system for chronic heart failure with preserved ejection fraction 24 
Chunli, Teresa Cantisani, Liliya Eugenevna Ziganshina, Hanneke Dominicus, Joanna Zajac, Anna Aryee, and Vaclav Papez for their help with the full text assessment of non-English language papers.
We are also grateful to Rui Providencia for assessing and extracting data from non-English language papers, and to Juan-Pablo Casas for his guidance in designing this review. 


\section{RE F E R E N C E S}

\section{References to studies included in this review}

Adamyan 2010 \{published data only\}

* Adamyan KG, Tumasyan LR. Independent and additive influence of statin and beta-blocker on long-term prognosis in patients with chronic heart failure and preserved systolic function. European Heart Journal 2010;31:850.

Tumasyan LR, Adamyan KG. Influence of statin and beta-blocker on long-term prognosis in patients with chronic heart failure and preserved systolic function. European Journal of Heart Failure Supplements 2010;9:S23-4.

\section{ALDO-DHF \{published data only\}}

Borlaug BA. Heart failure: Aldosterone antagonism for HFpEF. Nature Reviews Cardiology 2013;10(5):244-6.

Djawid Hashemi D, Dettmann L, Trippel TD, Bobenko A, Gelbrich G, Lindhorst R, et al. Economic impact of heart failure with preserved ejection fraction: Insights from the prospective, randomized placebo-controlled ALDO-DHF trial. European Journal of Heart Failure 2017;19:155.

Durstewitz K, Holzendorf V, Wachter R, Gelbrich G, Stahrenberg R, Hasenfuss G, et al. Galectin-3 in heart failure with preserved ejection fraction-the effects of chronic aldosterone receptor blockade (the ALDO-DHF trial). Internist 2013;54(2):104-5.

Edelmann F, Gelbrich G, Duvinage A, Stahrenberg R, Behrens A, Prettin C, et al. Differential interaction of clinical characteristics with key functional parameters in heart failure with preserved ejection fraction--results of the Aldo-DHF trial. International Journal of Cardiology 2013;169(6):408-17.

Edelmann F, Holzendorf V, Wachter R, Nolte K, Schmidt AG, Kraigher-Krainer E, et al. Galectin-3 in patients with heart failure with preserved ejection fraction: results from the Aldo-DHF trial. European Journal of Heart Failure 2015;17(2):214-23.

Edelmann F, Schmidt AG, Gelbrich G, Binder L, HerrmannLingen $C$, Halle $M$, et al. Rationale and design of the 'aldosterone receptor blockade in diastolic heart failure' trial: a double-blind, randomized, placebo-controlled, parallel group study to determine the effects of spironolactone on exercise capacity and diastolic function in patients with symptomatic diastolic heart failure (Aldo-DHF). European Journal of Heart Failure 2010;12(8):874-82

Edelmann F, Wachter R, Pieske B. Aldosterone inhibition in patients with heart failure with preserved ejection fraction-reply. JAMA 2013;310(2):205-7.

* Edelmann F, Wachter R, Schmidt AG, Kraigher-Krainer E, Colantonio C, Kamke W, et al. Effect of spironolactone on diastolic function and exercise capacity in patients with heart failure with preserved ejection fraction: the Aldo-DHF randomized controlled trial. JAMA 2013;309(8):781-91.

Elguindy AM. ALDO-DHF \& Paramount. Global Cardiology Science \& Practice 2013;2(2012):12-4.
EudraCT 2006-002605-31. Aldosterone receptor blockade in diastolic heart failure. A double-blind, randomised, placebo-controlled, parallel group study to determine the effects of spironolactone on exercise capacity and diastolic function in patients with symptomatic diastolic heart failure. www.clinicaltrialsregister.eu/ctr-search/trial/2006-002605-31/ DE (first received 30 November 2006).

ISRCTN94726526. Aldosterone receptor blockade in diastolic heart failure: a double-blind, randomised, placebo-controlled, parallel group study to determine the effects of spironolactone on exercise capacity and diastolic function in patients with symptomatic diastolic heart failure. www.isrctn.com/ ISRCTN94726526 (first received 7 November 2006).

Lund LH, Stahlberg M. Aldosterone inhibition in patients with heart failure with preserved ejection fraction. JAMA 2013;10(2):205

Trippel TD, Regitz-Zagrosek V, Gelbrich G, Mueller-Scholden L, Wachter R, Dungen HD, et al. Gender specific treatment effects of spironolactone in diastolic heart failure: Insight from ALDODHF. European Journal of Heart Failure 2016;18:130.

\section{AREA IN-CHF \{published and unpublished data\}}

Boccanelli A, Caciatore G, Mureddu GF, de Simone G, Clemenza F, De Maria R, et al. Baseline characteristics of patients recruited in the AREA IN-CHF study (Antiremodelling Effect of Aldosterone Receptors Blockade with Canrenone in Mild Chronic Heart Failure). Journal of Cardiovascular Medicine 2007;8(9):683-91.

* Boccanelli A, Mureddu GF, Cacciatore G, Clemenza F, Di Lenarda A, Gavazzi A, et al. Anti-remodelling effect of canrenone in patients with mild chronic heart failure (AREA IN-CHF study): final results. European Journal of Heart Failure 2009;11(1):68-76.

Cacciatore G, Boccanelli A, Mureddu GF, Maggioni AP, Latini R, Masson S, et al. The AREA IN-CHF trial (antiremodeling effect of aldosterone receptors blockade with canrenone in mild chronic heart failure): rationale and design. Italian Heart Journal 2005;6(Suppl 1):66S-74S.

De Simone G, Chinali M, Mureddu GF, Cacciatore G, Lucci D, Latini $R$, et al. Effect of canrenone on left ventricular mechanics in patients with mild systolic heart failure and metabolic syndrome: the AREA-in-CHF study. Nutrition, Metabolism and Cardiovascular Diseases 2011;21(10):783-91.

NCT00403910. Antiremodeling effect of aldosterone receptors blockade with canrenone in mild chronic heart failure. AREA IN-CHF study [Phase 3 study of antiremodeling effect of aldosterone receptors blockade with canrenone in mild chronic heart failure]. clinicaltrials.gov/ct2/show/NCT00403910 (first received 27 November 2006.

Aronow 1993 \{published data only\}

Aronow WS, Kronzon I. Effect of enalapril on congestive heart failure treated with diuretics in elderly patients with prior 
myocardial infarction and normal left ventricular ejection fraction. American Journal of Cardiology 1993;71(7):602-4.

\section{Aronow 1997 \{published data only\}}

Aronow WS, Ahn C, Kronzon I. Effect of propranolol versus no propranolol on total mortality plus nonfatal myocardial infarction in older patients with prior myocardial infarction, congestive heart failure, and left ventricular ejection fraction $>$ or $=40 \%$ treated with diuretics plus angiotensinconverting enzyme inhibitors. American Journal of Cardiology 1997;80(2):207-9.

\section{Aronow 1998 \{published data only\}}

Aronow WS, Mercando AD, Epstein S. Effect of benazepril on complex ventricular arrhythmias in older patients with congestive heart failure, prior myocardial infarction, and normal left ventricular ejection fraction. American Journal of Cardiology 1998;81(11):1368-70.

\section{CandHeart \{published data only\}}

2005-001306-87. Effects of Candesartan Cilexetil vs standard therapy on serum levels of brain natriuretic peptide in patients suffering from chronic heart failure with depressed and preserved systolic function. www.clinicaltrialsregister.eu/ctrsearch/trial/2005-001306-87/IT (first received 2 February 2007).

* Aleksova A, Masson S, Maggioni AP, Lucci D, Urso R, Staszewsky $L$, et al. Effects of candesartan on left ventricular function, aldosterone and BNP in chronic heart failure. Cardiovascular Drugs and Therapy 2012;26(6):131-43.

NCT00843154. Efficacy of Candesartan on Brain Natriuretic Peptide Levels in Subjects With Chronic Heart Failure (CANDHEART) [Effects Of Candesartan Cilexetil vs Standard Therapy on Serum Levels of Brain Natriuretic Peptide in Patients Suffering From Chronic Heart Failure With Depressed and Preserved Systolic Function]. clinicaltrials.gov/ct2/show/ NCT00843154 (First posted 13 February 2009).

\section{CAN-DHF $\{$ published data only}

* EudraCT 2007-003070-26. Candesartan "added" therapy for treatment optimization of symptomatic heart failure with diastolic dysfunction in diabetic and hypertensive patients. A randomized, placebo-controlled, double-blind, parallel-group and multicentre clinical phase III study investigating the effects on NT-proBNP over 6 months.. www.clinicaltrialsregister.eu/ctrsearch/trial/2007-003070-26/DE (first entered 10 July 2007).

NCT00775840. Efficacy of candesartan on symptomatic heart failure in treating diabetic and hypertensive patients [Candesartan "added" therapy for treatment optimization of symptomatic heart failure with diastolic dysfunction in diabetic and hypertensive patients. A randomized, placebo-controlled, double-blind, parallel-group and multicenter clinical phase III study investigating the effects on NT-proBNP over 6 months]. clinicaltrials.gov/ct2/show/NCT00775840 (first received 20 October 2008).

\section{CHARM-Preserved \{published data only\}}

Badar AA, Perez-Moreno AC, Hawkins NM, Brunton AP, Jhund PS, Wong CM, et al. Clinical characteristics and outcomes of patients with angina and heart failure in the CHARM
(Candesartan in Heart Failure Assessment of Reduction in Mortality and Morbidity) Programme. European Journal of Heart Failure 2015;17(2):196-204.

Bello NA, Claggett B, Desai AS, McMurray JJ, Granger CB, Yusuf $\mathrm{S}$, et al. Influence of previous heart failure hospitalization on cardiovascular events in patients with reduced and preserved ejection fraction. Circulation 2014;7(4):590-5.

Castagno D, Skali H, Takeuchi M, Swedberg K, Yusuf S, Granger CB, et al. Association of heart rate and outcomes in a broad spectrum of patients with chronic heart failure: results from the CHARM (Candesartan in Heart Failure: Assessment of Reduction in Mortality and morbidity) program. Journal of the American College of Cardiology 2012;59(20):1785-95.

Castagno D, Skali H, Takeuchi M, Swedberg K, Yusuf S, Granger CB, et al. Incidence and predictors of stroke in patients with chronic heart failure: Does left ventricular function Matter? Insights From the CHARM Program. Circulation 2011;124(Suppl 21):A17352.

Chang SM, Granger CB, Johansson PA, Kosolcharoen P, McMurray JJ, Michelson EL, et al. Efficacy and safety of angiotensin receptor blockade are not modified by aspirin in patients with chronic heart failure: a cohort study from the Candesartan in Heart failure--Assessment of Reduction in Mortality and morbidity (CHARM) programme. European Journal of Heart Failure 2010;12(7):738-45.

Cohen-Solal A, McMurray JJ, Swedberg K, Pfeffer MA, Puu M, Solomon SD, et al. Benefits and safety of candesartan treatment in heart failure are independent of age: insights from the Candesartan in Heart failure--Assessment of Reduction in Mortality and morbidity programme. European Heart Journal 2008;29(24):3022-8.

Colombo GL, Caruggi M, Ottolini C, Maggioni AP. Candesartan in heart failure: assessment of reduction in mortality and morbidity (CHARM) and resource utilization and costs in Italy. Vascular Health and Risk Management 2008;4(1):223-34.

Damman K, Solomon SD, Pfeffer MA, Swedberg K, Yusuf S, Young JB, et al. Worsening renal function and outcome in heart failure patients with reduced and preserved ejection fraction and the impact of angiotensin receptor blocker treatment: data from the CHARM-study programme. European Journal of Heart Failure 2016;18(12):1508-17.

Desai AS, Claggett B, Pfeffer MA, Bello N, Finn PV, Granger C, et al. Influence of hospitalization for cardiovascular versus noncardiovascular reasons on subsequent mortality in patients with chronic heart failure across the spectrum of ejection fraction. European Journal of Heart Failure 2013;34:284.

Desai AS, Claggett B, Pfeffer MA, Bello N, Finn PV, Granger CB, et al. Influence of hospitalization for cardiovascular versus noncardiovascular reasons on subsequent mortality in patients with chronic heart failure across the spectrum of ejection fraction. Circulation 2014;7(6):895-902.

Dubrey SW. Angiotensin II receptor antagonists in the treatment of heart failure: Background to and design of the CHARM study. British Journal of Cardiology 2002;9(5):280-2,284,286.

Beta-blockers and inhibitors of the renin-angiotensin aldosterone system for chronic heart failure with preserved ejection fraction 
Fruhwald FM, Vavrovsky AD. Resource utilization and costs for candesartan in heart failure: Assessment of reduction in mortality and morbidity (CHARM) programme for the Austrian setting. Value in Health 2011;14(7):A379.

Gerstein HC, Swedberg K, Carlsson J, McMurray JJ, Michelson EL, Olofsson B, et al. The hemoglobin A1c level as a progressive risk factor for cardiovascular death, hospitalization for heart failure, or death in patients with chronic heart failure: an analysis of the Candesartan in Heart failure: Assessment of Reduction in Mortality and Morbidity (CHARM) program. Archives of Internal Medicine 2008;168(15):1699-704.

Grewal, J, McKelvie RS, Persson H, Tait P, Carlsson J, Swedberg K, et al. Usefulness of $\mathrm{N}$-terminal Pro-Brain Natriuretic Peptide and Brain Natriuretic Peptide to predict cardiovascular outcomes in patients with heart failure and preserved left ventricular ejection fraction. American Journal of Cardiology 2008;102(6):733-7.

Gupta DK, Castagno D, Granger CB, Yusuf S, Swedberg K, McMurray J, et al. Prognostic impact of an ischemic etiology of chronic heart failure across the spectrum of ejection fractions in the charm program. Journal of Cardiac Failure 2012;18(8):S78.

Hawkins NM, Wang D, McMurray JJ, Pfeffer MA, Swedberg K, Granger $\mathrm{CB}$, et al. Prevalence and prognostic impact of bundle branch block in patients with heart failure: evidence from the CHARM programme. European Journal of Heart Failure 2007;9(5):510-7.

Hawkins NM, Wang D, McMurray JJ, Pfeffer MA, Swedberg K, Granger $\mathrm{CB}$, et al. Prevalence and prognostic implications of electrocardiographic left ventricular hypertrophy in heart failure: evidence from the CHARM programme. Heart 2007;93(1):59-64.

Hawkins NM, Wang D, Petrie MC, Pfeffer MA, Swedberg K, Granger CB, et al. Baseline characteristics and outcomes of patients with heart failure receiving bronchodilators in the CHARM programme. European Journal of Heart Failure 2010;12(6):557-65.

Jackson CE, Solomon SD, Gerstein HC, Zetterstrand S, Olofsson B, Michelson EL, et al. Albuminuria in chronic heart failure: prevalence and prognostic importance. Lancet 2009;374(9689):543-50.

Kochsiek K. Angiotensin receptor blockers in heart failure. CHARM Study [Angiotensinrezeptorblocker bei Herzinsuffizienz]. Internist 2004;45(9):1063-7.

Kristensen SL, Kober L, Jhund PS, Solom SD, Kjekshus J, McKelvie RS, et al. International geographic variation in event rates in trials of heart failure with preserved and reduced ejection fraction. Circulation 2015;131(1):43-53.

MacDonald MR, Petrie MC, Varyani F, Ostergren J, Michelson EL, Young JB, et al. Impact of diabetes on outcomes in patients with low and preserved ejection fraction heart failure: an analysis of the Candesartan in Heart failure: Assessment of Reduction in Mortality and morbidity (CHARM) programme. European Heart Journal 2008;29(11):1377-85.
McKelvie RS. The CHARM program: the effects of candesartan for the management of patients with chronic heart failure. Expert Review Cardiovascular Therapy 2009;7(1):9-16.

McMurray J, Ostergren J, Pfeffer M, Swedberg K, Granger C, Yusuf $S$, et al. Clinical features and contemporary management of patients with low and preserved ejection fraction heart failure: baseline characteristics of patients in the Candesartan in Heart failure-Assessment of Reduction in Mortality and morbidity (CHARM) programme. European Journal of Heart Failure 2003;5(3):261-70.

McMurray JJ. Angiotensin inhibition in heart failure. Journal of the Renin Angiotensin Aldosterone System 2004;5(Suppl 1):S17-22.

Meredith PA, Ostergren J, Anand I, Puu M, Solomon SD, Michelson EL, et al. Clinical outcomes according to baseline blood pressure in patients with a low ejection fraction in the CHARM (Candesartan in Heart Failure: Assessment of Reduction in Mortality and Morbidity) Program. Journal of the American College of Cardiology 2008;52(24):2000-7.

Meyer TE. The candesartan in heart failure-assessment of reduction in mortality and morbidity-preserved trial. Current Cardiology Reports 2004;6(3):197-8.

Mitchell GF, Arnold JM, Dunlap ME, O'Brien TX, Marchiori G, Warner $E$, et al. Pulsatile hemodynamic effects of candesartan in patients with chronic heart failure: the CHARM Program. European Journal of Heart Failure 2006;8(2):191-7.

O'Meara E, Clayton T, McEntegart MB, McMurray JJ, Lang CC, Roger S, et al. Clinical correlates and consequences of anemia in a broad spectrum of patients with heart failure: results of the Candesartan in Heart Failure: Assessment of Reduction in Mortality and Morbidity (CHARM) Program. Circulation 2006;113(7):986-94.

O'Meara E, Clayton T, McEntegart MB, McMurray JJ, Pina IL, Granger CB, et al. Sex differences in clinical characteristics and prognosis in a broad spectrum of patients with heart failure: results of the Candesartan in Heart failure: Assessment of Reduction in Mortality and morbidity (CHARM) program. Circulation 2007;115(24):3111-20.

Olsson LG, Swedberg K, Ducharme A, Granger CB, Michelson EL, McMurray JJ, et al. Atrial fibrillation and risk of clinical events in chronic heart failure with and without left ventricular systolic dysfunction: results from the Candesartan in Heart failure-Assessment of Reduction in Mortality and morbidity (CHARM) program. Journal of the American College of Cardiology 2006;47(10):1997-2004.

Ostergren JB. Angiotensin receptor blockade with candesartan in heart failure: findings from the Candesartan in Heart failure--assessment of reduction in mortality and morbidity (CHARM) programme. Journal of Hypertension. Supplements 2006;24(1):S3-7.

Persson H, Lonn E, Edner M, Baruch L, Lang CC, Morton JJ, et al. Diastolic dysfunction in heart failure with preserved systolic function: need for objective evidence:results from the CHARM 
Echocardiographic Substudy-CHARMES. Journal of the American College of Cardiology 2007;49(6):687-94.

Pocock SJ, McMurray JJ, Dobson J, Yusuf S, Granger CB, Michelson EL, et al. Weight loss and mortality risk in patients with chronic heart failure in the candesartan in heart failure: assessment of reduction in mortality and morbidity (CHARM) programme. European Heart Journal 2008;29(21):2641-50.

Rapp JA, Gheroghiade M. Role of neurohormonal modulators in heart failure with relatively preserved systolic function. Heart Failure Clinic 2005;1(1):77-93.

Sica DA. ACE inhibitor intolerance and lessons learned from the candesartan in heart failure: assessment of reduction in mortality and morbidity (CHARM) trials. Congestive Heart Failure 2004;10(3):160-4.

Solomon SD, Anavekar N, Skali H, McMurray JJ, Swedberg K, Yusuf $\mathrm{S}$, et al. Influence of ejection fraction on cardiovascular outcomes in a broad spectrum of heart failure patients. Circulationi 2005;112(24):3738-44.

Solomon SD, Dobson J, Pocock S, Skali H, McMurray JJ, Granger CB, et al. Influence of nonfatal hospitalization for heart failure on subsequent mortality in patients with chronic heart failure. Circulation 2007;116(13):1482-7.

Somon SD, Wang D, Finn P, Skali H, Zornoff L, McMurray JJ, et al. Effect of candesartan on cause-specific mortality in heart failure patients: the Candesartan in Heart failure Assessment of Reduction in Mortality and morbidity (CHARM) program. [Erratum appears in Circulation. 2005 Jan 25;111(3):378]. Circulation 2004;110(15):2180-3.

Swedberg K, Pfeffer M, Granger C, Held P, McMurray J, Ohlin G, et al. Candesartan in Heart Failure-Assessment of Reduction in Mortality and Morbidity (CHARM): Rationale and design. Journal of Cardiac Failure 1999;5(3):276-82.

Woisetschlager C. Congress of the European Society of Cardiology 2003 in Vienna. Convincing results of candesartan in heart failure. Journal fur Kardiologie 2003;10(10):453-4.

* Yusuf S, Pfeffer MA, Swedberg K, Granger CB, Held P, McMurray JJ, et al. Effects of candesartan in patients with chronic heart failure and preserved left-ventricular ejection fraction: the CHARM-Preserved Trial. Lancet 2003;362(9386):777-81.

\section{ELANDD \{published data only\}}

2004-000746-20. Effects of the long-term administration of nebivolol on the clinical symptoms, exercise capacity and left ventricular function of the patients with diastolic dysfunction (ELANDD). www.clinicaltrialsregister.eu/ctr-search/search? query=eudract_number:2004-000746-20 (date submitted 9 October 2006).

* Conraads VM, Metra M, Kamp O, De Keulenaer GW, Pieske B, Zamorano J, et al. Effects of the long-term administration of nebivolol on the clinical symptoms, exercise capacity, and left ventricular function of patients with diastolic dysfunction: results of the ELANDD study. European Journal of Heart Failure 2012;14(2):219-25
Kamp O, Metra M, De Keulenaer GW, Pieske B, Conraads V, Zamorano J, et al. Effect of the long-term administration of nebivolol on clinical symptoms, exercise capacity and left ventricular function in patients with heart failure and preserved left ventricular ejection fraction: background, aims and design of the ELANDD study. Clinical Research in Cardiology 2010;99:75-82.

\section{Hong Kong DHF \{published data only\}}

CUHK_CCT00035. Treatment of diastolic heart failure: the role of blockade of the renin-angiotensin system. A comparison of diuretics with an angiotensin converting enzyme inhibitor, angiotensin receptor blockade or diuretics alone. www2.ccrb.cuhk.edu.hk/registry/public/15 (trial registration 7 September 2005).

* Yip GW, Wang M, Wang T, Chan S, Fung JW, Yeung L, et al. The Hong Kong diastolic heart failure study: a randomised controlled trial of diuretics, irbesartan and ramipril on quality of life, exercise capacity, left ventricular global and regional function in heart failure with a normal ejection fraction. Heart 2008;94(5):573-80.

\section{I-PRESERVE \{published data only\}}

Adabag S, Rector TS, Anand IS, McMurray JJ, Zile M, Komajda M, et al. A prediction model for sudden cardiac death in patients with heart failure and preserved ejection fraction. European Journal of Heart Failure 2014;16(11):1175-82.

Anand IS, Rector TS, Cleland JG, Kuskowski M, McKelvie RS, Persson $\mathrm{H}$, et al. Prognostic value of baseline plasma aminoterminal pro-brain natriuretic peptide and its interactions with irbesartan treatment effects in patients with heart failure and preserved ejection fraction: findings from the I-PRESERVE trial. Circulation 2011;4(5):569-77.

Anonymous. Heart failure patients with preserved left ventricular ejection fraction did not benefit from additional ARB therapy. Cardiovascular Journal of Africa 2008;19(6):337-9.

Badar AA, Perez-Moreno AC, Hawkins NM, Jhund PS, Brunton AP, et al. Clinical characteristics and outcomes of patients with coronary artery disease and angina: analysis of the irbesartan in patients with heart failure and preserved systolic function trial. Circulation 2015;8(4):717-24.

Blandon JA. ARBs and the impact of worsening renal function in heart failure patients with preserved EF. Cardiology Review 2014;30(6):no pagination.

Bohm M, Perez AC, Jhund PS, Reil JC, Komajda M, Zile MR, et al. Relationship between heart rate and mortality and morbidity in the irbesartan patients with heart failure and preserved systolic function trial (I-Preserve). European Journal of Heart Failure 2014;16(7):778-87.

Cannon JA, Shen L, Jhund PS, Anand IS, Komajda M, McKelvie RS, et al. Clinical outcomes according to QRS duration and morphology in the irbesartan in patients with heart failure and preserved systolic function (I-PRESERVE) trial. European Journal of Heart Failure 2016;18(8):1021-31.

Beta-blockers and inhibitors of the renin-angiotensin aldosterone system for chronic heart failure with preserved ejection fraction (Review)

Copyright (c) 2018 The Cochrane Collaboration. Published by John Wiley \& Sons, Ltd. 
Carson P, Anand I, Win S, Zile M, Haas M, Little W, et al. Why are patients with heart failure and preserved ejection fraction hospitalized? Data from i-preserve. Circulation 2013;128(Suppl 22):A15844.

Carson P, Massie PM, McKelvie R, McMurray J, Komajda M, Zile $\mathrm{M}$, et al. The irbesartan in heart failure with preserved systolic function (I-PRESERVE) trial: rationale and design. Journal of Cardiac Failure 2005;11(8):576-85.

Carson PE, Zile M, McMurray J, McKelvie R, Komajda M, Hetzel S, et al. Heart failure with preserved ejection fraction: Mortality risk post first hospitalization - Data from I-preserve. Journal of the American College of Cardiology 2010;55(10):A141.E1321.

Chow SL, Krum H, O'Barr SA, Zile M, Carson P, Komajda M, et al. Markers of extracellular matrix turnover and risk of death in patients with heart failure with preserved ejection fraction: Results from I-PRESERVE. Journal of the American College of Cardiology 2015;65(10):A969.

Damman K, Perez AC, Anand IS, Komajda M, McKelvie RS, Zile MR, et al. Worsening renal function and outcome in heart failure patients with preserved ejection fraction and the impact of angiotensin receptor blocker treatment. Journal of the American College of Cardiology 2014;64(11):1106-13.

Ezekowitz JA, McAlister FA. ACP Journal Club. Irbesartan did not reduce all-cause death or $\mathrm{CV}$ hospitalization in heart failure and preserved ejection fraction. Annals of Internal Medicine 2009;150(10):JC5-10.

Gandhi PU, Chow SL, Rector TS, Krum H, Gaggin HK, McMurray JJ, et al. Prognostic value of insulin-like growth factor-binding protein 7 in patients with heart failure and preserved ejection fraction. Journal of Cardiac Failure 2017;23(1):20-8.

Gandhi PU, Chow SL, Rector TS, Krum H, Gaggin HK, McMurray JJ, et al. The prognostic value of insulin-like growth factor-binding protein 7 in patients with heart failure and preserved ejection fraction: Results from irbesartan in heart failure and preserved ejection fraction (I-preserve) trial. Circulation 2015;132(Suppl 3):A14299.

Haass M, Kitzman DW, Anand IS, Miller A, Zile MR, Massie BM, et al. Body mass index and adverse cardiovascular outcomes in heart failure patients with preserved ejection fraction: results from the Irbesartan in Heart Failure with Preserved Ejection Fraction (I-PRESERVE) trial. Circulationi 2011;4(3):324-31.

Kao DP, Lewsey JD, Anand IS, Massie BM, Zile MR, Carson PE, et al. Characterization of subgroups of heart failure patients with preserved ejection fraction with possible implications for prognosis and treatment response. European Journal of Heart Failure 2015;17(9):925-35.

Kao DP, Lewsey JK, Massie BM, McMurray J, Carson PE, Anand IS, et al. Characterization of heart failure patients with preserved ejection fraction in the I-PRESERVE trial who have improved outcomes with irbesartan therapy. European Journal of Heart Failure. Supplements 2012;11:S4.
Komajda M, Carson PE, Hetzel S, McKelvie R, McMurray J, Ptaszynska A, et al. Factors associated with outcome in heart failure with preserved ejection fraction: findings from the Irbesartan in Heart Failure with Preserved Ejection Fraction Study (I-PRESERVE). Circulation 2011;4(1):27-35.

Kristensen SL, Jhund PS, Kober L, McKelvie RS, Zile MR, Anand IS, et al. Relative importance of history of heart failure hospitalization and N-Terminal pro-b-type Natriuretic Peptide level as predictors of outcomes in patients with heart failure and preserved ejection fraction. JACC Heart Failure 2015;3(6):478-86

Kristensen SL, Jhund PS, Kober L, Preiss D, Kjekshus J, McKelvie RS, et al. Comparison of outcomes after hospitalization for worsening heart failure, myocardial infarction, and stroke in patients with heart failure and reduced and preserved ejection fraction. European Journal of Heart Failure 2015;17(2):169-76.

Kristensen SL, Kober L, Jhund PS, Solomon SD, Kjekshus J, McKelvie RS, et al. International geographic variation in event rates in trials of heart failure with preserved and reduced ejection fraction. Circulation 2015;131(1):43-53.

Kristensen SL, Mogensen UM, Jhund PS, Petrie MC, Preiss D, Win S, et al. Clinical and echocardiographic characteristics and cardiovascular outcomes according to diabetes status in patients with heart failure and preserved ejection fraction: A report from the I-Preserve Trial (Irbesartan in Heart Failure With Preserved Ejection Fraction). Circulation 2017;135(8):724-35.

Krum H, Elsik M, Schneider H, Ptaszynska A, Black M, Carson P, et al. Peripheral collagen markers predict all-cause mortality and cardiovascular hospitalisation in patients with heart failure and preserved ejection fraction: Results of the I-PRESERVE collagen sub-study. Heart, Lung and Circulation 2010;19:S77-8.

Krum H, Elsik M, Schneider HG, Ptaszynska A, Black M, Carson PE, et al. Relation of peripheral collagen markers to death and hospitalization in patients with heart failure and preserved ejection fraction: results of the I-PRESERVE collagen substudy. Circulation 2011;4(5):561-8.

Lam CS, Carson PE, Anand IS, Rector TS, Kuskowski M, Komajda M, et al. Sex differences in clinical characteristics and outcomes in elderly patients with heart failure and preserved ejection fraction: the Irbesartan in Heart Failurewith Preserved Ejection Fraction (I-PRESERVE) trial. Circulation 2012;5(5):571-8.

* Massie BM, Carson PE, McMurray JJ, Komajda M, McKelvie R, Zile M, et al. Irbesartan in patients with heart failure and preserved ejection fraction. New England Journal of Medicine 2008;359(23):2456-67.

McKelvie RS, Komajda M, McMurray J, Zile M, Ptaszynska A, Donovan M, et al. Baseline plasma NT-proBNP and clinical characteristics: results from the irbesartan in heart failure with preserved ejection fraction trial. Journal of Cardiac Failure 2010;16(2):128-34

McMurray JJ, Carson PE, Komajda M, McKelvie R, Zile MR, Ptaszynska A, et al. Heart failure with preserved ejection fraction: clinical characteristics of 4133 patients enrolled 
in the I-PRESERVE trial. European Journal of Heart Failure 2008;10(2):149-56.

NCT00095238. Irbesartan in heart failure with preserved systolic function (I-Preserve). clinicaltrials.gov/show/NCT00095238 (first posted 2 November 2004).

Oluleye O, Win S, Rector T, Komadja M, Zile M, McKelvie R, et al. Risk of clinical outcomes and baseline atrial fibrillation: Irbesartan in heart failure with preserved ejection fraction (IPRESERVE) trial. Circulation 2013;128(22):A15893.

Oluleye OW, Rector TS, Win S, McMurray JJ, Zile MR, Komajda M, et al. History of atrial fibrillation as a risk factor in patients with heart failure and preserved ejection fraction. Circulationi 2014;7(6):960-6.

Rector TS, Carson PE, Anand IS, McMurray JJ, Zile MR, McKelvie RS, et al. Assessment of long-term effects of irbesartan on heart failure with preserved ejection fraction as measured by the minnesota living with heart failure questionnaire in the irbesartan in heart failure with preserved systolic function (IPRESERVE) trial. Circulation 2012;5(2):217-25.

Schillaci G, Pucci G, Pirro M. Irbesartan for heart failure with preserved ejection fraction. New England Journal of Medicine 2009;360(12):1258; author reply 1258-9.

Schneider HG, Krum H, Elsik M, Ptaszynska A, Black M, Anand I, et al. I-preserve sub-study: Plasma collagen markers in the prediction of death and hospitalisation in patients with heart failure and preserved ejection fraction. Clinical Chemistry and Laboratory Medicine 2011;49:S337.

Teerlink JR, Zile MR, White M, Miller AB, Lopez-Sendon J, Little WC, et al. Acute coronary syndromes in patients with heart failure with preserved ejection fraction: A harbinger of death?. JACC 2010;55(10):A38.E368.

Win S, Anand I, McMurray J, Zile M, McKelvie R, Komajda M, et al. Morbidity and mortality in diabetics with heart failure and a preserved ejection fraction: Results from the i-preserve trial. Journal of the American College of Cardiology 2013;61(10):E706.

Zile MR, Gaasch WH, Anand I, Haass M, Little WC, Muller A, et al. Mode of death in patients with heart failure and a preserved ejection fraction: Results from irbesartan heart failure with preserved ejection fraction study (I-Preserve) trial. European Heart Journal 2009;30:867.

Zile MR, Gaasch WH, Anand IS, Haass M, Little WC, Miller AB, et al. Mode of death in patients with heart failure and a preserved ejection fraction: results from the Irbesartan in Heart Failure With Preserved Ejection Fraction Study (I-Preserve) trial. Circulation 2010;121(12):1393-405.

Zile MR, Gottdiener JS, Hetzel SJ, McMurray JJ, Komajda M, McKelvie R, et al. Prevalence and significance of alterations in cardiac structure and function in patients with heart failure and a preserved ejection fraction. Circulation 2011;124(23):2491-501.
J-DHF \{published data only\}

Hori M. Rationale and design of a randomized trial to assess the effects of $\beta$-blocker in diastolic heart failure; Japanese Diastolic Heart Failure Study (J-DHF). Journal of Cardiac Failure 2005;11(7):542-7.

UMIN: C000000318. Japanese Diastolic Heart Failure Study. upload.umin.ac.jp/cgi-open-bin/ctr_e/ctr_view.cgi? recptno=R000000411 (Registered 1 February 2006).

* Yamamoto K, Origasa H, Hori M. Effects of carvedilol on heart failure with preserved ejection fraction: the Japanese Diastolic Heart Failure Study (J-DHF). European Journal of Heart Failure 2013;15(1):110-8.

Yamamoto K, Origasa H, Hori M. Left atrial dilatation as a predictive factor of beneficial response to carvedilol in patients with HFPEF: A finding from the Japanese Diastolic Heart Failure study (J-DHF). European Heart Journal 2013;34:161.

Yamamoto K, Origasa H, Suzuki Y, Takahashi T, Shinozaki T, Watanabe T, et al. Relation of risk factors with response to carvedilol in heart failure with preserved ejection fraction - a report from the Japanese Diastolic Heart Failure Study (J-DHF). Journal of Cardiology 2014;63(6):424-31.

\section{Karapysh 2015 \{published data only\}}

Karapysh VA, Vatutin NT, Shevelok AN. Effects of spironolactone on the left ventricular hypertrophy in chronic heart failure with preserved ejection fraction. European Journal of Heart Failure 2015;17:48.

\section{Kasama 2005 \{published data only\}}

Kasama S, Toyama T, Kumakura H, Takayama Y, Ichikawa S, Suzuki T, et al. Effects of candesartan on cardiac sympathetic nerve activity in patients with congestive heart failure and preserved left ventricular ejection fraction. Journal of the American College of Cardiology 2005;45(5):661-7.

\section{Kitzman 2010 \{published data only\}}

* Kitzman DW, Hundley WG, Brubaker PH, Morgan TM, Moore JB, Stewart KP, et al. A randomized double-blind trial of enalapril in older patients with heart failure and preserved ejection fraction: effects on exercise tolerance and arterial distensibility. Circulation 2010;3(4):477-85.

NCT01411735. Evaluation of enalapril versus placebo in patients with diastolic heart failure (PIE-I). clinicaltrials.gov/show/ NCT01411735 (first posted 8 August 2011).

\section{Kurrelmeyer 2014 \{published and unpublished data\}}

* Kurrelmeyer KM, Ashton Y, Xu J, Nagueh SF, Torre-Amione G, Deswal A. Effects of spironolactone treatment in elderly women with heart failure and preserved left ventricular ejection fraction. Journal of Cardiac Failure 2014;20(8):560-8.

NCT00206232. Novel treatment for diastolic heart failure in women. clinicaltrials.gov/show/NCT00206232 (first posted 21 September 2005). 
Mak 2009 \{published data only\}

Mak G, Ledwidge M, Murphy NF, Phelan D, Dawkins I, Watson C, et al. Eplerenone favourably alters collagen metabolism in diastolic heart failure. European Heart Journal 2009;30:866.

* Mak GJ, Ledwidge MT, Watson CJ, Phelan DM, Dawkins IR, Murphy N, et al. Natural history of markers of collagen turnover in patients with early diastolic dysfunction and impact of eplerenone. Journal of the American College of Cardiology 2009;54(18):1674-82.

NCT00505336. The effect of eplerenone and atorvastatin on markers of collagen turnover in diastolic heart failure. clinicaltrials.gov/show/NCT00505336 (first posted 23 July 2007).

\section{Mittal 2017 \{published and unpublished data\}}

CTRI/2010/091/000438. Evaluation of efficacy and safety of metoprolol in patients having heart failure with normal ejection fraction: a randomised, double-blind, placebocontrolled trial [A clinical trial to study the efficacy and safety of metoprolol in heart failure with normal ejection fraction]. http://www.ctri.nic.in/Clinicaltrials/pmaindet2.php? trialid=1626 (registered on 19 May 2010).

* Mittal N, Shafiq N, Reddy S, Malhotra S, Kumari S, Varma S. Evaluation of efficacy of metoprolol in patients having heart failure with preserved ejection fraction: A randomized, doubleblind, placebo-controlled pilot trial. Perspectives in Clinical Research 2017;8(3):124-31.

\section{Mottram 2004 \{published data only\}}

* Mottram PM, Haluska B, Leano R, Cowley D, Stowasser M, Marwick TH. Effect of aldosterone antagonism on myocardial dysfunction in hypertensive patients with diastolic heart failure. Circulation 2004;110:558-65.

Mottram PM, Haluska BA, Leano R, Cowley D, Stowasser M, Marwick TH. Myocardial dysfunction in hypertensive patients with isolated diastolic heart failure is reversible.A randomized trial of aldosterone antagonism. European Heart Journal 2004;25(Suppl S):47-8.

\section{Orea-Tejeda 2007 \{published data only\}}

Orea-Tejeda A, Colin-Ramirez E, Castillo-Martinez L, AsensioLafuente E, Corzo-Leon D, Gonzalez-Toledo R, et al. Aldosterone receptor antagonists induce favorable cardiac remodeling in diastolic heart failure patients. Revista de Investigacion Clinica 2007:59(2):103-7.

\section{Parthasarathy 2009 \{published and unpublished data\}}

CVAL489B2401. Novartis Clinical Trial Results Database. www.novctrd.com/CtrdWeb/displaypdf.nov?trialresultid $=2460$ (date accessed 30 November 2017).

NCT00171106. Efficacy and safety of valsartan versus placebo on exercise tolerance in patients with heart failure [A doubleblind, randomised, placebo-controlled, parallel group study to determine the effects of valsartan on exercise time in subjects with symptomatic diastolic heart failure]. clinicaltrials.gov/ show/NCT00171106 (first posted 15 September 2005).
* Parthasarathy HK, Pieske B, Weisskopf M, Andrews CD, Brunel $P$, Struthers $A D$, et al. A randomized, double-blind, placebo-controlled study to determine the effects of valsartan on exercise time in patients with symptomatic heart failure with preserved ejection fraction. European Journal of Heart Failure 2009;11(10):980-9.

\section{PEP-CHF \{published data only\}}

Cleland JG, Taylor J, Freemantle N, Goode KM, Rigby AS, Tendera M. Relationship between plasma concentrations of $\mathrm{N}$ terminal pro brain natriuretic peptide and the characteristics and outcome of patients with a clinical diagnosis of diastolic heart failure: a report from the PEP-CHF study. European Journal of Heart Failure 2012;14(5):487-94.

Cleland JG, Tendera M, Adamus J, Freemantle N, Gray CS, Lye $\mathrm{M}$, et al. Perindopril for elderly people with chronic heart failure: the PEP-CHF study. European Journal of Heart Failure 1999;1(3):211-7.

* Cleland JG, Tendera M, Adamus J, Freemantle N, Polonski L, Taylor J. The perindopril in elderly people with chronic heart failure (PEP-CHF) study. European Heart Journal 2006;27(16):2338-45.

McMurray J. Renin angiotensin blockade in heart failure with preserved ejection fraction: The signal gets stronger. European Heart Journal 2006;27(19):2257-9.

Widimsky J. Managing diastolic heart failure. Results of PEP-CHF [Lecba diastolickeho srdecniho selhani. Vysledky studie PEPCHF]. Cor Vasa 2006;48(11):403-7.

RAAM-PEF \{published and unpublished data\}

* Deswal A, Richardson P, Bozkurt B, Mann DL. Results of the Randomized Aldosterone Antagonism in Heart Failure with Preserved Ejection Fraction trial (RAAM-PEF). Journal of Cardiac Failure 2011;17(8):634-42.

NCT00108251. Aldosterone antagonism in diastolic heart failure. clinicaltrials.gov/ct2/show/NCT00108251 (first posted 15 April 2005).

\section{Sahoo 2016 \{published data only\}}

Sahoo D, Kapoor A, Sinha A, Khanna R, Kumar S, Garg N, et al. Targeting the sympatho-adrenergic link in chronic rheumatic mitral regurgitation: assessing the role of oral beta-blockers. Cardiovascular Therapeutics 2016;34(4):261-7.

\section{SENIORS \{published data only\}}

Cohen-Solal A, Kotecha D, van Veldhuisen DJ, Babalis D, Bohm M, Coats AJ, et al. Efficacy and safety of nebivolol in elderly heart failure patients with impaired renal function: insights from the SENIORS trial. European Journal of Heart Failure 2009;11(9):872-80.

* Flather MD, Shibata MC, Coats AJS, Van Veldhuisen DJ, Parkhomenko A, Borbola J, et al. Randomized trial to determine the effect of nebivolol on mortality and cardiovascular hospital admission in elderly patients with heart failure (SENIORS). European Heart Journal 2005;26:215-25. 
Ghio S, Magrini G, Serio A, Klersy C, Fucili A, Ronaszeki A, Karpati $P$, et al. Effects of nebivolol in elderly heart failure patients with or without systolic left ventricular dysfunction: results of the SENIORS echocardiographic substudy. European Heart Journal 2006;27(5):562-8.

Lindsey ML, Freeman GL. Beta-blockade in heart failure: adding SENIORS to the mix. European Heart Journal 2006;27(5):506-7.

Montero-Perez-Barquero M, Flather M, Roughton M, Coats A, Bohm M, Van Veldhuisen DJ, et al. Influence of systolic blood pressure on clinical outcome in elderly heart failure patients with preserved and reduced ejection fraction treated with nebivolol: data from SENIORS trial. European Heart Journal 2014;35:339.

Montero-Perez-Barquero M, Flather M, Roughton M, Coats A, Bohm M, Van Veldhuisen DJ, et al. Influence of systolic blood pressure on clinical outcomes in elderly heart failure patients treated with nebivolol: data from the SENIORS trial. European Journal of Heart Failure 2014;16(9):1009-15.

Mulder BA, van Veldhuisen DJ, Crijns HJ, Bohm M, CohenSolal A, Babalis D, et al. Effect of nebivolol on outcome in elderly patients with heart failure and atrial fibrillation: insights from SENIORS. European Journal of Heart Failure 2012;14(10):1171-8.

Shibata MC, Flather MD, Bohm M, Borbola J, CohenSolal A, Dumitrascu D, et al. Study of the effects of nebivolol intervention on outcomes and reshospitalisation in seniors with heart failure (SENIORS). International Journal of Cardiology 2002;86:77-85.

Von Haehling S, Babalis D, Roghton M, Van Veldhuisen DJ, Poole-Wilson PA, Flather M, et al. Prevalence of anaemia and the effects of nebivolol on haemoglobin values in patients with chronic heart failure: Results from the SENIORS database. Journal of Cardiac Failure 2009;15(6):S96.

de Boer RA, Doehner W, van der Horst IC, Anker SD, Babalis D, Rougthon $\mathrm{M}$, et al. Influence of diabetes mellitus and hyperglycemia on prognosis in patients $>$ or $=70$ years old with heart failure and effects of nebivolol (data from the Study of Effects of Nebivolol Intervention on Outcomes and Rehospitalization in Seniors with heart failure [SENIORS]). American Journal of Cardiology 2010;106(1):78-86.

van Veldhuisen DJ, Cohen-Solal A, Bohm M, Anker SD, Babalis D, Roughton $\mathrm{M}$, et al. Beta-blockade with nebivolol in elderly heart failure patients with impaired and preserved left ventricular ejection fraction: Data From SENIORS (Study of Effects of Nebivolol Intervention on Outcomes and Rehospitalization in Seniors With Heart Failure). Journal of the American College of Cardiology 2009;53(23):2150-8.

von Haehling S, van Veldhuisen DJ, Roughton M, Babalis D, de Boer RA, Coats AJ, et al. Anaemia among patients with heart failure and preserved or reduced ejection fraction: results from the SENIORS study. European Journal of Heart Failure 2011;13(6):656-63.

\section{Shu 2005 \{published data only\}}

Shu M, Xi R, Zhang P, He G, Song Z, Chi L, et al. Short-term and long-term effects of bisoprolol on chronic heart failure related to rheumatic heart disease and atrial fibrillation. Pharmacy and Therapeutics 2005;30(7):400-7.

\section{SNEGOVIK \{published data only\}}

Mareev V, Skvortsov A, Danielyan M, Belenkov YU. Quinapril in treatment of ambulatory patients with arterial hypertension and congestive heart failure and preserved systolic left ventricular function. (Results from the SNEGOVIK Study). European Journal of Heart Failure. Supplement 2011;10:S78.

\section{STRUCTURE \{published data only\}}

ACTRN12614000088640. Spironolactone in myocardial dysfunction with reduced exercise capacity [Effects of spironolactone or control on LV filling pressure and exercise capacity in patients with myocardial dysfunction with reduced exercise capacity]. www.anzctr.org.au/Trial/Registration/ TrialReview.aspx?id=365563 (data submitted 6 January 2014).

Kosmala W, Rojek A, Przewlocka-Kosmala M, Wright L, Mysiak A, Marwick TH. Beneficial effect of aldosterone antagonism on exercise tolerance in heart failure with preserved ejection fraction-SpironolacTone in myocaRdial dysfunction with reduced exercise capacity (STRUCTURE). European Heart Journal 2016;37:795.

* Kosmala W, Rojek A, Przewlocka-Kosmala M, Wright L, Mysiak A, Marwick TH. Effect of aldosterone antagonism on exercise tolerance in heart failure with preserved ejection fraction. Journal of the American College of Cardiology 2016;68(17):1823-34.

\section{SUPPORT \{published data only\}}

Miura M, Sakata Y, Miyata S, Shiba N, Takahashi J, Nochioka K, et al. Influence of left ventricular ejection fraction on the effects of supplemental use of angiotensin receptor blocker olmesartan in hypertensive patients with heart failure. Circulation Journal 2016;80(10):2155-64.

Miura M, Sakata Y, Miyata S, Tadaki S, Ushigome R, Yamouchi T, et al. The supplemental benefit of an angiotensin receptor blocker in hypertensive patients with stable heart failure using olmesartan (SUPPORT) trial. Journal of Cardiac Failure 2015;21(10):S159.

NCT00417222. Supplemental benefit of angiotensin receptor blocker in hypertensive patients with stable heart failure using olmesartan (SUPPORT). clinicaltrials.gov/ct2/show/ NCT00417222 (first posted 29 December 2006).

* Sakata Y, Shiba N, Takahashi J, Miyata S, Nochioka K, Miura M, et al. Clinical impacts of additive use of olmesartan in hypertensive patients with chronic heart failure: The supplemental benefit of an angiotensin receptor blocker in hypertensive patients with stable heart failure using olmesartan (SUPPORT) trial. European Heart Journal 2015;36(15):915-23.

\section{SWEDIC \{published data only\}}

Bergstrom A, Andersson B, Edner M, Nylander E, Persson $\mathrm{H}$, Dahlstrom U. Effect of carvedilol on diastolic function in patients with diastolic heart failure and preserved systolic function. Results of the Swedish Doppler-echocardiographic study (SWEDIC). European Journal of Heart Failure 2004;6(4):453-61.

Beta-blockers and inhibitors of the renin-angiotensin aldosterone system for chronic heart failure with preserved ejection fraction (Review)

Copyright (c) 2018 The Cochrane Collaboration. Published by John Wiley \& Sons, Ltd. 
Takeda 2004 \{published data only\}

Takeda Y, Fukutomi T, Suzuki S, Yamamoto K, Ogata M, Kondo H, et al. Effects of carvedilol on plasma B-type natriuretic peptide concentration and symptoms in patients with heart failure and preserved ejection fraction. American Journal of Cardiology 2004;94:448-53.

\section{TOPCAT \{published data only\}}

Anand IS, Claggett B, Liu J, Shah AM, Rector TS, Shah SJ, et al. Interaction between spironolactone and natriuretic peptides in patients with heart failure and preserved ejection fraction: from the TOPCAT trial. JACC. Heart Failure 2017;5(4):241-52.

Anand IS, Solomon SD, Claggett B, Shah SJ, O'Meara E, Boineau R, et al. Prognostic value of baseline BNP and NTproBNP and its interaction with spironolactone in patients with heart failure and preserved ejection fraction in the TOPCAT trial. Circulation 2015;132:no pagination.

Bajaj NS, Claggett B, Lewis E, Desai A, Fang J, Omeara E, et al. Influence of left ventricular ejection fraction on cause-specific mortality in heart failure with preserved ejection fraction: The TOPCAT trial. Journal of the American College of Cardiology 2017;69(11):884.

Bristow MR, Enciso JS, Gersh BJ, Grady C, Rice MM, Singh S, et al. Detection and management of geographic disparities in the TOPCAT trial: lessons learned and derivative recommendations. JACC: Basic to Translational Science 2016;1(3):180-9.

Desai AS, Lewis EF, Li R, Solomon SD, Assmann SF, Boineau R, et al. Rationale and design of the treatment of preserved cardiac function heart failure with an aldosterone antagonist trial: a randomized, controlled study of spironolactone in patients with symptomatic heart failure and preserved ejection fraction. American Heart Journal 2011;162(6):966-72.

Desai AS, Liu J, Claggett B, Bristow M, Fleg J, Lewis EF, et al. Incidence and predictors of doubling of serum creatinine during treatment of heart failure and preserved ejection fraction with spironolactone. European Heart Journal 2015;36:662-3.

Girerd N, Ferreira JP, Rossignol P, Zannad F. A tentative interpretation of the TOPCAT trial based on randomized evidence from the brain natriuretic peptide stratum analysis. European Journal of Heart Failure 2016;18(12):1411-4.

Hamo CE, Heitner JF, Pfeffer MA, Kim HY, Kenwood CT, Assmann SF, et al. Baseline distribution of participants with depression and impaired quality of life in the Treatment of Preserved Cardiac Function Heart Failure with an Aldosterone Antagonist Trial. Circulation 2015;8(2):268-77.

Hegde S, Claggett B, Shah AM, Lewis EF, Anand IS, Shah SJ, et al. Physical activity and prognosis in the treatment of preserved cardiac function heart failure with an aldosterone antagonist (TOPCAT) trial. Circulation 2017;21:21.

Joseph J, Claggett BC, Anand IS, Fleg JL, Huynh T, Desai AS, et al. QRS duration is a predictor of adverse outcomes in heart failure with preserved ejection fraction. JACC. Heart Failure 2016;4(6):477-86.
Joseph J, Claggett BL, Anand IS, Fleg JL, Huynh T, Desai AS, et al. Prolonged QRS duration predicts outcomes in heart failure with preserved ejection fraction. Circulation 2015;132(Suppl 3):A11159.

Kao DP, Flint KM, Merrill M. Spironolactone reduces all-cause mortality in women but not men with heart failure with preserved ejection fraction enrolled in TOPCAT from the Americas. European Journal of Heart Failure 2017;19:530-1.

Kelly J, Granger CB. Spironolactone did not reduce cardiac outcomes in symptomatic heart failure with preserved ejection fraction. Annals of Internal Medicine 2014;161(8):JC6.

Kelsey Fling K, Merrill M, Kao D. Sex differences in long-term health status in heart failure with preserved ejection fraction. European Journal of Heart Failure 2017;19:530-1.

Kitai T, Grodin J, Wilson Tang WH. Paradoxical impact of proportional pulse pressure on mortality in patients with heart failure with preserved ejection fraction. Journal of the American College of Cardiology 2017;69(11):882.

Kristensen SL, Kober L, Jhund PS, Solomon SD, Kjekshus J, McKelvie RS, et al. International geographic variation in event rates in trials of heart failure with preserved and reduced ejection fraction. Circulation 2015;131(1):43-53.

Morawietz $\mathrm{H}$, Bornstein SR. Spironolactone for heart failure with preserved ejection fraction. New England Journal of Medicine 2014;371(2):181.

NCT00094302. Aldosterone Antagonist Therapy for Adults With Heart Failure and Preserved Systolic Function (TOPCAT) [Treatment of Preserved Cardiac Function Heart Failure With an Aldosterone Antagonist (TOPCAT)]. clinicaltrials.gov/ct2/show/ NCT00094302 (First posted 15 October 2004).

O'Meara E, Kenwood CT, Anand IS, Desai AS, De Denus S, Sweitzer NK, et al. Anemia in heart failure with preserved ejection fraction: insights from the Topcat trial. Circulation 2015;132(Suppl 3):A17975.

O'Neal WT, Sandesara P, Patel N, Venkatesh S, SammanTahhan A, Hammadah M, et al. Echocardiographic predictors of atrial fibrillation in patients with heart failure with preserved ejection fraction. European Heart Journal - Cardiovascular Imaging 2017;30:30.

O'Neal WT, Sandesara PB, Samman-Tahhan A, Kelli HM, Hammadah M, Soliman EZ. Heart rate and the risk of adverse outcomes in patients with heart failure with preserved ejection fraction. European Journal of Preventive Cardiology 2017;24(11):1212-9.

Pfeffer MA, Braunwald E. Treatment of heart failure with preserved ejection fraction: reflections on its treatment with an aldosterone antagonist. JAMA Cardiology 2016;1(1):7-8.

Pfeffer MA, Claggett B, Assmann SF, Boineau R, Anand IS, Clausell N, et al. Regional variation in patients and outcomes in the Treatment of Preserved Cardia Function Heart Failure with an Aldosterone Antagonist (TOPCAT) trial. Circulation 2015;131(1):34-42.

Beta-blockers and inhibitors of the renin-angiotensin aldosterone system for chronic heart failure with preserved ejection fraction 
Pfeffer MA, McKinlay S, Pitt B. Treatment of preserved cardiac function heart failure with an aldosterone antagonist (TOPCAT). Circulation 2013;128(24):2709.

* Pitt B, Pfeffer MA, Assmann S, Boineau R, Anand IS, Claggett $B$, et al. Spironolactone for heart failure with preserved ejection fraction. New England Journal of Medicine 2014;370(15):1383-92.

Sandesara PB, Hammadah M, Samman-Tahhan A, Kelli HM, O'Neal WT. Peripheral artery disease and risk of adverse outcomes in heart failure with preserved ejection fraction. Clinical Cardiology 2017;26:26.

Santos AB, Roca GQ, Claggett B, Sweitzer NK, Shah SJ, Anand IS, et al. Prognostic relevance of left atrial dysfunction in heart failure with preserved ejection fraction. Circulation 2016;9(4):e002763.

Shah AM, Claggett B, Sweitzer NK, Shah SJ, Anand IS, Liu L, et al. Impaired systolic function assessed by strain imaging predicts cardiovascular morbidity and mortality in heart failure with preserved ejection fraction. Circulation 2014;130(Suppl 1):A16989.

Shah AM, Claggett B, Sweitzer NK, Shah SJ, Anand IS, Liu L, et al. Prognostic importance of impaired systolic function in heart failure with preserved ejection fraction and the impact of spironolactone. Circulation 2015;132(5):402-14.

Shah AM, Claggett B, Sweitzer NK, Shah SJ, Anand IS, O'Meara E, et al. Cardiac structure and function and prognosis in heart failure with preserved ejection fraction. Circulation. Heart Failure 2014;7(5):740-51.

Shah AM, Claggett B, Sweitzer NK, Shah SJ, Deswal A, Anand IS, et al. Prognostic importance of changes in cardiac structure and function in heart failure with preserved ejection fraction and the impact of spironolactone. Circulation 2015;8(6):1052-8.

Shah AM, Shah SJ, Anand IS, Sweitzer NK, O'Meara E, Heitner JF, et al. Cardiac structure and function in heart failure with preserved ejection fraction: baseline findings from the echocardiographic study of the Treatment of Preserved Cardiac Function Heart Failure with an Aldosterone Antagonist trial. Circulation 2014;7(1):104-15.

Shah SJ, Heitner JF, Sweitzer NK, Anand IS, Kim HY, Harty B, et al. Baseline characteristics of patients in the treatment of preserved cardiac function heart failure with an aldosterone antagonist trial. Circulation 2013;6(2):184-92.

Solomon SD, Claggett B, Lewis EF, Desai A, Anand I, Sweitzer NK, et al. Influence of ejection fraction on outcomes and efficacy of spironolactone in patients with heart failure with preserved ejection fraction. European Heart Journal 2016;37(5):455-62.

\section{Upadhya 2017 \{published and unpublished data\}}

NCT00123955. PIE II: pharmacological intervention in the elderly II [Exercise intolerance in elderly diastolic heart failure]. clinicaltrials.gov/show/NCT00123955 (first posted 26 July 2005).

* Upadhya B, Hundley WG, Brubaker PH, Morgan TM, Stewart KP, Kitzman DW. Effect of spironolactone on exercise tolerance and arterial function in older adults with heart failure with preserved ejection fraction. Journal of the American Geriatric Society 2017;19:19.

Wang 2010 \{published data only\}

Wang YC, Yu CC, Chiu FC, Tsai CT, Lai LP, Hwang JJ, et al. Aldosterone antagonism increases post-exercise recruitment of systolic myocardial motion over left ventricular lateral wall in hypertensive patients with diastolic heart failure. Circulation 2010;122(2):P1059.

\section{Yuksek 2012 \{published data only\}}

Yuksek U, Hamza D, Zehra A, Ugur K, Nihan KE, Rida B, et al. The effect of perindopril treatment on echocardiographic diastolic and systolic functional parameters and serum NT-proBNP values in diastolic heart failure patients. European Journal of Heart Failure. Supplements 2012;11:S231.

\section{Zi 2003 \{published data only\}}

Zi M, Carmichael N, Lye M. The effect of quinapril on functional status of elderly patients with diastolic heart failure. Cardiovascular Drugs and Therapy 2003;17:133-9.

\section{References to studies excluded from this review}

\section{ACTRN12610001087044 \{published data only\}}

ACTRN12610001087044. Use of exercise and medical therapies to improve cardiac function among patients with exertional shortness of breath due to lung congestion. www.anzctr.org.au/ ACTRN12610001087044.aspx (date received 13 December 2010).

Kosmala W, Holland DJ, Rojek A, Wright L, PrzewlockaKosmala M, Marwick TH. Effect of If-channel inhibition on hemodynamic status and exercise tolerance in heart failure with preserved ejection fraction: a randomized trial. Journal of the American College of Cardiology 2013;62(15):1330-8.

\section{Adgey 1992 \{published data only\}}

Adgey J, Clarke M, Raza A, Meddis D. Study of the safety and efficacy of ACE inhibitors and their effects on 24-hour electrocardiographic monitoring in the treatment of moderateto-severe heart failure: an interim analysis. American Journal of Cardiology 1992;70(10):142C-4C.

\section{Ammon 2001 \{published data only\}}

Ammon S. Managing patients with heart failure. American Journal of Nursing 2001;101(12):34-40.

\section{Andersson 1996 \{published data only\}}

Andersson B, Caidahl K, di Lenarda A, Warren SE, Goss F, Waldenstrom $A$, et al. Changes in early and late diastolic filling patterns induced by long-term adrenergic beta-blockade in patients with idiopathic dilated cardiomyopathy. Circulation 1996;94(4):673-82

\section{Andersson 1999 \{published data only\}}

Andersson B, Stromblad SO, Lomsky M, Waagstein F. Heart rate dependency of cardiac performance in heart failure patients treated with metoprolol. European Heart Journal 1999;20(8):575-83.

Beta-blockers and inhibitors of the renin-angiotensin aldosterone system for chronic heart failure with preserved ejection fraction (Review)

Copyright (c) 2018 The Cochrane Collaboration. Published by John Wiley \& Sons, Ltd. 
Andersson 2000 \{published data only\}

Andersson B, Waagstein F, Caidahl K, Eurenius I, Tang MS, Wikh R. Early changes in longitudinal performance predict future improvement in global left ventricular function during long term beta adrenergic blockade. Heart 2000;84(6):599-605.

\section{Anonymous 1996 \{published data only\}}

Anonymous. Effectiveness of spironolactone added to an angiotensin-converting enzyme inhibitor and a loop diuretic for severe chronic congestive heart failure (the Randomized Aldactone Evaluation Study [RALES]). American Journal of Cardiology 1996;78(8):902-7.

\section{Anonymous 1999 \{published data only\}}

Anonymous. Heart failure management in primary care: implications of the ATLAS study. International Journal of Clinical Practice. Supplement 1999;100:25-30.

\section{Anonymous 2000 \{published data only\}}

Anonymous. Effects of metoprolol CR in patients with ischemic and dilated cardiomyopathy : the randomized evaluation of strategies for left ventricular dysfunction pilot study. Circulation 2000;101(4):378-84.

\section{Anonymous 2001 \{published data only\}}

Anonymous. Carvedilol saves lives - new data from landmark trials prove survival benefits in heart failure and post myocardial infarction. Cardiovascular Journal of South Africa 2001;12(2):122-3.

\section{Anonymous 2002 \{published data only\}}

Anonymous. Stress intolerance in diastolic dysfunction. A case for AT1 blocker?. MMW Fortschritte der Medizin 2002;144(1-2):69.

\section{Anonymous 2003 \{published data only\}}

Anonymous. When after myocardial infarction a pump weakness remains. ACE inhibitors and AT-1 blockers equivalent. MMW Fortschritte der Medizin 2003;145(49):18-9.

\section{Anonymous 2003a $\{$ published data only\}}

Anonymous. CHARM shows benefits of Atacand for symptomatic heart failure. Cardiovascular Journal of South Africa 2003;14(5):284

\section{Anonymous 2003b \{published data only\}}

Anonymous. Heart failure symptoms despite normal pump function. Beta blockers also improve diastole. MMW Fortschritte der Medizin 2003;145(26):58.

\section{Anonymous 2003c \{published data only\}}

Anonymous. NMR shows how beta blockers change the failing ventricle. Decreased size and better output performance. MMW Fortschritte der Medizin 2003;145(25):56.

\section{Anonymous 2005 \{published data only\}}

Anonymous. Heart failure after acute myocardial infarct. Early aldosterone blockade increases survival rate. MMW Fortschritte der Medizin 2005;147(27-28):44.
Anonymous 2008 \{published data only\}

Anonymous. Diastolic heart failure: AT1 blocker without effect. MMW Fortschritte der Medizin 2008;150(47):13.

\section{Anonymous 2008a \{published data only\}}

Anonymous. Misdiagnosed emergency: heart failure symptoms after infarct. Rapid aldosterone block can safe the tired heart. MMW Fortschritte der Medizin 2008;150(22):48-9.

Anonymous 2013 \{published data only\} Anonymous. Spironolactone made no difference to patients with mild diastolic heart failure. BMJ 2013;346:f1290.

\section{ANZ HF carvedilol \{published data only\}}

* Australia/New Zealand Heart Failure Research Collaborative Group. Randomised, placebo-controlled trial of carvedilol in patients with congestive heart failure due to ischaemic heart disease. Lancet 1997;349(9049):375-80.

Australia-New Zealand Heart Failure Research Collaborative Group. Effects of carvedilol, a vasodilator-beta-blocker, in patients with congestive heart failure due to ischemic heart disease. Australia-New Zealand Heart Failure Research Collaborative Group. Circulation 1995;92(2):212-8.

Doughty RN, Whalley GA, Gamble G, MacMahon S, Sharpe N. Effects of carvedilol on left ventricular regional wall motion in patients with heart failure caused by ischemic heart disease. Journal of Cardiac Failure 2000;6(1):11-8.

Doughty RN, Whalley GA, Gamble G, MacMahon S, Sharpe N. Left ventricular remodeling with carvedilol in patients with congestive heart failure due to ischemic heart disease. Australia-New Zealand Heart Failure Research Collaborative Group. Journal of the American College of Cardiology 1997;29(5):1060-6.

Krum H, Shusterman N, MacMahon S, Sharpe N. Efficacy and safety of carvedilol in patients with chronic heart failure receiving concomitant amiodarone therapy. Australia/New Zealand Heart Failure Research Collaborative Group. Journal of Cardiac Failure 1998;4(4):281-8.

Krum H, Tonkin A, Trotter A, Burton R, Garrett J, Lane G, et al. Effects of carvedilol, a vasodilator- $\beta$-blocker, in patients with congestive heart failure due to ischemic heart disease. Circulation 1995;92(2):212-8.

Richards AM, Doughty R, Nicholls MG, MacMahon S, Sharpe N, Murphy J, et al. Plasma N-terminal pro-brain natriuretic peptide and adrenomedullin: prognostic utility and prediction of benefit from carvedilol in chronic ischemic left ventricular dysfunction. Journal of the American College of Cardiology 2001;37(7):1781-7.

Richards AM, Doughty R, Nicholls MG, Macmahon S, Ikram H, Sharpe N, et al. Neurohumoral prediction of benefit from carvedilol in ischemic left ventricular dysfunction. Circulation 1999;99(6):768-92.

Sharpe N, Doughty RN. Left ventricular remodelling and improved long-term outcomes in chronic heart failure. European Heart Journal 1998;19(Suppl B):B36-9. 
Aoyama 2007 \{published data only\}

Aoyama N. Effect of combination therapy with angiotensin II type I receptor and aldosterone receptor blockers in heart failure. Nippon Rinsho 2007;65(Suppl 5):145-9.

\section{Apostolovic 2013 \{published data only\}}

Apostolovic S, Stanojevic D, Jankovic-Tomasevic R, SalingerMartinovic S, Djordjevic-Radojkovic D, Pavlovic M, et al. Influence of optimal beta blocker therapy on biomarkers of inflammation and proliferation in elderly patients with chronic stable heart failure. European Journal of Heart Failure 2013;12:S200.

\section{Apostolovic 2014a \{published data only\}}

Apostolovic S, Stanojevic D, Jankovic-Tomasevic R, SalingerMartinovic S, Pavlovic M, Djordjevic-Radojkovic D, et al. Betablockers in heart failure-influence on left ventricle remodeling CIBIS ELD sub-study. European Heart Journal Cardiovascular Imaging 2014;15:ii213.

\section{Apostolovic 2014b \{published data only\}}

Apostolovic S, Stanojevic D, Salinger-Martinovic S, JankovicTomasevic R, Djordjevic-Radojkovic D, Pavlovic M, et al. Influence of optimization of beta blocker therapy in heart failure patients on natriuretic peptide levels and exercise capacity. European Heart Journal: Acute Cardiovascular Care 2014;3(2):176.

\section{Arena 2007 \{published data only\}}

Arena RA, Guazzi M, Myers J, Abella J. The prognostic value of ventilatory efficiency with beta-blocker therapy in heart failure. Medicine \& Science in Sports \& Exercise 2007;39(2):213-9.

\section{Armstrong 1999 \{published data only\}}

Armstrong PW. Improved outcome in heart failure. International Journal of Clinical Practice. Supplement 1999;100:10-1.

\section{Aronow 1991 \{published data only\}}

Aronow WS. Digoxin or angiotensin converting enzyme inhibitors for congestive heart failure in geriatric patients. Which is the preferred treatment?. Drugs and Aging 1991;1(2):98-103.

\section{Aronow 2001 \{published data only\}}

Aronow WS, Ahn C, Kronzon I. Effect of beta blockers alone, of angiotensin-converting enzyme inhibitors alone, and of beta blockers plus angiotensin-converting enzyme inhibitors on new coronary events and on congestive heart failure in older persons with healed myocardial infarcts and asymptomatic left ventricular systolic dysfunction. American Journal of Cardiology 2001;88(11):1298-300.

\section{Axelsson 2015 \{published data only\}}

Axelsson A, Iversen K, Vejlstrup N, Ho C, Havndrup O, Jensen M $\mathrm{K}$, et al. The effect of losartan on diastolic function, exercise capacity and symptoms in hypertrophic cardiomyopathy. JACC 2015;65(10):A857.

\section{Balaban 2007 \{published data only\}}

Balaban Y, Ozhan H, Albayrak S, Kaya A, Ordu, Yazici M. Efficacy of spiranolactone therapy in patients with impaired left ventricular filling [Sol ventrikul doluzu bozulmus hastalarda spironolakton tedavisinin etkinligi]. MN Kardiyoloji 2007;14(3):182-6.

Bao 2005 \{published data only\}

Bao ZH, Han Y, Sheng ZS. Carvedilol for the intervention of the cardiac function and exercise tolerance in patients with congestive heart failure. Chinese Journal of Clinical Rehabilitation 2005;9(15):53-5.

\section{Barr 1995 \{published data only\}}

Barr CS, Lang CC, Hanson J, Arnott M, Kennedy N, Struthers AD. Effects of adding spironolactone to an angiotensin-converting enzyme inhibitor in chronic congestive heart failure secondary to coronary artery disease. American Journal of Cardiology 1995;76(17):1259-65.

\section{Barrios 2009 \{published data only\}}

Barrios V, Escobar C, Echarri R. Letter by Barrios et al regarding article, "Heart failure with preserved and reduced left ventricular ejection fraction in the antihypertensive and lipidlowering treatment to prevent heart attack trial". Circulation 2009;120(5):e31.

\section{Barry 2003 \{published data only\}}

Barry WH, Gilbert EM. How do beta-blockers improve ventricular function in patients with congestive heart failure?. Circulation 2003;107(19):2395-7.

\section{Bartels 1999 \{published data only\}}

Bartels GI, Heuvel FM, Veldhuisen DJ, Ent M, Remme WJ. Acute anti-ischemic effects of perindoprilat in men with coronary artery disease and their relation with left ventricular function. American Journal of Cardiology 1999; Vol. 83, issue 3:332-6.

\section{Baruch 1999 \{published data only\}}

Baruch L, Anand I, Cohen IS, Ziesche S, Judd D, Cohn JN. Augmented short- and long-term hemodynamic and hormonal effects of an angiotensin receptor blocker added to angiotensin converting enzyme inhibitor therapy in patients with heart failure. Vasodilator Heart Failure Trial (V-HeFT) Study Group. Circulation 1999;99(20):2658-64.

\section{Baruch 2004 \{published data only\}}

Baruch L, Glazer RD, Aknay N, Vanhaecke J, Heywood JT, Anand I, et al. Morbidity, mortality, physiologic and functional parameters in elderly and non-elderly patients in the Valsartan Heart Failure Trial (Val-HeFT). American Heart Journal 2004;148(6):951-7.

\section{Bauersachs 2004 \{published data only\}}

Bauersachs J. Aldosterone antagonism in heart failure: improvement of cardiac remodelling, endothelial dysfunction and platelet activation. European Journal of Clinical Investigation 2004;34(10):649-52.

\section{Baumhakel 2008 \{published data only\}}

Baumhakel M, Muller U, Bohm M. Valsartan improves symptoms and quality of life in patients with chronic heart failure. MMW Fortschritte der Medizin 2008;150(Suppl 1):48-53.

Beta-blockers and inhibitors of the renin-angiotensin aldosterone system for chronic heart failure with preserved ejection fraction (Review)

Copyright (c) 2018 The Cochrane Collaboration. Published by John Wiley \& Sons, Ltd. 
Bellenger 2004 \{published data only\}

Bellenger NG, Rajappan K, Rahman SL, Lahiri A, Raval U, Webster J, et al. Effects of carvedilol on left ventricular remodelling in chronic stable heart failure: a cardiovascular magnetic resonance study. Heart 2004;90(7):760-4.

Berry 2001 \{published data only\}

Berry C, Norrie J, McMurray JJV. Are angiotensin II receptor blockers more efficacious than placebo in heart failure? Implications of ELITE-2. American Journal of Cardiology 2001;87(5):606-7.

\section{Bettencourt 1999 \{published data only\}}

Bettencourt P. Treating diastolic heart failure: the role of ACE inhibitors. Revista Portuguesa de Cardiologia 1999;18(Suppl 5):V101-6

\section{Beygui 2016 \{published data only\}}

Beygui F, Cayla G, Roule V, Roubille F, Delarche N, Silvain J, et al. Early aldosterone blockade in acute myocardial infarction: The ALBATROSS randomized clinical trial. Journal of the American College of Cardiology 2016;67(16):1917-27.

Blagodar 2003 \{published data only\}

Blagodar VN, Petrii VV, Makolkin VI. Effect of lisinopril on cardiac remodeling in patients with cardiosclerosis after myocardial infarction and signs of chronic heart failure. Kardiologiia 2003;43(9):17-20.

\section{Blomer 1990 \{published data only\}}

Blomer H. Treatment of heart failure: what - when - how? Verhandlungen Der Deutschen Gesellschaft Fur Innere Medizin 1990;96:157-67.

\section{Borghi 2011 \{published data only\}}

Borghi C. Double-blind, randomized comparison of zofenopril vs. ramipril in MI patients treated with ASA: The SMILE 4 study and subgroup analysis. Circulation 2011;124(21):no pagination.

\section{Borgi 1990 \{published data only\}}

Borgi C, Magelli C, Costa FV, Magnani B, Ambrosioni E. Captopril improves hemodynamic response to static exercise in patients with congestive heart failure: a double-blind, placebo-controlled, randomized trial. Clinical Cardiology 1990;13(5):329-34.

\section{Borlaug 2014 \{published data only\}}

Borlaug BA. MY APPROACH to heart failure with preserved ejection fraction. Trends in Cardiovascular Medicine 2014;24(8):369-70.

\section{Bornkessel 1992 \{published data only\}}

Bornkessel B, Heinzl S. ACE-inhibitors and heart failure. Results of studies of left ventricular dysfunction. Medizinische Monatsschrift für Pharmazeuten 1992;15(3):76-80.

\section{Bounhoure 1991 \{published data only\}}

Bounhoure J P. Perindopril and chronic heart failure. Archives Des Maladies Du Coeur Et Des Vaisseaux 1991;84(Spec No 4):89-92.

\section{Braunwald 2004 \{published data only\}}

Braunwald E, Domanski MJ, Fowler SE, Geller NL, Gersh BJ, $\mathrm{Hsia} \mathrm{J}$, et al. Angiotensin-converting-enzyme inhibition in stable coronary artery disease. New England Journal of Medicine 2004;351(20):2058-68

Brilla 1989 \{published data only\}

Brilla CG, Kramer B, Hoffmeister HM, Muller-Schauenburg W, Risler T, Seipel L. Low-dose enalapril in severe chronic heart failure. Cardiovascular Drugs and Therapy 1989;3(2):211-8.

Brilla 1991 \{published data only\}

Brilla CG, Kramer B, Risler T, Seipel L. Low-dose enalapril in severe chronic heart failure [Niedrigdosiertes Enalapril bei schwerer chronischer Herzinsuffizienz]. Zeitschrift für Kardiologie 1991;80(Suppl 2):44-9.

Bristow 1994 \{published data only\}

Bristow MR, O'Connell JB, Gilbert EM, French WJ, Leatherman G, Kantrowitz NE, et al. Dose-response of chronic beta-blocker treatment in heart failure from either idiopathic dilated or ischemic cardiomyopathy. Bucindolol Investigators. Circulation 1994;89(4):1632-42.

\section{Bristow 1996 \{published data only\}}

Bristow MR, Gilbert EM, Abraham WT, Adams KF, Fowler MB, Hershberger RE, et al. Carvedilol produces dose-related improvements in left ventricular function and survival in subjects with chronic heart failure. MOCHA Investigators. Circulation 1996;94(11):2807-16.

\section{Bussmann 1987 \{published data only\}}

Bussmann WD, Storger H, Hadler D, Reifart N, Fassbinder W, Jungmann $\mathrm{E}$, et al. Long-term treatment of severe chronic heart failure with captopril: a double-blind, randomized, placebo-controlled, long-term study. Journal of Cardiovascular Pharmacology 1987;9(Suppl 2):S50-60.

\section{Butler 2017 \{published data only\}}

* Butler J, Anstrom KJ, Felker GM, Givertz MM, Kalogeropoulos AP, Konstam MA, et al. Efficacy and safety of spironolactone in acute heart failure: the ATHENA-HF randomized clinical trial. JAMA Cardiology 2017;2(9):950-8.

Butler J, Hernandez AF, Anstrom KJ, Kalogeropoulos A, Redfield MM, Konstam MA, et al. Rationale and design of the ATHENA-HF trial: aldosterone targeted neurohormonal combined with natriuresis therapy in heart failure. Journal of the American College of Cardiology. Heart Failure 2016;4(9):726-35.

NCT02235077. Study of high-dose spironolactone vs placebo therapy in acute heart failure (ATHENA-HF). clinicaltrials.gov/ show/NCT02235077 (first received 9 September 2014).

\section{Cafaro 2010 \{published data only\}}

Cafaro B, Barr S, Brand JL. Question: does beta-blocker therapy improve outcomes in patients with congestive heart failure with normal left ventricular function (diastolic dysfunction)?. Journal of the Oklahoma State Medical Association 2010;103(2):51-2. 
Cardoso 1999 \{published data only\}

Cardoso JS. Treating diastolic heart failure: the role of betablockers. Revista Portuguesa de Cardiologia 1999;18(Suppl 5):v97-9.

\section{Castagno 2010 \{published data only\}}

Castagno D, Jhund PS, Weir CJ, Colucci WS, Lopez Sendon JL, Remme WJ, et al. Effect of carvedilol in patients with or without renal impairment after myocardial infarction:analysis of the carvedilol post-infarct survival control in left ventricular dysfunction (CAPRICORN) study. European Heart Journal 2010;31:571.

\section{Choi 2001 \{published data only\}}

Choi JY, Lee KH, Hong KP, Kim BT, Seo JD, Lee WR, et al. lodine-123 MIBG imaging before treatment of heart failure with carvedilol to predict improvement of left ventricular function and exercise capacity. Journal of Nuclear Cardiology 2001;8(1):4-9.

\section{Cicoira 2002 \{published data only\}}

Cicoira M, Rossi A, Bonapace S, Zanolla L, Perrot A, Francis A, et al. Effects of ACE gene insertion/deletion polymorphism on response to spironolactone in patients with chronic heart failure. American Journal of Medicine 2004;116(10):657-61.

* Cicoira M, Zanolla L, Rossi A, Golia G, Franceschini L, Brighetti $G$, et al. Long-term, dose-dependent effects of spironolactone on left ventricular function and exercise tolerance in patients with chronic heart failure. Journal of the American College of Cardiology 2002;40(2):304-10.

\section{Cleland 1984 \{published data only\}}

Cleland JG, Dargie HJ, Hodsman GP, Ball SG, Robertson JI, Morton JJ, et al. Captopril in heart failure. A double blind controlled trial. British Heart Journal 1984;52(5):530-5.

\section{Cleland 1999 \{published data only\}}

Cleland JG, Pennel D, Ray S, Murray G, MacFarlane P, Cowley A, et al. The carvedilol hibernation reversible ischaemia trial; marker of success (CHRISTMAS). The CHRISTMAS Study Steering Committee and Investigators. European Journal of Heart failure 1999;1(2):191-6.

\section{Cleland 2001 \{published data only\}}

Cleland JG. ACE inhibitors for 'diastolic' heart failure? reasons not to jump to premature conclusions about the efficacy of ACE inhibitors among older patients with heart failure. European Journal of Heart Failure 2001;3(6):637-9.

\section{Cleland 2003 \{published data only\}}

Cleland JG, Pennell DJ, Ray SG, Coats AJ, Macfarlane PW, Murray GD, et al. Myocardial viability as a determinant of the ejection fraction response to carvedilol in patients with heart failure (CHRISTMAS trial): randomised controlled trial. Lancet 2003;362(9377):14-21.

\section{Cleland 2004 \{published data only\}}

Cleland JG, Huan Loh P, Freemantle N, Clark AL, Coletta AP. Clinical trials update from the European Society of Cardiology:
SENIORS, ACES, PROVE-IT, ACTION, and the HF-ACTION trial. European Journal of Heart Failure 2004;6(6):787-91.

Cleland 2006 \{published data only\}

Cleland JG, Coletta AP, Clark AL. Clinical trials update from the joint European Society and World Congress of Cardiology meeting: PEP-CHF, ACCLAIM and the HHH study. European Journal of Heart Failure 2006;8(6):658-61.

Cleland 2007 \{published data only\}

Cleland JGF, Coletta AP, Clark AL. Clinical trials update from the American College of Cardiology 2007: ALPHA, EVEREST, FUSION II, VALIDD, PARR-2, REMODEL, SPICE, COURAGE, COACH, REMADHE, pro-BNP for the evaluation of dyspnoea and THIS diet. European Journal of Heart Failure 2007;9(6-7):740-5.

Cleland 2010 \{published data only\}

Cleland JG, Coletta AP, Freemantle N, Ahmed D, Rubis P, Clark AL. Clinical trials update from the American Heart Association meeting 2009: HEAAL, FAIR-HF, J-CHF, HeartMate II, PACE and a meta-analysis of dose-ranging studies of betablockers in heart failure. European Journal of Heart Failure 2010;12(2):197-201.

\section{Cleland 2011 \{published data only\}}

Cleland JGF, Coletta AP, Cullington D, Castiello T, De Boer RA, Clark AL. Clinical trials update from the European Society of Cardiology Meeting 2011: ARISTOTLE, SMART-AV: QLV substudy, SHIFT: Echocardiography and quality of life substudies, European CRT Survey, and Basic Science Update. European Journal of Heart Failure 2011;13(12):1376-80.

Cleland 2013 \{published data only\}

Cleland JG, Clark AL, Costanzo P, Francis DP. Diabetes, aliskiren, and heart failure: Let's bring ASTRONAUT down to earth. European Heart Journal 2013;34(40):3097-9.

\section{Cohen-Solal 2005 \{published data only\}}

Cohen-Solal A, Rouzet F, Berdeaux A, Le Guludec D, Abergel E, Syrota A, et al. Effects of carvedilol on myocardial sympathetic innervation in patients with chronic heart failure. Journal of Nuclear Medicine 2005;46(11):1796-803.

Cohn 1993 \{published data only\}

Cohn JN. ACE inhibitors. Cardiovascular Drugs and Therapy 1993;7(3):379.

Cohn 1996a \{published data only\}

Cohn JN. Slowing the progression of heart failure. European Heart Journal 1996;17(11):1609-11.

Cohn 1996b \{published data only\}

Cohn JN. The management of chronic heart failure. New England Journal of Medicine 1996;335(7):490-8.

Cohn 2007 \{published data only\}

Cohn JN. Myocardial structural effects of aldosterone receptor antagonism in heart failure. JACC 2007;50(7):597-9.

Beta-blockers and inhibitors of the renin-angiotensin aldosterone system for chronic heart failure with preserved ejection fraction 
Coletta 2008 \{published data only\}

Coletta AP, Cullington D, Clark AL, Cleland JGF. Clinical trials update from European Society of Cardiology meeting 2008: TIME-CHF, BACH, BEAUTIFUL, GISSI-HF, and HOME-HF. European Journal of Heart Failure 2008;10(12):1264-7.

Coletta 2009 \{published data only\}

Coletta AP, Clark AL, Cleland JG. Clinical trials update from the Heart Failure Society of America and the American Heart Association meetings in 2008: SADHART-CHF, COMPARE, MOMENTUM, thyroid hormone analogue study, HF-ACTION, IPRESERVE, beta-interferon study, BACH, and ATHENA. European Journal of Heart Failure 2009;11(2):214-9.

\section{Comin-Colet 2002 \{published data only\}}

Comin-Colet J, Sanchez-Corral MA, Manito N, Gomez-Hospital JA, Roca J, Fernandez-Nofrerias E, et al. Effect of carvedilol therapy on functional mitral regurgitation, ventricular remodeling, and contractility in patients with heart failure due to left ventricular systolic dysfunction. Transplantation Proceedings 2002;34(1):177-8.

\section{CONSENSUS \{published data only\}}

Eriksson SV, Caidahl K, Hall C, Eneroth P, Kjekshus J, Offstad J, et al. Atrial natriuretic peptide ANP(1-98) and ANP(99-126) in patients with severe chronic congestive heart failure: relation to echocardiographic measurements. A subgroup analysis from the Cooperative North Scandinavian Enalapril Survival Study (CONSENSUS). Journal of Cardiac Failure 1995;1(2):109-16.

Ljungman S, Kjekshus J, Swedberg K. Renal function in severe congestive heart failure during treatment with enalapril (the Cooperative North Scandinavian Enalapril Survival Study Trial). American Journal of Cardiology 1992;70(4):479-87.

Swedberg K, Kjekshus J, CONSENSUS Trial Study Group. Effects of enalapril on mortality in severe congestive heart failure: results of the Cooperative North Scandinavian Enalapril Survival Study (CONSENSUS). American Journal of Cardiology 1988;62(2):60A-66A.

* The CONSENSUS Trial Study Group. Effects of enalapril on mortality in severe congestive heart failure. Results of the Cooperative North Scandinavian Enalapril Survival Study (CONSENSUS). New England Journal of Medicine 1987;316(23):1429-35.

\section{CONSENSUS II \{published data only\}}

Edner M, Bonarjee VV, Nilsen DW, Berning J, Carstensen S, Caidahl K. Effect of enalapril initiated early after acute myocardial infarction on heart failure parameters, with reference to clinical class and echocardiographic determinants. CONSENSUS II Multi-Echo Study Group. Clinical Cardiology 1996;19(7):543-8.

\section{Conti 2005 \{published data only\}}

Conti CR. Management of heart failure and left ventricular systolic dysfunction following acute myocardial infarction. Clinical Cardiology 2005;28(1):1-2.

\section{Corder 1993 \{published data only\}}

Corder CN, Rubler S, Deere LF, Puls A, Peguero-Rivera A, Nagarajan R, et al. Effect of cilazapril on exercise tolerance in congestive heart failure. Pharmacology 1993;46(3):148-54.

\section{Crouse 2011 \{published data only\}}

Crouse M, Flack D, Kerns JW, Martin L, Pham D, Sudireddy R, et al. Clinical inquiries. Which medications benefit patients with diastolic heart failure?. Journal of Family Practice 2011;60(2):101-2, 108

\section{Dahlstrom 2007 \{published data only\}}

Dahlstrom U, Boman K, Brodin L A, Hagerman I, Willenheimer R. Treatment of heart failure and preserved systolic function. Lakartidningen 2007;104(34):2348-50.

Davie 2001 \{published data only\}

Davie AP, Rumley A, Lowe GD, McMurray JJ. Effect of chronic angiotensin II type I receptor antagonism and angiotensin converting enzyme inhibition on plasma fibrinolytic variables in patients with heart failure. Thrombosis and Haemostasis 2001;86(6):1585-6.

DeBock 1994 \{published data only\}

DeBock V, Mets T, Romagnoli M, Derde MP. Captopril treatment of chronic heart failure in the very old. Journal of Gerontology 1994;49(3):M148-52.

\section{Dekleva 2012 \{published data only\}}

Dekleva M, Dungen HD, Gelbrich G, Incrot S, Suzic Lazic J, Pavlovic Kleut M, et al. Beta blockers therapy is associated with improved left ventricular systolic function and sustained exercise capacity in elderly patients with heart failure. CIBISELD sub-study. Aging Clinical and Experimental Research 2012;24(6):675-81.

\section{De Melo 2011 \{published data only\}}

De Melo D, Barretto AC, Ramires JF. The impact of the rapid use of beta-blockers on ventricular remodeling and mortality in end-stage heart failure. JACC 2011;57(14):E259.

\section{Demers 2001 \{published data only\}}

Demers C, McKelvie RS, Negassa A, Yusuf S, Investigators Resolvd Pilot Study. Reliability, validity, and responsiveness of the six-minute walk test in patients with heart failure. American Heart Journal 2001;142(4):698-703.

\section{Desai 2013 \{published data only\}}

Desai AS. Heart failure with preserved ejection fraction: Time for a new approach?. JACC 2013;62(4):272-4.

\section{Deswal 2010 \{published data only\}}

Deswal A, Richardson P, Bozkurt B, Mann DL. Randomized trial of aldosterone antagonism in diastolic heart failure (RAAMDHF). Journal of Cardiac Failure 2010;16(8):S7.

\section{de Teresa 1995 \{published data only\}}

de Teresa E, Espinosa JS, Gomez Doblas JJ. Cardiovascular pharmacology (IX). Angiotensin-converting enzyme inhibitors in hypertension and heart failure. Revista Espanola de Cardiologia 1995;48(2):128-41.

Beta-blockers and inhibitors of the renin-angiotensin aldosterone system for chronic heart failure with preserved ejection fraction 
Ding 2008 \{published data only\}

Ding P, Li L, Xu ZY, Han L, He B, Hu Y. Ramipril in combination with irbesartan for treatment of chronic heart failure in patients with rheumatic heart disease. Academic Journal of Second Military Medical University 2008;29(6):675-8.

Ditiatkov 1999 \{published data only\}

Ditiatkov AE, Radzevich AE, Tikhonov VA, Gal IG. Ramipril treatment of heart failure in disseminated forms of pulmonary tuberculosis. Problemy Tuberkuleza 1999;2:31-2.

\section{Donal 2008 \{published data only\}}

Donal E. Heart failure with preserved ejection fraction. La Revue de Médecine Interne 2008;29(Suppl 1):6-7.

\section{Dragana 2015 \{published data only\}}

Dragana Stanojevic D, Apostolovic S, Salinger-Martinovic S, Djordjevic-Radojkovic D, Jankovic-Tomasevic R, Pavlovic M, et al. Beta blockers in heart failure with preserved left ventricle ejection fraction. European Journal of Heart Failure 2015;17:364.

\section{Edner 2013 \{published data only\}}

Edner M, Lund LH. Renin-angiotensin system antagonists associated with reduced [corrected] mortality in diastolic heart failure. Lakartidningen 2013;110(7):331

\section{Eichhorn 1994 \{published data only\}}

Eichhorn EJ, Hatfield B, Marcoux L, Risser RC. Functional importance of myocardial relaxation in patients with congestive heart failure. Journal of Cardiac Failure 1994;1(1):45-56.

\section{Eichhorn 2003 \{published data only\}}

Eichhorn EJ, Grayburn PA, Mayer SA, St John Sutton M, Appleton C, Plehn J, et al. Myocardial contractile reserve by dobutamine stress echocardiography predicts improvement in ejection fraction with beta-blockade in patients with heart failure: the Beta-Blocker Evaluation of Survival Trial (BEST). Circulation 2003;108(19):2336-41.

\section{Er 2005 \{published data only\}}

Er F, Hoppe UC. Ivabradine -- a novel approach for heart rate lowering. Deutsche Medizinische Wochenschrift 2005;130(24):1501-2.

\section{Ertl 1999 \{published data only\}}

Ertl G, Hu K. Left ventricular remodelling during treatment with beta-blockers. Journal of Cardiovascular Risk 1999;6(3):145-50.

\section{EudraCT 2004-004169-13 \{published data only\}}

EudraCT 2004-004169-13. A Pilot study to assess the effects of beta-blockade on exercise capacity and BNP levels in patients with predominantly diastolic heart failure. www.clinicaltrialsregister.eu/ctr-search/search? query=eudract_number:2004-004169-13 (first received 21 April 2005).

\section{Fauchier 2009 \{published data only\}}

Fauchier L, Grimard C, Pierre B, Nonin E, Gorin L, Rauzy B, et al. Comparison of beta blocker and digoxin alone and in combination for management of patients with atrial fibrillation and heart failure. American Journal of Cardiology 2009;103(2):248-54.

Feola 2003 \{published data only\}

Feola M, Menardi E, Ribichini F, Vado A, Deorsola A, Ferrero V, et al. Effects of the addition of a low dose of spironolactone on brain natriuretic peptide plasma level and cardiopulmonary function in patients with moderate congestive heart failure. Medical Science Monitor 2003;9(8):CR341-5.

Flammer 2013 \{published data only\}

Flammer A, Sudano I, Enseleit F, Luscher TF, Noll G, Ruschitzka F. Mineralocorticoid receptor antagonism in patients with coronary artery disease and preserved ejection fractiona randomized, double-blind trial. European Journal of Heart Failure 2013;12:S222-3.

Flather 2016 \{published data only\}

Flather MD, Gollop ND. Understanding mechanisms of action of beta-blockers in heart failure with reduced and preserved ejection fraction. JACC Heart Failure 2016;4(2):150-1.

Flesch 2006 \{published data only\}

Flesch M. Combined administration of AT1-receptor antagonists and beta-blockers in patients with chronic heart insufficiency. Internistische Praxis 2006;46(4):829-32.

Follath 1996 \{published data only\}

Follath F. Beta-blockers in cardiac insufficiency. Time to reconsider?. Schweizer Medizinische Wochenschrift 1996;126(18):747-9.

\section{Fonarow 2004 \{published data only\}}

Fonarow G, Cannon C, Epstein A. Questions and answers. Journal of Invasive Cardiology 2004;16 Suppl E:16E-7E.

\section{Fonarow 2007 \{published data only\}}

Fonarow GC, Lukas MA, Robertson M, Colucci WS, Dargie HJ. Effects of carvedilol early after myocardial infarction: analysis of the first 30 days in Carvedilol Post-Infarct Survival Control in Left Ventricular Dysfunction (CAPRICORN). American Heart Journal 2007;154(4):637-44

\section{Fowler 1999 \{published data only\}}

Fowler MB. The influence of beta-adrenergic blocking drugs on morbidity and mortality in heart failure. Journal of Cardiovascular Risk 1999;6(3):141-4.

\section{Franciosa 2002 \{published data only\}}

Franciosa JA, Taylor AL, Cohn JN, Yancy CW, Ziesche S, Olukotun A, et al. African-American Heart Failure Trial (A-HeFT): rationale, design, and methodology. Journal of Cardiac Failure 2002;8(3):128-35.

\section{Fukunami 1991 \{published data only\}}

Fukunami M, Hashimura K, Ohmori M, Ikeda T, Umemoto K, Kumagai K, et al. Effectiveness of long-term beta-blocker therapy for dilated cardiomyopathy--echocardiographical follow-up. Cardiovascular Drugs and Therapy 1991;5(2):463-9. 
Galinier 2007 \{published data only\}

Galinier M. Treatment of heart failure with preserved ejection fraction. Archives des Maladies du Coeur et des Vaisseaux Pratique 2007;158:17-21.

\section{Galloe 2006 \{published data only\}}

Galloe AM, Skagen K, Christensen NJ, Nielsen SL, Frandsen EK, Bie $P$, et al. Dosage dependent hormonal counter regulation to combination therapy in patients with left ventricular dysfunction. Journal of Clinical Pharmacology and Therapy 2006;31(2):139-47.

\section{Gardner 2003 \{published data only\}}

Gardner RS, Martin W, Carter R, McDonagh TA. Importance of beta blockade in the treatment of advanced heart failure. Heart 2003;89(12):1442-4.

\section{Gardner 2004 \{published data only\}}

Gardner RS, McDonagh TA. The treatment of chronic heart failure due to left ventricular systolic dysfunction. Clinical Medicine 2004;4(1):18-22.

\section{Ghali 2002 \{published data only\}}

Ghali JK, Pina IL, Gottlieb SS, Deedwania PC, Wikstrand JC Group Merit-Hf Study. Metoprolol CR/XL in female patients with heart failure: analysis of the experience in Metoprolol ExtendedRelease Randomized Intervention Trial in Heart Failure (MERITHF). Circulation 2002;105(13):1585-91.

\section{Gheorghiade 2009 \{published data only\}}

Gheorghiade M, Khan S, Blair JE, Harinstein ME, Krum H, Mukherjee R, et al. The effects of eplerenone on length of stay and total days of heart failure hospitalization after myocardial infarction in patients with left ventricular systolic dysfunction. American Heart Journal 2009;158(3):437-43.

\section{Good 1994 \{published data only\}}

Good JM, Brady AJ, Noormohamed FH, Oakley CM, Cleland JG. Effect of intense angiotensin II suppression on the diuretic response to furosemide during chronic ACE inhibition. Circulation 1994;90(1):220-4.

\section{Goodfield 1999 \{published data only\}}

Goodfield NE, Newby DE, Ludlam CA, Flapan AD. Effects of acute angiotensin II type 1 receptor antagonism and angiotensin converting enzyme inhibition on plasma fibrinolytic parameters in patients with heart failure. Circulation 1999;99(23):2983-5.

\section{Gottlieb 1996 \{published data only\}}

Gottlieb SS, Singh S, Munger M, Eichhorn EJ, Ilgenfritz J, Hanyok J. Hemodynamic effects of the class III antiarrhythmic drug, d-sotalol, in patients with congestive heart failure. American Journal of Cardiology 1996;78(12):1411-5.

\section{Grajek 2008 \{published data only\}}

Grajek S. Do angiotensin receptor blockers increased the risk of myocardial infarction? The landscape after ONTARGET study. Kardiologia Polska 2008;66(12):1313-24.

\section{Greenberg 1996 \{published data only\}}

Greenberg BH, Quinones MA, Koilpillai C, Limacher M, Shindler D, Benedict C, et al. Left ventricular dysfunction: Effects of long-term enalapril therapy on remodeling. Cardiology Review 1996;13(7):40-6.

\section{Gremmler 2000 \{published data only\}}

Gremmler B, Kunert M, Schleiting H, Ulbricht LJ. Improvement of cardiac output in patients with severe heart failure by use of ACE-inhibitors combined with the AT1-antagonist eprosartan. European Journal of Heart Failure 2000;2(2):183-7.

Groenning 2000 \{published data only\} Groenning BA, Nilsson JC, Sondergaard L, Fritz-Hansen T, Larsson HB, Hildebrandt PR. Antiremodeling effects on the left ventricle during beta-blockade with metoprolol in the treatment of chronic heart failure. Journal of the American College of Cardiology 2000;36(7):2072-80.

\section{Groenning 2001 \{published data only\}}

Groenning BA, Nilsson JC, Sondergaard L. Antiremodeling effects on the left ventricle during beta-blockage with metaprolol in the treatment of chronic heart failure. Congestive Heart Failure 2001;7(1):58.

\section{Groenning 2002 \{published data only\}}

Groenning BA, Nilsson JC, Hildebrandt PR, Kjaer A, FritzHansen T, Larsson HB, et al. Neurohumoral prediction of leftventricular morphologic response to beta-blockade with metoprolol in chronic left-ventricular systolic heart failure. European Journal of Heart Failure 2002;4(5):635-46.

\section{Gruner 2007 \{published data only\}}

Gruner Svealv B, Tang M S, Waagstein F, Andersson B. Pronounced improvement in systolic and diastolic ventricular long axis function after treatment with metoprolol. European Journal of Heart Failure 2007;9(6-7):678-83.

\section{Guazzi 1998 \{published data only\}}

Guazzi M, Pontone G, Trevisi N, Lomanto M, Matturri M, Agostoni P. A failed improvement in pulmonary function and exercise capacity with carvedilol in congestive heart failure despite an excellent effect on left ventricular function. Cardiologia 1998;43(2):181-7.

\section{Guazzi 1999 \{published data only\}}

Guazzi M, Agostoni P, Matturri M, Pontone G, Guazzi M D. Pulmonary function, cardiac function, and exercise capacity in a follow-up of patients with congestive heart failure treated with carvedilol. American Heart Journal 1999;138(3 Pt 1):460-7.

\section{Gøtzsche 1992 \{published data only\}}

Gøtzsche CO, Søgaard P, Ravkilde J, Thygesen K. Effects of captopril on left ventricular systolic and diastolic function after acute myocardial infarction. American Journal of Cardiology 1992;70(2):156-60.

\section{Hanping 1997 \{published data only\}}

Hanping Z, Guolong Y, Jing L, Jin H. The changes of PRA, ATII, ALD, ET and ANP in patients with left ventricular and 
intervention with enalapril. Bulletin of Hunan Medical University 1997;22(4):323-6.

\section{Hara 2000 \{published data only\}}

Hara Y, Hamada M, Shigematsu Y, Suzuki M, Kodama K, Kuwahara T, et al. Effect of beta-blocker on left ventricular function and natriuretic peptides in patients with chronic heart failure treated with angiotensin-converting enzyme inhibitor. Circulation Journal - Official Journal of the Japanese Circulation Society 2000;64(5):365-9.

Hauf 1993 \{published data only\}

Hauf GF, Roskamm H. Heart failure in coronary heart disease. Internist 1993;34(10):953-60.

\section{Hole 2004 \{published data only\}}

Hole T, Frøland G, Gullestad L, Offstad J, Skjaerpe T. Metoprolol $\mathrm{CR} / \mathrm{XL}$ improves systolic and diastolic left ventricular function in patients with chronic heart failure. Echocardiography 2004;21(3):215-23.

\section{Holland 2010 \{published data only\}}

Holland DJ, Mottram PM, Hare JL, Jenkins C, Marwick TH. Extended duration of aldosterone blockade fails to improve diastolic dysfunction over the effects of blood pressure in patients with heart failure and normal ejection fraction. European Heart Journal 2010;31:731-2.

\section{Hong 2003 \{published data only\}}

Hong Y, Li Y, Wang XM, Liu XS, Li YN, Ouyang WM, et al. Effects of perindopril on plasma soluble TRAIL and receptor soluble DR5 in patients with congestive heart failure. Xi Bao Yu Fen Zi Mian Yi Xue Za Zhi 2003;19(4):366-8.

\section{Hoppe 2007 \{published data only\}}

Hoppe UC. Treatment of heart failure with ACE inhibitors and beta-blockers: what is next? AT1-receptor antagonists?. Clinical Research in Cardiology 2007;96(4):196-8.

\section{Hori 2004 \{published data only\}}

Hori M, Sasayama S, Kitabatake A, Toyo-oka T, Handa S, Yokoyama M, et al. Low-dose carvedilol improves left ventricular function and reduces cardiovascular hospitalization in Japanese patients with chronic heart failure: the Multicenter Carvedilol Heart Failure Dose Assessment (MUCHA) trial. American Heart Journal 2004;147(2):324-30.

\section{Hung 2010 \{published data only\}}

Hung CL, Verma A, Uno H, Shin SH, Bourgoun M, Hassanein AH, et al. Longitudinal and circumferential strain rate, left ventricular remodeling, and prognosis after myocardial infarction. Journal of the American College of Cardiology 2010;56(22):1812-22.

\section{IRIS-HF \{published data only\}}

ACTRN12609000789268. Non-invasive cardiac imaging in the detection and assessment of subclinical diabetic heart disease [Non-invasive cardiac imaging in the detection and assessment of subclinical diabetic heart disease in type 2 diabetes mellitus patients - outcome of antifibrotic therapy with spironolactone].
www.anzctr.org.au/Trial/Registration/TrialReview.aspx? id=308109 (date received 10 September 2009).

* Doehner W, Todorovic J, Kennecke C, Rauchhaus M, Sandek A, Lainscak M, et al. Improved insulin sensitivity by the angiotensin receptor antagonist irbesartan in patients with systolic heart failure: a randomized double-blinded placebo-controlled study. International Journal of Cardiology 2012;161(3):137-42.

NCT00347087. Effect of irbesartan on insulin sensitivity in chronic heart failure [Effect of the angiotensin II receptor antagonist irbesartan on insulin sensitivity and metabolic profile in patients with chronic heart failure]. clinicaltrials.gov/ ct2/show/NCT00347087 (first received 4 July 2006).

\section{Ito 2012 \{published data only\}}

Ito H, Ishii K, Kihara H, Kasayuki N, Nakamura F, Shimada K, et al. Adding thiazide to a renin-angiotensin blocker improves left ventricular relaxation and improves heart failure in patients with hypertension. Hypertension Research 2012;35(1):93-9.

\section{Jamieson 1991 \{published data only\}}

Jamieson MJ, Webster J, Fowler G, Rawles J, Smith FW, Petrie JC. A comparison of the chronic effect of oral xamoterol and enalapril on blood pressure and renal function in mild to moderate heart failure. British Journal of Clinical Pharmacology 1991;31(3):305-12.

\section{Jellis 2014 \{published data only\}}

* Jellis CL, Sacre JW, Wright J, Jenkins C, Haluska B, Jeffriess L, et al. Biomarker and imaging responses to spironolactone in subclinical diabetic cardiomyopathy. European Heart Journal 2014;15:776-86.

Jellis CL, Wright J, Sacre J, Kennedy D, Jeffriess L, Fenwick J, et al. Backscatter, $\mathrm{T} 1$ mapping or pro-collagen biomarkers for non-invasive assessment of treatment response to antifibrotic therapy in subclinical diabetic cardiomyopathy? A randomized trial. Journal of the American College of Cardiology 2012;59(13):E1076

\section{Jessup 2003 \{published data only\}}

Jessup M. Aldosterone blockade and heart failure. New England Journal of Medicine 2003;348(14):1380-2.

\section{Jong 2010 \{published data only\}}

Jong P, McKelvie R, Yusuf S. Should treatment for heart failure with preserved ejection fraction differ from that for heart failure with reduced ejection fraction?. BMJ 2010;341:c4202.

Kanoupakis 2008 \{published data only\}

Kanoupakis EM, Manios EG, Mavrakis HE, Kallergis EM, Lyrarakis GM, Koutalas EP, et al. Electrophysiological effects of carvedilol administration in patients with dilated cardiomyopathy. Cardiovascular Drugs and Therapy 2008;22(3):169-76

\section{Kapel'ko 2011 \{published data only\}}

Kapel'ko VI. Diastolic dysfunction. Kardiologiia 2011;51(1):79-90.

Beta-blockers and inhibitors of the renin-angiotensin aldosterone system for chronic heart failure with preserved ejection fraction 


\section{Kasama 2007 \{published data only\}}

Kasama S, Toyama T, Sumino H, Matsumoto N, Sato Y, Kumakura $\mathrm{H}$, et al. Additive effects of spironolactone and candesartan on cardiac sympathetic nerve activity and left ventricular remodeling in patients with congestive heart failure. Journal of Nuclear Medicine 2007;48(12):1993-2000.

\section{Keren 1992 \{published data only\}}

Keren G, Pardes A, Eschar Y, Hansch E, Scherez J, Laniado S. Left ventricular filling dynamics by Doppler echocardiography in dilated cardiomyopathy: one-year follow-up in patients treated with captopril compared to placebo. Cardiology 1992;81(4-5):196-206

\section{Keren 1994 \{published data only\}}

Keren G, Pardes A, Eschar Y, Koifman B, Scherez J, Geleranter I, et al. One-year clinical and echocardiographic follow-up of patients with congestive cardiomyopathy treated with captopril compared to placebo. Israel Journal of Medical Sciences 1994;30(1):90-8.

\section{Khalid 2013 \{published data only\}}

Khalid U, Deswal A. Lack of definitive evidence for the use of renin-angiotensin system antagonists for heart failure with preserved ejection fraction. Evidence Based Medicine 2013;18(6):226-7.

\section{Khand 2015 \{published data only\}}

Khand AU, Chew PG, Douglas H, Jones J, Jan A, Cleland JG. The effect of carvedilol on B-type natriuretic peptide and cardiac function in patients with heart failure and persistent atrial fibrillation. Cardiology 2015;130(3):153-8.

\section{Kikuchi 2016 \{published data only\}}

Kikuchi N, Jujo K, Yamaguchi J, Ogawa H, Hagiwara N. Impact of left ventricular ejection function on blood pressure-lower ing therapy in hypertensive patients with coronary artery disease. Journal of Hypertension 2016;34(5):1011-8.

\section{Kimura 2011 \{published data only\}}

Kimura M, Ogawa H, Wakeyama T, Takaki A, Iwami T, Hadano Y, et al. Effects of mineralocorticoid receptor antagonist spironolactone on atrial conduction and remodeling in patients with heart failure. Journal of Cardiology 2011;57(2):208-14.

Kinugawa 2007 \{published data only\}

Kinugawa S. Diabetic heart disease. Nippon Rinsho 2007;65(Suppl 5):465-9.

\section{Kjekshus 2007 \{published data only\}}

Kjekshus J. Prescription of beta-blockers in patients with advanced heart failure and preserved left ventricular ejection fraction. Clinical implications and survival. European Journal of Heart Failure 2007;9(9):962; author reply 962-3.

\section{Kjøller-Hansen 1998 \{published data only\}}

Kjøller-Hansen L, Steffensen R, Grande P. The Angiotensin Converting Enzyme Inhibition Post Revascularization Study (APRES). Effects of ramipril in patients with reduced left ventricular function. Rationale, design, methods, baseline characteristics and first-year experience. Scandinavian Cardiovascular Journal 1998;32(4):225-32.

Kleber 1991a \{published data only\}

Kleber FX, Doering W. Prognosis of mild chronic heart failure: effects of the ACE inhibitor captopril [Prognose bei leichter chronischer Herzinsuffizienz: Einflüsse des ACE-Hemmers Captopril]. Herz 1991;16(Spec No 1):283-93.

\section{Kleber 1991b \{published data only\}}

Kleber FX, Nussberger J, Niemoller L, Doering W, Brunner H. Development of heart failure after myocardial infarct: changes in plasma renin activity, angiotensin II, catecholamines and atrial natriuretic peptide [Entwicklung der Herzinsuffizienz nach Myokardinfarkt: Veränderungen von Plasma-Reninaktivität, Angiotensin II, Katecholaminen und atrialem natriuretischen Peptid]. Zeitschrift für Kardiologie 1991;80(Suppl 8):111-2.

\section{Kongstad-Rasmussen 1998 \{published data only\}}

Kongstad-Rasmussen O, Blomstrand M, Dahlstrom U, Wranne B. Treatment with ramipril improves systolic function even in patients with mild systolic dysfunction and symptoms of heart failure after acute myocardial infarction. Clinical Cardiology 1998;21(11):807-11.

\section{Krum 1996 \{published data only\}}

Krum H, Gu A, Wilshire-Clement M, Sackner-Bernstein J, Goldsmith R, Medina N, et al. Changes in plasma endothelin-1 levels reflect clinical response to beta-blockade in chronic heart failure. American Heart Journal 1996;131(2):337-41.

\section{Krum 2015 \{published data only\}}

Krum H, McMurray JJ, Abraham WT, Dickstein K, Kober L, Desai AS, et al. The Aliskiren Trial to Minimize OutcomeS in Patients with HEart failure trial (ATMOSPHERE): revised statistical analysis plan and baseline characteristics. European Journal of Heart Failure 2015;17(10):1075-83.

\section{Kulbertus 2003 \{published data only\}}

Kulbertus $\mathrm{H}$. Clinical study of the month. The CHARM study. Revue Medicale de Liege 2003;58(10):646-52.

\section{Kuznar 2003 \{published data only\}}

Kuznar W. Blocking aldosterone reduces deaths in post-MI heart failure. Cardiology Review 2003;20(6):1+14.

\section{Lang 1995 \{published data only\}}

Lang CC, McAlpine HM, Kennedy N, Rahman AR, Lipworth BJ, Struthers AD. Effects of lisinopril on congestive heart failure in normotensive patients with diastolic dysfunction but intact systolic function. European Journal of Clinical Pharmacology 1995;49(1-2):15-9.

\section{Larsen 1996 \{published data only\}}

Larsen J, Sykulski R, Jensen G, Dossegger L, Trimarco B, Moccetti T, et al. Adaptive changes in the acute haemodynamic effects of cilazapril during chronic treatment. Comparison with long-term clinical effect. European Journal of Clinical Pharmacology 1996;50(6):433-41. 


\section{Lechat 1993 \{published data only\}}

Bounhoure JP. Perindopril and chronic cardia failure. Archives des Maladies du Coeur et des Vaisseaux 1991;84(Spec Iss IV):89-92.

Bounhoure JP, Bottineau G, Lechat P, Garnham J, Lapeyre G. Contribution of perindopril to the treatment of chronic congestive cardiac insufficiency. Multicenter pilot double blind study versus placebo. Archives des Maladies du Coeur et des Vaisseaux 1989;82(Spec No 1):73-8.

Bounhoure JP, Bottineau G, Lechat P, Garnham J, Lapeyre G. Value of perindopril in the treatment of chronic congestive heart failure. Multicenter double-blind placebo-controlled study. Clinical and experimental hypertension. Part A, Theory and practice 1989;11(Suppl 2):575-86.

* Lechat P, Garnham SP, Desche P, Bounhoure JP. Efficacy and acceptability of perindopril in mild to moderate chronic congestive heart failure. American Heart Journal 1993;126(3 II Suppl):798-806.

\section{Leonetti 1999 \{published data only\}}

Leonetti Luparini R, Celli V, Piccirillo G, Guidi V, Cacciafesta M, Marigliano V. Carvedilol in elderly patients with chronic heart failure, a 12 weeks randomized, placebo controlled open trial. Archives of Gerontology and Geriatrics 1999;29(3):275-82.

Lewis 1988 \{published data only\}

Lewis GR. Lisinopril versus placebo in older congestive heart failure patients. American Journal of Medicine 1988;85(3B):48-54.

\section{Li 2005 \{published data only\}}

Li ZK, Mei X, Zhu SJ, Wang J, Tian Y, Zhou YZ, et al. Ventricular remodeling and cardiovascular events in patients with chronic heart failure and the interventional effects of metoprolol. Chinese Journal of Clinical Rehabilitation 2005;9(35):28-30.

\section{Liebson 2004 \{published data only\}}

Liebson PR. VALIANT and EUROPA. Preventive Cardiology 2004;7(1):42-4.

\section{Lindenfeld 2001 \{published data only\}}

Lindenfeld J, Robertson AD, Lowes BD, Bristow MR, Investigators Mocha. Aspirin impairs reverse myocardial remodeling in patients with heart failure treated with betablockers. JACC 2001;38(7):1950-6.

\section{Lindsay 1999 \{published data only\}}

Lindsay J, Freemantle N, Nazareth I. Beta-blockers in heart failure. Lancet 1999;353(9157):1011-2.

\section{Liu 2014 \{published data only\}}

Liu X, Zhong C, Zhao P, Zhang Z, Jia N, Su S, et al. Analysis of therapeutic effect and safety of target-dose metoprolol in the treatment of patients with diabetes mellitus with chronic heart failure. Pakistan Journal of Medical Sciences 2014;30(1):7-11.

\section{Logeart 2006 \{published data only\}}

Logeart D. Diastolic heart failure. Archives des Maladies du Coeur et des Vaisseaux - Pratique 2006;147:23-7.

\section{Lopez 2000 \{published data only\}}

Lopez Herrero F, Pardo Alvarez J. Spironolactone in heart failure. Atención Primaria 2000;25(4):281.

Lou 2009 \{published data only\}

Lou YF, Shi XP, Tong H, Yu GY, Yao GD, Dong K. Re: Effect of carvedilol on plasma adiponectin concentration in patients with chronic heart failure. Circulation Journal 2009;73(12):2363; author reply 2364 .

\section{Luo 2007 \{published data only\}}

Luo M, Bi Y, Xu YX. Effects of metoprolol on beta1 adrenergic receptor polymorphism and receptor density in urban Chinese patients with heart failure. Chinese Medical Journal 2007;120(19):1720-3.

\section{Ma 2005 \{published data only\}}

Ma HY. Effect of valsartan and hydrochloric benazepril on ventricular remodeling and cardiac function of patients with heart failure. Journal of Clinical Rehabilitative Tissue Engineering Research 2005;9(47):22-4.

\section{MacGregor 2009 \{published data only\}}

MacGregor JF, Wachter SB, Munger M, Stoddard G, Bristow MR, Gilbert EM. Carvedilol produces sustained long-term benefits: follow-up at 12 years. Congestive Heart Failure 2009;15(1):5-8.

\section{Mak 2008 \{published data only\}}

Mak G, Murphy NM, Phelan D, Watson C, O'Loughlin C, Baugh J, et al. The effects of low dose eplerenone on markers of collagen turnover in diastolic heart failure. Irish Journal of Medical Science 2008;177(Suppl 12):S398.

Malnick 2007 \{published data only\}

Malnick SD, Somin M. The VALIDD study. Lancet 2007;370(9591):931.

\section{Maron 2013 \{published data only\}}

Maron M, Kerur B, Chan RH, McGraw AP, Qiao X, Paruchuri V, et al. Can spironolactone mitigate myocardial fibrosis and alter sudden death risk and heart failure symptoms in patients with hypertrophic cardiomyopathy? A prospective, randomized trial. Circulation 2013;128(22):A16910.

\section{Mazayev 1998 \{published data only\}}

Mazayev VP, Fomina IG, Kazakow EN, Sulimov VA, Zvereva TV, Lyusov VA, et al. Valsartan in heart failure patients previously untreated with an ACE inhibitor. International Journal of Cardiology 1998;65(3):239-46.

\section{McAnulty 2004 \{published data only\}}

McAnulty JH Jr. Valsartan, captopril, or both in myocardial infarction. New England Journal of Medicine 2004;350(9):943-5; author reply 943.

\section{McCullough 2012 \{published data only\}}

McCullough PA, Cowan S. Mineralocorticoid receptor antagonists and mortality in heart failure with concurrent atrial fibrillation. Circulation 2012;5(5):550-1.

Beta-blockers and inhibitors of the renin-angiotensin aldosterone system for chronic heart failure with preserved ejection fraction (Review)

Copyright (c) 2018 The Cochrane Collaboration. Published by John Wiley \& Sons, Ltd. 
Mcllwain 1997 \{published data only\}

Mcllwain JS. HCQIP Project Report--findings released in Use of Ace Inhibitors in Heart Failure Project. Journal of the Mississippi State Medical Association 1997;38(7):282.

McKelvie 2012 \{published data only\}

McKelvie RS. Heart failure. American Family Physician 2012;86(2):182-4.

\section{McMurray 2000 \{published data only\}}

McMurray J. AT(1) receptor antagonists-beyond blood pressure control: possible place in heart failure treatment. Heart 2000;84 Suppl 1:i42-5: discussion i50.

\section{McMurray 2004 \{published data only\}}

McMurray JJ, Pfeffer MA, Swedberg K, Dzau VJ. Which inhibitor of the renin-angiotensin system should be used in chronic heart failure and acute myocardial infarction?. Circulation 2004;110(20):3281-8.

\section{Melo 2011 \{published data only\}}

Melo DSB, Barretto ACP, Oliveira AI, Uchida AH, Ochiai ME, Cardoso JN, et al. The impact of the rapid use of beta blockers on ventricular mortality and remodeling in and-stage heart failure. European Journal of Heart Failure. Supplement 2011;10:S173.

\section{Melo 2012 \{published data only\}}

Melo DB, Barretto AP, Ochiai M, Cardoso J, Oliveira A, Melo F, et al. The impact of the rapid use of beta-blockers on ventricular remodeling and mortality in end-stage heart failure (the FAST study). Circulation 2012;125(19):e754.

\section{Messias 2016 \{published data only\}}

Messias L R, Ferreira A G, Miranda S M, Teixeira J A, Azevedo J C, Messias A C, et al. Effect of Nebivolol on MIBG Parameters and Exercise in Heart Failure with Normal Ejection Fraction. Arquivos Brasileiros de Cardiologia 2016;106(5):358-66.

\section{Meuleman 2007 \{published data only\}}

Meuleman C. Diastolic dysfunction in heart failure with CHARMES (candesartan in heart failure assessment of reduction in mortality and morbidity) preserved systolic function: Results of the CHARM echocardiographic sub-study. Medecine Therapeutique - Cardio 2007;3(5):346-9.

\section{Mitrovic 2005 \{published data only\}}

Mitrovic V. Conclusions from CHARM interview with Prof. Veselin Mitrovich, Bad Nauheim. Strong evidence: more help for weak hearts. MMW Fortschritte der Medizin 2005;147(13):48-9.

\section{Mochizuki 2004 \{published data only\}}

Mochizuki S, Shimizu M, Taniguchi I, Kanae K, Yoshida S, Tajima N, et al. JIKEI HEART Study--a morbi-mortality and remodeling study with valsartan in Japanese patients with hypertension and cardiovascular disease. Cardiovascular Drugs and Therapy 2004;18(4):305-9.

\section{Morales 2011 \{published data only\}}

Morales H, Espinoza F, Larrea R, Gonzalez B, Puga L, Vukusich A, et al. A randomized, double-blind, placebo-controlled trial of spironolactone on diastolic dysfunction in diabetic patients. Diabetes 2011;60:A562.

Murdoch 2001 \{published data only\}

Murdoch DR, McDonagh TA, Farmer R, Morton JJ, McMurray JJ, Dargie HJ. ADEPT: Addition of the AT1 receptor antagonist eprosartan to ACE inhibitor therapy in chronic heart failure trial: hemodynamic and neurohormonal effects. American Heart Journal 2001;141(5):800-7.

NCT00293150 \{published data only\}

NCT00293150. Reversing endothelial and diastolic dysfunction and improving collagen turnover in diastolic heart failure (PREDICT). clinicaltrials.gov/show/NCT00293150 (first posted 17 February 2006).

\section{NCT00523757 \{published data only\}}

NCT00523757. Aldosterone blockade in heart failure (ARCTICD) [Aldosterone-blockade randomized controlled trial In CHF diastolic]. clinicaltrials.gov/show/NCT00523757 (first received 31 August 2007).

\section{NCT01691118 \{published data only\}}

NCT01691118. A trial of fimasartan for early diastolic heart failure (FINE) [Fimasartan for improvement of diastolic dysfunction in hypertensive patients]. clinicaltrials.gov/show/ NCT01691118 (first posted 24 September 2012).

\section{Nodari 2003 \{published data only\}}

Nodari S, Metra M, Dei Cas L. Beta-blocker treatment of patients with diastolic heart failure and arterial hypertension. A prospective, randomized, comparison of the long-term effects of atenolol vs. nebivolol. European Journal of Heart Failure 2003;5(5):621-7.

\section{Nunez 2016 \{published data only\}}

Nunez J, Nunez E, Sanchis J. Spironolactone in patients with heart failure and preserved ejection fraction. Revista Clinica Espanola 2016;216(2):111.

\section{O'Callaghan 1995 \{published data only\}}

O'Callaghan PA, Walsh MJ. ACE inhibitors in the management and prevention of heart failure. Irish Medical Journal $1995 ; \mathbf{8 8}(2): 48,50$

\section{O'Keefe 2008 \{published data only\}}

O'Keefe JH, Abuissa H, Pitt B. Eplerenone improves prognosis in postmyocardial infarction diabetic patients with heart failure: results from EPHESUS. Diabetes Obesity and Metabolism 2008;10(6):492-7.

\section{O'Keeffe 2015 \{published data only\}}

O'Keeffe St, Sharma N, Donnellan Ca, Lye M. Does stopping diuretics prevent first dose hypotension in older heart failure patients commencing ACE inhibitor therapy?. European Geriatric Medicine 2015; Vol. 6, issue 4:366-7.

O'Meara 2012 \{published data only\}

O'Meara E, Khairy P, Blanchet MC, de Denus S, Pedersen OD, Levesque $S$, et al. Mineralocorticoid receptor antagonists and cardiovascular mortality in patients with atrial fibrillation and

Beta-blockers and inhibitors of the renin-angiotensin aldosterone system for chronic heart failure with preserved ejection fraction (Review)

Copyright (c) 2018 The Cochrane Collaboration. Published by John Wiley \& Sons, Ltd. 
left ventricular dysfunction: insights from the Atrial Fibrillation and Congestive Heart Failure Trial. Circulation 2012;5(5):586-93.

\section{Ostergren 2004 \{published data only\}}

Ostergren J. Candesartan for the treatment of hypertension and heart failure. Expert Opinion in Pharmacotherapy 2004;5(7):1589-97.

\section{Palazzuoli 2005 \{published data only\}}

Palazzuoli A, Quatrini I, Vecchiato L, Calabria P, Gennari L, Martini G, et al. Left ventricular diastolic function improvement by carvedilol therapy in advanced heart failure. Journal of Cardiovascular Pharmacology 2005;45(6):563-8.

\section{Paolisso 1992 \{published data only\}}

Paolisso G, Gambardella A, Marrazzo G, Verza M, Teasuro P, Varricchio $\mathrm{M}$, et al. Metabolic and cardiovascular benefits deriving from beta-adrenergic blockade in chronic congestive heart failure. American Heart Journal 1992;123(1):103-10.

\section{Paraskevaidis 2006 \{published data only\}}

Paraskevaidis IA, Tsiapras D, Karavolias G, Adamopoulos S, Dodouras T, Cokkinos P, et al. The effect of carvedilol therapy on myocardial functional reserve in patients with advanced heart failure caused by nonischemic dilated cardiomyopathy. Journal of the American Society of Echocardiography 2006;19(5):529-35.

\section{Park 2016 \{published data only\}}

Park K, Park TH. Comparative effects of nebivolol and carvedilol on left ventricular diastolic function in older heart failure patients with preserved ejection fraction: study protocol for a randomized controlled trial. Trials 2016;17(1):530.

\section{Patten 1997 \{published data only\}}

Patten RD, Kronenberg MW, Benedict CR, Udelson JE, Kinan D, Stewart $D$, et al. Acute and long-term effects of the angiotensinconverting enzyme inhibitor, enalapril, on adrenergic activity and sensitivity during exercise in patients with left ventricular systolic dysfunction. American Heart Journal 1997;134(1):37-43.

\section{Pennell 2000 \{published data only\}}

Pennell DJ, Ray SG, Davies G, Burgess M, Webster J, Slomka P, et al. The carvedilol hibernation reversible ischaemia trial, marker of success (CHRISTMAS) study. Methodology of a randomised, placebo controlled, multicentre study of carvedilol in hibernation and heart failure. International Journal of Cardiology 2000;72(3):265-74.

\section{Pierard 2002 \{published data only\}}

Pierard L. Clinical study of the month. Effects of valsartan in chronic heart failure: the VAL-HeFT study. Revue Medical de Liege 2002;57(1):57-9.

\section{Pina 2004 \{published data only\}}

Pina IL. Valsartan in acute myocardial infarction trial. Current Cardiology Reports 2004;6(3):159-60.

\section{Pitt 2005 \{published data only\}}

Pitt B, White H, Nicolau J, Martinez F, Gheorghiade M, Aschermann $\mathrm{M}$, et al. Eplerenone reduces mortality 30 days after randomization following acute myocardial infarction in patients with left ventricular systolic dysfunction and heart failure. JACC 2005;46(3):425-31.

Pitt 2008 \{published data only\}

Pitt B, Bakris G, Ruilope LM, DiCarlo L, Mukherjee R, Investigators Ephesus. Serum potassium and clinical outcomes in the Eplerenone Post-Acute Myocardial Infarction Heart Failure Efficacy and Survival Study (EPHESUS). Circulation 2008;118(16):1643-50

Pitt 2011 \{published data only\}

Pitt B, Latini R, Maggioni AP, Solomon SD, Smith BA, Wright M, et al. Neurohumoral effects of aliskiren in patients with symptomatic heart failure receiving a mineralocorticoid receptor antagonist: the Aliskiren Observation of Heart Failure Treatment study. European Journal of Heart Failure 2011;13(7):755-64

Pourdjabbar 2015 \{published data only\} Pourdjabbar A, Dwivedi G, Haddad R, Saikali A, Mielniczuk L, Haddad $\mathrm{H}$. Heart rate control in patients with left ventricular systolic dysfunction and heart failure. International Journal of Cardiology 2015;184:276-7.

\section{Premkumar 2016 \{published data only\}}

Premkumar M, Rangegowda D, Shasthry SM, Vyas TS, Goyal R, Singh JK, et al. Targeted heart rate reduction using carvedilol ivabradine improves left ventricular diastolic dysfunction,clinical progression and survival in cirrhosis. Indian Journal of Gastroenterology 2016;35(1):A46-7.

Quaife 1998 \{published data only\} Quaife RA, Christian PE, Gilbert EM, Datz FL, Volkman K, Bristow MR. Effects of carvedilol on right ventricular function in chronic heart failure. American Journal of Cardiology 1998;81(2):247-50.

\section{Ramaswamy 2003 \{published data only\}}

Ramaswamy K. Beta blockers improve outcome in patients with heart failure and atrial fibrillation: U.S. carvedilol study. Cardiac Electrophysiology Review 2003;7(3):229-32.

Remme 2001 \{published data only\}

Remme WJ, Committee Carmen Steering, Investigators. The Carvedilol and ACE-Inhibitor Remodelling Mild Heart Failure EvaluatioN trial (CARMEN)--rationale and design. Cardiovascular Drugs and Therapy 2001;15(1):69-77.

Remme 2004 \{published data only\}

Remme WJ, Riegger G, Hildebrandt P, Komajda M, Jaarsma W, Bobbio $\mathrm{M}$, et al. The benefits of early combination treatment of carvedilol and an ACE-inhibitor in mild heart failure and left ventricular systolic dysfunction. The carvedilol and ACEinhibitor remodelling mild heart failure evaluation trial (CARMEN). Cardiovascular Drugs and Therapy 2004;18(1):57-66.

Remme 2005 \{published data only\}

Remme WJ. Could beta-blockers precede or replace angiotensin-converting enzyme inhibitors in heart failure? Heart Failure Clinic 2005;1(1):67-75.

Beta-blockers and inhibitors of the renin-angiotensin aldosterone system for chronic heart failure with preserved ejection fraction 
Rimatori 1990 \{published data only\}

Rimatori C, Zayat M. Captopril in the early phase of cardiac failure: effects on left ventricular diastolic function. Journal of International Medicine Supplement 1990;228(733):58.

\section{Roongsritong 2005 \{published data only\}}

Roongsritong C, Sutthiwan P, Bradley J, Simoni J, Power S, Meyerrose GE. Spironolactone improves diastolic function in the elderly. Clinical Cardiology 2005;28(10):484-7.

\section{Rosa 2011 \{published data only\}}

Rosa MLD. Effect of aliskiren and antihypertensive drugs on diastolic function in hypertensives with diastolic dysfunction: A randomised study. Journal of Clinical Hypertension 2011;13(4):A81.

\section{Rosenkranz 2003 \{published data only\}}

Rosenkranz S, Erdmann E. Hemodynamic effects of the beta blocker nebivolol. Internist 2003;44(4):481-2.

\section{Rossignol 2011 \{published data only\}}

Rossignol P, Manard J, Fay R, Gustafsson F, Pitt B, Zannad F. Eplerenone survival benefits in heart failure patients post-myocardial infarction are independent from its diuretic and potassium-sparing effects: Insights from an EPHESUS (Eplerenone Post-Acute Myocardial Infarction Heart Failure Efficacy and Survival Study) substudy. JACC 2011;58(19):1958-66.

\section{Sakai 2011 \{published data only\}}

Sakai H, Tsutamoto T, Kawahara C, Fujii M, Yamaji M, Ohnishi M, et al. Effects of aliskiren on Left ventricular remodeling in patients with dilated cardiomyopathy. European Heart Journal 2011;32:787.

\section{Sanderson 1998 \{published data only\}}

Sanderson JE, Chan SKW, Yu CM, Yeung LYC, Chan WM, Raymond K, et al. Beta blockers in heart failure: a comparison of a vasodilating beta blocker with metoprolol. Heart 1998;79:86-92.

\section{Sanghera 2011 \{published data only\}}

Sanghera KM. Keep patients with heart failure out of hospital: Ensure they get target doses. Pharmaceutical Journal 2011;286(7658):727-8.

\section{Santulli 2015 \{published data only\}}

Santulli G. beta-Blockers in diabetic patients with heart failure. JAMA Internal Medicine 2015;175(4):657.

\section{Sardu 1991 \{published data only\}}

Sardu G. Treatment of mild-to-moderate congestive heart failure with the angiotensin converting enzyme inhibitor quinapril. Advances in Therapy 1991;8(3):124-32.

\section{Schindler 2008 \{published data only\}}

Schindler B. Angiotensin receptor antagonists: No advantage for hypertensive patients with diastolic dysfunction. Medizinische Monatsschrift fur Pharmazeuten 2008;31(5):195-6.

\section{Schwab 2009 \{published data only\}}

Schwab J, Schneider M P, Pauschinger M, Schmieder RE. Hypertension and diastolic dysfunction. MMW Fortschritte der Medizin 2009;151(23):41-3.

\section{Segovia 2008 \{published data only\}}

Segovia J, Bermejo J, Alfonso F. Summary of the clinical studies reported in the 57th Scientific Session of the American College of Cardiology (Chicago, USA, 30 march-2 april 2008). Revista Espanola de Cardiologia 2008;61(7):726-37.

\section{Shimamoto 2007 \{published data only\}}

Shimamoto K, Kawana M. The Carvedilol and ACE-Inhibitor Remodelling Mild Heart Failure Evaluation Trial. Nippon Rinsho 2007;65 Suppl 4:531-6.

\section{Sidorenko 2008 \{published data only\}}

Sidorenko BA, Bugrimova MA, losava IK, Pataraia SA, Preobrazhenskii DV. Controlled release metoprolol succinate in MERIT-HF. Analysis of patients subgroups. Kardiologiia 2008;48(3):85-8.

\section{Silva 2014 \{published data only\}}

Silva MC, Rassi CH, Meira ZM, Giannetti JG, Vainzof M, Zatz M, et al. Progression of myocardial fibrosis by magnetic resonance imaging in patients with duchenne and becker muscular dystrophy and preserved left ventricular ejection fraction-a randomized clinical trial for treatment with ACE inhibitors. Journal of Cardiovascular Magnetic Resonance 2014;16:P311.

Smith 2012 \{published data only\} Smith JG, Kohl S, Kornhall B, Ekmehag B. Congestive heart failure, part 2: treatment. Lakartidningen 2012;109(41):1829-34.

Spoto 2002 \{published data only\} Spoto S, Palma Modoni A, De Galasso L. Diastolic cardiac insufficiency. La Clinica Terapeutica 2002;153(5):355-7.

Stecker 2005 \{published data only\}

Stecker EC, McAnulty JH. Letter regarding article by Weintraub et al, "Cost-effectiveness of eplerenone compared with placebo in patients with myocardial infarction complicated by left ventricular dysfunction and heart failure". Circulation 2005;112(5):e74.

Stiefelhagen 2006 \{published data only\}

Stiefelhagen P. New study results in cardiology. Internist 2006;47(3):311-6.

\section{Struthers 2004 \{published data only\}}

Struthers AD. Aldosterone in heart failure: pathophysiology and treatment. Current Heart Failure Reports 2004;1(4):171-5.

\section{Swedberg 1996 \{published data only\}}

Swedberg K, Sharpe N. The value of angiotensin converting enzyme inhibitors for the treatment of patients with left ventricular dysfunction, heart failure or after acute myocardial infarction. European Heart Journal 1996;17(9):1306-11. 
Swedberg 1999 \{published data only\}

Swedberg K. Beta-blockers and heart failure. Journal of Cardiovascular Risk 1999;6(3):129-30.

\section{Szajnbok 1993 \{published data only\}}

Szajnbok FE, Barretto AC, Mady C, Parga Filho J, Gruppi C, Alfieri RG, et al. Beneficial effects of enalapril on the diastolic ventricular function in Chagas myocardiopathy. Arquivos Brasileiros de Cardiologia 1993;60(4):273-8.

\section{Szymanski 2009 \{published data only\}}

Szymanski P, Klisiewicz A, Hoffman P. Therapeutic options for systemic right ventricular failure. Heart 2009;95(23):1950-1; author reply 1951.

\section{Taheri 2009 \{published data only\}}

Taheri S, Mortazavi M, Shahidi S, Pourmoghadas A, Garakyaraghi M, Seirafian S, et al. Spironolactone in chronic hemodialysis patients improves cardiac function. Saudi Journal of Kidney Diseases and Transplantation 2009;20(3):392-7.

Takekoshi 2004 \{published data only\}

Takekoshi N, Asaji T, Tada N. Hypertension in patients with heart failure. Nippon Rinsho 2004;62 Suppl 3:478-83.

\section{Tala 2011a \{published data only\}}

Tala S, Rossignol P, Fay R, Pitt B, Zannad F. Relation of loop diuretic dose to morbimortality in patients with heart failure and left ventricular systolic dysfunction: Insights from EPHESUS. European Journal of Heart Failure. Supplement 2011;10:S114-5.

\section{Tala 2011b \{published data only\}}

Tala S, Rossignol P, Fay R, Pitt B, Zannad F. Relation of loop diuretic dose to morbimortality in patients with heart failure and left ventricular systolic dysfunction: Insights from the eplerenone post-acute myocardial infarction heart failure efficacy and survival study (EPHESUS). Fundamental and Clinical Pharmacology 2011;25:2.

\section{Tan 2013 \{published data only\}}

Tan LB, Schlosshan D, Hall AS. Cardiac functional benefits of ivabradine therapy in patients with severe heart failure. International Journal of Cardiology 2013;165(2):389-90.

\section{Tatsumi 2006 \{published data only\}}

Tatsumi T, Matsubara H. Cardioprotective effect of aldosterone antagonists for ventricular remodeling. Nippon Rinsho 2006;64 Suppl 5:524-9.

\section{Taylor 2003 \{published data only\}}

Taylor AL. The African-American Heart Failure Trial (A-HeFT): rationale and methodology. [Erratum appears in J Card Fail. 2003 Dec;9(6):481 Note: Dosage error in article text]. Journal of Cardiac Failure 2003;9(5 Suppl Nitric Oxide):S216-9.

\section{Teerlink 2003 \{published data only\}}

Teerlink JR, Massie BM. Late breaking heart failure trials from the 2003 ACC meeting: EPHESUS and COMPANION. Journal of Cardiac Failure 2003;9(3):158-63.

\section{Tereshchenko 2005 \{published data only\}}

Tereshchenko SN, Kositsyna IV, Dzhaiani NA, Golubev AV, Kochetov AG. The use of esmolol in patients with myocardial infarction complicated with acute left ventricular failure. Kardiologiia 2005;45(6):19-22.

\section{Thornton 2004 \{published data only\}}

Thornton PL, Ahmed A. Angiotensin-converting enzyme inhibitors, beta-blockers, and mortality in systolic heart failure. JACC 2004;43(7):1333; author reply 1333-4.

\section{Thune 2008 \{published data only\}}

Thune JJ, Signorovitch J, Kober L, Velazquez EJ, McMurray JJ, Califf RM, et al. Effect of antecedent hypertension and followup blood pressure on outcomes after high-risk myocardial infarction. Hypertension 2008;51(1):48-54.

\section{Tinoco 2004 \{published data only\}}

Tinoco Mesquita E, Socrates J, Rassi S, Villacorta H, Mady C. Heart failure with preserved systolic function. Arquivos Brasileiros de Cardiologia 2004;82(5):494-500.

\section{Tsutamoto 2000 \{published data only\}}

Tsutamoto T, Wada A, Maeda K, Mabuchi N, Hayashi M, Tsutsui T, et al. Spironolactone inhibits the transcardiac extraction of aldosterone in patients with congestive heart failure. JACC 2000;36(3):838-44.

\section{Tsutamoto 2001 \{published data only\}}

Tsutamoto T, Wada A, Maeda K, Mabuchi N, Hayashi M, Tsutsui T, et al. Effect of spironolactone on plasma brain natriuretic peptide and left ventricular remodeling in patients with congestive heart failure. Journal of the American College of Cardiology 2001;37(5):1228-33.

Tsutamoto 2005 \{published data only\}

Tsutamoto T, Horie M, Hayashi M. Left ventricular remodeling post myocardial infarction. Nippon Rinsho 2005;63 Suppl 3:323-9.

\section{Tumasyan 2010 \{published data only\}}

Tumasyan LR, Adamyan KG. Comparative efficacy of combined therapy with angiotensin converting enzyme inhibitor and angiotensin receptor blocker and direct renin inhibitor in patients with severe chronic heart failure. European Heart Journal 2010;31:463-4.

\section{Umemoto 2003 \{published data only\}}

Umemoto S, Kawahara S, Hashimoto R, Matsuzaki M. Angiotensin receptor blockers in chronic heart failure. Nippon Rinsho 2003;61(9):1683-9.

\section{Uusimaa 2001 \{published data only\}}

Uusimaa P, Tokola H, Ruskoaho H, Vuolteenaho O, Risteli J, Ylitalo A, et al. Vasoactive peptides and procollagen propeptides in patients with hypertension in relation to cardiac hypertrophy and diastolic heart failure: design of the study and patient characteristics. Journal of Human Hypertension 2001;15 Suppl 1:S19-22. 
Van den Berg 1993 \{published data only\}

Van den Berg MP, van Veldhuisen DJ, Crijns HJ, Lie KI. Reversion of tachycardiomyopathy after beta-blocker. Lancet 1993;341(8861):1667.

\section{Van den Berg 1995 \{published data only\}}

Van den Berg MP, Crijns HJ, Van Veldhuisen DJ, Grief N, De Kam PJ, Lie KI. Effects of lisinopril in patients with heart failure and chronic atrial fibrillation. Journal of Cardiac Failure 1995;1(5):355-63.

\section{Vasiuk 2001 \{published data only\}}

Vasiuk IA, Kopelev MV, Khadzegova AB, Krikunov PV, lushchuk EN, Sologub KN. The role of beta-blockers in the treatment of chronic cardiac failure. Klinicheskaia Meditsina 2001;79(1):5-8

\section{Vincent 2012 \{published data only\}}

Vincent J, Sutradhar S, Beckerman B, Pitt B, Zannad F. Changes in sodium and renal function may contribute to the beneficial effects of eplerenone on mortality and morbidity in the EPHESUS trial. Circulation 2012;125(19):e745.

\section{Vizir 2000 \{published data only\}}

Vizir VA, Berezin AE. Losartan in therapy of chronic heart failure. Klinicheskaia Meditsina 2000;78(2):36-9.

\section{Vizzardi 2010 \{published data only\}}

Vizzardi E, D'Aloia A, Giubbini R, Bordonali T, Bugatti S, Pezzali N, et al. Effect of spironolactone on left ventricular ejection fraction and volumes in patients with class I or II heart failure. American Journal of Cardiology 2010;106(9):1292-6.

\section{Vizzardi 2012 \{published data only\}}

Vizzardi E, D'Aloia A, Della Pina P, Lombardi C, Bonadei I, Rovetta $\mathrm{R}$, et al. The effect of aldosterone-antagonist therapy on aortic elastic properties in patients with moderate heart failure. European Heart Journal 2012;33:934.

\section{Vizzardi 2015a \{published data only\}}

Vizzardi E, Sciatti E, Bonadei I, D'Aloia A, Tartiere-Kesri L, Tartiere J M, et al. Effects of spironolactone on ventriculararterial coupling in patients with chronic systolic heart failure and mild symptoms. Clinical Research in Cardiology 2015;104(12):1078-87.

\section{Vizzardi 2015b \{published data only\}}

Vizzardi E, Pina P D, Caretta G, Bonadei I, Sciatti E, Lombardi C, et al. The effect of aldosterone-antagonist therapy on aortic elastic properties in patients with nonischemic dilated cardiomyopathy. Journal of Cardiovascular Medicine 2015;16(9):597-602.

\section{Volpe 1992 \{published data only\}}

Volpe M, Tritto C, DeLuca N, Rubattu S, Mele AF, Lembo G, et al. Angiotensin converting enzyme inhibition restores cardiac and hormonal responses to volume overload in patients with dilated cardiomyopathy and mild heart failure. Circulation 1992;86(6):1800-9.
Volpe 2010 \{published data only\}

Volpe M, Taddei S. The HEAAL study. Giornale Italiano di Cardiologia 2010;11(9):625-9.

Voors 2008 \{published data only\}

Voors AA, de Jong RM. Treating diastolic heart failure. Heart 2008;94(8):971-2.

\section{Waagstein 2003 \{published data only\}}

Waagstein F, Stromblad O, Andersson B, Bohm M, Darius M, Delius W, et al. Increased exercise ejection fraction and reversed remodeling after long-term treatment with metoprolol in congestive heart failure: a randomized, stratified, double-blind, placebo-controlled trial in mild to moderate heart failure due to ischemic or idiopathic dilated cardiomyopathy. European Journal of Heart Failure 2003;5(5):679-91.

Waldo 1995 \{published data only\}

Waldo AL, Camm AJ, deRuyter H, Freidman PL, MacNeil DJ, Pitt B, et al. Survival with oral d-sotalol in patients with left ventricular dysfunction after myocardial infarction: rationale, design, and methods (the SWORD trial). American Journal of Cardiology 1995;75(15):1023-7.

Waldo 1996 \{published data only\}

Waldo AL, Camm AJ, deRuyter H, Friedman PL, MacNeil DJ, Pauls JF, et al. Effect of d-sotalol on mortality in patients with left ventricular dysfunction after recent and remote myocardial infarction. The SWORD Investigators. Survival With Oral dSotalol.[Erratum appears in Lancet 1996 Aug 10;348(9024):416]. Lancet 1996;348(9019):7-12.

\section{Warner 1999 \{published data only\}}

Warner JG Jr, Metzger DC, Kitzman DW, Wesley DJ, Little WC. Losartan improves exercise tolerance in patients with diastolic dysfunction and a hypertensive response to exercise. JACC 1999;33(6):1567-72.

\section{Weinberg 2001 \{published data only\}}

Weinberg EO, Herzig JW. Management of hypertension and heart failure with AT1 receptor blockade. JPMA 2001;51(2):81-5.

Weintraub 2005 \{published data only\}

Weintraub WS, Zhang Z, Mahoney EM, Kolm P, Spertus JA, Caro J, et al. Cost-effectiveness of eplerenone compared with placebo in patients with myocardial infarction complicated by left ventricular dysfunction and heart failure. Circulation 2005;111(9):1106-13.

\section{Weir 2011 \{published data only\}}

Weir RA, Tsorlalis IK, Steedman T, Dargie HJ, Fraser R, McMurray JJ, et al. Aldosterone and cortisol predict medium-term left ventricular remodelling following myocardial infarction. European Journal of Heart Failure 2011;13(12):1305-13

\section{Wong 2002 \{published data only\}}

Wong M, Staszewsky L, Latini R, Barlera S, Volpi A, Chiang YT, et al. Valsartan benefits left ventricular structure and function in heart failure: Val-HeFT echocardiographic study. JACC 2002;40(5):970-5.

Beta-blockers and inhibitors of the renin-angiotensin aldosterone system for chronic heart failure with preserved ejection fraction 
Wong 2004 \{published data only\}

Wong M, Staszewsky L, Latini R, Barlera S, Glazer R, Aknay N, et al. Severity of left ventricular remodeling defines outcomes and response to therapy in heart failure: Valsartan heart failure trial (Val-HeFT) echocardiographic data. JACC 2004;43(11):2022-7.

\section{Woodley 1991 \{published data only\}}

Woodley SL, Gilbert EM, Anderson JL, O'Connell JB, Deitchman D, Yanowitz FG, et al. Beta-blockade with bucindolol in heart failure caused by ischemic versus idiopathic dilated cardiomyopathy. Circulation 1991;84(6):2426-41.

Wright 2014 \{published data only\}

Wright LM, Jellis C, Kosmala W, Marwick T. Use of plasma markers of fibrosis to predict responders to the use of spironolactone in stage $b$ heart failure: A strain analysis. JACC 2014;63(12):A1127.

\section{Wu 2002 \{published data only\}}

Wu DQ, Yang YJ. Improving effect of carvedilol on cardiac function and exercise tolerance in patients with congestive heart failure of dilated cardiomyopathy. Chinese Journal of Clinical Rehabilitation 2002;6(15):2342-3.

\section{Xu 2007 \{published data only\}}

Xu JL, Zuo XH, Sha YB, Han CY, Liu XY, Zhang CJ. Effect of carvedilol on left ventricular function of patients with congestive heart failure evaluated by Doppler image. Journal of Clinical Rehabilitative Tissue Engineering Research 2007;11(13):2537-9.

\section{Yamamoto 2005 \{published data only\}}

Yamamoto T, Yano M. Aldosterone antagonist therapy for chronic heart failure. Nippon Naika Gakkai Zasshi 2005;94(2):262-9.

\section{Yan 2012 \{published data only\}}

Yan ZL, Wei L, Zhong YM, Xie DM, Yang YH. Effects of benazepril on left ventricular remodelling and exercise tolerance in patients with valvular heart failure. Heart 2012;98:E262.

\section{Yoshihiro 2011 \{published data only\}}

Yoshihiro I, Takaki T, Akira Y. The addition of direct renin inhibitor aliskiren to standard therapy suppresses enhanced cardiac sympathetic activity in patients with systolic heart failure. Circulation 2011;124(21):A8406.

\section{Young 2004 \{published data only\}}

Young JB, Dunlap ME, Pfeffer MA, Probstfield JL, CohenSolal A, Dietz R, et al. Mortality and morbidity reduction with Candesartan in patients with chronic heart failure and left ventricular systolic dysfunction: results of the CHARM low-left ventricular ejection fraction trials. Circulation 2004;110(17):2618-26

\section{Zeng 2006 \{published data only\}}

Zeng QL, He L. Effectiveness of losartan and benazepril in improving diastolic function of left ventricle in patients with heart failure and hypertension. Pharmaceutical Care and Research 2006;6(4):294-6.

\section{References to studies awaiting assessment}

Anonymous 2003d \{published data only\}

Anonymous. Selective aldosterone blocking in heart failure. Eplerenone reduces the risk after infarction. MMW Fortschritte der Medizin 2003;145(44):42-3.

Botoni 2010 \{published data only\}

Botoni F, Poole-Wilson PPW, Ribeiro ALP, Guedes VC, Oliveira BMR, Teixeira MM, et al. Assessment of the Quality of Life (SF36) after optimized cardiovascular therapy in Chagas cardiomyopathy. European Journal of Heart Failure Supplement 2010;9:S108.

Dielievska 2015 \{published data only\}

Dielievska VY. The effect of aldosterone receptor blockade in diastolic heart failure in patients with arterial hypertension combined with chronic obstructive pulmonary disease. General Medicine 2015;17(3):3-7.

Gao 2010 \{published data only\}

Gao WQ, Han CG, Zhao YX, Wang Q, Zhu P, Yang TS, et al. Effect of metoprolol on the expression of GRK2 in lymphocyte of advanced elderly patients with chronic heart failure. Nan Fang Yi Ke Da Xue Xue Bao 2010;30(5):1132-3.

\section{Liu 2006 \{published data only\}}

Liu G, Ji Z, Liu K. Effects of spironolactone in treatment of elderly hypertensive patients with diastolic heart failure. Chinese Journal of New Drugs and Clinical Remedies 2006;25(8):567-70.

\section{Metra 1999 \{published data only\}}

Metra M, Nodari S, Bordonali T, Cagnazzi E, Boldi E, Dei Cas L. ACE-inhibitors, AT1 receptor antagonists and diastolic dysfunction. Cardiologio 1999;44(Suppl 1):53-8.

\section{Rapezzi 1999 \{published data only\}}

Rapezzi C, Perugini E, Amati S, Branzi A. Beta blockers and calcium antagonists in diastolic dysfunction. Cardiologia 1999;44(Suppl 1):61-4

\section{Zheng 2009 \{published data only\}}

Zheng Y, Meng L, Dong JS, Wu JY. Effect of carvedilol on heart function and glucolipometabolic in elder patients with diastolic heart failure. Journal of Jilin University (Medicine Edition) 2009;35(6):1111-4.

\section{References to ongoing studies}

\section{EudraCT 2013-000867-10 \{published data only\}}

EudraCT 2013-000867-10. Effects of spironolactone in heart failure with preserved ejection fraction: measured by CMR, echo, excercise capacity and quality of life questionaire [Effects of aldosterone antagonism in heart failure with preserved ejection fraction (HF-PEF): cardiac MRI, echocardiography, exercise physiology \& quality of life assessment]. www.clinicaltrialsregister.eu/ctr-search/ trial/2013-000867-10/GB (first received 13 February 2014). 
IMPRESS-AF \{published data only\}

EudraCT 2014-003702-33. IMPRESS-AF: IMproved exercise tolerance in patients with PReserved Ejection fraction by Spironolactone on myocardial fibrosis in Atrial Fibrillation [Effect of spironolactone on ability to exercise and heart stiffness in people with irregular heart beats (atrial fibrillation) and normal pumping capacity of the heart]. www.clinicaltrialsregister.eu/ctr-search/trial/2014-003702-33/ GB (first entered 2 July 2015).

ISRCTN10259346. IMPRESS-AF: Improved exercise tolerance in heart failure with preserved ejection fraction by spironolactone on myocardial fibrosis in atrial fibrillation. www.isrctn.com/ ISRCTN10259346 (first received 15 January 2015).

NCT02673463. Spironolactone in atrial fibrillation (IMPRESSAF) [Improved exercise tolerance in participants with preserved ejection fraction by spironolactone on myocardial fibrosis in atrial fibrillation]. clinicaltrials.gov/show/NCT02673463 (first posted 4 February 2016).

* Shantsila E, Haynes R, Calvert M, Fisher J, Kirchhof P, Gill PS, et al. IMproved exercise tolerance in patients with PReserved Ejection fraction by Spironolactone on myocardial fibrosiS in Atrial Fibrillation rationale and design of the IMPRESS-AF randomised controlled trial. BMJ Open 2016;6(10):e012241.

\section{NCT02901184 \{published data only\}}

NCT02901184. Spironolactone initiation registry randomized interventional trial in heart failure with preserved ejection fraction (SPIRRIT). clinicaltrials.gov/show/NCT02901184 (first posted 15 September 2016).

\section{NCT03066804 \{published data only\}}

NCT03066804. A randomized, double-blind controlled study comparing LCZ696 to medical therapy for comorbidities in HFpEF patients (PARALLAX) [A 24-week, randomized, doubleblind, multi-center, parallel group, active controlled study to evaluate the effect of LCZ696 on NT-proBNP, symptoms, exercise function and safety compared to individualized medical management of comorbidities in patients with heart failure and preserved ejection fraction]. clinicaltrials.gov/show/ NCT03066804 (first posted 28 February 2017).

Tomasik A, Jachec W, Wojciechowska C, Kawecki D, Bialkowska B, Romuk E, et al. Randomized placebo controlled blinded study to assess valsartan efficacy in preventing left ventricle remodeling in patients with dual chamber pacemaker - Rationale and design of the trial. Contemporary Clinical Trials 2015;42:239-43.

\section{Zhou 2010 \{published data only\}}

Zhou J, Shi H, Zhang J, Lu Y, Fu M, Ge J, beta-PRESERVE Study Investigators. Rationale and design of the beta-blocker in heart failure with normal left ventricular ejection fraction (beta-PRESERVE) study. European Journal of Heart Failure 2010;12(2):181-5.

\section{Additional references}

\section{CIBIS Investigators 1999}

II CIBIS. The Cardiac Insufficiency Bisoprolol Study II (CIBIS-II): a randomised trial. Lancet 1999;353(9146):9-13.

\section{Consensus Trial Study Group 1987}

Group CONSENSUS Trial Study. Effects of enalapril on mortality in severe congestive heart failure: results of the Cooperative North Scandinavian Enalapril Survival Study (CONSENSUS). New England Journal of Medicine 1987;316(23):1429-35.

\section{de Denus 2017}

de Denus S, O'Meara E, Desai AS, Claggett B, Lewis EF, Leclair G, et al. Spironolactone metabolites in TOPCAT - new insights into regional variation. New England Journal of Medicine 2017;376(17):1690-2.

\section{Deeks 2011}

Deeks JJ, Higgins JPT, Altman DG (editors). Chapter 9: Analysing data and undertaking meta-analyses. In: Higgins JPT, Green S editor(s). Cochrane Handbook for Systematic Reviews of Interventions Version 5.1.0 (updated March 2011). The Cochrane Collaboration, 2011.

\section{Ezekowitz 2017}

Ezekowitz JA, O'Meara E, McDonald MA, Abrams H, Chan M, Ducharme A, et al. 2017 Comprehensive Update of the Canadian Cardiovascular Society Guidelines for the Management of Heart Failure. Canadian Journal of Cardiology 2017;33(11):1342-433.

\section{Flather 2005}

Flather MD, Shibata MC, Coats AJ, Van Veldhuisen DJ, Parkhomenko A, Borbola J, et al. SENIORS Investigators. Randomized trial to determine the effect of nebivolol on mortality and cardiovascular hospital admission in elderly patients with heart failure (SENIORS). European Heart Journal 2005;26(3):215-25.

\section{Gerber 2015}

Gerber Yariv, Weston Susan A, Redfield Margaret M, Chamberlain Alanna M, Manemann Sheila M, Jiang Ruoxiang, et al. A contemporary appraisal of the heart failure epidemic in Olmsted County, Minnesota, 2000 to 2010. JAMA Internal Medicine 2015;175(6):996.

\section{GRADEpro GDT [Computer program]}

McMaster University (developed by Evidence Prime). GRADEpro GDT. Version accessed prior to 12 February 2018. Hamilton, ON: McMaster University (developed by Evidence Prime), 2015.

\section{Granger 2003}

Granger CB, McMurray JJ, Yusuf S, Held P, Michelson EL, Olofsson $B$, et al. Effects of candesartan in patients with chronic heart failure and reduced left-ventricular systolic function intolerant to angiotensin-converting-enzyme inhibitors: the CHARM-Alternative trial. Lancet 2003;362(9386):772-6. 


\section{Higgins 2011}

Higgins JPT, Green S (editors). Cochrane Handbook for Systematic Reviews of Interventions Version 5.1 [updated March 2011]. The Cochrane Collaboration, 2011.

\section{Hjalmarson 2000}

Hjalmarson A, Goldstein S, Fagerberg B, Wedel H, Waagstein F, Kjekshus J, et al. Effects of controlled-release metoprolol on total mortality, hospitalizations, and well-being in patients with heart failure: the Metoprolol CR/XL Randomized Intervention Trial in congestive heart failure (MERIT-HF). MERIT-HF Study Group. JAMA 2000;283(10):1295-302.

\section{Hogg 2005}

Hogg K, McMurray J. Neurohumoral pathways in heart failure with preserved systolic function. Progress in Cardiovascular Diseases 2005;47(6):357-66.

\section{Kotecha 2014}

Kotecha D, Holmes J, Krum H, Altman DG, Manzano L, Cleland JGF, et al. Beta-Blockers in Heart Failure Collaborative Group. Efficacy of $\beta$ blockers in patients with heart failure plus atrial fibrillation: an individual-patient data meta-analysis. Lancet 2014;384(9961):2235-43.

\section{Lefebvre 2011}

Lefebvre C, Manheimer E, Glanville J. Chapter 6: Searching for studies. In: Higgins JPT, Green S editor(s). Cochrane Handbook for Systematic Reviews of Interventions. Version 5.1 [updated March 2011]. The Cochrane Collaboration, 2011. Available from www.cochrane-handbook.org.

\section{McMurray 2014}

McMurray JJ, Packer M, Desai AS, Gong J, Lefkowitz MP, Rizkala AR, et al. PARADIGM-HF Investigators and Committees. Angiotensin-Neprilysin Inhibition versus Enalapril in Heart Failure. New England Journal of Medicine 2014;371(11):993-1004.

\section{MERIT-HF Study Group 1999}

MERIT-HF. Effect of metoprolol CR/XL in chronic heart failure: Metoprolol CR/XL Randomised Intervention Trial in Congestive Heart Failure (MERIT-HF). Lancet 1999;353(9169):2001-7.

\section{NCT01920711}

NCT01920711. Efficacy and Safety of LCZ696 Compared to Valsartan, on Morbidity and Mortality in Heart Failure Patients With Preserved Ejection Fraction (PARAGON-HF). clinicaltrials.gov/ct2/show/NCT01920711 (first posted 12 August 2013).

\section{NCT02884206}

NCT02884206. Efficacy and Safety of LCZ696 Compared to Valsartan on Cognitive Function in Patients With Chronic Heart Failure and Preserved Ejection Fraction (PERSPECTIVE). clinicaltrials.gov/ct2/show/NCT02884206 (first posted 30 August 2016).

\section{NICE 2010}

NICE. Chronic heart failure in adults: management. Retrieved from http://www.nice.org.uk/guidance/cg108/.

\section{Packer 1999}

Packer M, Poole-Wilson PA, Armstrong PW, Cleland JG, Horowitz JD, Massie BM, et al. Comparative effects of low and high doses of the angiotensin-converting enzyme inhibitor, lisinopril, on morbidity and mortality in chronic heart failure. ATLAS Study Group. Circulation 1999;100(23):2312-8.

\section{Packer 2001}

Packer M, Coats AJ, Fowler MB, Katus HA, Krum H, Mohacsi P, et al. Effect of carvedilol on survival in severe chronic heart failure. New England Journal of Medicine 2001;344(22):1651-8.

\section{Packer 2002}

Packer M, Fowler MB, Roecker EB, Coats AJS, Katus Hugo A, Krum $\mathrm{H}$, et al. Effect of carvedilol on the morbidity of patients with severe chronic heart failure: results of the carvedilol prospective randomized cumulative survival (COPERNICUS) study. Circulation 2002;106(17):2194-9.

\section{Pfeffer 2015}

Pfeffer MA, Claggett B, Assmann SF, Boineau R, Anand IS, Clausell N, et al. Regional variation in patients and outcomes in the Treatment of Preserved Cardiac FunctionHeart Failure With an Aldosterone Antagonist (TOPCAT) trial. Circulation 2015;131(1):34-42.

\section{Pitt 1999}

Pitt Bertram, Zannad Faiez, Remme Willem J, Cody Robert, Castaigne Alain, Perez Alfonso, et al. The Effect of Spironolactone on Morbidity and Mortality in Patients with Severe Heart Failure. New England Journal of Medicine 1999;341(10):709-17.

\section{Pitt 2014}

Pitt B, Pfeffer MA, Assmann SF, Boineau R, Anand IS, Claggett $B$, et al. Spironolactone for heart failure with preserved ejection fraction. New England Journal of Medicine 2014;370(15):1383-92.

\section{Ponikowski 2016}

Ponikowski P, Voors AA, Anker SD, Bueno H, Cleland JGF, Coats AJS, et al. Authors/Task Force Members. 2016 ESC Guidelines for the diagnosis and treatment of acute and chronic heart failure: The Task Force for the diagnosis and treatment of acute and chronic heart failure of the European Society of Cardiology (ESC)Developed with the special contribution of the Heart Failure Association (HFA) of the ESC. European Heart Journal 2016;37(27):2129-200.

\section{Rector 1995}

Rector T S, Tschumperlin L K, Kubo S H, Bank A J, Francis G $\mathrm{S}$, McDonald K M, et al. Use of the Living With Heart Failure questionnaire to ascertain patients' perspectives on improvement in quality of life versus risk of drug-induced death. Journal of Cardiac Failure 1995;1(3):201-6.

\section{RevMan 2014 [Computer program]}

The Cochrane Collaboration. Review Manager (RevMan). Version 5.3. Copenhagen: The Nordic Cochrane Centre: The Cochrane Collaboration, 2014.

Beta-blockers and inhibitors of the renin-angiotensin aldosterone system for chronic heart failure with preserved ejection fraction (Review)

Copyright (c) 2018 The Cochrane Collaboration. Published by John Wiley \& Sons, Ltd. 


\section{Roger 2013}

Roger VL. Epidemiology of heart failure. Circulation Research 2013;113(6):646-59.

\section{Rogers 2014}

Rogers JK, Pocock SJ, McMurray JJ, Granger CB, Michelson EL, Östergren J, et al. Analysing recurrent hospitalizations in heart failure: a review of statistical methodology, with application to CHARM-Preserved. European Journal of Heart Failure 2014;16(1):33-40.

\section{Sackner-Bernstein 1995}

Sackner-Bernstein JD, Mancini DM. Rationale for treatment of patients with chronic heart failure with adrenergic blockade. JAMA 1995;274(18):1462-7.

\section{Sharma 2014}

Sharma K, Kass DA. Heart failure with preserved ejection fraction mechanisms, clinical features, and therapies. Circulation Research 2014;115:79-96.

\section{Solomon 2012}

Solomon SD, Zile M, Pieske B, Voors A, Shah A, KraigherKrainer E, et al. The angiotensin receptor neprilysin inhibitor LCZ696 inheart failure with preserved ejection fraction: a phase 2double-blind randomised controlled trial. Lancet 2012;380:1387-95.

\section{Solomon 2016}

Solomon Scott D, Claggett Brian, Lewis Eldrin F, Desai Akshay, Anand Inder, Sweitzer Nancy K, et al. Influence of ejection fraction on outcomes and efficacy of spironolactone in patients with heart failure with preserved ejection fraction. European Heart Journal 2016;37(5):455-62.

\section{SOLVD Investigators 1991}

SOLVD Investigators, Yusuf S, Pitt B, Davis CE, Hood WB, Cohn JN. Effect of enalapril on survival in patients with reduced left ventricular ejection fractions and congestive heart failure. New England Journal of Medicine 1991;325(5):293-302.

\section{SOLVD Investigators 1992}

SOLVD Investigators. Effect of enalapril on mortality and the development of heart failure in asymptomatic patients with reduced left ventricular ejection fractions. New England Journal of Medicine 1992;1992(327):685-91.

\section{Spertus 2005}

Spertus J, Peterson E, Conard MW, Heidenreich PA, Krumholz HM, Jones P, et al. Cardiovascular Outcomes Research Consortium. Monitoring clinical changes in patients with heart failure: a comparison of methods. American Heart Journal 2005;150:707-15.

\section{CHARACTERISTICS OF STUDIES}

\section{Characteristics of included studies [ordered by study ID]}

\section{Wong 2006}

Wong SS, Wilczynski NL, Haynes RB. Developing optimal search strategies for detecting clinically sound treatment studies in EMBASE. Journal of the Medical Library Association 2006;94(1):41-7.

\section{Yancy 2013}

Yancy CW, Jessup M, Bozkurt B, Butler J, Casey DE, Drazner MH, et al. 2013 ACCF/AHA guideline for the management of heart failure: a report of the American College of Cardiology Foundation/American Heart Association Task Force on Practice Guidelines. Journal of the American College of Cardioliology 2013;62(16):e147-239.

\section{Yusuf 2003}

Yusuf S, Pfeffer MA, Swedberg K, Granger CB, Held P, McMurray JJV, et al. Effects of candesartan in patients with chronic heart failure and preserved left-ventricular ejection fraction: the CHARM-Preserved Trial. Lancet 2003;362(9386):777-81.

\section{Zannad 2011}

Zannad F, McMurray JJV, Krum H, van Veldhuisen DJ, Swedberg K, Shi H, et al. Eplerenone in patients with systolic heart failure and mild symptoms. New England Journal of Medicine 2011;364(1):11-21.

\section{Zheng 2017}

Zheng SL, Chan FT, Nabeebaccus AA, Shah AM, McDonagh T, Okonko DO, et al. Drug treatment effects on outcomes in heart failure with preserved ejection fraction: a systematic review and meta-analysis. Heart 2017;August:Epub ahead of print.

\section{Zile 2016}

Zile MR, Jhund PS, Baicu CF, Claggett BL, Pieske B, Voors AA, et al. Plasma biomarkers reflecting profibrotic processes in heart failure with a preserved ejection fraction: data from the prospective comparison of ARNI with ARB on management of heart failure with preserved ejection fraction study. Circulation. Heart Failure 2016;9(1):e002551.

\section{References to other published versions of this review}

\section{Lumbers 2017}

Lumbers RT, Martin N, Manoharan K, Nyong J, Thomas J, Casas JP, et al. Beta-blockers and inhibitors of the reninangiotensin aldosterone system for chronic heart failure with preserved ejection fraction. Cochrane Database of Systematic Reviews 2017, Issue 7. [DOI: 10.1002/14651858.CD012721]

* Indicates the major publication for the study

Adamyan 2010

Methods Study design: four arm factorial RCT

Beta-blockers and inhibitors of the renin-angiotensin aldosterone system for chronic heart failure with preserved ejection fraction (Review)

Copyright @ 2018 The Cochrane Collaboration. Published by John Wiley \& Sons, Ltd. 
Start of enrolment: not reported

End of enrolment: not reported

Mean follow-up: 12 months

Run-in period: not reported

Participants
Inclusion criteria: "III NYHA class chronic ischemic heart failure (CHF) patients (pts) with normal cholesterol who have preserved LV ejection fraction (PEF) and restrictive diastolic filling pattern"

Exclusion criteria: not reported

Randomised (N): 118 in total, of interest are: carvedilol, no simvastatin $(\mathrm{N}=31)$ versus no carvedilol, no simvastatin $(\mathrm{N}=28)$

Withdrawn (N): not reported

Lost to follow-up (N): not reported

Analysed (N): not reported

Age (years, mean, unspecified): $64.5,0.3$

Sex (\% men): not reported

Ethnicity (\%): not reported

Systolic blood pressure: not reported

Heart rate: not reported

BMI: not reported

Serum creatinine: not reported

B-type natriuretic peptide $(\mathrm{pg} / \mathrm{mL})$ : not reported

NT pro B-type natriuretic peptide $(\mathrm{pg} / \mathrm{mL})$ : not reported

LVEF "preserved LV ejection fraction" but not defined

NYHA class I (\%): 0

NYHA class II (\%): 0

NYHA class III (\%): 100

NYHA class IV (\%): 0

Hypertension: not reported

Diabetes: not reported

Atrial fibrillation: not reported

Hospitalisation for heart failure: not reported

Coronary heart disease: not reported

Stroke: not reported

Diuretic: not reported

Digoxin: not reported 
Beta-blockers: study drug

ACEI: not reported

ARB: not reported

MRA: not reported

Interventions Intervention: carvedilol (up to $50 \mathrm{mg}$ ), simvastatin, carvedilol and simvastatin

Comparator: not receiving carvedilol or simvastatin

Concomitant medication: "in addition to ACE inhibitors, aldosterone antagonists and diuretics"

\begin{tabular}{ll}
\hline Outcomes & $\begin{array}{l}\text { Planned: not reported } \\
\text { Reported: "prognosis, left ventricular (LV) diastolic function, plasma BNP level and inflammation sta- } \\
\text { tus", "Assessment of relation of early (E) and late (A) diastolic filling velocities, deceleration time (DT) of } \\
\text { E wave, levels of BNP, interleukin-6 (IL-6) and high sensitivity C-reactive protein (CRP)", mortality, hospi- } \\
\text { talisation }\end{array}$ \\
\hline Notes & Two conference abstracts only. \\
Comparison between carvedilol and no treatment was of interest for this review. & No outcome data relevant to this review. \\
Trialists were contacted; no response. \\
Source of funding: not reported.
\end{tabular}

\section{Risk of bias}

\begin{tabular}{lll}
\hline Bias & Authors' judgement & Support for judgement \\
\hline $\begin{array}{l}\text { Random sequence genera- } \\
\text { tion (selection bias) }\end{array}$ & Unclear risk & "Randomly assigned" but no details given \\
\hline $\begin{array}{l}\text { Allocation concealment } \\
\text { (selection bias) }\end{array}$ & Unclear risk & Not reported \\
\hline $\begin{array}{l}\text { Blinding of participants } \\
\text { and personnel (perfor- } \\
\text { mance bias) } \\
\text { All outcomes }\end{array}$ & Unclear risk & Not reported \\
\hline
\end{tabular}

Blinding of outcome as- Unclear risk Not reported
sessment (detection bias)

All outcomes

\begin{tabular}{lll}
\hline $\begin{array}{l}\text { Incomplete outcome data } \\
\text { (attrition bias) } \\
\text { All outcomes }\end{array}$ & Unclear risk & Not reported \\
\hline $\begin{array}{l}\text { Selective reporting (re- } \\
\text { porting bias) }\end{array}$ & Unclear risk & Not reported \\
\hline Other bias & High risk & Published as conference abstracts only \\
\hline
\end{tabular}




\begin{tabular}{|c|c|}
\hline \multirow[t]{6}{*}{ Methods } & Study design: parallel RCT \\
\hline & Centres: 10 centres in Germany and Austria \\
\hline & Start of enrolment: March 2007 \\
\hline & End of enrolment: April 2011 \\
\hline & Mean follow-up: 11.6 months \\
\hline & Run-in period: not reported \\
\hline \multirow[t]{2}{*}{ Participants } & $\begin{array}{l}\text { Inclusion criteria: "men and women aged } 50 \text { years or older were eligible to participate in the study if } \\
\text { they had current heart failure symptoms consistent with New York Heart Association (NYHA) class II or } \\
\text { III, left ventricular ejection fraction (LVEF) of } 50 \% \text { or greater, echocardiographic evidence of diastolic } \\
\text { dysfunction (grade I) or atrial fibrillation at presentation, and maximum exercise capacity (peak VO2) of } \\
25 \mathrm{~mL} / \mathrm{kg} / \mathrm{min} \text { or less." }\end{array}$ \\
\hline & $\begin{array}{l}\text { Exclusion criteria: "Major exclusion criteria included prior documented reduced left ventricular ejec- } \\
\text { tion fraction (LVEF } 40 \% \text { ), significant coronary artery disease (current angina pectoris or ischemia on } \\
\text { stress tests; untreated coronary stenosis } 50 \% \text { ), myocardial infarction or coronary artery bypass graft } \\
\text { surgery } 3 \text { months or less prior to enrolment, clinically relevant pulmonary disease (vital capacity } 80 \% \\
\text { or forced expiratory volume in } 1 \text { second } 80 \% \text { of reference values on spirometry), significant laboratory } \\
\text { abnormalities (potassium } 5.1 \mathrm{mmol} / \mathrm{L} \text {; hemoglobin } 11 \mathrm{~g} / \mathrm{dL} \text {; hematocrit } 33 \% \text {; serum creatinine } 1.8 \mathrm{mg} / \\
\mathrm{dL} \text {; or estimated glomerular filtration rate [eGFR] } 30 \mathrm{~mL} / \mathrm{min} / 1.73 \mathrm{~m}^{2} \text {, calculated using the Modifica- } \\
\text { tion of Diet in Renal Disease formula: } 186 \text { [serum creatinine } \text { in micromoles per liter\}/ } 88.4] 1.154 \text { age [in } \\
\text { years] } 0.2031 .21 \text { [if patient is black] } 0.742 \text { [if patient is female]), known contraindications for spirono- } \\
\text { lactone or known intolerance to or therapy with a mineralocorticoid receptor antagonist within the } \\
\text { last } 3 \text { months, concomitant therapy with a potassium-sparing diuretic (eg, triamterene, amiloride), or } \\
\text { potassium supplementation." }\end{array}$ \\
\hline
\end{tabular}

Randomised (N): 422 (213 intervention, 209 control)

Withdrawn $(\mathrm{N})$ : for reasons other than death 16 (6 intervention, 10 control)

Lost to follow-up (N): 5 (2 intervention, 3 control)

Analysed (N): 422 (213 intervention, 209 control)

Age (years, mean, SD): intervention: 67, 8; control: 67, 8

Sex (\% men): intervention: 48 ; control: 47

Ethnicity (\%): not reported

Systolic blood pressure (mmHg, mean, SD): intervention: 135, 18; control: 135, 18

Heart rate (beats/min, mean, SD): intervention: 66, 14; control: 64, 12

BMI (mean, SD): intervention: 28.9, 3.6; control: 28.9, 3.6

Serum creatinine: not reported

B-type natriuretic peptide: not reported

NT pro B-type natriuretic peptide (pg/mL, median, IQR): intervention: 179,81 to 276 ; control: 148 , $80-276$

LVEF (\%, mean, SD): intervention: 67,8 ; control: 68,7

NYHA class I (\%): 0

NYHA class II (\%): intervention: 85; control: 88 
ALDO-DHF (Continued)

NYHA class III (\%): intervention: 15; control: 12

NYHA class IV (\%): 0

Hypertension (\%): intervention: 92; control: 91

Diabetes (\%): intervention: 17; control: 16

Atrial fibrillation (\%): intervention: 6; control: 4

Hospitalisation for HF: (\%): intervention: 38; control: 36

Coronary heart disease (\%): intervention: 43; control: 37

Stroke (\%): not reported

Diuretic (\%); intervention: 55; control: 52

Digoxin (\%): not reported

Beta-blocker (\%): intervention: 69; control: 75

ACEI (\%): intervention: 78 ; control: 76

ARB (\%): nor reported

MRA (\%): study drug

\begin{abstract}
Interventions Intervention: spironolactone
"The study drug could be decreased temporarily to $25 \mathrm{mg}$ every other day for a potassium level greater than $5.2 \mathrm{mmol} / \mathrm{L}$ or in the presence of other reversible, non-life-threatening adverse effects. For safety reasons, study medication was stopped for relevant hyperkalaemia (serum potassium $5.5 \mathrm{mmol} / \mathrm{L}$ ) and/or hyperkalaemia-associated clinical symptoms, significant renal impairment (serum creatinine $2.5 \mathrm{mg} / \mathrm{dL}$; eGFR $20 \mathrm{~mL} / \mathrm{min} / 1.73 \mathrm{~m}^{2}$ ), significant breast pain or gynaecomastia, or withdrawal of informed consent; rechallenge was encouraged wherever possible." "mean daily dose of spironolactone was $21.6 \mathrm{mg}(95 \% \mathrm{Cl}, 20.8-22.3 \mathrm{mg}) "$
\end{abstract}

Comparator: matching placebo

Concomitant medication: "Standard therapies for risk factor and symptom control were at the discretion of treating physicians and required to be unchanged within the 2 weeks prior to randomization." "concomitant therapy with a potassium-sparing diuretic (eg, triamterene, amiloride), or potassium supplementation."

Planned: primary outcomes: exercise capacity, left ventricular end-diastolic pressure.

Reported: all-cause mortality, QoL, diastolic function, exercise capacity, "changes in echocardiographic measures of cardiac function and remodeling, measures of submaximal and maximal exercise capacity, serum biomarkers, and quality of life. Clinical tolerability was assessed as the safety end point. Morbidity and mortality (all-cause and cardiovascular-specific) were also predefined exploratory end points."

Notes Received outcome data for CV mortality, heart failure hospitalisation and hyperkalaemia from investigators.

\title{
Risk of bias
}

\begin{tabular}{lll}
\hline Bias & Authors' judgement & Support for judgement \\
\hline $\begin{array}{l}\text { Random sequence genera- } \\
\text { tion (selection bias) }\end{array}$ & Low risk & "Pocock minimisation algorithm". \\
\hline
\end{tabular}

Beta-blockers and inhibitors of the renin-angiotensin aldosterone system for chronic heart failure with preserved ejection fraction 
ALDO-DHF (Continued)

$\begin{aligned} & \text { Allocation concealment } \\ & \text { (selection bias) }\end{aligned} \quad$ Low risk $\quad$ "The allocation sequence was implemented remotely via Internet/fax by the
Coordination Center for Clinical Trials Leipzig."

Blinding of participants Low risk
and personnel (performance bias)

All outcomes

"Patients, the investigator team, individuals performing the assessments, and data analysts remained blinded to the identity of treatment until after database lock".

\begin{tabular}{|c|c|c|}
\hline $\begin{array}{l}\text { Blinding of outcome as- } \\
\text { sessment (detection bias) } \\
\text { All outcomes }\end{array}$ & Low risk & $\begin{array}{l}\text { "Patients, the investigator team, individuals performing the assessments, and } \\
\text { data analysts remained blinded to the identity of treatment until after data- } \\
\text { base lock". }\end{array}$ \\
\hline
\end{tabular}

Incomplete outcome data Low risk

(attrition bias)

ITT used, except for QoL.

All outcomes

\begin{tabular}{|c|c|c|}
\hline $\begin{array}{l}\text { Selective reporting (re- } \\
\text { porting bias) }\end{array}$ & Low risk & $\begin{array}{l}\text { primary outcomes reported as planned, some secondary outcomes not report- } \\
\text { ed as planned, eg all-cause mortality, cardiovascular mortality. }\end{array}$ \\
\hline
\end{tabular}

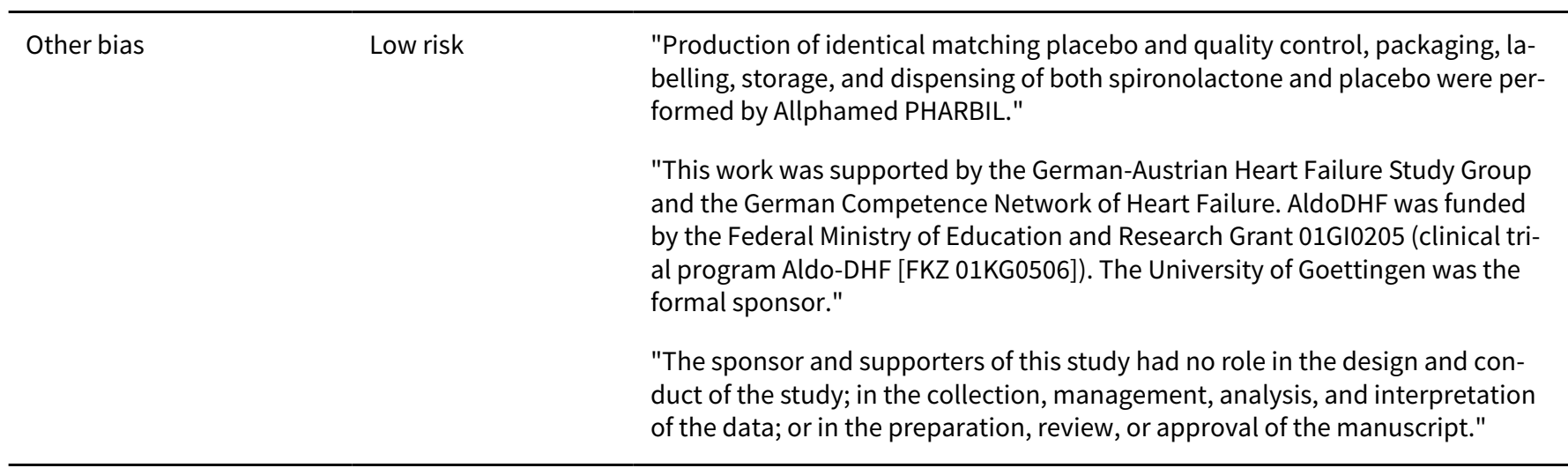

\section{AREA IN-CHF}

Study design: RCT.
Centres: 46 cardiology centres in Italy.
Start of enrolment: September 2002.
End of enrolment: July 2005.
Follow-up: 12 months.
Run-in period: not reported.
Inclusion criteria: aged 18 to 80 years, established evidence of NYHA class II HF, stable, optimised ther-
apy according to European Society of Cardiology criteria, and an LV ejection fraction (EF) $\leq 45 \%$, as
measured locally up to 6 months before enrolment.
Exclusion criteria: creatinine 2.5 mg/dL; K 5.0 mEq/L; valvular heart disease amenable to surgical
treatment; congenital heart disease; unstable angina or acute myocardial infarction or coronary revas-
cularisation procedure within 3 months before enrolment; intravenous therapy with inotropic drugs
within 3 months before enrolment; treatment with lithium salts, Kp-sparing diuretics, TNF-a antago-
nists, or MRA during the last 3 months; history of resuscitated ventricular arrhythmias (unless this oc-
curred within 24 h of a previous acute myocardial infarction or in subjects with an implantable car-
dioverter defibrillator); other clinical or general conditions contraindicating participation in a clinical
trial.

Beta-blockers and inhibitors of the renin-angiotensin aldosterone system for chronic heart failure with preserved ejection fraction 
Randomised (N): 467 total (225 LVEF > 40\%) (231 (116) intervention, 236 (109) control)

Withdrawn (N): for reasons other than death 18 (14 intervention,4 control)

Lost to follow-up: not reported

Analysed: not reported

Age (years, mean, SD): intervention: 62.3, 9.5; control: 62.7, 9.5

Sex (\% men): intervention: 81.8 ; control: 85.2

Ethnicity: not reported

Systolic blood pressure (mmHg, mean, SD): intervention: 127.9, 16.2; control: 128.0, 17.2

Heart rate (beats/min, mean, SD): intervention: 68.0, 11.8; control: 65.7, 10.7

BMI (mean, SD): intervention: 26.7, 3.5; control: 26.9, 3.6

Serum creatinine (mg/dL, mean, SD): intervention: 1.1, 0.3; control: 1.1, 0.2

B-type natriuretic peptide: not reported

NT pro B-type natriuretic peptide: not reported

LVEF (\%, mean, SD): intervention: 39.9, 8.6; control: 39.7, 8.6

NYHA class: not reported

Hypertension (\%): intervention: 48.5; control: 42.4

Diabetes (\%): intervention: 20.9; control: 19.9

Chronic atrial fibrillation (\%): intervention: 7.4; control: 8.5

Hospitalisation for heart failure (\%): intervention: 44.6; control: 49.2

Coronary heart disease: not reported

Stroke (\%): intervention: 1.7 ; control: 3

Diuretic (\%); intervention: 67.8; control: 72

Digoxin: not reported

Beta-blocker (\%): intervention: 81.3; control: 77.5

ACEI (\%): intervention: 84.9; control: 74.6

ARB (\%): intervention: 12.1 ; control: 24.2

MRA (\%): study drug

Intervention: canrenone. "The dose of $25 \mathrm{mg} /$ o.d. of canrenone at randomization was increased to $50 \mathrm{mg} / \mathrm{o} . \mathrm{d}$. after the first month, if serum $\mathrm{Kp}$ was $5 \mathrm{mEq} / \mathrm{L}$, and in the absence of deterioration in renal function. During follow-up, if serum $\mathrm{Kp}$ increased up to $5 \mathrm{mEq} / \mathrm{L}$ and/or creatinine increased up to 2.5 $\mathrm{mg} / \mathrm{dL}$, the dosage of canrenone was reduced to $25 \mathrm{mg} /$ o.d. Subjects requiring down-titration of study medications were asked to return to the outpatient clinic within 2 weeks for a supplemental visit to evaluate the effectiveness of this change in therapy. If serum Kp remained $.5 .5 \mathrm{mEq} / \mathrm{L}$, or if creatinine was $3 \mathrm{mg} / \mathrm{dL}$ or had increased by over $1 \mathrm{mg} / \mathrm{dL}$, the study medication was discontinued and the patient managed with conventional treatment only."

Comparator: placebo 
AREA IN-CHF (Continued)

Concomitant medication: "Aspirin, diuretics, digoxin, nitrates, antiarrhythmic agents, oral anticoagulants, and any other therapy were allowed when indicated by the local investigators."

\begin{tabular}{ll}
\hline Outcomes & Planned: unclear \\
& Reported: "The pre-specified primary endpoint was the change in echocardiographic LV end-diastolic \\
volume (LVEDV) over 12 months, measured centrally at the Echocardiographic Reading Centre. Se- \\
condary endpoints included changes in EF, estimated diastolic filling pressure, NYHA class, BNP, car- \\
diac mortality, hospitalization for cardiac causes, and the combination of cardiac mortality and hospi- \\
talization for cardiac causes"
\end{tabular}

\begin{tabular}{ll}
\hline Notes & Subgroup of participants of interest; response with outcome data for subgroup of participants LVEF > \\
$40 \%$ received from trialists; baseline characteristics above are for all trial participants.
\end{tabular}

\section{Risk of bias}

\begin{tabular}{|c|c|c|}
\hline Bias & Authors' judgement & Support for judgement \\
\hline $\begin{array}{l}\text { Random sequence genera- } \\
\text { tion (selection bias) }\end{array}$ & Unclear risk & not reported \\
\hline $\begin{array}{l}\text { Allocation concealment } \\
\text { (selection bias) }\end{array}$ & Unclear risk & not reported \\
\hline $\begin{array}{l}\text { Blinding of participants } \\
\text { and personnel (perfor- } \\
\text { mance bias) } \\
\text { All outcomes }\end{array}$ & Low risk & double blind, placebo-controlled \\
\hline $\begin{array}{l}\text { Blinding of outcome as- } \\
\text { sessment (detection bias) } \\
\text { All outcomes }\end{array}$ & Unclear risk & $\begin{array}{l}\text { echocardiography data were "read at the end of the study by one experienced } \\
\text { independent observer who was blinded to all clinical data and treatment allo- } \\
\text { cation" } \\
\text { not reported for other outcomes }\end{array}$ \\
\hline $\begin{array}{l}\text { Incomplete outcome data } \\
\text { (attrition bias) } \\
\text { All outcomes }\end{array}$ & Unclear risk & ITT for all outcomes \\
\hline $\begin{array}{l}\text { Selective reporting (re- } \\
\text { porting bias) }\end{array}$ & Unclear risk & $\begin{array}{l}\text { unable to assess as protocol and NCT record published/registered after enrol- } \\
\text { ment completed }\end{array}$ \\
\hline Other bias & Low risk & $\begin{array}{l}\text { "The ANMCO Research Center coordinated the study, managed the data, and } \\
\text { undertook analyses, under the supervision of the steering committee, who de- } \\
\text { signed the AREA IN-CHF study. The funding source (Therabel GiEnne Pharma } \\
\text { SpA) had no role in the trial design, conduct, data collection, analyses and da- } \\
\text { ta interpretation." }\end{array}$ \\
\hline
\end{tabular}

\section{Aronow 1993}

Methods Study design: parallel RCT

Centres: not reported

Start of enrolment: not reported

End of enrolment: not reported 
Aronow 1993 (Continued)

\section{Mean follow-up: 3 months}

Run-in period: 2 mornings of control period

Participants

Inclusion criteria: "New York Heart Association functional class III CHF associated with prior myocardial infarction and normal LV ejection fraction (>50\%) who were able to perform a maximal treadmill exercise test were included in the study".

Exclusion criteria: "No patient had valvular heart disease, systolic blood pressure $100 \mathrm{~mm} \mathrm{Hg}$, lung disease, hepatic disease or renal insufficiency."

Randomised (N): 21 (10 intervention, 11 control)

Withdrawn (N): not reported

Lost to follow-up (N): not reported

Analysed (N): not reported

Age (years, mean, SD): intervention: 80, 3; control: 79, 4

Sex (\% men): 14.3

Ethnicity (\%): not reported

Systolic blood pressure (mmHg, mean, SD): intervention: 126, 12; control: 127, 10

Heart rate (beats/min, mean, SD): intervention: 85, 6; control: 84, 3

BMI not reported

Serum creatinine not reported

B-type natriuretic peptide $(\mathrm{pg} / \mathrm{mL})$ : not reported

NT pro B-type natriuretic peptide $(\mathrm{pg} / \mathrm{mL})$ : not reported

LVEF (\%, mean, SD): intervention: 64, 9; control: 64, 7

NYHA class I (\%): 0

NYHA class II (\%): 0

NYHA class III (\%): 100

NYHA class IV (\%): 0

Hypertension not reported

Diabetes not reported

Atrial fibrillation not reported

Hospitalisation for heart failure: not reported

Coronary heart disease not reported

Stroke not reported

Diuretic (\%): 100

Digoxin (\%): 0

Beta-blocker (\%): 0

ACEl study drug 
Aronow 1993 (Continued)

\section{ARB not reported \\ MRA not reported}

Interventions

Intervention: enalapril. "The initial dose of enalapril was $2.5 \mathrm{mg} /$ day, which was increased to $5 \mathrm{mg} /$ day during week 2, to $10 \mathrm{mg} /$ day ( $5 \mathrm{mg}$ twice daily) during week 3, to $15 \mathrm{mg} /$ day ( $7.5 \mathrm{mg}$ twice daily) during week 4 and up to a maximum of $20 \mathrm{mg}$ ( $10 \mathrm{mg}$ twice daily) during week 5 , tf tolerated. If the patient developed symptomatic hypotension or an increase in serum creatinine level, the dose of enalapril was reduced to the previous dose. At the time of the follow-up studies, 3 months after beginning enalapril, the dose of enalapril was $2.5 \mathrm{mg} /$ day in 1 patient, $5 \mathrm{mg} /$ day in 1 patient, $10 \mathrm{mg} /$ day in 3 patients, 1.5 $\mathrm{mg} /$ day in 2 patients, and $20 \mathrm{mg} /$ day in 3 patients."

Comparator: no treatment

Concomitant medication: "All patients received diuretic treatment with furosemide for 2 weeks before the beginning of the study and a constant dose of furosemide during the study. Digitalis and other cardiac drugs (except enalapril) were not administered to any patient during the study."

\begin{tabular}{ll}
\hline Outcomes & Planned: not reported \\
& Reported: NYHA class, blood pressure, heart rate, cardiothoracic ratio, treadmill exercise time, LVEF, \\
peak mitral E/A ratio, left ventricular mass
\end{tabular}

Notes no outcome data relevant for this review.

\section{Risk of bias}

\begin{tabular}{|c|c|c|}
\hline Bias & Authors' judgement & Support for judgement \\
\hline $\begin{array}{l}\text { Random sequence genera- } \\
\text { tion (selection bias) }\end{array}$ & Unclear risk & not reported \\
\hline $\begin{array}{l}\text { Allocation concealment } \\
\text { (selection bias) }\end{array}$ & Unclear risk & not reported \\
\hline $\begin{array}{l}\text { Blinding of participants } \\
\text { and personnel (perfor- } \\
\text { mance bias) } \\
\text { All outcomes }\end{array}$ & Unclear risk & not reported \\
\hline $\begin{array}{l}\text { Blinding of outcome as- } \\
\text { sessment (detection bias) } \\
\text { All outcomes }\end{array}$ & Unclear risk & $\begin{array}{l}\text { "Chest roentgenograms were interpreted by a radiologist who was unaware } \\
\text { of the study medication. M-mode, } 2 \text { - dimensional and pulsed-wave Doppler } \\
\text { echocardiograms were interpreted by an experienced echocardiographer (IK) } \\
\text { who was unaware of the study medication. Treadmill exercise tests were per- } \\
\text { formed under the guidance of the senior author who was aware of which pa- } \\
\text { tients were receiving enalapril." }\end{array}$ \\
\hline $\begin{array}{l}\text { Incomplete outcome data } \\
\text { (attrition bias) } \\
\text { All outcomes }\end{array}$ & Unclear risk & not reported \\
\hline $\begin{array}{l}\text { Selective reporting (re- } \\
\text { porting bias) }\end{array}$ & Unclear risk & not reported \\
\hline Other bias & Unclear risk & unable to assess \\
\hline
\end{tabular}


Aronow 1997

Study design: parallel RCT
Centres: not reported
Start of enrolment: not reported
End of enrolment: not reported
Mean follow-up: 32 months (intervention), 31 months (control)
Run-in period: not reported

Participants

Inclusion criteria: " $\geq 62$ years of age with New York Heart Association functional class II or III CHF, prior Qwave myocardial infarction, and a LV ejection fraction $\geq 40 \%$ after 2 months of treatment with diuretics and ACE inhibitors were included in the study."

Exclusion criteria: "No patient had valvular heart disease, systolic blood pressure $<100 \mathrm{~mm} \mathrm{Hg}$, lung disease with bronchospasm, hepatic disease, renal insufficiency, sinus bradycardia, greater than firstdegree atrioventricular block, or severe peripheral arterial disease."

Randomised (N): 158 (79 intervention, 79 control)

Withdrawn $(\mathrm{N})$ : not reported

Lost to follow-up (N): not reported

Analysed (N): 158 (79 intervention, 79 control)

Age (years, mean, SD): intervention: 81, 8; control: 81, 7

Sex (\% men): intervention: 29 ; control: 30

Ethnicity (\%): not reported

Systolic blood pressure not reported

Heart rate not reported

BMI not reported

Serum creatinine not reported

B-type natriuretic peptide not reported

NT pro B-type natriuretic peptide $(\mathrm{pg} / \mathrm{mL})$ :

LVEF (\%, mean, SD): intervention: 56, 11; control: 57, 11

NYHA class I (\%): 0

NYHA class II (\%): intervention: 53; control: 51

NYHA class III (\%): intervention: 47; control: 49

NYHA class IV (\%): 0

Hypertension (\%): intervention: 67; control: 65

Diabetes: not reported

Atrial fibrillation (\%): intervention: 33; control: 34

Hospitalisation for HF: not reported

Coronary heart disease (\%): 100 
Aronow 1997 (Continued)

Stroke not reported

Diuretic (\%): 100

Digoxin (\%): intervention: 33; control: 34

Beta-blocker study drug

ACEI (\%): 100

ARB not reported

MRA not reported

Interventions

Intervention: propranolol. "The initial dose of propranolol was $10 \mathrm{mg} /$ day. This dose was increased by 10 -mg increments at 10-day intervals until a dose of $30 \mathrm{mg} 3$ times daily was given. All patients treated with propranolol received a final daily dose of propranolol of $30 \mathrm{mg} 3$ times daily."

Comparator: no treatment

Concomitant medication: "All patients continued diuretic and ACE inhibitor therapy during the study. Digoxin was administered only if the patient had atrial fibrillation."

Outcomes

Planned: no published protocol or clinical trial registry entry

Reported: "total mortality and total mortality plus nonfatal myocardial infarction"

Notes

\section{Risk of bias}

\begin{tabular}{lll}
\hline Bias & Authors' judgement & Support for judgement \\
\hline $\begin{array}{l}\text { Random sequence genera- } \\
\text { tion (selection bias) }\end{array}$ & Unclear risk & not reported \\
\hline $\begin{array}{l}\text { Allocation concealment } \\
\text { (selection bias) }\end{array}$ & Unclear risk & not reported \\
\hline $\begin{array}{l}\text { Blinding of participants } \\
\text { and personnel (perfor- } \\
\text { mance bias) }\end{array}$ & Unclear risk & not reported \\
$\begin{array}{l}\text { All outcomes } \\
\text { Blinding of outcome as- } \\
\text { sessment (detection bias) }\end{array}$ & Unclear risk & "LV ejection fraction and LV mass were interpreted by an experienced echocar- \\
All outcomes & & diographer (IK) who was unaware of the study medications" \\
\hline $\begin{array}{l}\text { Incomplete outcome data } \\
\text { (attrition bias) } \\
\text { All outcomes }\end{array}$ & Unclear risk & ITT analyses \\
\hline $\begin{array}{l}\text { Selective reporting (re- } \\
\text { porting bias) }\end{array}$ & Unclear risk & not reported \\
\hline \begin{tabular}{l} 
Other bias \\
\hline
\end{tabular} & Unclear risk & funding not reported \\
\hline
\end{tabular}


Aronow 1998

\begin{tabular}{ll}
\hline Methods & Study design: RCT \\
Centres: not reported \\
Start of enrolment: not reported \\
End of enrolment: not reported \\
Median follow-up: 6 months \\
Run-in period: not reported
\end{tabular}

Participants

Inclusion criteria: "with New York Heart Association functional class II or III CHF associated with prior Q-wave myocardial infarction, a normal LV ejection fraction ( 50\%),7 and 30 ventricular premature complexes per hour detected by 24 -hour ambulatory electrocardiograms were included in the study."

Exclusion criteria: not reported

Randomised (N): 60 (30 intervention, 30 control)

Withdrawn $(\mathrm{N})$ : not reported

Lost to follow-up (N): not reported

Analysed (N): 53 completed study (27 intervention, 26 control)

Age (years, mean, SD): intervention: 82, 8; control: 82, 7

Sex (\% men): intervention: 27; control: 23

Ethnicity (\%): not reported

Systolic blood pressure not reported

Heart rate not reported

BMI not reported

Serum creatinine not reported

B-type natriuretic peptide not reported

NT pro B-type natriuretic peptide not reported

LVEF (\%, median, IQR): intervention: 61, 7; control: 62, 6

NYHA class not reported

Hypertension (\%): intervention: 73; control: 70

Diabetes not reported

Atrial fibrillation not reported

\section{Hospitalisation for HF:}

Coronary heart disease (\%): 100

Stroke not reported

Diuretic (\%): 100

Digoxin not reported

Beta-blocker not reported

ACEI study drug 
Aronow 1998 (Continued)
ARB not reported
MRA not reported

Interventions $\quad$ Comparator: no treatment
Concomitant medication: not reported

\begin{tabular}{ll}
\hline Outcomes & Planned: unclear \\
& $\begin{array}{l}\text { Reported: decrease in number of ventricular premature complexes } / \mathrm{h} \text {, decrease in ventricular cou- } \\
\text { plets } / \mathrm{h} \text {, decrease in number of runs of ventricular tachycardia/ } 24 \mathrm{~h}\end{array}$
\end{tabular}

Notes

\section{Risk of bias}

\begin{tabular}{|c|c|c|}
\hline Bias & Authors' judgement & Support for judgement \\
\hline $\begin{array}{l}\text { Random sequence genera- } \\
\text { tion (selection bias) }\end{array}$ & Unclear risk & not reported \\
\hline $\begin{array}{l}\text { Allocation concealment } \\
\text { (selection bias) }\end{array}$ & Unclear risk & not reported \\
\hline $\begin{array}{l}\text { Blinding of participants } \\
\text { and personnel (perfor- } \\
\text { mance bias) } \\
\text { All outcomes }\end{array}$ & Unclear risk & not reported \\
\hline $\begin{array}{l}\text { Blinding of outcome as- } \\
\text { sessment (detection bias) } \\
\text { All outcomes }\end{array}$ & Unclear risk & $\begin{array}{l}\text { "The cardiologists interpreting the } 24 \text {-hour ambulatory electrocardiograms } \\
\text { were blinded to the study medications" }\end{array}$ \\
\hline $\begin{array}{l}\text { Incomplete outcome data } \\
\text { (attrition bias) } \\
\text { All outcomes }\end{array}$ & Unclear risk & not reported \\
\hline $\begin{array}{l}\text { Selective reporting (re- } \\
\text { porting bias) }\end{array}$ & Unclear risk & $\begin{array}{l}\text { unable to assess as we are unaware of published protocol or pre-registered } \\
\text { clinical trial registry entry }\end{array}$ \\
\hline Other bias & Unclear risk & unable to assess \\
\hline
\end{tabular}

Centres: 8 sites in Germany

Start of enrolment: January 2008

End of enrolment: December 2008

Follow-up: 24 weeks

Run-in period: not reported 
CAN-DHF (Continued)

Participants
Inclusion criteria: "Male or female patients of at least 45 years of age suffering from a non-insulin dependent diabetes mellitus type 2 orally treated for at least 3 months and showing normotension or controlled hypertension with sitting systolic blood pressure (sSBP) $<140 \mathrm{mmHg}$ and/or sitting diastolic blood pressure (sDBP) $<90 \mathrm{mmHg}$. Evidence of an abnormal left ventricular relaxation, diastolic distensibility or diastolic stiffness confirmed by echocardiography under the prerequisite of a preserved Left ventricular ejection fraction (LVEF) $\geq 45 \%$. NT-proBNP $\geq 250 \mathrm{pg} / \mathrm{ml}$ at baseline, NYHA class II or III in stable condition since 3 months, and standard HF- therapy with an ACE-inhibitor alone or with further preparations in a constant regimen since at least 1 month ( 3 months in terms of $\beta$-blockers). Signed written informed consent available."

Exclusion criteria: The following criteria must not be met to enrol a single patient into the study: Impaired renal function (serum creatinine $>2.2 \mathrm{mg} / \mathrm{dL}$ or $>194 \mu \mathrm{mol} / \mathrm{l}$ ), Known bilateral renal artery stenosis (RAS) or interventional treatment for RAS in the last year, State after kidney transplantation, Serum potassium $>5.5 \mathrm{mmol} / \mathrm{l}$ or $\mathrm{HbA} 1 \mathrm{C}>9.5 \%$, Cor pulmonale or primary pulmonary disease with dyspnea at rest, Known disposition to episodes of symptomatic hypotension or sSBP $<95 \mathrm{mmHg}$ at baseline, Acute coronary syndrome or unstable angina pectoris and any coronary artery disease that was not stable during the last 3 months prior to inclusion, CABG or PTCA (incl. stent implantation) within 3 months before inclusion, Myocardial infarction or stroke within 6 months before inclusion, Patients who are dependent on a permanently paced pacemaker (i.e. a patient with a device that is not pacing during the echocardiographic examination can enter the study), Open heart surgery for other reasons than coronary revascularization, Tachycardia at rest $>100$ bpm as confirmed by ECG-recordings, Known clinically relevant rhythm disorders (e.g. tachyarrhythmias, salves of supraventricular or ventricular extrasystoles or atrial fibrillation without ventricular rate control) or symptoms suggesting a significant rhythm disorder (e.g. recurrent syncopes), Primary valvular diseases and/or restrictive or obstructive cardiomyopathy - Existing ventricular assist devices, Relevant liver diseases (cholestasis or ALAT/ASAT > 2xULN or GT > 3xULN), History of primary hyperaldosteronism, of cancer in the last 5 years (exception: nonmetastasizing skin cancer) or of another wasting disease with life expectancy of < 2 years, Known hypersensitivity to Candesartan Cilexetil, Need for maintenance therapy with NSAIDs or Cox-2-inhibitors, Use of other ARBs throughout the entire study period, Any history of life-threatening diseases, History of drug addiction and/or an extensive use of alcohol, Female patients who are pregnant or breast feeding, Sexually active women of childbearing potential not consistently and correctly practicing highly effective birth control with a low failure rate (less than $1 \%$ / year) such as implants, injectables, combined oral contraceptives, hormonal intrauterine devices (IUDs), sexual abstinence or vasectomised partner, Psychological and/or emotional problems, which render the informed consent invalid or limit the ability of the patient to comply with the study requirements, Patient is an employee or at least in dependence of the investigator and/or the sponsor or of another institution directly involved in the study or other trials under the investigator's direction, Participation in another clinical investigation within 30 days prior to enrolment or for the course of the present study (incl. studies for compassionate use or experimental medical devices)

Randomised (N): 22 (11 intervention, 11 control)

Withdrawn $(\mathrm{N})$ : for reasons other than death 14 (intervention: 3 premature study termination, 3 adverse events, 1 randomisation /enrolment error, control: 4 premature study termination, 2 adverse events, 1 randomisation / enrolment error)

Lost to follow-up (N): 0

Analysed (N): 22 (11 intervention, 11 control)

Age (years, mean, SD): intervention: 67.0, 16.8; control: 69.0, 7.1

Sex (\% men): intervention: 64; control: 55

Ethnicity (\%): not reported

Systolic blood pressure not reported

Heart rate not reported

BMI (mean, SD): intervention: 31.4, 5.0; control: 30.0, 5.7

Serum creatinine not reported 
CAN-DHF (Continued)

B-type natriuretic peptide $(\mathrm{pg} / \mathrm{mL})$ : not reported

NT pro B-type natriuretic peptide $(\mathrm{pg} / \mathrm{mL})$ : not reported

LVEF not reported

NYHA class: not reported

Hypertension (\%): not reported

Diabetes (\%): not reported

Atrial fibrillation (\%): not reported

Hospitalisation for heart failure: not reported

Myocardial infarction (\%): not reported

Stroke (\%): not reported

Diuretic (\%): not reported

Digoxin (\%): not reported

Beta-blocker (\%): not reported

ACEI (\%): not reported

ARB (\%): study drug

MRA (\%): not reported

Intervention: candesartan. 8-32mg as tolerated. "The treatment comprised a titration period of 6 weeks and a period of constant study therapy of at least 18 weeks"

Comparator: placebo

Concomitant medication: "in an "added" regimen to a constant background-HF-therapy with at least ACE-inhibitors (or further drugs) for the treatment of symptomatic heart failure with diastolic dysfunction in diabetic and hypertensive patients"

exclusion criteria: use of other ARB

\begin{tabular}{lll}
\hline Outcomes & $\begin{array}{l}\text { Planned: primary: mean change from baseline for NT-proBNP, secondary: QoL, kidney function, NYHA, } \\
\text { body weight, BP and echocardiographic measures, adverse events, rate of premature withdrawals } \\
\text { Reported: as planned except QoL }\end{array}$ \\
\hline Notes & $\begin{array}{l}\text { This trial was terminated prematurely and the results are available via a clinical trial registry entry only. } \\
\text { No outcome data relevant to this review reported (confirmed by sponsor Takeda via Email). }\end{array}$ \\
\hline Risk of bias & Authors' judgement & Support for judgement \\
\hline Bias & Unclear risk & not reported \\
\hline $\begin{array}{l}\text { Random sequence genera- } \\
\text { tion (selection bias) }\end{array}$ & Unclear risk & not reported \\
\hline $\begin{array}{l}\text { Allocation concealment } \\
\text { (selection bias) }\end{array}$ & Low risk & \\
\hline $\begin{array}{l}\text { Blinding of participants } \\
\text { and personnel (perfor- } \\
\text { mance bias) }\end{array}$ & "double-blind" but no detail \\
\hline
\end{tabular}

Beta-blockers and inhibitors of the renin-angiotensin aldosterone system for chronic heart failure with preserved ejection fraction 
CAN-DHF (Continued)

All outcomes

\begin{tabular}{lll}
$\begin{array}{l}\text { Blinding of outcome as- } \\
\text { sessment (detection bias) } \\
\text { All outcomes }\end{array}$ & Unclear risk & not reported \\
\hline $\begin{array}{l}\text { Incomplete outcome data } \\
\text { (attrition bias) }\end{array}$ & Unclear risk & no information \\
All outcomes & &
\end{tabular}

\begin{tabular}{|c|c|c|}
\hline $\begin{array}{l}\text { Selective reporting (re- } \\
\text { porting bias) }\end{array}$ & Low risk & all outcomes reported as planned except QoL \\
\hline \multirow[t]{3}{*}{ Other bias } & High risk & $\begin{array}{l}\text { "the study was terminated prematurely as a whole by the sponsor in Decem- } \\
\text { ber } 2008 \text { since randomization of patients was very poor until that date (low } \\
\text { and slow recruitment }(\mathrm{N}=42) \text { with a high number }(\mathrm{N}=20) \text { of screening fail- } \\
\text { ures)" }\end{array}$ \\
\hline & & Takeda funded the study. \\
\hline & & $\begin{array}{l}\text { The study results are unpublished and only available via the clinical trial reg- } \\
\text { istry entry. }\end{array}$ \\
\hline
\end{tabular}

CandHeart

$\begin{array}{ll}\text { Methods } & \text { Study design: parallel RCT } \\ \text { Centres: } 70, \text { Italy } \\ \text { Start of enrolment: December } 2005 \\ \text { End of enrolment: May } 2008 \\ \text { Mean follow-up: } 48 \text { weeks } \\ \text { Run-in period: not reported }\end{array}$

Participants

Inclusion criteria: congestive HF, "Patients aged $\geq 18$ years, of both genders, with stable symptomatic NYHA II-IV HF and any LVEF measured at screening visit, and who provided a written informed consent were eligible. Patients with LVEF $>40 \%$ had to be hospitalized for cardiovascular events during the past 12 months before randomization."

Exclusion criteria: "Exclusion criteria were history of prior treatment with ARBs within 2 weeks from screening; severe or malignant hypertension (SBP/DBP > 180/110 mmHg); symptomatic hypotension; prior acute myocardial infarction, stroke or transient ischemic attack (TIA), percutaneous transluminal coronary angioplasty (PTCA) or coronary artery by-pass graft (CABG) within 1 month from screening; hemodynamically relevant arrhythmias or cardiac valvular defect; prior implant of pacemakers, cardiac resynchronization therapy or cardioverters within 6 months from randomization; constrictive pericarditis or active myocarditis; likelihood of cardiac surgical intervention during the overall treatment period; evidence of angina pectoris in the previous month; poorly controlled diabetes mellitus (blood glucose $>140 \mathrm{mg} / \mathrm{mL}$ or $\mathrm{HbA} 1 \mathrm{c}>8 \%$ ); untreated thyroid dysfunction; renal artery stenosis; angio-edema of any etiology; significant liver (AST, ALT, total bilirubin or alkaline phosphatase $>2 x$ the upper limit of normal range) or renal impairment (serum creatinine $>2.0 \mathrm{mg} / \mathrm{dL}$ or serum potassium $>5.0 \mathrm{mmol} /$ $\mathrm{L})$; anemia of any etiology $(\mathrm{Hb}<10.5 \mathrm{~g} / \mathrm{dL})$ or any other clinically relevant hematological disease; pregnant or lactating females or females at risk of pregnancy; any disease with malabsorption; presence of any non-cardiac disease that is likely to significantly shorten life expectancy; history of chronic alcohol or drug/substance abuse, or presence of other conditions potentially able to affect study subjects' compliance; known allergy, sensitivity or intolerance to study drugs and/or study drugs' formulation in- 
gredients; patients unlikely to comply with the protocol or unable to understand the nature, scope and possible consequences of the study; participation in another trial in the month preceding study entry."

Randomised (N): 128

Withdrawn (N): not reported

Lost to follow-up (N): not reported

Analysed (N): not reported

Age (years, mean, SD): 66, 12

Sex (\% men): 67.2

Ethnicity (\%): not reported

Systolic blood pressure (mmHg, mean, SD): 134, 19

Heart rate (beats/min, mean, SD): 67, 14

BMI (mean, SD): 28.2, 4.5

Serum creatinine $(\mathrm{mg} / \mathrm{dL}$, mean, DS): 1.0, 0.3

B-type natriuretic peptide (pg/mL): 163, 202

NT pro B-type natriuretic peptide $(\mathrm{pg} / \mathrm{mL})$ : not reported

LVEF (\%, mean, SD): 48.7, 8.2

NYHA class I (\%): 0

NYHA class II (\%): 71.9

NYHA class III (\%): not reported

NYHA class IV (\%): not reported

Hypertension (\%): 59.8

Diabetes (\%): 28.1

Atrial fibrillation (\%): 21.1

Hospitalisation for HF: not reported

Coronary heart disease (\%): 30.7

Stroke: not reported

Diuretic (\%): 86.7

Digoxin (\%): 26.6

Beta-blocker (\%): 76.6

ACEI (\%): 88.3

ARB (\%): study drug

MRA (\%): 32.8
Intervention: candesartan cilexetil, "1 candesartan cilexetil was administered at an initial dose of $4 \mathrm{mg}$ o.d. (one tablet) and, if tolerated, it was up titrated to $8 \mathrm{mg}$ (one tablet o.d.) after 2 weeks of treatment, to $16 \mathrm{mg}$ (one tablet o.d.) after 4 weeks of treatment, and to $32 \mathrm{mg}$ (two tablets of $16 \mathrm{mg}$ o.d.) after 6 weeks of treatment"

Beta-blockers and inhibitors of the renin-angiotensin aldosterone system for chronic heart failure with preserved ejection fraction 
CandHeart (Continued)

\section{Comparator: no treatment}

Concomitant medication: ongoing standard therapy

Planned: both trial register entries were post-hoc, unclear what was planned
Reported: primary: 3-month (12-week) changes of BNP from baseline, "The secondary objectives of
the study after a 48-week treatment period were to assess:1) change of BNP at 48 weeks from baseline
values; 2 ) changes from baseline of aldosterone. Other exploratory analyses included (1) changes from
baseline of LVEF, LVIDD, E wave peak velocity/A wave peak velocity (E/A), deceleration time of E wave
(E-DT), atrial dimensions; (2) changes from baseline of BP and heart rate (HR); (3) persistence of active
treatment and discontinuation rate; (4) quality of life by Kansas City Cardiomyopathy Questionnaire
(KCCQ)."

Notes

Only subgroup of participants with LVEF $>40 \%$ of interest to this review. The above data are for this subgroup only. No outcome data reported for this review. Emailed trialists. No response.

\section{Risk of bias}

\begin{tabular}{lll}
\hline Bias & Authors' judgement & Support for judgement \\
\hline $\begin{array}{l}\text { Random sequence genera- } \\
\text { tion (selection bias) }\end{array}$ & Low risk & "centrally randomized" \\
\hline $\begin{array}{l}\text { Allocation concealment } \\
\text { (selection bias) }\end{array}$ & Unclear risk & not reported \\
\hline $\begin{array}{l}\text { Blinding of participants } \\
\text { and personnel (perfor- } \\
\text { mance bias) } \\
\text { All outcomes }\end{array}$ & High risk & open label \\
\hline
\end{tabular}

\begin{tabular}{|c|c|c|}
\hline $\begin{array}{l}\text { Blinding of outcome as- } \\
\text { sessment (detection bias) } \\
\text { All outcomes }\end{array}$ & Unclear risk & $\begin{array}{l}\text { "Thirty percent of all echocardiographic exams performed during the study } \\
\text { were randomly selected and read at the core laboratory by an experienced car- } \\
\text { diologist unaware of study group and visit." }\end{array}$ \\
\hline
\end{tabular}

Unclear risk

unable to assess

Incomplete outcome data Unclear risk unable to assess

(attrition bias)

All outcomes

\begin{tabular}{|c|c|c|}
\hline $\begin{array}{l}\text { Selective reporting (re- } \\
\text { porting bias) }\end{array}$ & Unclear risk & unclear as post-hoc trial registration and published protocol not identified \\
\hline \multirow[t]{2}{*}{ Other bias } & Unclear risk & $\begin{array}{l}\text { The study was funded by Takeda Italia Farmaceutici and endorsed by the Asso- } \\
\text { ciazione Nazionale Medici Cardiologi Ospedalieri (ANMCO). }\end{array}$ \\
\hline & & $\begin{array}{l}\text { "The study was stopped before reaching the target number of patients since } \\
\text { an interim analysis by the DSMB showed that an unacceptable number of pa- } \\
\text { tients ( } n=1500 \text { per group) would have been needed to show the observed dif- } \\
\text { ference in } 3 \text {-month change of BNP with the predefined power of } 0.80 \text {, when } \\
\text { data on } 371 \text { patients were available" }\end{array}$ \\
\hline
\end{tabular}

\section{CHARM-Preserved}

Methods Study design: parallel RCT


Centres: 618, 26 countries (Australia, Belgium, Canada, Czech Republic, Denmark, Finland, France, Germany, Hungary, Iceland, Italy, Luxembourg, Malaysia, Netherlands, Norway, Poland, Portugal, Russia, Singapore, South Africa, Spain, Sweden, Switzerland, UK/Ireland, USA)

Start of enrolment: March 1999

End of enrolment: July 2000

Median follow-up: 36.6 months

Run-in period: no

Participants

Inclusion criteria: "Eligible patients were aged 18 years or older, had New York Heart Association functional class II-IV of at least 4 weeks' duration, had a history of hospital admission for a cardiac reason, and had LVEF higher than $40 \%$."

Exclusion criteria: Important exclusion criteria for any of the studies include current serum-creatinine $>265 \mathrm{mmol} / \mathrm{L}$ (>3 mg/dL); current serum-potassium $>5.5 \mathrm{mmol} / \mathrm{L}$ (>5.5 mEq/L) or a history of marked ACE inhibitor-induced hyperkalemia resulting in either a serum potassium greater than or equal to 6.0 $\mathrm{mmol} / \mathrm{L}$ (>6.0 mEq/L) or a life-threatening adverse event; known bilateral renal artery stenosis; current symptomatic hypotension; persistent systolic or diastolic hypertension; stroke, acute myocardial infarction, or open heart surgery within the last 4 weeks; previous heart transplant or heart transplant expected to be performed within the next 6 months; presence of any noncardiac disease (eg, cancer) that is likely to significantly shorten life expectancy to less than 2 years.

Randomised (N): 3023 (1514 intervention, 1509 control)

Withdrawn (N): for reasons other than death (270 intervention, 204 control)

Lost to follow-up (N): (2 intervention, 1 control)

Analysed (N): 3020 (1512 intervention, 1508 control)

Age (years, mean, SD): intervention: 67.2, 11.1; control: 67.1, 11.1

Sex (\% men): intervention: 60.8 ; control: 59.0

Ethnicity (\%): intervention: European 90.8 , control: European 92.3

Systolic blood pressure (mmHg, mean, SD): intervention: 136.0, 18.6; control: 136.3, 18.3

Heart rate (beats/min, mean, SD): intervention: 71.2, 12.4; control: 71.4, 12.5

BMI (mean, SD): intervention: 29.3, 5.9; control: 29.0, 5.6

Serum creatinine $(\mathrm{mg} / \mathrm{dL})$ : not reported

B-type natriuretic peptide $(\mathrm{pg} / \mathrm{mL})$ : not reported

NT pro B-type natriuretic peptide $(\mathrm{pg} / \mathrm{mL})$ : not reported

LVEF (\%, mean, SD): intervention: 54.0, 9.4; control: 54.1, 9.4

NYHA class I (\%): 0

NYHA class II (\%): intervention: 61.5; control: 60.0

NYHA class III (\%): intervention: 36.7 ; control: 38.7

NYHA class IV (\%): intervention: 1.8; control: 1.3

Hypertension (\%): intervention: 65.0; control: 63.6

Diabetes (\%): intervention: 28.7 ; control: 28.0

Atrial fibrillation (\%): intervention: 29.0 ; control: 29.3 
Hospitalisation for heart failure (\%): intervention: 69.6; control: 68.8

Coronary heart disease (\%): intervention: 45.0; control: 43.7

Stroke (\%): intervention: 9.2; control: 8.5

Diuretic (\%); intervention: diuretic: 75.2 , spironolactone 11.3 ; control: diuretic 74.3 , spironolactone 12.0

Digoxin (\%): intervention: 28.5 ; control: 27.2

Beta-blocker (\%): intervention: 55.9; control: 55.5

ACEI (\%): intervention: 19.6; control: 18.6

ARB (\%): study drug

MRA (\%): intervention: 11.3; control: 12.0

Interventions

Intervention: candesartan. "which could be started at 4 or $8 \mathrm{mg}$ once daily, the assignment code being held by an independent centre and the data safety monitoring board. The treatment dose was doubled every 2 weeks, as tolerated, according to a forced titration protocol, with recommended monitoring of blood pressure, serum creatinine, and potassium. The target dose was $32 \mathrm{mg}$ once daily from 6 weeks onwards."

Comparator: "matching placebo"

Concomitant medication: "physicians were free to prescribe all treatments other than angiotensin-receptor blockers." "Initially, angiotensin converting-enzyme inhibitors were not allowed as concomitant treatment, but after publication of the Heart Outcomes Prevention Evaluation trial results, (The Heart Outcomes Prevention Evaluation Study Investigators. Effects of an angiotensin-converting-enzyme inhibitor, ramipril, on cardiovascular events in high-risk patients. N Engl J Med 2000; 342: 145-53.) their use was optional in appropriate patients." "By the end of the study, $298(20 \%)$ in the candesartan and $340(23 \%)$ in the placebo group were receiving angiotensin-converting-enzyme inhibitors, $712(47 \%)$ and 748 (50\%) were receiving blockers, and $136(9 \%)$ and 201 (13\%) were receiving spironolactone. Non-study angiotensin-receptor blockers were used in $3 \%$ of patients in each of the two groups."

Outcomes

Planned: Planned: "The primary outcome was cardiovascular death or unplanned admission to hospital for the management of worsening CHF. Prespecified secondary outcomes were: cardiovascular death, admission to hospital for CHF, or non-fatal myocardial infarction; cardiovascular death, admission to hospital for CHF, non-fatal myocardial infarction, or non-fatal stroke; cardiovascular death, admission to hospital for CHF, non-fatal myocardial infarction, non-fatal stroke, or coronary revascularisation; death (any cause) or admission to hospital for CHF; and development of new diabetes."

Reported: as planned

Notes

The CHARM program consisted of 3 strands, one of which was CHARM-Preserved.

Contacted investigators for end scores of MLHF QoL by treatment arms. No response.

\section{Risk of bias}

\begin{tabular}{lll}
\hline Bias & Authors' judgement & Support for judgement \\
\hline $\begin{array}{l}\text { Random sequence genera- } \\
\text { tion (selection bias) }\end{array}$ & Unclear risk & "We randomly assigned patient" \\
\hline $\begin{array}{l}\text { Allocation concealment } \\
\text { (selection bias) }\end{array}$ & Low risk & $\begin{array}{l}\text { "the assignment code being held by an independent centre and the data safe- } \\
\text { ty monitoring board" }\end{array}$ \\
\hline
\end{tabular}


CHARM-Preserved (Continued)

Blinding of participants Low risk "We randomly assigned patients, in a double-blind way", "matching placebo" and personnel (performance bias)

All outcomes

\section{Blinding of outcome as- Low risk} sessment (detection bias) All outcomes

\begin{abstract}
"A committee unaware of treatment assignment and which component of the CHARM programme was being undertaken adjudicated the cause of death, first myocardial infarctions, and first hospital admissions for heart failure."

"All final data analyses were done by the sponsor and verified independently by the statistical centre at the London school of Hygiene and Tropical Medicine, London, UK"
\end{abstract}

Incomplete outcome data Low risk
(attrition bias)
"two patients who mistakenly received randomisation numbers but had no other data recorded and never received study medication"

"Two candesartan patients and one placebo patient were lost to follow-up"

207/204 withdrew due to $\mathrm{AE}$

"Anaysis was done by intention to treat."

\begin{tabular}{|c|c|c|}
\hline $\begin{array}{l}\text { Selective reporting (re- } \\
\text { porting bias) }\end{array}$ & Low risk & outcomes reported as planned \\
\hline Other bias & Low risk & $\begin{array}{l}\text { "MA Pfeffer, K Swedberg, CB Granger, JJV McMurray, and S Yusuf have served } \\
\text { as consultants to or received research grants from AstraZeneca and other ma- } \\
\text { jor cardiovascular pharmaceutical companies. J Östergren has served as a } \\
\text { consultant and received research grants from AstraZeneca. P Held, E L Michel- } \\
\text { son, and B Olofsson are employees of AstraZeneca." }\end{array}$ \\
\hline & & "This study was supported by AstraZeneca R\&D, Mölndal, Sweden" \\
\hline
\end{tabular}

\section{ELANDD}

Methods

Study design: multicenter, double-blind, placebo controlled, randomised, parallel group trial

Centres: 12 in 8 European countries

Start of enrolment: not reported

End of enrolment: not reported

Follow-up: 6 months

Run-in period: not reported

Participants 
or a duration of reverse pulmonary vein atrial systole flow-mitral valve atrial wave flow $>30 \mathrm{~ms}$, and/or a left atrial volume index $>40 \mathrm{~mL} / \mathrm{m}^{2}$, and/or an increased LV mass index"

Exclusion criteria: "Major exclusion • Patients unable to perform 6-mi walking test • Planned invasive cardiac procedures or cardiac surgery during the time of the study $\bullet$ Recent ( $<3$ months) acute coronary syndrome or stroke Exercise-induced myocardial ischaemia as main cause of exercise limitation as shown by symptoms (angina) or by previous exams (exercise test, stress echocardiography or myocardial scintigraphy) • Concomitant diseases (COPD, peripheral vasculopathy, orthopaedic disease) as main cause of exercise limitation - Major contraindications to beta-blocker therapy (sinus bradycardia, 150/min; atrio-ventricular block, bronchial asthma sensitive to beta-agonists administration) - Ongoing treatment with beta-blockers, diltiazem or verapamil • Systolic blood pressure $\backslash 100 \mathrm{~mm} \mathrm{Hg} \cdot$ Pregnancy, breast feeding or childbearing potential during the study $\bullet$ History of alcohol or other illicit drug abuse - Expected poor compliance to drug therapy $•$ Participation in any other clinical trial with an investigational product or scheduled to receive any such product during the study or in the 4 weeks following the study - Suffering from any other medical condition that may exclude the patient for safety reasons or interfere with the objective of the study."

Randomised (N): 116 (57 intervention, 59 control)

Withdrawn (N): for reasons other than death 22 (14 intervention (9 lack of tolerance, 1 protocol violation, 3 consent withdrawal, 1 other), 8 control (consent withdrawal 1, protocol violation 5, 2 other))

Lost to follow-up (N): 1 (1 intervention, 0 control)

Analysed (N): 93 (42 intervention, 51 control)

Age (years, mean, SD): intervention: 66.5, 9.8; control: 65.3, 11.3

Sex (\% men): intervention: 35; control: 36

Ethnicity (\%): not reported

Systolic blood pressure (mmHg, mean, SD): intervention: 128, 17 (Table 3 of Conraads), 134, 21 (Table 2); control: 129, 23 (Table 3) 133, 18 (Table 2)

Heart rate (beats/min, mean, SD): intervention: 76, 15 (Table 3) 73, 14 (Table 2); control: 78, 13 (Table 3), 73, 11 (Table 2)

BMI (mean, SD): intervention: 30.3, 4.5; control: 30.2, 4.9

Serum creatinine (mg/dL, mean, SD): intervention: 88.5, 33.1; control: 85.8, 25.1

B-type natriuretic peptide $(\mathrm{pg} / \mathrm{mL})$ : not reported

NT pro B-type natriuretic peptide (pg/mL, median, range): intervention: 147 (9-3577); control: 126 (15-2055)

LVEF (\%, mean, SD): intervention: 61.9, 7.8; control: 63.2, 9.2

NYHA class I (\%): 0

NYHA class II (\%): intervention: 77; control: 78

NYHA class III (\%): intervention: 21 ; control: 22

NYHA class IV (\%): 0

Hypertension (\%): intervention: 86; control: 86.4

Diabetes (\%): intervention: 21; control: 20

Atrial fibrillation (\%): not reported

Hospitalisation for heart failure: not reported

Coronary heart disease (\%): intervention: 17 ; control: 20

Beta-blockers and inhibitors of the renin-angiotensin aldosterone system for chronic heart failure with preserved ejection fraction (Review)

Copyright (c) 2018 The Cochrane Collaboration. Published by John Wiley \& Sons, Ltd. 
ELANDD (Continued)

Stroke (\%): not reported

Diuretic (\%); intervention: 49; control: 54

Digoxin (\%): not reported

Beta-blocker (\%): study drug

ACEI (\%): intervention: 75; control: 80

ARB (\%): not reported

MRA (\%): not reported

Interventions

Intervention: nebivolol. "Nebivolol was started at $2.5 \mathrm{mg} /$ day and gradually up-titrated to $10 \mathrm{mg} /$ day over a period of 5 weeks. Down-titration to lower doses was allowed if the higher dose was not tolerated. Treatment at maintenance doses was continued for an additional 21 weeks ( 6 months of treatment in total)."

Comparator: placebo

Concomitant medication: "Ongoing treatment with other drugs was maintained throughout the study."

Outcomes

Planned: " The primary endpoint of the study is the change from baseline in the distance walked during the 6-min walking test (6MWT) after 6 months of treatment with nebivolol versus placebo. Additional secondary endpoints are the changes from baseline after 6 months, with nebivolol versus placebo, in the following measurements: • Symptoms, assessed using a five-level scale (extremely worsened, moderately worsened, unchanged, moderately improved, extremely improved); • New York Heart Association (NYHA) functional class; • Minnesota living with heart failure questionnaire [21]; - Maximal exercise duration, peak oxygen consumption, [VO2] and slope of the minute ventilation [VE] to carbon dioxide [VCO2] relation, at cardiopulmonary exercise testing. $\bullet$ Changes in parameters related to LV diastolic function, including peak E velocity at the Doppler recording of transmitral inflow tracing, peak E0 velocity of the mitral valve annulus measured at the level of the septal and lateral wall, respectively, by tissue Doppler recording, and the E/E' ratio. Lastly, the effects of treatment on major outcomes (death, hospitalization and unexpected visit to the outpatient clinic or heart failure unit) as well as adverse events are assessed."

Reported: as planned

Notes

Risk of bias

\begin{tabular}{lll}
\hline Bias & Authors' judgement & Support for judgement \\
\hline $\begin{array}{l}\text { Random sequence genera- } \\
\text { tion (selection bias) }\end{array}$ & Low risk & "computer-generated 1:1 randomization" \\
\hline $\begin{array}{l}\text { Allocation concealment } \\
\text { (selection bias) }\end{array}$ & Unclear risk & not reported \\
\hline $\begin{array}{l}\text { Blinding of participants } \\
\begin{array}{l}\text { and personnel (perfor- } \\
\text { mance bias) }\end{array}\end{array}$ & Low risk & "double-blinded" \\
All outcomes & & \\
\hline
\end{tabular}

Blinding of outcome as- Unclear risk not reported


ELANDD (Continued)

Incomplete outcome data Low risk reasons provided for withdrawal
(attrition bias)

All outcomes

Selective reporting (re- Low risk reported as planned
porting bias)

\begin{tabular}{ll}
\hline Other bias & Tow risk \\
& $\begin{array}{l}\text { The trial is funded by a grant from Menarini. "We thank Joachim Klinger Direc- } \\
\text { tor of Data Management and Statistics, Harrison Clinical Research Deutsch- } \\
\text { land, and Lieven Huysse, who worked at Menarini at the time of the study, for } \\
\text { management and statistical support." }\end{array}$
\end{tabular}

Centres: multicentre, no details

Start of enrolment: not reported

End of enrolment: not reported

Mean follow-up: 1 year

Run-in period: none

Participants

Inclusion criteria: "The inclusion criteria were age .18 years, clinical history of heart failure within 2 months prior to screening including a chest $x$ ray demonstrating pulmonary congestion, NYHA functional class II - IV, left ventricular ejection fraction .45\% by 2D-echocardiography or a radionuclide technique, and therapy with diuretics with stable dose .14 days prior to recruitment."

Exclusion criteria: "NYHA functional class I, myocardial infarction within 3 months, unstable angina within 1 month, significant valvular heart disease, uncontrolled hypertension, serious cardiac arrhythmias, concurrent therapy with calcium channel antagonist, b-blockers (a-methyl dopa was used for treating hypertension if required), positive inotropic agents (except digoxin for control of atrial fibrillation) and other angiotensin converting enzyme inhibitors or receptor blockers."

Randomised (N): 151 (intervention R: 45, intervention I: 56, control: 50)

Withdrawn (N): for reasons other than death: intervention R: 6 (4 persistent irritating cough, 1 uncontrolled blood pressure, 1 refused to continue), intervention I: 1 due to onset of fast atrial fibrillation, control: 3 (1 uncontrolled high blood pressure, 1 defaulted, 1 refused to continue)

\section{Lost to follow-up (N): 0}

Analysed (N): 151 (intervention R: 45, intervention I: 56, control: 50)

Age (years, mean, SD): intervention R: 74, 6.1; intervention I: 75, 8.5; control: 73, 8.4

Sex (\% men): intervention R: 40; intervention I: 34; control: 42

Ethnicity (\%): not reported

Systolic blood pressure (mmHg, mean, SD): intervention R: 143, 22; intervention I: 145, 19; control: 145,23

Heart rate (beats/min, mean, SD): intervention R: 79, 13; intervention I: 77, 9; control: 76, 14

BMI (mean, SD): intervention R: 26.8, 3.9; intervention I: 27.2, 4.1; control: 26.8, 4.2

Serum creatinine: not reported 
B-type natriuretic peptide (pg/mL, mean, SEM): intervention R: 488, 701; intervention I: 568, 757; control: 566, 944

NT pro B-type natriuretic peptide: not reported

LVEF (\%, median, IQR): intervention R: 65, 1; intervention I: 66, 1; control: 69, 2

NYHA class I (\%): 0

NYHA class II (\%): intervention R: 66.7; intervention I: 67.9; control: 72

NYHA class III (\%): intervention R: 33.3; intervention I: 30.4; control: 28

NYHA class IV (\%): 0

Hypertension (\%): intervention R: 73; intervention I: 71; control: 76

Diabetes (\%): intervention R: 22; intervention I: 18; control: 20

Atrial fibrillation (\%): intervention R: 16; intervention I: 21; control: 10

Hospitalisation for HF: $100 \%$ as it was an inclusion criteria

Coronary heart disease (\%): intervention R: 18; intervention I: 11; control: 18

Stroke (\%): not reported

Diuretic (\%): intervention R: Hydrocholorthiazide 8.9 furosemide 80 , dyazide 2.2; intervention I: Hydrocholorthiazide 10.7, furosemide 80.4, dyazide 10.7; control: Hydrocholorthiazide 6, furosemide 68 , dyazide 12

Digoxin (\%): not reported

Beta-blocker (\%): 0

ACEI (\%): study drug (R)

ARB (\%): study drug (I)

MRA (\%): not reported

Intervention R: "Ramipril was started at $2.5 \mathrm{mg}$ daily and similarly titrated to $10 \mathrm{mg}$ daily"

Intervention I: "The initial dose of irbesartan was $18.75 \mathrm{mg}$ daily which was titrated at 4 and 8 weeks to 75 mg daily."

Comparator: usual care, "continue with diuretics alone"

Concomitant medication: "Exclusion criteria were: ...concurrent therapy with calcium channel antagonist, b-blockers (a-methyl dopa was used for treating hypertension if required), positive inotropic agents (except digoxin for control of atrial fibrillation) and other angiotensin converting enzyme inhibitors or receptor blockers."

Outcomes

Planned: planned as per clinical trial registry entry: primary: 1 . Number of hospital admissions for heart failure or mortality 2. Quality of life assessed by the Minnesota Quality of life Questionnaire 3. In ambulatory patients the exercise duration assessed by 6 min corridor walk test. Secondary: The incidence of side-effects, effect on levels of natriuretic peptides, effect on doppler-echocardiographic derived measurements of left ventricular diastolic function.

Reported: cardiovascular mortality, hospitalisation for heart failure, all-cause mortality, quality of life, $6 \mathrm{MWT}$, blood pressure, NT-proBNP, peak early diastolic mitral annular velocities, peak systolic velocity, LV mass 
Hong Kong DHF (Continued)

Risk of bias

\begin{tabular}{lll}
\hline Bias & Authors' judgement & Support for judgement \\
\hline $\begin{array}{l}\text { Random sequence genera- } \\
\text { tion (selection bias) }\end{array}$ & Low risk & $\begin{array}{l}\text { "randomly allocated using computer-generated random numbers in blocks of } \\
10 "\end{array}$ \\
\hline $\begin{array}{l}\text { Allocation concealment } \\
\text { (selection bias) }\end{array}$ & Unclear risk & not reported \\
\hline $\begin{array}{l}\text { Blinding of participants } \\
\text { and personnel (perfor- } \\
\text { mance bias) }\end{array}$ & High risk & "open-label" \\
All outcomes & \\
\hline
\end{tabular}

$\begin{array}{ll}\text { Blinding of outcome as- } & \text { Low risk } \quad \text { "All outcomes were reviewed blind to treatment allocation." } \\ \text { sessment (detection bias) } & \text { "with blinded end point design" }\end{array}$

All outcomes

whign

Incomplete outcome data Unclear risk unable to assess

(attrition bias)

All outcomes

Selective reporting (re- Unclear risk retrospective clinical trial registration, no published protocol identified porting bias)

\begin{tabular}{ll}
\hline Other bias & $\begin{array}{l}\text { "None of the authors received any lecture, advisory board, or consultancy fees } \\
\text { relating to this study from the sponsors." }\end{array}$ \\
& "This study was initially supported by a small grant from the manufacturers of \\
Irbesartan, who also donated the irbesartan medication (Sanofi-Synthelabo). & Design, conduct, retention of data, analysis and writing were all entirely inde- \\
pendent and carried out by the authors only. Data were kept at the Chinese \\
University of Hong Kong and are available for public scrutiny."
\end{tabular}

\section{I-PRESERVE}

Methods Study design: parallel RCT

Centres: 293 centres in 25 countries (Argentina, Australia, Belgium, Brazil, Canada, Czech Republic, Denmark, France, Germany, Greece, Hungary, Ireland, Italy, Mexico, The Netherlands, Norway, Poland, Portugal, Russia, South Africa, Spain, Sweden, Switzerland, UK, USA)

Start of enrolment: June 2002

End of enrolment: April 2005

Mean follow-up: mean follow-up time was 49.5 months, and the trial included 16,798 patient-years of follow-up

Run-in period: "Eligible patients were treated with single-blind placebo for 1 to 2 weeks before randomization"

Participants

Inclusion criteria: "All patients were at least 60 years of age and had heart failure symptoms and a left ventricular ejection fraction of at least $45 \%$. In addition, we required patients to have been hospitalized for heart failure during the previous 6 months and have current New York Heart Association (NYHA) class II, III, or IV symptoms with corroborative evidence; if they had not been hospitalized, they were required to have ongoing class III or IV symptoms with corroborative evidence. Such evidence could in-

Beta-blockers and inhibitors of the renin-angiotensin aldosterone system for chronic heart failure with preserved ejection fraction 
clude findings of pulmonary congestion on radiography, left ventricular hypertrophy or left atrial enlargement on echocardiography, or left ventricular hypertrophy or left bundle-branch block on electrocardiography. Treatment with an angiotensin-converting-enzyme (ACE) inhibitor was permitted only when such therapy was considered essential for an indication other than uncomplicated hypertension."

Exclusion criteria: "Exclusion criteria included previous intolerance to an angiotensin-receptor blocker; an alternative probable cause of the patient's symptoms (e.g. significant pulmonary disease); any previous left ventricular ejection fraction below $40 \%$; a history of acute coronary syndrome, coronary revascularization, or stroke within the previous 3 months; substantial valvular abnormalities; hypertrophic or restrictive cardiomyopathy; pericardial disease; cor pulmonale or other cause of isolated right heart failure; a systolic blood pressure of less than $100 \mathrm{~mm} \mathrm{Hg}$ or more than $160 \mathrm{~mm} \mathrm{Hg}$ or a diastolic blood pressure of more than $95 \mathrm{~mm} \mathrm{Hg}$ despite antihypertensive therapy; other systemic disease limiting life expectancy to less than 3 years; substantial laboratory abnormalities (such as a hemoglobin level of less than $11 \mathrm{~g}$ per deciliter, a creatinine level of more than $2.5 \mathrm{mg}$ per deciliter $[221 \mu \mathrm{mol}$ per liter], or liver-function abnormalities); or characteristics that might interfere with compliance with the study protocol"

Randomised (N): 4128 (2067 intervention, 2061 control)

Withdrawn (N): for reasons other than death 1368 (702 intervention, 684 control)

Lost to follow-up (N): 73 (29 intervention, 44 control)

Analysed (N): 4128 (2067 intervention, 2061 control)

Age (years, mean, SD): intervention: 72, 7; control: 72, 7

Sex (\% men): intervention: 41; control: 39

Ethnicity (\%): intervention: white 94, control: white 93

Systolic blood pressure (mmHg, mean, SD): intervention: 137, 15; control: 136, 15

Heart rate (beats/min, mean, SD): intervention: 72, 11; control: 71,10

BMI (mean, SD): intervention: 29.7, 5.2; control: 29.6, 5.3

Serum creatinine (mg/dL, mean, SD): intervention: 1.0, 0.32; control: 1.0, 0.34

B-type natriuretic peptide $(\mathrm{pg} / \mathrm{mL})$ : not reported

NT pro B-type natriuretic peptide (pg/mL, median, IQR): intervention: 360, 139-987; control: 320, $131-946$

LVEF (\%, mean, SD): intervention: 59, 9; control: 60, 9

NYHA class I (\%): 0

NYHA class II (\%): intervention: 21 ; control: 22

NYHA class III (\%): intervention: 77; control: 76

NYHA class IV (\%): intervention: 3; control: 3

Hypertension (\%): intervention: 89; control: 88

Diabetes (\%): intervention: 28; control: 27

Atrial fibrillation (\%): intervention: 29; control: 29

Hospitalisation for heart failure in the last six months (\%): intervention: 44; control: 44

Myocardial infarction (\%): intervention: 24; control: 23

Stroke or TIA (\%): intervention: 10; control: 10 
Diuretic (\%): intervention: loop: 52, thiazide: 38 , spironolactone 15; control: loop: 52, thiazide: 38 , spironolactone 15

Digoxin (\%): intervention: 14; control: 13

Beta-blocker (\%): intervention: 59; control: 58

ACEI (\%): intervention: 26 ; control: 25

ARB (\%): study drug

MRA (\%): intervention: 15; control: 15

Interventions

Intervention: irbesartan. "Patients were started on $75 \mathrm{mg}$ of irbesartan or placebo once daily. The dose was doubled to $150 \mathrm{mg}$ after 1 to 2 weeks and was doubled again to $300 \mathrm{mg}$ after an additional 1 to 2 weeks, according to a forced-titration protocol as tolerated." "At the end of the titration phase, $84 \%$ of the patients in the irbesartan group and $88 \%$ of those in the placebo group had reached the 300-mg dose (mean doses, $275 \mathrm{mg}$ and $284 \mathrm{mg}$, respectively)."

Comparator: "matching placebo"

Concomitant medication: "During the study, the proportion of patients receiving an ACE inhibitor rose from $25 \%$ in the two groups at baseline to $39 \%$ in the irbesartan group and $40 \%$ in the placebo group, the use of spironolactone rose from $15 \%$ in the two groups at baseline to $28 \%$ in the irbesartan group and $29 \%$ in the placebo group, and the use of beta-blockers rose from $59 \%$ in the irbesartan group and $58 \%$ in the placebo group to $73 \%$ in the two groups."

Outcomes Planned: "The primary end point is defined as time from randomization to the first occurrence of the composite outcome of death (all cause) or cardiovascular hospitalization. [...] The endpoint additionally includes myocardial infarction or stroke occurring during any hospitalization at any point during the study.

Secondary endpoints include the effect of irbesartan as compared with placebo in reducing the risk of: cardiovascular death, all-cause mortality, combined vascular endpoint: cardiovascular death, nonfatal myocardial infarction (MI) or nonfatal stroke; or combined HF endpoint: HF mortality or hospitalizations; [...] quality of life as measured by the Minnesota Living with Heart Failure questionnaire, change in New York Heart Associatioin (NYHA) functional class, change in global assessment of symptoms, Nterminal B-type natriuretic peptide levels in blood." (Carson 2005)

Reported: all planned outcomes reported No response.

\section{Risk of bias}

\begin{tabular}{|c|c|c|}
\hline Bias & Authors' judgement & Support for judgement \\
\hline $\begin{array}{l}\text { Random sequence genera- } \\
\text { tion (selection bias) }\end{array}$ & Low risk & "using an automated, central randomization system" \\
\hline $\begin{array}{l}\text { Allocation concealment } \\
\text { (selection bias) }\end{array}$ & Low risk & $\begin{array}{l}\text { "The randomization schedule was implemented with the use of an interactive } \\
\text { voice-response system." }\end{array}$ \\
\hline \multirow[t]{3}{*}{$\begin{array}{l}\text { Blinding of participants } \\
\text { and personnel (perfor- } \\
\text { mance bias) } \\
\text { All outcomes }\end{array}$} & Low risk & $\begin{array}{l}\text { "All investigators and committee members who were involved in the conduct } \\
\text { of the study (except for members of the data and safety monitoring board) } \\
\text { were unaware of study-group assignments." }\end{array}$ \\
\hline & & "double-blind" (Carson 2005) \\
\hline & & "matching placebo" \\
\hline
\end{tabular}

Beta-blockers and inhibitors of the renin-angiotensin aldosterone system for chronic heart failure with preserved ejection fraction (Review)

Copyright (c) 2018 The Cochrane Collaboration. Published by John Wiley \& Sons, Ltd. 
I-PRESERVE (Continued)

Blinding of outcome assessment (detection bias)

All outcomes
Unclear risk "blinded review of event rates in 2004" but blinding of event adjudication not specified overall
Incomplete outcome data Low risk (attrition bias)

All outcomes
"At the end of the study, vital-status data were not available for 29 patients $(1 \%)$ in the irbesartan group and 44 patients $(2 \%)$ in the placebo group. If contact could not be made at end of study, data for these patients were censored from the analysis at the date they were last known to be alive."

"Data from all patients who underwent randomization were analyzed according to the intention-to-treat principle."

all planned outcomes reported (comparison between published protocol (Carson 2005) and main results paper (Massie 2008)
Selective reporting (re- Low risk porting bias)
Low risk

\begin{abstract}
"Dr. Massie reports receiving grant support from Bristol-Myers Squibb, SanofiAventis, and Merck, consulting fees from Bristol- Myers Squibb, Sanofi-Aventis, Merck, Duke Clinical Research Institute, Momentum Research, Novartis, GlaxoSmithKline, Scios-Johnson \& Johnson, Corthera, and Niles Therapeutics, and lecture fees from Merck; Dr. Carson, receiving consulting fees from Bristol-Myers Squibb, Sanofi-Aventis, and Merck and lecture fees from AstraZeneca and Novartis; Dr. McMurray, receiving support from Bristol-Myers Squibb (to Glasgow University) for his work on this trial; Dr. Komajda, receiving consulting fees from Bristol-Myers Squibb and Servier and lecture fees from Servier, Sanofi-Aventis, and AstraZeneca; Dr. McKelvie, receiving consulting fees from Bristol-Myers Squibb and Sanofi-Aventis and lecture fees from Bristol-Myers Squibb, Sanofi-Aventis, Pfizer, Merck, and AstraZeneca; Dr. Zile, receiving consulting fees from Bristol-Myers Squibb and Sanofi-Aventis; Ms. Anderson, being employed by the Statistical Data Analysis Center at the University of Wisconsin-Madison, which conducted statistical analysis for this trial, supported by Bristol-Myers Squibb and Sanofi-Aventis; Drs. Donovan and Ptaszynska, being employees of and having an equity interest in Bristol-Myers Squibb; and Dr. Staiger, being an employee of and having an equity interest in Sanofi-Aventis."
\end{abstract}

study sponsors: Bristol-Myers Squibb and Sanofi-Aventis. "The sponsors or a contract research organization collected the trial data, which were then analyzed at the Statistical Data Analysis Center at the University of Wisconsin, Madison, independently of the sponsors."

Centres: "multicenter" but no further details

Start of enrolment: May 2004

End of enrolment: March 2009

Mean follow-up: 3.2 years

Run-in period: no nosed as having heart failure. Clinical diagnosis of heart failure was based on a slight modification of the Framingham criteria as previously described within the 12 months before study entry. There were no changes in baseline therapy and symptoms of heart failure within a month before study entry in any patients." 
Exclusion criteria: Current symptomatic hypotension, $\bullet$ Hypertension that has not been controlled to the satisfaction of the investigator by drugs other than $\beta$-blocker $\bullet$ Hemodynamically significant (in the investigators opinion) LV outflow tract obstruction (from either aortic stenosis or ventricular hypertrophy) or mitral valve stenosis - Important aortic or mitral regurgitation in the investigator's opinion • Heart rate $<50$ beats/min - Second- or third-degree heart block without permanent pacemaker in situ - Acute coronary syndrome - Arrhythmogenic right ventricular cardiomyopathy • Primary pulmonary hypertension or pulmonary hypertension not from LV dysfunction - Serious cerebrovascular disease - Acute myocardial infarction within the last 3 months • Patients who require intravenous inotropes • Cerebrovascular accident within the last 6 months $\cdot$ Percutaneous coronary intervention or open heart surgery within the last 3 months $\bullet$ On the waiting list for percutaneous coronary intervention or open heart surgery $\cdot$ Serum creatinine $>3.0 \mathrm{mg} / \mathrm{dL}$ or creatinine clearance $\leq 30 \mathrm{~mL} / \mathrm{min} \cdot$ Known bilateral renal artery stenosis $\bullet$ Serum potassium $>5.5 \mathrm{mEq} / \mathrm{L} \cdot$ Serious liver disease $\bullet$ Prescription of $\beta$-blocker within the last month or a history of a life-threatening adverse event induced by $\beta$-blocker $\bullet$ Any change in cardiovascular drug therapy within a month before randomization $•$ History of chronic obstructive pulmonary disease or restrictive lung disease $\cdot$ Diabetes mellitus that has not been controlled to the satisfaction of the investigator $\bullet$ History of any life-threatening noncardiac disease (eg, cancer) within 5 years $\bullet$ Other diseases likely to cause death or serious disability within 1 year $\bullet$ Patients unable to walk without personal aid • Arteriosclerosis obliterans with Fontaine Grade II or more. • Severe anemia (hemoglobin $\leq 6.0 \mathrm{~g} / \mathrm{dL}) \cdot$ Uncontrolled thyroid dysfunction

Randomised (N): 245 (120 intervention, 125 control)

Withdrawn $(\mathrm{N})$ : for reasons other than death (6 intervention, 0 control)

Lost to follow-up (N): (5 intervention, 3 control)

Analysed (N): (120 intervention, 125 control)

Age (years, mean, SD): intervention: 73, 10; control: 71, 11

Sex (\% men): intervention: 57.5 ; control: 58.4

Ethnicity (\%): not reported

Systolic blood pressure (mmHg, mean, SD): intervention: 134, 21; control: 133, 21

Heart rate (beats/min, mean, SD): intervention: 72,11 ; control: 74,13

BMI (mean, SD): intervention: 24.2, 4.4; control: 24.1, 4.1

Serum creatinine (mg/dL, mean, SD): intervention: 0.98, 0.37; control: 1.01, 0.45

B-type natriuretic peptide (pg/mL, mean, SD): intervention: 219.2, 294.9; control: 234.9, 281.6

NT pro B-type natriuretic peptide $(\mathrm{pg} / \mathrm{mL})$ : not reported

LVEF (\%, mean, SD): intervention: 62, 10; control: 63, 11

NYHA class I (\%): intervention: 18.3; control: 18.4

NYHA class II (\%): intervention: 69.2; control: 75.2

NYHA class III (\%): intervention: 10.8; control: 4.8

NYHA class IV (\%): intervention: 1.7; control: 1.6

Hypertension (\%): intervention: 80.0; control: 80.8

Diabetes (\%): intervention: 27.5 ; control: 33.6

Atrial fibrillation (\%): intervention: 50.8; control: 45.6

Hospitalisation for heart failure (\%): intervention: 60.0; control: 60.0

Ischaemic heart disease (\%): intervention: 28.3 ; control: 24.0 
J-DHF (Continued)

Stroke (\%): intervention: 11.7 ; control: 12.8

Diuretic (\%); intervention: 63.3; control: 56.8

Digoxin (\%): intervention: 19.2; control: 21.6

Beta-blocker (\%): study drug

ACEI (\%): intervention: 24.2; control: 22.4

ARB (\%): intervention: 50.8; control: 56.0

MRA (\%): intervention: 20.8; control: 25.6

Interventions

Intervention: carvedilol. "In the carvedilol arm, carvedilol was up-titrated from $1.25 \mathrm{mg}$ twice daily to the target dose of $10 \mathrm{mg}$ twice daily within 8 weeks based on tolerability. Patients were maintained at the target dose or the maximum tolerated dose for the remainder of the study."

Comparator: usual care

Concomitant medication: "In both arms, patients were treated with standard cardiovascular therapy excluding beta-blockers."

Outcomes

Planned: "The primary outcome is a composite of cardiovascular death and unplanned admission to hospital for congestive heart failure. The secondary outcomes are listed as follows: all-cause mortality; worsening of the symptoms (defined by either a decrease by 1 Mets in the SAS questionnaire score or an increase by 1 class in the New York Heart Association functional class for at least 3 months compared with the baseline); an increase in brain natriuretic peptide by $30 \%$ of the value at the randomization in patients with brain natriuretic peptide $200 \mathrm{pg} / \mathrm{mL}$ at the randomization; unplanned admission to hospital for congestive heart failure; or a need for modification of the treatment for heart failure (changes in oral medicine for at least 1 month or addition of intravenous inotropes for at least 4 hours)." (Hori 2005)

Reported: as planned

Notes

Emailed investigators on 13 November 2017 to ask about data on cardiovascular mortality and allcause mortality as different numbers are provided in Table 2 of Yamamoto 2013 (primary reference). No response.

\section{Risk of bias}

\begin{tabular}{|c|c|c|}
\hline Bias & Authors' judgement & Support for judgement \\
\hline $\begin{array}{l}\text { Random sequence genera- } \\
\text { tion (selection bias) }\end{array}$ & Unclear risk & "patients were randomized to the arm " but no details \\
\hline $\begin{array}{l}\text { Allocation concealment } \\
\text { (selection bias) }\end{array}$ & Unclear risk & no information \\
\hline $\begin{array}{l}\text { Blinding of participants } \\
\text { and personnel (perfor- } \\
\text { mance bias) } \\
\text { All outcomes }\end{array}$ & High risk & "open" \\
\hline $\begin{array}{l}\text { Blinding of outcome as- } \\
\text { sessment (detection bias) } \\
\text { All outcomes }\end{array}$ & Low risk & $\begin{array}{l}\text { "Deaths and hospitalizations were adjudicated by a blinded independent End- } \\
\text { point Committee, using prespecified criteria." } \\
\text { "Outcomes were assessed by the Endpoint Committee (see Appendix) where } \\
\text { all the committee members were blinded to the allocated group." }\end{array}$ \\
\hline
\end{tabular}

Beta-blockers and inhibitors of the renin-angiotensin aldosterone system for chronic heart failure with preserved ejection fraction 
J-DHF (Continued)

Incomplete outcome data Low risk "The primary outcome was a composite of cardiovascular death and un(attrition bias) planned hospitalization for heart failure using a time-to-first-event ana- lysis and the intention-to-treat principle."

unspecified for secondary outcomes

lost to follow-up low/similar in both groups (4.2\% intervention, $2.4 \%$ control)

Selective reporting (re- Low risk outcomes reported as planned in published protocol (Hori 2005) porting bias)

Other bias Low risk authors Col: "none declared"

funding: "The Ministry of Health, Labor andWelfare, Japan; the Japan Heart Foundation."

\section{Karapysh 2015}

$\begin{array}{ll}\text { Methods } & \text { Study design: RCT } \\ \text { Centres: not reported } \\ \text { Start of enrolment: not reported } \\ \text { End of enrolment: not reported } \\ \text { Follow-up: } 6 \text { months } \\ \text { Run-in period: not reported }\end{array}$

Participants

Inclusion criteria: "patients with chronic heart failure (CHF) with preserved ejection fraction (EF)." "with stable coronary arterial disease (CAD) and mild CHF (no higher Ilfunctional class (NYHA)) with preserved systolic function of the LV (EF $>45 \%) "$

Exclusion criteria: not reported

Randomised (N): 79

Withdrawn (N): not reported

Lost to follow-up (N): not reported

Analysed (N): not reported

Age (years, mean, SD): 54.5, 10.5

Sex (\% men): 61

Ethnicity (\%): intervention: white , control: white

Systolic blood pressure not reported

Heart rate not reported

BMI not reported

Serum creatinine not reported

B-type natriuretic peptide $(\mathrm{pg} / \mathrm{mL})$ : not reported

NT pro B-type natriuretic peptide $(\mathrm{pg} / \mathrm{mL})$ : not reported 
LVEF not reported

NYHA class: not reported

Diabetes not reported

Atrial fibrillation not reported

Hospitalisation for heart failure: not reported

Coronary heart disease not reported

Stroke (\%): not reported

Diuretic (\%); not reported

Digoxin (\%): not reported

Beta-blocker (\%): not reported

ACEI (\%): not reported

ARB (\%): not reported

MRA (\%): not reported

Interventions

Intervention: spironolactone. "SPRL group was treated with the standard therapy (ACE inhibitors or angiotensin receptor blockers II, beta-blockers,statins, antiplatelet agents) plus SPRL ( $25 \mathrm{mg} /$ day, titrated to $50 \mathrm{mg} /$ day if tolerated)"

Comparator: standard therapy

Concomitant medication: standard therapy (ACEI, ARB, beta-blocker, statins, antiplatelet agents)

$\begin{array}{ll}\text { Outcomes } & \text { Planned: unclear } \\ & \text { Reported: "V posterior wall thickness (LVPWT), intraventricular septal thickness (IVST), relative wall } \\ & \text { thickness (RWT) and LV mass index (LVMI)" }\end{array}$

Notes Intended to contact trialists to obtain missing details and to enquire whether outcomes of interest to this review were measured. This was not possible as we could not find contact details for trialists.

No relevant outcome data for this review.

\section{Risk of bias}

\begin{tabular}{lll}
\hline Bias & Authors' judgement & Support for judgement \\
\hline $\begin{array}{l}\text { Random sequence genera- } \\
\text { tion (selection bias) }\end{array}$ & Unclear risk & "were randomly divided" but no further detail \\
\hline $\begin{array}{l}\text { Allocation concealment } \\
\text { (selection bias) }\end{array}$ & Unclear risk & not reported \\
\hline $\begin{array}{l}\text { Blinding of participants } \\
\text { and personnel (perfor- } \\
\text { mance bias) }\end{array}$ & Unclear risk & not reported \\
$\begin{array}{l}\text { All outcomes } \\
\text { Blinding of outcome as- } \\
\text { sessment (detection bias) } \\
\begin{array}{l}\text { All outcomes } \\
\hline\end{array}\end{array}$ & Unclear risk & not reported \\
\hline
\end{tabular}

Beta-blockers and inhibitors of the renin-angiotensin aldosterone system for chronic heart failure with preserved ejection fraction 
Karapysh 2015 (Continued)

Incomplete outcome data (attrition bias)

All outcomes
Unclear risk could not be assessed

Selective reporting (re- Unclear risk could not be assessed
porting bias)

Other bias High risk reported only as conference abstract

Kasama 2005

Methods

Study design: individual, parallel RCT

Centres: 1 , Japan

Start of enrolment: January 2002

End of enrolment: September 2003

Follow-up: 6 months

Run-in period: not reported

Participants

Inclusion criteria: "first episode of nonischemic heart failure and preserved LVEF. We confirmed that all patients had symptoms and signs of congestive heart failure in this study."..."they were in New York Heart Association (NYHA) functional class II or III at the time of enrollment, and all had an LVEF $>40 \%$. "

Exclusion criteria: "Patients were excluded if they had a history of myocardial infarction, coronary artery disease, congenital heart disease, primary hepatic failure, or active cancer."

Randomised (N): 50 (intervention: 25, control: 25)

Withdrawn $(\mathrm{N})$ : not reported

Lost to follow-up (N): not reported

Analysed (N): not reported

Age (years, mean, SD): intervention: 66, 10; control: 67,8

Sex (\% men): intervention: 68; control: 64

Ethnicity (\%): not reported

Systolic blood pressure (mmHg, mean, SD): intervention: 132, 18; control: 130, 20

Heart rate (beats/min, mean, SD): intervention: 72 , 12; control: 74,14

BMI not reported

Serum creatinine not reported

B-type natriuretic peptide (pg/mL): intervention: 202, 125; control: 204, 127

NT pro B-type natriuretic peptide $(\mathrm{pg} / \mathrm{mL})$ : not reported

LVEF (\%, mean, SD): intervention: 54, 7; control: 55, 7

NYHA class I (\%): 0

NYHA class II (\%): intervention: 64; control: 68 
NYHA class III (\%): intervention: 36; control: 32

NYHA class IV (\%): 0

Hypertension (\%): intervention: 64; control: 60

Diabetes (\%): not reported

Atrial fibrillation (\%): not reported

Hospitalisation for heart failure (\%): 100

Coronary heart disease (\%): intervention: 0 ; control: 0

Stroke (\%): not reported

Diuretic (\%); intervention: 92; control: 88

Digoxin (\%): not reported

Beta-blocker (\%): intervention: 12; control: 12

ACEI (\%): intervention: 92; control: 96

ARB (\%): study drug

MRA (\%): intervention: 16; control: 20

Intervention: candesartan. "the initial daily dose of candesartan was 2 to $4 \mathrm{mg}$, which was increased to a maintenance dose of 8 to $12 \mathrm{mg} /$ day (mean $102 \mathrm{mg} /$ day)."

Comparator: placebo

Concomitant medication: "in addition to baseline therapy"

Planned: unclear as unaware of published protocol or pre-registration with a clinical trial registry
Reported: hemodynamics, I-MIBG, echocardiographic findings, NYHA functional class, BNP

Notes

No outcomes reported for relevance to this review. Emailed trialist to ask for outcome data relevant to this review. No response.

\begin{tabular}{|c|c|c|}
\hline \multicolumn{3}{|l|}{ Risk of bias } \\
\hline Bias & Authors' judgement & Support for judgement \\
\hline $\begin{array}{l}\text { Random sequence genera- } \\
\text { tion (selection bias) }\end{array}$ & Unclear risk & "randomly classified" but no further details \\
\hline $\begin{array}{l}\text { Allocation concealment } \\
\text { (selection bias) }\end{array}$ & Unclear risk & no information \\
\hline $\begin{array}{l}\text { Blinding of participants } \\
\text { and personnel (perfor- } \\
\text { mance bias) } \\
\text { All outcomes }\end{array}$ & Low risk & "double-blinded" but no further details \\
\hline $\begin{array}{l}\text { Blinding of outcome as- } \\
\text { sessment (detection bias) } \\
\text { All outcomes }\end{array}$ & Low risk & $\begin{array}{l}\text { "assessment was performed in a blinded fashion by two independent ob- } \\
\text { servers with no knowledge of the clinical status or medical therapy of the pa- } \\
\text { tients." }\end{array}$ \\
\hline $\begin{array}{l}\text { Incomplete outcome data } \\
\text { (attrition bias) }\end{array}$ & High risk & ITT used for all outcomes, but loss to follow-up and withdrawals not reported \\
\hline
\end{tabular}

Beta-blockers and inhibitors of the renin-angiotensin aldosterone system for chronic heart failure with preserved ejection fraction 
Kasama 2005 (Continued)

All outcomes

\begin{tabular}{|c|c|c|}
\hline $\begin{array}{l}\text { Selective reporting (re- } \\
\text { porting bias) }\end{array}$ & Unclear risk & $\begin{array}{l}\text { unable to assess as we are not aware of a published protocol or a pre-registra- } \\
\text { tion in a clinical trial registry }\end{array}$ \\
\hline
\end{tabular}

Other bias Unclear risk funding source not reported

Kitzman 2010

Methods

Study design: individual parallel RCT

Centres: not reported

Start of enrolment: not reported

End of enrolment: not reported

Follow-up: 12 months

Run-in period: not reported

Participants

Inclusion criteria: "As previously described, isolated HFPEF was defined as history, symptoms, and signs of HF; a preserved LVEF (50\%); and no evidence of significant coronary, valvular, or pulmonary disease or other medical condition that could mimic HF symptoms, such as anemia or thyroid dysfunction."

Exclusion criteria: "Coronary disease was excluded by history, medical records, ECG, and rest and exercise echocardiogram." "Patients were excluded if they had ever been prescribed an ACEI or ARB."

Randomised (N): 71 (35 intervention, 36 control)

Withdrawn $(\mathrm{N})$ : for reasons other than death 12 (10 intervention (3 patient request, 1 pancreatitis, 1 elective rotator cuff surgery, 1 alopecia, 1 worsening cough, 1 hypotension, 1 ankle fracture, exacerbation of knee arthritis, 1 leg and hip pain and fatigue), 2 control (1 elective knee replacement surgery, no details for second participants)

Lost to follow-up (N): not reported

Analysed (N): 59 completed study (25 intervention, 34 control)

Age (years, mean, SD): intervention: 69, 8; control: 70, 7

Sex (\% men): intervention: 20; control: 11

Ethnicity (\%): intervention: black 9, control: black 6

Systolic blood pressure (mmHg, mean, SD): intervention: 143, 17; control: 144, 18

Heart rate (beats/min, mean, SD): intervention: 129, 20; control: 133, 16

BMI (mean, SD): intervention: 30, 5; control: 30, 5

Serum creatinine (mg/dL, mean, SD): intervention: 1.1, 0.2; control: 1.1, 0.2

B-type natriuretic peptide $(\mathrm{pg} / \mathrm{mL})$ : not reported

NT pro B-type natriuretic peptide $(\mathrm{pg} / \mathrm{mL})$ : not reported

LVEF (\%, mean, SD): intervention: 65, 8; control: 65, 7

NYHA class I (\%): 0: 
NYHA class II (\%): intervention: 83; control: 75

NYHA class III (\%): intervention: 17; control: 25

NYHA class IV (\%): 0

Hypertension (\%): intervention: 71; control: 75

Diabetes (\%): intervention: 9; control: 17

Atrial fibrillation not reported

Hospitalisation for heart failure: not reported

Coronary heart disease (\%): 0

Stroke not reported

Diuretic (\%); intervention: 49; control: 58

Digoxin (\%): 0

Beta-blocker (\%): intervention: 29; control: 39

ACEI (\%): study drug

ARB not reported

MRA not reported

Interventions

Intervention: enalapril. "The study drug was initiated at $2.5 \mathrm{mg}$ BID and titrated up to $10 \mathrm{mg}$ BID as tolerated by the patient within the first 4 weeks of the study."

Comparator: placebo

Concomitant medication: not reported

Outcomes Planned: unclear as clinical trial registration was post hoc

Reported: exercise capacity, aortic distensibility and LV structure and function, carotid artery stiffness, LV diastolic filling, QoL

\section{Notes}

\section{Risk of bias}

\begin{tabular}{lll}
\hline Bias & Authors' judgement & Support for judgement \\
\hline $\begin{array}{l}\text { Random sequence genera- } \\
\text { tion (selection bias) }\end{array}$ & Unclear risk & not reported \\
\hline $\begin{array}{l}\text { Allocation concealment } \\
\text { (selection bias) }\end{array}$ & Unclear risk & not reported \\
\hline $\begin{array}{l}\text { Blinding of participants } \\
\begin{array}{l}\text { and personnel (perfor- } \\
\text { mance bias) }\end{array}\end{array}$ & Low risk & "All investigators, staff, and patients were fully blinded to treatment group as- \\
$\begin{array}{l}\text { All outcomes } \\
\text { signment throughout the entire study period." }\end{array}$ & \\
\hline $\begin{array}{l}\text { Blinding of outcome as- } \\
\text { sessment (detection bias) } \\
\text { All outcomes }\end{array}$ & Low risk & "All investigators, staff, and patients were fully blinded to treatment group as- \\
\hline
\end{tabular}

Beta-blockers and inhibitors of the renin-angiotensin aldosterone system for chronic heart failure with preserved ejection fraction 


\section{Kitzman 2010 (Continued)}

Incomplete outcome data (attrition bias)

All outcomes
Unclear risk not reported

Selective reporting (re- Unclear risk not reported
porting bias)

\begin{tabular}{ll}
\hline Other bias & Low risk \\
& vista $(\$ 10000)$, Bristol-Meyers Squibb $(\$ 10000)$, Novartis $(\$ 10000)$, Boston Sci- \\
& entific $(\$ 10000)$, Relypsa $(\$ 10000)$, Forest Laboratories, and Medtronic. Dr Lit- \\
& tle has served as consultant for CorAssist Cardiovascular Ltd, Celladon, Boston \\
& Scientific, Medtronic $(\$ 10000)$, Bio-Control Medical, CVRx $(\$ 10000)$, Amylin \\
& Pharmaceuticals, Gilead, and BristolMeyers Squibb $(\$ 1000)$. Drs Hundley, \\
& Brubaker, and Morgan; Mr Moore; and Ms Steward report no conflicts."
\end{tabular}

Kurrelmeyer 2014

Methods

Study design: parallel RCT

Centres: 1 hospital, Houston, Texas

Start of enrolment: 2004

End of enrolment: 2008

Follow-up: 6 months

Run-in period: "patients were treated with $25 \mathrm{mg}$ open-label spironolactone for 1 week before randomization to ensure drug tolerability, defined as serum potassium $<5 \mathrm{mEq} / \mathrm{L}$ and absence of other major side effects."

Participants

Inclusion criteria: " $\geq 18$ years old with a previous diagnosis of HFpEF. HFpEF was defined as current New York Heart Association (NYHA) functional class II or III HF symptoms or signs, left ventricular ejection fraction (LVEF) $\geq 50 \%$ according to echocardiography, diastolic dysfunction with elevated LV filling pressure according to Dopplerechocardiograph" "the subjects had to have a blood pressure of $\leq 150 / 95$ $\mathrm{mm} \mathrm{Hg}$ for 4 weeks before enrollment and the ability to walk $\geq 50 \mathrm{~m}$ at the time of enrollment. Treatment with an ACEI, or ARB if ACEI intolerant, was required for $\geq 4$ weeks before enrollment. "

Exclusion criteria: "Exclusion criteria included current treatment with spironolactone or epleronone, previous intolerance to spironolactone, creatinine $>2.5 \mathrm{mg} / \mathrm{dL}$, serum potassium $>5.0 \mathrm{mEq} / \mathrm{L}$, significant valvular heart disease, pericardial disease, severe chronic lung disease with cor pulmonale, unstable angina or myocardial infarction $\leq 4$ weeks before enrollment, severe peripheral vascular disease with claudication that limited walking distance, presence of other severe comorbid conditions with a life expectancy $<6$ months, and pregnant or lactating women."

Randomised (N): 48 (24 intervention, 24 control)

Withdrawn (N): for reasons other than death (3 intervention (hyperkalaemia), 0 control)

Lost to follow-up (N): not reported

Analysed (N): not reported

Age (years, mean, SEM): intervention: 66.3, 2.2; control: 76.4, 1.6

Sex (\% men): 0

Ethnicity (\%): not reported

Systolic blood pressure (mmHg, mean, SEM): intervention: 137.0, 4.1; control: 133.1, 2.8

Beta-blockers and inhibitors of the renin-angiotensin aldosterone system for chronic heart failure with preserved ejection fraction 
Heart rate (beats/min, mean, SEM): intervention: 64.2, 2.3; control: 61.1, 1.2

BMI (mean, SEM): intervention: 29.4, 2.2; control: 26.3, 1.2

Serum creatinine not reported

B-type natriuretic peptide $(\mathrm{pg} / \mathrm{mL})$ : not reported

NT pro B-type natriuretic peptide $(\mathrm{pg} / \mathrm{mL})$ : not reported

LVEF (\%, mean, SEM): intervention: 62.5, 1.2; control: 62.9, 1.2

NYHA class I (\%): 0

NYHA class II (\%): intervention: 33; control: 42

NYHA class III (\%): intervention: 67; control: 58

NYHA class IV (\%): 0

Hypertension (\%): intervention: 87.5; control: 79.2

Diabetes (\%): intervention: 50; control: 25

Atrial fibrillation (\%): intervention: 25; control: 25

Hospitalisation for heart failure (\%): intervention: 58.3; control: 54.2

Coronary heart disease (\%): intervention: 37.5 ; control: 33.3

Stroke (\%): not reported

Diuretic (\%): intervention: 83.3; control: 75

Digoxin (\%): intervention: 12.5 ; control: 8.3

Beta-blocker (\%): intervention: 62.5; control: 62.5

ACEI (\%): intervention: 70.8; control: 66.7

ARB (\%): intervention: 29.2; control: 37.5

MRA (\%): study drug

Comparator: placebo

Concomitant medication: not reported

Outcomes Planned: no known published protocol or pre-enrolment clinical trial registry record

Reported: 6 min walk distance, clinical composite score, doppler echocardiography, biomarkers, Kansas City Cardiomyopathy Questionnaire clinical summary score

Notes

\section{Risk of bias}

\begin{tabular}{lll}
\hline Bias & Authors' judgement & Support for judgement \\
\hline $\begin{array}{l}\text { Random sequence genera- } \\
\text { tion (selection bias) }\end{array}$ & Unclear risk & "randomly allocated", no further details \\
\hline
\end{tabular}


Kurrelmeyer 2014 (Continued)

$\begin{aligned} & \text { Allocation concealment } \quad \text { Low risk } \\ & \text { (selection bias) }\end{aligned}$
cealed randomization methods.", no further details

\begin{tabular}{lll}
$\begin{array}{l}\text { Blinding of participants } \\
\text { and personnel (perfor- } \\
\text { mance bias) } \\
\text { All outcomes }\end{array}$ & Low risk & double-blind, placebo controlled, no further details \\
\hline $\begin{array}{l}\text { Blinding of outcome as- } \\
\text { sessment (detection bias) } \\
\text { All outcomes }\end{array}$ & Unclear risk & not reported \\
\hline $\begin{array}{l}\text { Incomplete outcome data } \\
\text { (attrition bias) } \\
\text { All outcomes }\end{array}$ & Unclear risk & not reported \\
\hline $\begin{array}{l}\text { Selective reporting (re- } \\
\text { porting bias) }\end{array}$ & Unclear risk & $\begin{array}{l}\text { no able to assess due to lack of pre-registration in clinical trial registry and } \\
\text { published protocol }\end{array}$ \\
\hline $\begin{array}{l}\text { Other bias } \\
\text { clinical trial registry entry after start of enrolment, was originally marked as an } \\
\text { observational study (2005-2013) and changed to a randomised trial status in } \\
\text { 2013. reported as a RCT in 2014 publication. } \\
\text { funded by Women's Fund; Houston, Texas }\end{array}$
\end{tabular}

Study design: RCT
Centres: 1
Start of enrolment: not reported
End of enrolment: not reported
Follow-up: 12 months
Run-in period: not reported
Inclusion criteria: heart failure with preserved systolic function, "prior New York Heart Association
(NYHA) functional class IV HF admission or symptoms consistent with HF, B-type natriuretic peptide
(BNP) $>100$ pg/ml, left ventricular ejection fraction $>45 \%$, and evidence of diastolic dysfunction on
Doppler-echocardiographic study."
Exclusion criteria: "Patients were excluded if they were clinically unstable as defined by any change
in diuretic dose a month before enrollment or were already receiving eplerenone or spironolactone
therapy. Other exclusion criteria were evidence of significant inflammatory disease, hepatic disease, or
metabolic bone disease that may alter parameters of collagen metabolism, serum creatinine $>200$ mol/
I, prior documented left ventricular ejection fraction $<45 \%$, hemodynamically significant valvular dis-
ease, corpulmonale, hypertrophic, restrictive, or constrictive cardiomyopathy, atrial fibrillation or flut-
ter with resting ventricular rate $>120$ beats/min, severe anemia, clinically significant pulmonary disease
as evidenced by hospitalizations, or use of oral corticosteroids for pulmonary decompensation within
12 months or patients who require home oxygen therapy."

Randomised (N): 44 (24 intervention, 20 control)

Withdrawn (N): for reasons other than death 0

Lost to follow-up (N): 2 (0 intervention, 2 control) 
Analysed (N): 40 (23 intervention, 17 control)

Age (years, mean, SD): intervention: 80, 7.7; control: 79, 7.9

Sex (\% men): intervention: 38; control: 55

Ethnicity (\%): Caucasian: 100

Systolic blood pressure (mmHg, mean, SD): intervention: 140, 20; control: 146, 20

Heart rate (beats/min, mean, SD): intervention: 69, 13; control: 66, 13

BMI (mean, SD): intervention: 31.3, 6.9; control: 31.8, 5.7

Serum creatinine: not reported

B-type natriuretic peptide (pg/mL, median, IQR): intervention: 219 (157-317); control: 192 (132-330)

NT pro B-type natriuretic peptide: not reported

LVEF (\%, mean, SD): intervention: 63, 9.0; control: 64, 9.6

NYHA class I (\%): not reported

NYHA class II (\%): $87 \%$

NYHA class III (\%): not reported

NYHA class IV (\%): not reported

Hypertension (\%): intervention: 92; control: 90

Diabetes (\%): intervention: 21; control: 35

Atrial fibrillation (\%): intervention: 58; control: 60

Hospitalisation for heart failure: not reported

Coronary heart disease (\%): not reported

Stroke (\%): not reported

Diuretic (\%); intervention: 88; control: 90

Digoxin (\%): intervention: 38; control: 30

Beta-blocker (\%): intervention: 62; control: 75

ACEI (\%): intervention: 67; control: 60

ARB (\%): intervention: 29; control: 40

MRA (\%): study drug

Intervention: eplerenone. "we evaluated patients with a dose of $25 \mathrm{mg}$ daily for 6 months followed by a dose increment to $50 \mathrm{mg}$ until the 12-month time point"

Comparator: usual heart failure treatment

Concomitant medication: not reported

Reported: serum levels of markers of collagen turnover, inflammatory markers, doppler-echocardiographic indexes, clinical and biochemical measurements, withdrawals, quality of life 
Mak 2009 (Continued)

Notes Emailed investigators to ask whether ITT or PP analysis was used. No response.

\section{Risk of bias}

\begin{tabular}{|c|c|c|}
\hline Bias & Authors' judgement & Support for judgement \\
\hline $\begin{array}{l}\text { Random sequence genera- } \\
\text { tion (selection bias) }\end{array}$ & Unclear risk & "randomly allocated" but no further detail \\
\hline $\begin{array}{l}\text { Allocation concealment } \\
\text { (selection bias) }\end{array}$ & Unclear risk & nor reported \\
\hline $\begin{array}{l}\text { Blinding of participants } \\
\text { and personnel (perfor- } \\
\text { mance bias) } \\
\text { All outcomes }\end{array}$ & High risk & "open label" \\
\hline $\begin{array}{l}\text { Blinding of outcome as- } \\
\text { sessment (detection bias) } \\
\text { All outcomes }\end{array}$ & Low risk & "all parameters were assessed by persons blinded to treatment" \\
\hline $\begin{array}{l}\text { Incomplete outcome data } \\
\text { (attrition bias) } \\
\text { All outcomes }\end{array}$ & Unclear risk & unable to assess \\
\hline $\begin{array}{l}\text { Selective reporting (re- } \\
\text { porting bias) }\end{array}$ & Unclear risk & unable to assess as unaware of published protocol or pre-trial registration \\
\hline Other bias & Low risk & $\begin{array}{l}\text { Dr. Mak received grant support from the Irish Heart Foundation (The Noel Hick- } \\
\text { ey Bursary) sponsored by Pfizer. Drs. Ledwidge and McDonald have received } \\
\text { honoraria from Pfizer. }\end{array}$ \\
\hline
\end{tabular}

Mittal 2017

Study design: RCT
Centres: 1, Cardiology Outpatient Department and HTN clinic of Postgraduate Institute of Medical Edu-
cation and Research, India

Start of enrolment: 15 November 2009 (from clinical trial registry)

End of enrolment: not reported for pilot study, full study ongoing

Follow-up: 12 weeks

Run-in period: 2 weeks placebo run in (beta-blocker withdrawn but co-existing therapies were continued)

\section{Participants}

Inclusion criteria: "18 years and above, had New York Heart Association (NYHA) functional Class IIIII of at least 4 weeks' duration, LVEF $\geq 50 \%$ in a nondilated LV (LV enddiastolic volume $<97 \mathrm{ml} / \mathrm{m}$ measured by echocardiography), echocardiographic evidence of LV diastolic dysfunction, and were willing to give written informed consent."

Exclusion criteria: "They were excluded if: (1) Clinically unstable as defined by any change in diuretic dose in the month before enrollment, (2) significant valvular heart disease, pericardial disease, hypertrophic or restrictive cardiomyopathy, (3) unstable angina or MI within past 4 weeks, (4) any previous LVEF below $40 \%$, (5) any contraindication to metoprolol use, (6) patients already on beta blockers which cannot be withdrawn, (7) current participation (including prior 30 days) in any other therapeutic

Beta-blockers and inhibitors of the renin-angiotensin aldosterone system for chronic heart failure with preserved ejection fraction 
trial, and (8) any condition that, in the opinion of investigator, may prevent the participant from adhering to the trial protocol."

Randomised (N): 40 (20 intervention, 20 control)

Withdrawn (N): for reasons other than death 0

Lost to follow-up (N): 6 (3 intervention, 3 control)

Analysed (N): 40 (20 intervention, 20 control)

Age (years, mean, SD): intervention: 55.2, 7.1; control: 57.2, 9.8

Sex (\% men): intervention: 45; control: 50

Ethnicity (\%): not reported

Systolic blood pressure not reported

Heart rate not reported

BMI not reported

Serum creatinine not reported

B-type natriuretic peptide not reported

NT pro B-type natriuretic peptide (pg/mL, median (IQR)): intervention: 238.2 (107.7-2230.2); control: $227.6(58.3-3645)$

LVEF (\%, mean, SD): intervention: $62.9,6.2$; control: $62.1,6.57$

NYHA class I (\%): 0

NYHA class II (\%): intervention: 55; control: 65

NYHA class III (\%): intervention: 45; control: 35

NYHA class IV (\%): 0

Hypertension (\%): not reported

Diabetes (\%): not reported

Atrial fibrillation (\%): not reported

Hospitalisation for heart failure: not reported

Coronary heart disease (\%): not reported

Stroke (\%): not reported

Diuretic (\%); intervention: 35; control: 40

Digoxin (\%): not reported

Beta-blocker (\%): intervention: 40; control: 45

ACEI (\%): intervention: 15; control: 60

ARB (\%): intervention: 15; control: 15

MRA (\%): not reported
Intervention: metoprolol succinate, $25 \mathrm{mg}$. "A dose upward titration protocol with monitoring of blood pressure and heart rate (target blood pressure and heart rate as 120/80 mm Hg and 60 beats/min, respectively) was implemented for dose increments up to a maximum dose of $100 \mathrm{mg}$ once daily. For pa-

Beta-blockers and inhibitors of the renin-angiotensin aldosterone system for chronic heart failure with preserved ejection fraction 
Mittal 2017 (Continued)

tients not tolerating increased titration of drug, temporary reduction in dosage was done and decision on further escalation made on individual basis by the treating cardiologist."

Comparator: placebo

Concomitant medication: "During the study, calcium channel blockers were added in three patients (one in placebo and two in metoprolol group) due to high blood pressure records." coexisting therapies were continued

\begin{tabular}{ll} 
Outcomes & Planned: unable to assess \\
& Reported: primary: NYHA class. Secondary: exercise capacity, diastolic dysfunction, change in LV wall \\
& thickness, LV mass, NT-proBNP, PICP, QoL (SF-36), adverse events, withdrawals \\
\hline Notes & published results after our search date, identified via search for clinical trial registry number: \\
& CTRI/2010/091/000438 which was retrieved by search of the WHO ICTRP register \\
& Emailed investigators to ask when completion of full trial is anticipated. Response confirmed that full \\
trial was not conducted.
\end{tabular}

\section{Risk of bias}

\begin{tabular}{|c|c|c|}
\hline Bias & Authors' judgement & Support for judgement \\
\hline $\begin{array}{l}\text { Random sequence genera- } \\
\text { tion (selection bias) }\end{array}$ & Unclear risk & "block randomised" but no further details \\
\hline \multirow[t]{2}{*}{$\begin{array}{l}\text { Allocation concealment } \\
\text { (selection bias) }\end{array}$} & Low risk & $\begin{array}{l}\text { "Randomization and allocation sequence generation were done by investiga- } \\
\text { tors not directly involved in the evaluation of outcomes" }\end{array}$ \\
\hline & & $\begin{array}{l}\text { From clinical trial registry: "sequentially numbered, sealed, opaque en- } \\
\text { velopes" }\end{array}$ \\
\hline \multirow{3}{*}{$\begin{array}{l}\text { Blinding of participants } \\
\text { and personnel (perfor- } \\
\text { mance bias) } \\
\text { All outcomes }\end{array}$} & Low risk & "double-blind" \\
\hline & & From clinical trial registry entry: "participant and outcome assessor blinded" \\
\hline & & Unclear whether personnel was blinded. \\
\hline
\end{tabular}

\begin{tabular}{|c|c|c|}
\hline $\begin{array}{l}\text { Blinding of outcome as- } \\
\text { sessment (detection bias) } \\
\text { All outcomes }\end{array}$ & Low risk & $\begin{array}{l}\text { "To avoid interobserver variability, all the echocardiographic parameters were } \\
\text { evaluated by a single cardiologist who was blinded to study medication and } \\
\text { the order of assessment." }\end{array}$ \\
\hline & & From clinical trial registry entry: "participant and outcome assessor blinded" \\
\hline
\end{tabular}

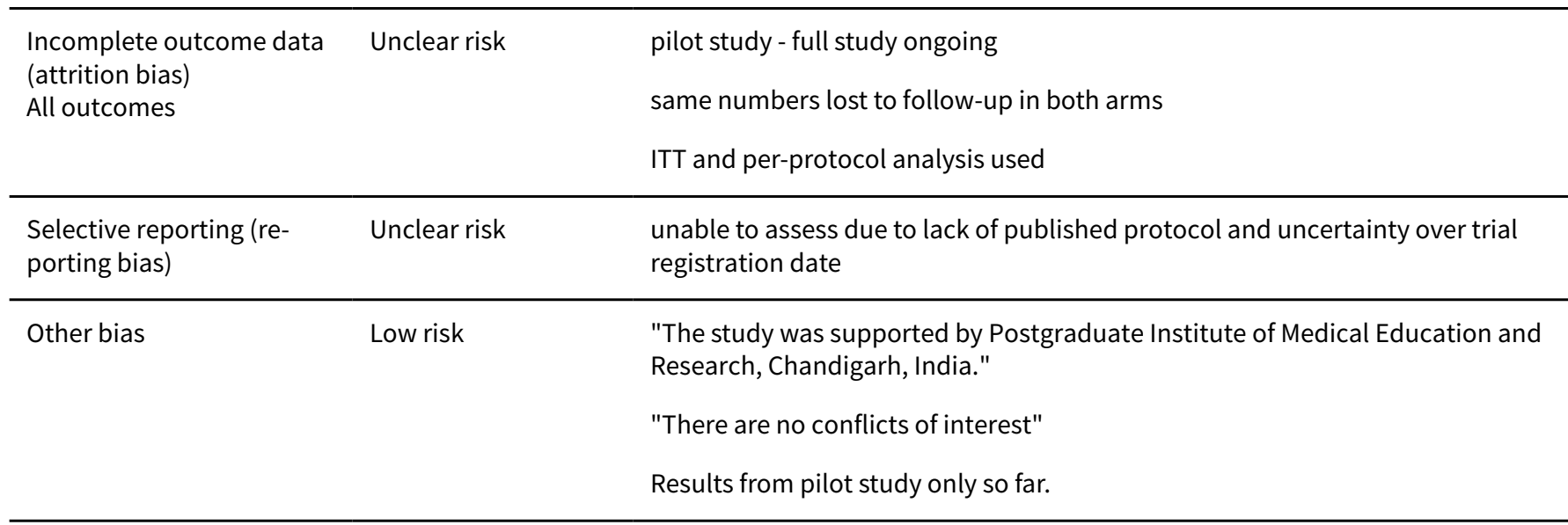


Centres: 1 , Australia

Start of enrolment: February 2002

End of enrolment: October 2002

Follow-up: 6 months

Run-in period: not reported

Inclusion criteria: "To be eligible, patients had to have hypertension requiring antihypertensive medication and report exertional dyspnea (New York Heart Association class II) but no history of angina or myocardial infarction."

Exclusion criteria: "Patients taking angiotensin converting enzyme inhibitors, angiotensin-receptor blockers, or spironolactone were excluded, as were patients with renal impairment (creatinine 0.20 $\mathrm{mmol} / \mathrm{dL}$ ) or hyperkalemia at baseline." "we excluded patients with evidence of pulmonary disease, ischemic heart disease, abnormal regional or global resting LV systolic function (ejection fraction $<50 \%$ ), or significant (>mild) valvular dysfunction."

Randomised (N): 30 (not reported by treatment arm, assumed 15 in each)

Withdrawn (N): not reported

Lost to follow-up (N): 1 (intervention: 1 (migrated overseas); control: 0)

Analysed (N): not reported

Age (years, mean, SD): intervention: 61, 6; control: 62, 5

Sex (\% men): intervention: 40; control: 34

Ethnicity (\%): not reported

Systolic blood pressure (mmHg): intervention: 199, 18; control: 198, 26

Heart rate (beats/min): intervention: 139, 24; control: 153, 13

BMI: intervention: 29.8, 4.7; control: 31.2, 4.6

Serum creatinine $(\mathrm{mg} / \mathrm{dL})$ : intervention: $0.07,0.01$; control: $0.07,0.01$

B-type natriuretic peptide (pg/mL) intervention: 29.3, 26.8; control: 29.7, 27.8

NT pro B-type natriuretic peptide not reported

LVEF: intervention: 68, 5; control: 67, 4

NYHA class not reported

Hypertension (\%): not reported

Diabetes (\%): intervention: 7; control: 0

Atrial fibrillation (\%): not reported

Hospitalisation for heart failure: not reported

Coronary heart disease (\%): not reported

Stroke (\%): not reported 
Diuretic (\%); intervention: 40; control: 27

Digoxin (\%): not reported

Beta-blocker (\%): intervention: 40; control: 20

ACEI (\%): not reported

ARB (\%): not reported

MRA (\%): study drug

\begin{tabular}{ll}
\hline Interventions & Intervention: spironolactone, $25 \mathrm{mg} / \mathrm{d}$ \\
Comparator: placebo \\
Concomitant medication: not reported
\end{tabular}

Outcomes Planned: unable to assess as we are not aware of a published protocol or pre-registered clinical trial registry entry

Reported: mean $24 \mathrm{hr}$ ambulatory blood pressure, posterior wall thickness, left atrial area, SR, peak systolic strain, and CVIB

Notes no outcome data of interest to this review

\section{Risk of bias}

\begin{tabular}{|c|c|c|}
\hline Bias & Authors' judgement & Support for judgement \\
\hline $\begin{array}{l}\text { Random sequence genera- } \\
\text { tion (selection bias) }\end{array}$ & Unclear risk & randomised, but no details \\
\hline $\begin{array}{l}\text { Allocation concealment } \\
\text { (selection bias) }\end{array}$ & Unclear risk & not reported \\
\hline $\begin{array}{l}\text { Blinding of participants } \\
\text { and personnel (perfor- } \\
\text { mance bias) } \\
\text { All outcomes }\end{array}$ & Low risk & double blind, matching placebo \\
\hline $\begin{array}{l}\text { Blinding of outcome as- } \\
\text { sessment (detection bias) } \\
\text { All outcomes }\end{array}$ & Low risk & $\begin{array}{l}\text { "Investigators remained blinded to the treatment until after analysis of re- } \\
\text { sults." }\end{array}$ \\
\hline $\begin{array}{l}\text { Incomplete outcome data } \\
\text { (attrition bias) } \\
\text { All outcomes }\end{array}$ & Unclear risk & not reported \\
\hline $\begin{array}{l}\text { Selective reporting (re- } \\
\text { porting bias) }\end{array}$ & Unclear risk & unable to assess \\
\hline Other bias & Unclear risk & $\begin{array}{l}\text { "This work was supported in part by a grant and scholarship from the Nation- } \\
\text { al Heart Foundation of Australia, Melbourne, Australia, in association with a } \\
\text { Centers of Clinical Research Excellence Award, National Health and Medical } \\
\text { Research Council, Canberra, Australia. The authors are grateful to the Princess } \\
\text { Alexandra Hospital Pharmacy for supervision of randomization and dispensing } \\
\text { of active and placebo tablets." }\end{array}$ \\
\hline
\end{tabular}




\begin{tabular}{ll}
\hline Methods & Study design: RCT \\
Centres: not reported \\
Start of enrolment: not reported \\
End of enrolment: not reported \\
Mean follow-up: 13.8 months \\
Run-in period: not reported
\end{tabular}

Participants

Inclusion criteria: "Patients with diastolic heart failure attending to Heart Failure Clinic were considered eligible, independently of etiology, if they had history of arterial hypertension (and/or were on antihypertensive treatment), but no history of angina, myocardial infarction or myocardial revascularization (PTCA and / or aortocoronary bypass grafting) during the 3 months previous to recruitment and they referred fatigue, dyspnea on exercise and/or orthopnea." "Diastolic dysfunction was considered when the ejection fraction was over $45 \%$, and shortening fraction $=28 \%$, without severe segmental dyskynesia of the left ventricle, left atrial enlargement, or increased thickness or posterior wall, interventricular septum, and left ventricular mass index."

Exclusion criteria: not reported

Randomised (N): 28 (14 intervention, 14 control)

Withdrawn (N): not reported

Lost to follow-up (N): not reported

Analysed (N): not reported

Age (years, mean, SD): intervention: 63.7, 21.6; control: 64.8, 11.9

Sex (\% men): intervention: 28.6; control: 71.4

Ethnicity (\%): not reported

Blood pressure (mmHg): intervention: 112, 12; control: 114, 8

Heart rate (beats/min): intervention: 86 , 4; control: 82,6

BMI (mean, SD): intervention: 27.5, 9.4; control: 26.9, 4.7

Serum creatinine not reported

B-type natriuretic peptide $(\mathrm{pg} / \mathrm{mL})$ : not reported

NT pro B-type natriuretic peptide $(\mathrm{pg} / \mathrm{mL})$ : not reported

LVEF (\%, mean, SD): intervention: 48.79, 4.65; control: 51.57, 11.71

NYHA class I (\%): intervention: 42.9; control: 75.0

NYHA class II (\%): intervention: 0; control: 16.7

NYHA class III (\%): intervention: 57.1; control: 8.3

NYHA class IV (\%): 0

Hypertension (\%): intervention: 85.7; control: 92.9

Diabetes (\%): intervention: 28.6; control: 64.3

Atrial fibrillation (\%): not reported 
Hospitalisation for heart failure: not reported

Ischaemic heart disease (\%): intervention: 42.9; control: 57.1

Stroke (\%): not reported

Diuretic (\%): intervention: thiazide: 76.9, loop: 5.1; control: thiazide: 62.3, loop: 13

Digoxin (\%): not reported

Beta-blocker (\%): intervention: 79.5; control: 79.7

ACEI (\%): intervention: 38.5; control: 29

ARB (\%): intervention: 69.2; control: 73.9

MRA (\%): study drug

Comparator: no treatment

Concomitant medication: "In our study, patients with diastolic heart failure were all treated with ACE inhibitors/ARA and Beta blockers."

\begin{tabular}{|c|c|c|}
\hline Outcomes & \multicolumn{2}{|c|}{$\begin{array}{l}\text { Planned: We are not aware of a published protocol or pre-registered clinical trial register entry } \\
\text { Reported: echocardiographic parameters, adverse events }\end{array}$} \\
\hline Notes & \multicolumn{2}{|c|}{ no outcome data of interest to this review } \\
\hline \multicolumn{3}{|l|}{ Risk of bias } \\
\hline Bias & Authors' judgement & Support for judgement \\
\hline $\begin{array}{l}\text { Random sequence genera- } \\
\text { tion (selection bias) }\end{array}$ & Unclear risk & not reported \\
\hline $\begin{array}{l}\text { Allocation concealment } \\
\text { (selection bias) }\end{array}$ & Unclear risk & not reported \\
\hline $\begin{array}{l}\text { Blinding of participants } \\
\text { and personnel (perfor- } \\
\text { mance bias) } \\
\text { All outcomes }\end{array}$ & Unclear risk & not reported \\
\hline
\end{tabular}

\begin{tabular}{|c|c|c|}
\hline $\begin{array}{l}\text { Blinding of outcome as- } \\
\text { sessment (detection bias) } \\
\text { All outcomes }\end{array}$ & Low risk & $\begin{array}{l}\text { "The echocardiogram was made by a Cardiologist blinded to the clinical evalu- } \\
\text { ation and treatment received." }\end{array}$ \\
\hline $\begin{array}{l}\text { Incomplete outcome data } \\
\text { (attrition bias) } \\
\text { All outcomes }\end{array}$ & Unclear risk & not reported \\
\hline $\begin{array}{l}\text { Selective reporting (re- } \\
\text { porting bias) }\end{array}$ & Unclear risk & unable to assess \\
\hline Other bias & Unclear risk & no funding reported \\
\hline
\end{tabular}


Parthasarathy 2009

Methods

\author{
Study design: RCT \\ Centres: 10 ( 5 in Germany, 5 in UK) \\ Start of enrolment: December 2002 (from clinical trial registry) \\ End of enrolment: March 2007 (from clinical trial registry) \\ Mean follow-up: 13.8 weeks \\ Run-in period: not reported
}

Participants

Inclusion criteria: "Patients were $\geq 21$ years of age and had the following characteristics: symptoms of breathlessness on exertion (based on patient questioning) with normal lung function at rest, an extrapolated maximum oxygen consumption (EMOC) and/or peak oxygen consumption $<85 \%$ of the age-corrected normal value on cardiopulmonary exercise testing, preserved systolic function (ejection fraction $\geq 40 \%$ ) with evidence of diastolic dysfunction on echocardiography ( $\geq 1$ of the following: abnormal flow propagation velocity, prolongation of isovolumic relaxation time, $\mathrm{E} / \mathrm{A}$ ratio reversal, and abnormal $\mathrm{E}$ deceleration time), and ability to exercise for $\geq 3$ min on a treadmill."

Exclusion criteria: "Uncontrolled hypertension (sitting systolic blood pressure $>160 \mathrm{mmHg}$ or sitting diastolic blood pressure $>100 \mathrm{mmHg}$ ) Presence of clinically significant asthma or chronic obstructive pulmonary disease Abnormal lung function (forced expiratory volume in $1 \mathrm{~s}$ [FEV1]/ forced vital capacity $[\mathrm{FVC}]$ ratio $<75 \%$ ) Treatment with $\geq 2$ bronchodilators Exercise limiting symptomatic angina Haemodynamically significant cardiac valvular disease Documented evidence of systolic heart failure (ejection fraction $<40 \%$, fractional shortening $<25 \%$ ) Uncontrolled atrial fibrillation (> 100 b.p.m. at rest) History of myocardial infarction, percutaneous transluminal coronary angioplasty, or coronary artery bypass within the previous 3 months Use of ARBs within the previous 1 month"

Randomised (N): 152 (70 intervention, 82 control)

Withdrawn (N): for reasons other than death 5 (4 intervention ( $N=2$ adverse events, $N=1$ protocol violation, $\mathrm{N}=1$ withdrew consent), 1 control ( $\mathrm{N}=1$ protocol violation))

Lost to follow-up (N): 0

Analysed (N): 152 (70 intervention, 82 control), except QoL: 67 intervention, 82 placebo

Age (years, mean, SD): intervention: 61.0, 11.5; control: 63.1, 10.3

Sex (\% men): intervention: 50; control: 50

Ethnicity (\%): intervention: Caucasian: 95.6, Other: 4.4 , control: Caucasian: 93.9, other: 6.1

Systolic blood pressure not reported

Heart rate not reported

BMI (mean, SD): intervention: 31.0, 4.7; control: 29.3, 5.3

Serum creatinine not reported

B-type natriuretic peptide (pg/mL): intervention: 93.2, 80.2; control: 120.3, 119.5

NT pro B-type natriuretic peptide $(\mathrm{pg} / \mathrm{mL})$ : not reported

LVEF (\%, mean, SD): intervention: 70.48, 11.43; control: 71.52, 12.08

NYHA class not reported

Hypertension (\%): intervention: 92.2; control: 89.0

Diabetes (\%): intervention: 22.1 ; control: 14.6

Atrial fibrillation (\%): intervention: 16.2; control: 9.8 
Parthasarathy 2009 (Continued)

Hospitalisation for heart failure: not reported

Coronary heart disease (\%): not reported

Stroke (\%): not reported

Diuretic (\%): not reported

Digoxin (\%): not reported

Beta-blocker (\%): intervention: 33.8; control: 34.1

ACEI (\%): intervention: 41.2; control: 37.8

ARB (\%): study drug

MRA (\%): not reported

Interventions

Intervention: valsartan. $80 \mathrm{mg}$ once daily. "Study medication was force-titrated between days 5 and 14 (Visit 3) to valsartan $160 \mathrm{mg}$ daily or matching placebo, and between days 10 and 28 (Visit 4) to valsar$\tan 320 \mathrm{mg}$ daily or matching placebo. Up-titration occurred provided the current dose was adequately tolerated. Down-titration occurred for any of the following: evidence of persistent symptomatic hypotension, systolic blood pressure $<100 \mathrm{mmHg}$ or decrease of $>40 \mathrm{~mm} \mathrm{Hg}$ from baseline, creatinine increase of $>50 \%$ from baseline, or if the investigators judged the given dose level as potentially harmful to the patient. A safety evaluation was performed between days 15 and 42 (Visit 5). After the dose-titration period, patients received their maximum tolerated dose through to the end of the study at week 14 (+7 days) (Visit 6$). "$

Comparator: matching placebo

Concomitant medication: "Use of other ARBs as concomitant medication was prohibited, but other background medications (e.g. diuretics, calcium channel blockers) were allowed and continued throughout the study. Angiotensin-converting enzyme inhibitors and beta-blockers were permitted, although therapy was to be maintained at the same level throughout the study and no new treatment with one of these drugs was permitted during the trial."

\section{Outcomes}

Planned: unclear

Reported: exercise time, neurohormone levels, echocardiographic parameters, QoL, adverse events

Notes

Response to email enquiring for further details received on 2 December 2017: confirmed that no outcome data are available for heart failure hospitalisation and hyperkalaemia and provided number of centres.

\section{Risk of bias}

Bias Authors' judgement Support for judgement

Random sequence genera- Unclear risk tion (selection bias)

"Eligible patients were allocated to either the active treatment group or the placebo group according to a stratified randomization process in order to minimize the differences between study groups. Stratification was based on exercise test time at Visit 2 divided into sections of: 3-6 min, .6 min to 9 min, and .9 min, each stratum being randomized in blocks of 4 ."

No details on how the random sequence was generated.

\begin{tabular}{lll}
\hline $\begin{array}{l}\text { Allocation concealment } \\
\text { (selection bias) }\end{array}$ & Unclear risk & not reported \\
\hline $\begin{array}{l}\text { Blinding of participants } \\
\text { and personnel (perfor- } \\
\text { mance bias) }\end{array}$ & Low risk & "double-blind" but not specified \\
\hline
\end{tabular}

Beta-blockers and inhibitors of the renin-angiotensin aldosterone system for chronic heart failure with preserved ejection fraction (Review)

Copyright @ 2018 The Cochrane Collaboration. Published by John Wiley \& Sons, Ltd. 
Parthasarathy 2009 (Continued)

All outcomes
"To maintain blinding, valsartan and placebo capsules were identical in appearance."

Blinding of outcome as- $\quad$ Unclear risk not reported
sessment (detection bias)

$\begin{array}{ll}\text { Incomplete outcome data } & \text { Low risk } \\ \text { (attrition bias) } & \text { ITT, higher withdrawals in intervention group (5.7\%) compared to control } \\ \text { All outcomes } & (1.2 \%)\end{array}$

\begin{tabular}{|c|c|c|}
\hline $\begin{array}{l}\text { Selective reporting (re- } \\
\text { porting bias) }\end{array}$ & Unclear risk & $\begin{array}{l}\text { unable to assess, unaware of published protocol and clinical trial register en- } \\
\text { try (Sept 2005) after planned study start (Dec 2002) }\end{array}$ \\
\hline
\end{tabular}

Other bias Low risk "H.K.P. and B.P. have no conflicts of interest; C.D.A., M.W., and P.B. remain in
the employ of Novartis Pharma and have no other conflicts of interest; A.D.S. received one honorarium ( $£ 1000$ ) from Novartis for intellectual input to the rationale and the design of the study; T.M.MacD: competing interests statement Nov 2008: my department has had research grants from GSK, Aventis, Novartis, AstraZeneca, BMS, Bohringer Ingelheim, Pfizer, and Novartis, I am or have been the principal investigator on trials paid for by Pfizer and Novartis, I have been paid Consulting fees by Pfizer, Novartis, Kaiser Permanante, Takeda, Recordati, Quintiles, and Speedel."

"The study was funded by Novartis."

\section{PEP-CHF}

Methods Study design: RCT

Centres: 53 centres (Bulgaria (3), Czech Republic (5), Hungary (10), Ireland (1), Poland (26), Russia (1), Slovakia (2), and the UK (5))

Start of enrolment: 2000

End of enrolment: 2003

Mean follow-up: mean follow-up 26.2 months (range, excluding deaths 12.0-54.2)

Run-in period: "A 24-h open label run in phase, during which patients will receive a single 2-mg dose of perindopril"

Participants

Inclusion criteria: "Patients had to be aged $\geq 70$ years and treated with diuretics for a clinical diagnosis of CHF due to LV diastolic dysfunction as defined below and to have had a cardiovascular hospitalization within the previous 6 months. Patients had to be able to walk without the aid of another person in order to exclude very frail patients who might not respond to any treatment.""Patients had to be aged 70 years and treated with diuretics for a clinical diagnosis of CHF due to LV diastolic dysfunction as defined below and to have had a cardiovascular hospitalization within the previous 6 months. Patients had to be able to walk without the aid of another person in order to exclude very frail patients who might not respond to any treatment." "As there are no widely agreed criteria for the diagnosis of diastolic heart failure, at least three out of nine clinical and at least two out of four additional echocardiographic criteria were required. Clinical criteria were: exertional breathlessness; orthopnoea or paroxysmal nocturnal dyspnoea; ankle swelling; improved breathlessness with diuretic therapy; increased jugular venous pressure; prior episode of clinical pulmonary oedema; prior MI; cardiothoracic ratio > 0.55 ; and previous radiological pulmonary oedema. Echocardiographic criteria were: an LV wall motion index of 1.4-1.6 inclusive, roughly equivalent to an LVEF fraction between 40 and 50\%, since abnormal diastolic dysfunction is often associated with some impairment of systolic function; a left atrial diameter $>25 \mathrm{~mm} / \mathrm{m}^{2}$ body surface area or $>40 \mathrm{~mm}$ because chronic elevation of LV filling pressure should lead to atrial dilatation; an interventricular septum or posterior LV wall $\geq 12 \mathrm{~mm}$ in thickness suggesting

Beta-blockers and inhibitors of the renin-angiotensin aldosterone system for chronic heart failure with preserved ejection fraction 
hypertrophy, a common cause of impaired diastolic function or, finally, evidence of impaired LV filling by at least one of the criteria recommended by the European Society of Cardiology Study Group on Diastolic Heart Failure. These included an E/A ratio $<0.5$ or deceleration time of $>280 \mathrm{~ms}$ from the mitral inflow pattern or an isovolumic relaxation time of $>105 \mathrm{~ms}$. These criteria effectively exclude patients with atrial fibrillation (AF) and therefore, in a protocol modification early in the course of the study, this arrhythmia was counted as equivalent to evidence of impaired LV filling by Doppler."

Exclusion criteria: "Patients with a wall motion index of $<1.4$, roughly equivalent to an LVEF of $40 \%$, were excluded." "Important exclusion criteria were haemodynamically significant valve disease, stroke within the previous month, sitting systolic arterial pressure $<100 \mathrm{mmHg}$, serum creatinine $>200 \mathrm{mmol} /$ $\mathrm{L}$ or potassium $>5.4 \mathrm{mmol} / \mathrm{L}$, history of ACE-inhibitor intolerance or use of an ACE-inhibitor or angiotensin receptor blocker within the previous week, potassium-sparing diuretics (other than low-dose spironolactone), or potassium supplements."

Randomised (N): 850 (424 intervention, 426 control)

Withdrawn (N): due to serious adverse events 13 (9 intervention, 4 control)

Lost to follow-up (N): 4 (4 intervention, 0 control)

Analysed (N): 846 (420 intervention, 426 control)

Age (years, median, IQR): intervention: 75, 72-79; control:75, 72-79

Sex (\% men): intervention: 46; control: 43

Ethnicity (\%): not reported

Systolic blood pressure (mmHg, median, IQR): intervention: 138, 128-150; control: 140, 129-150

Heart rate (beats/min, median, IQR): intervention: 74, 66 to 81; control: 73, 66 to 82

BMI (median, IQR): intervention: 27.5, 25.1 to 30.0; control: 27.6, 25.3 to 30.7

Serum creatinine (mg/dL, median, IQR, converted from umol/L using http://www.endmemo.com/medical/unitconvert/Creatinine.php): intervention: 1.07, 0.92-1.24; control: 1.10, 0.95-1.26

B-type natriuretic peptide $(\mathrm{pg} / \mathrm{mL})$ : not reported

NT pro B-type natriuretic peptide (pg/mL): intervention: 335, 160-1014 (for subgroup $\mathrm{n}=191$ ); control: 453, 206-1045 (for subgroup $n=184$ )

LVEF (\%, median, IQR): intervention: 65, 56- 66; control: 64, 56- 66

NYHA class I/II (\%): intervention: 77; control: 74

NYHA class III/IV (\%): intervention: 23; control: 26

Hypertension (\%): intervention: 79; control: 79

Diabetes (\%): intervention: 21 ; control: 20

Atrial fibrillation (\%): intervention: 19; control: 22

Hospitalisation for heart failure: not reported

Coronary heart disease (\%): intervention: 27 ; control: 26

Stroke not reported

Diuretic (\%); intervention: loop: 47, thiazide 54, low dose spironolactone 9; control: loop: 44, thiazide 55 , low dose spironolactone 11

Digoxin (\%): intervention: 11; control: 13

Beta-blocker (\%): intervention: 55; control: 54 
PEP-CHF (Continued)

ACEI: study drug

ARB not reported

MRA (\%): intervention: 9; control: 11

Interventions

Intervention: perindopril. "Patients were reviewed weekly for the first 5 weeks to ensure that treatment was tolerated and to check serum potassium and creatinine. The dose of perindopril was increased to $4 \mathrm{mg}$ once daily at the second follow-up visit if no clinical contraindication, such as hypotension or worsening renal function existed. Study medication was reduced or discontinued if serum creatinine rose to $>250 \mathrm{mmol} / \mathrm{L}$ or by $>50 \mathrm{mmol} / \mathrm{L}$ from baseline or potassium rose to $>5.5 \mathrm{mmol} / \mathrm{L}$. $\mathrm{Pa}$ tients were reviewed at 8,12 , and every 12 weeks thereafter until 1 year follow-up, then according to the investigator's judgment until the end of the study."

Comparator: placebo

Concomitant medication: not reported

Outcomes

Planned: "The primary end-point of this study will be the time to first occurrence of the combined endpoint of total mortality and unplanned heart failure related hospitalisation."

"Secondary

1. Death all causes

2. Death or worsening symptoms and/or signs of $\mathrm{CHF}$ requiring hospitalisation or an increase in diuretic treatment for $\mathrm{CHF}$ of $>40 \mathrm{mg} /$ day of frusemide compared to baseline or equivalent. This will be a time to first event analysis.

3. Cardiovascular mortality.

4. Number of days alive and out of hospital.

5. Number of days alive and not in hospital for cardiovascular reasons including CHF

6. QoL questionnaire change from baseline to 1 year.

7. CHF symptom score change from baseline to 1 year.

8. NYHA heart failure score change from baseline to 1 year." (Cleland 1999)

Reported: primary outcome, all-cause mortality, cardiovascular mortality, HF hospitalisation, days in hospital for cardiovascular reasons, days in hospital for any reason, NYHA class, 6-min walk distance, plasma concentrations of NTproBNP, cardiovascular death or unplanned HF related hospitalisation, stroke, acute coronary syndrome, blood pressure, serum potassium and creatinine

Planned but not reported: QoL Emailed investigators. No response.

\section{Risk of bias}

\begin{tabular}{lll}
\hline Bias & Authors' judgement & Support for judgement \\
\hline $\begin{array}{l}\text { Random sequence genera- } \\
\text { tion (selection bias) }\end{array}$ & Low risk & $\begin{array}{l}\text { "patients were randomly assigned from a computer-generated list in blocks of } \\
\text { four within treatment centres" }\end{array}$ \\
\hline $\begin{array}{l}\text { Allocation concealment } \\
\text { (selection bias) }\end{array}$ & Low risk & $\begin{array}{l}\text { "through a centrally administered process, concealed from the study investi- } \\
\text { gators." }\end{array}$ \\
\hline
\end{tabular}




\section{PEP-CHF (Continued)}

Blinding of participants and personnel (perfor-

"The study medication was provided in externally indistinguishable tablets." mance bias)

All outcomes

\begin{tabular}{ll}
\hline $\begin{array}{l}\text { Blinding of outcome as- } \\
\text { sessment (detection bias) }\end{array}$ & Low risk
\end{tabular} $\begin{aligned} & \text { "Potential classifying events were independently classified by MT and JGFC, } \\
& \text { All outcomes }\end{aligned} \quad$\begin{tabular}{l} 
blind to treatment allocation." \\
\hline
\end{tabular}

\begin{tabular}{|c|c|c|}
\hline $\begin{array}{l}\text { Incomplete outcome data } \\
\text { (attrition bias) } \\
\text { All outcomes }\end{array}$ & Low risk & $4 / 850$ lost to follow up \\
\hline $\begin{array}{l}\text { Selective reporting (re- } \\
\text { porting bias) }\end{array}$ & Low risk & $\begin{array}{l}\text { Primary outcomes reported, but not all secondary outcomes reported as } \\
\text { planned (eg QoL) }\end{array}$ \\
\hline Other bias & Low risk & $\begin{array}{l}\text { "Servier funded the trial and provided site monitors for source data verifica- } \\
\text { tion. The sponsor had access to the database and participated in the analysis } \\
\text { under the supervision of an independent statistician (NF). The Steering Com- } \\
\text { mittee wrote the manuscript. Servier representatives commented on it prior to } \\
\text { submission." }\end{array}$ \\
\hline
\end{tabular}

\section{RAAM-PEF}

Methods Study design: individual, placebo-controlled, double-blind RCT

Centres: 1 medical centre, USA

Start of study: August 2004

End of Study: October 2007

Follow-up: 24 weeks

Run-in period: "2-week open label period of eplerenone $25 \mathrm{mg}$ daily to establish tolerability"

Participants

Inclusion criteria: "All patients were defined as having HFpEF based on the presence of all the following criteria: 1) Clinical HF for $\geq 2$ months before the screening visit with New York Heart Association (NYHA) functional Class II or III HF symptoms at enrollment; 2) left ventricular ejection fraction $\geq 50 \%$ (by echocardiography, radionuclide ventriculography, or contrast angiography) within 2 months of screening; and 3) B-type natriuretic peptide (BNP) levels $\geq 100 \mathrm{pg} / \mathrm{mL}$ within 2 months of screening. Other inclusion criteria included age $\geq 18$ years, systolic blood pressure $\leq 150$, and diastolic blood pressure $\leq 95$ $\mathrm{mm} \mathrm{Hg}$ for 4 weeks before and at enrollment, ability to walk $\geq 50 \mathrm{~m}$, current use of angiotensin-converting enzyme (ACE) inhibitors or angiotensin receptor blockers (ARBs), if tolerated, for at least 4 weeks before enrollment. Patients were expected to be euvolemic on clinical examination or all attempts were made to achieve euvolemia with change in diuretic doses prior to enrollment into the study."

Exclusion criteria: "Exclusion criteria included the need for eplerenone or spironolactone for treatment of other comorbid illnesses (eg, ascites); hepatic impairment; serum creatinine $>2.5 \mathrm{mg} / \mathrm{dL}$ or serum potassium $>5.0 \mathrm{mEq} / \mathrm{L}$; prior intolerance to eplerenone or spironolactone; significant valvular heart disease, pericardial disease or severe chronic lung disease; patients with technically inadequate echocardiographic windows; patients with severe mitral annular calcification; unstable angina or acute myocardial infarction within 4 weeks before enrollment; severe peripheral vascular disease with claudication or other physical conditions limiting the distance walked; pregnant or lactating females; history of active alcohol or substance abuse or history of repeated noncompliance; history of cancer within 3 years (other than resected cutaneous basal or squamous cell carcinoma); and participation in any other drug trial within 30 days before enrollment."

Randomised (N): 46 (23 intervention, 23 control) 


\section{Withdrawn (N): 0}

Lost to follow-up (N): 2 (2 intervention (relocation))

Analysed (N): 44 (21 intervention, 23 control)

Age (years, mean, SD): intervention: 72.2, 9.8; control: 68.7, 9.1

Sex (\% men): intervention: 95.2; control: 91.3

Ethnicity (\%): not reported

Systolic blood pressure (mmHg, mean, SD): intervention: 129.7, 12.4; control: 130.6, 10.7

Heart rate (beats/min, mean, SD): intervention: 65.0, 9.3; control: 63.0, 12.1

BMI (mean, SD): intervention: 30.1, 6.1; control: 34.6, 5.8

Serum creatinine (mg/dL, mean, SD): intervention: 1.62, 0.50; control: 1.43, 0.51

B-type natriuretic peptide (pg/mL): intervention: 254.9, 163.0; control: 283.5, 211.6

NT pro B-type natriuretic peptide $(\mathrm{pg} / \mathrm{mL})$ : not reported

LVEF (\%, median, IQR): intervention: 62.1, 5.0; control: 62.5, 7.5

NYHA class I (\%): 0

NYHA class II (\%): intervention: 66.7; control: 52.2

NYHA class III (\%): intervention: 33.3; control: 47.8

NYHA class IV (\%): 0

Hypertension (\%): 100

Diabetes (\%): intervention: 61.9; control: 60.9

Atrial fibrillation (\%): intervention: 14.3; control: 13.0

Hospitalisation for heart failure (\%): intervention: 42.9; control: 60.9

Coronary heart disease (\%): intervention: 66.7 ; control: 47.8

Stroke (\%): nor reported

Diuretic (\%); intervention: 95.2; control: 100

Digoxin (\%): not reported

Beta-blocker (\%): intervention: 76.2; control: 82.6

ACEI or ARB (\%): intervention: 95.2; control: 100

MRA (\%): study drug

Intervention: eplerenone. "After randomization, patients received study drug at a dose of $25 \mathrm{mg}$ daily for 2 weeks followed by $50 \mathrm{mg}$ daily for 22 weeks, if tolerated" "Study drug dose was adjusted according to the following algorithm. If the serum $\mathrm{K}+$ was $\geq 5.0 \mathrm{mEq} / \mathrm{L}$ but $<5.5 \mathrm{mEq} / \mathrm{L}$, the dose of eplerenone was not increased. If the level was $\geq 5.5 \mathrm{but}<6.0 \mathrm{mEq} / \mathrm{L}$, the dose of eplerenone was reduced to half. If the serum potassium was $\geq 6.0 \mathrm{mEq} / \mathrm{L}$ eplerenone was stopped, at least transiently. If an underlying condition that was correctable was identified, the medication could be restarted at the lowest dose once the serum $\mathrm{K}+$ was $<5.0 \mathrm{mEq} / \mathrm{L}$. If no correctable cause was identified for the serum potassium $\geq$ $6.0 \mathrm{mEq} / \mathrm{L}$, eplerenone was discontinued permanently and serum $\mathrm{K}+$ was followed with adjustments in other medications as indicated. Oral potassium supplements were allowed if the serum potassium was $<4.0 \mathrm{mEq} / \mathrm{L}$ after the study drug was started." 
RAAM-PEF (Continued)

Comparator: matching placebo

Concomitant medication: "Potassium supplements were stopped when eplerenone was initiated."

Outcomes $\quad$ Planned: in clinical trial register: all of the below, except NYHA class, hospitalisation and mortality

Reported: primary: 6MWD. Secondary: echocardiographic measures of diastolic dysfunction, biomarkers including markers of collagen turnover and B-type natriuretic peptide, HF-related quality of life measured by the Kansas City Cardiomyopathy Questionnaire, NYHA class, hospitalisation, mortality

Notes

\section{Risk of bias}

\begin{tabular}{|c|c|c|}
\hline Bias & Authors' judgement & Support for judgement \\
\hline $\begin{array}{l}\text { Random sequence genera- } \\
\text { tion (selection bias) }\end{array}$ & Unclear risk & not reported \\
\hline $\begin{array}{l}\text { Allocation concealment } \\
\text { (selection bias) }\end{array}$ & Unclear risk & not reported \\
\hline $\begin{array}{l}\text { Blinding of participants } \\
\text { and personnel (perfor- } \\
\text { mance bias) } \\
\text { All outcomes }\end{array}$ & Low risk & "double-blind" but no details \\
\hline
\end{tabular}

Blinding of outcome as- Low risk "all end points were evaluated blinded to treatment allocation"
sessment (detection bias)

All outcomes

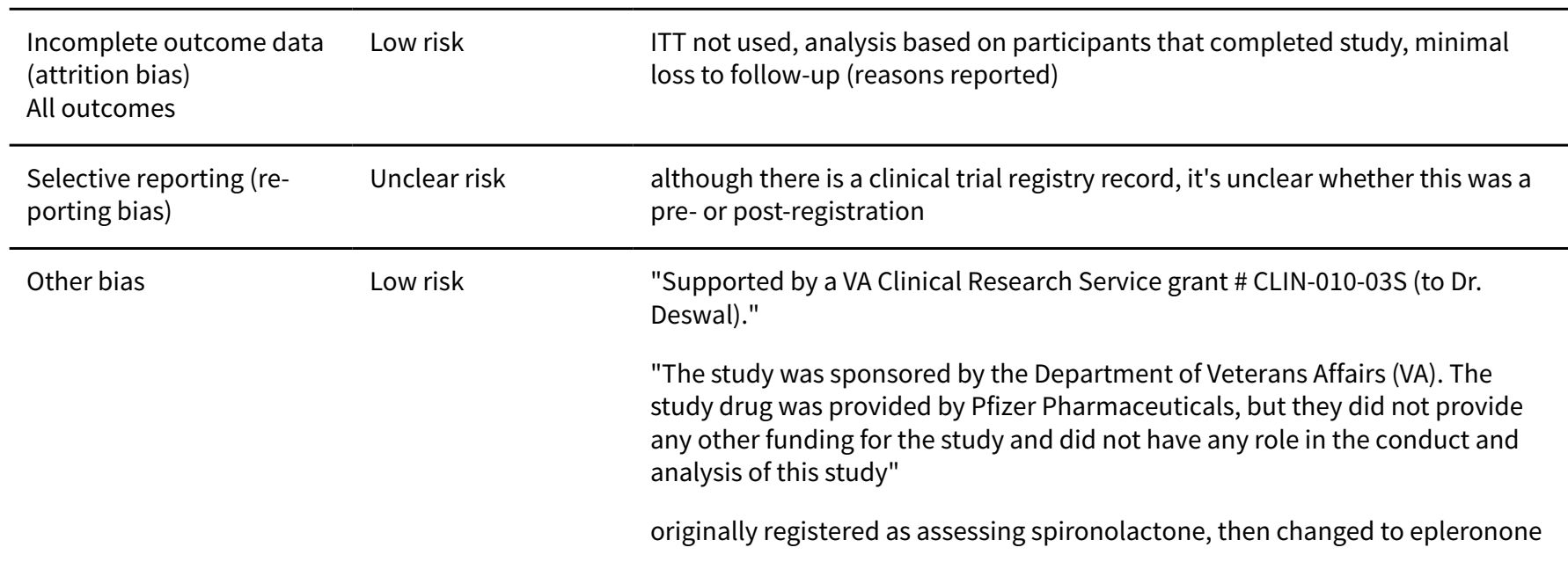

Sahoo 2016

Methods Study design: RCT

Centres: 1 , India

Start of enrolment: not reported

End of enrolment: not reported 
Sahoo 2016 (Continued)

\section{Mean follow-up: 3-6 months}

Run-in period: not reported

Participants
Inclusion criteria: "Patients with moderate or severe MR on color flow Doppler, LVEF $\geq 55 \%$, and LV end-systolic dimension $<40 \mathrm{~mm}$ were included"

Exclusion criteria: "Patients with NYHA class IV symptoms, known coronary artery disease, significant other valvular disease, serum creatinine $>2.5 \mathrm{mg} / \mathrm{dL}$, and hypertension were excluded"

Randomised (N): 100 (48 intervention, 52 control)

Withdrawn not reported

Lost to follow-up not reported

Analysed (N): at 3 months: 100 (48 intervention, 52 control); at 6 months: 75 (39 intervention, 36 control)

Age (years, mean, SD): intervention: 30.24, 12.76; control: 29.6, 15.58

Sex (\% men): intervention: 35.6 ; control: 22.7

Ethnicity (\%): not reported

Systolic blood pressure (mmHg, mean, SD): intervention: 125, 10.1; control: 124.4, 7.4

Heart rate (beats/min, mean, SD): intervention: 90.1, 11.78; control: 88.5, 18.12

BMI: intervention: 21.04, 4.74; control: 19.04, 4.7

Serum creatinine not reported

B-type natriuretic peptide (pg/mL): intervention: 194, 178.5; control: 166, 165.7

NT pro B-type natriuretic peptide $(\mathrm{pg} / \mathrm{mL})$ : not reported

LVEF (\%, mean, SD): intervention: $62.5,6.5$; control: $61.4,6.9$

NYHA class: "most patients were in NYHA class II (77\%) while $23 \%$ were in NYHA class III"

Hypertension (\%): intervention: 61.1 ; control: 62.3

Diabetes (\%): intervention: 26.9; control: 25.3

Atrial fibrillation (\%): intervention: 33.8; control: 35.5

Hospitalisation for heart failure: not reported

Coronary heart disease (\%): intervention: 68.9; control: 67.6

Stroke (\%): intervention: 0.1 ; control: 0

Diuretic (\%): 92

Digoxin (\%): 33

Beta-blocker (\%): study drug

ACEI (\%): 58

ARB (\%): not reported

MRA (\%): not reported 
Sahoo 2016 (Continued)

Interventions
Intervention: metoprolol succinate. "initiated at 12.5-25 mg/day and titrated as tolerated at 2-week intervals to a maximum of $100 \mathrm{mg} /$ day. Prior to each escalation, care was taken to ensure that resting heart rate was > $60 \mathrm{bpm}$ and systolic BP > $100 \mathrm{~mm} \mathrm{Hg"}$

Comparator: placebo

Concomitant medication: "in addition to ongoing therapy"
Planned: unclear as we did not identify a published protocol or clinical trial registry entry

Reported: withdrawals due to adverse events, echocardiographic outcomes, blood pressure, MR grade, NYHA class

\section{Notes}

\section{Risk of bias}

\begin{tabular}{lll}
\hline Bias & Authors' judgement & Support for judgement \\
\hline $\begin{array}{l}\text { Random sequence genera- } \\
\text { tion (selection bias) }\end{array}$ & Low risk & "by a computerized random number generating protocol" \\
\hline $\begin{array}{l}\text { Allocation concealment } \\
\text { (selection bias) }\end{array}$ & Unclear risk & not reported \\
\hline $\begin{array}{l}\text { Blinding of participants } \\
\begin{array}{l}\text { and personnel (perfor- } \\
\text { mance bias) }\end{array}\end{array}$ & Unclear risk & not reported \\
All outcomes & \\
\hline
\end{tabular}

\begin{tabular}{|c|c|c|}
\hline $\begin{array}{l}\text { Blinding of outcome as- } \\
\text { sessment (detection bias) } \\
\text { All outcomes }\end{array}$ & Low risk & $\begin{array}{l}\text { "Detailed echocardiography [...] was performed by two operators who were } \\
\text { blinded to the treatment protocol." }\end{array}$ \\
\hline
\end{tabular}

\begin{tabular}{lll}
\hline $\begin{array}{l}\text { Incomplete outcome data } \\
\text { (attrition bias) } \\
\text { All outcomes }\end{array}$ & Unclear risk & unclear loss-to-follow up of 25 participants at 6 months as no reasons given \\
\hline $\begin{array}{l}\text { Selective reporting (re- } \\
\text { porting bias) }\end{array}$ & Unclear risk & unable to assess \\
\hline Other bias & Unclear risk & "The authors declare no conflict of interest" \\
& no funding source reported \\
\hline
\end{tabular}

\section{SENIORS}

\section{Methods}

\section{Study design: RCT}

Centres: multi-centre, international (Czech Republic, Hungary, Italy, Ukraine, UK, France, Germany, Romania, Spain, Switzerland, The Netherlands)

Start of enrolment: September 2000

End of enrolment: December 2002

Mean follow-up: 21 months 


\section{Run-in period: no}

Participants
Inclusion criteria: "To be eligible, patients had to be age $\geq 70$ years, provide written informed consent, and have a clinical history of chronic HF with at least 1 of the following features: documented hospital admission within the previous 12 months with a discharge diagnosis of congestive HF or documented LVEF $\leq 35 \%$ within the previous 6 months. "

Exclusion criteria: "The main exclusion criteria were new drug therapy for heart failure in the 6 weeks prior to randomization, any change in cardiovascular drug therapy in the 2 weeks prior to randomization, heart failure due primarily to uncorrected valvular heart disease, contraindication or previous intolerance to beta-blockers (e.g. heart rate $<60$ beats/min or systolic blood pressure $<90 \mathrm{mmHg}$ ), current use of beta-blockers, significant hepatic or renal dysfunction, cerebrovascular accidents within the previous 3 months, and being on a waiting list for percutaneous coronary intervention or cardiac surgery or other major medical conditions that may have reduced survival during the period of the study."

Randomised (N): 2128 (1067 intervention, 1061 control); subgroup of interest: 643 (nebivolol $N=320$, placebo $\mathrm{N}=323$ )

Withdrawn not reported

Lost to follow-up (N): 37 (16 intervention, 21 control)

Analysed (N): 2128 (1067 intervention, 1061 control)

Age (years, mean, SD): intervention: 76.1, 4.8; control: 76.1, 4.6

Sex (\% men): intervention: 61.6 ; control: 64.7

Ethnicity (\%): not reported

Systolic blood pressure (mmHg, mean, SD): intervention: 138.6, 20.1; control: 139.5, 21.1

Heart rate (beats/min, mean, SD): intervention: 79.2, 13.6; control: 78.9, 13.7

BMI: not reported

Serum creatinine $(\mathrm{mg} / \mathrm{dL} \text {, mean, } \mathrm{SD})^{\star}$ : intervention: 1.2, 0.4; control: 1.2, 0.4

B-type natriuretic peptide $(\mathrm{pg} / \mathrm{mL})$ : not reported

NT pro B-type natriuretic peptide $(\mathrm{pg} / \mathrm{mL})$ : not reported

LVEF (\%, mean, SD): intervention: 36, 13; control: 36, 12

NYHA class I (\%): intervention: 3.0; control: 2.7

NYHA class II (\%): intervention: 56.5; control: 56.3

NYHA class III (\%): intervention: 38.7 ; control: 38.7

NYHA class IV (\%): intervention: 1.8; control: 2.3

Hypertension (\%): intervention: 61.1 ; control: 62.3

Diabetes (\%): intervention: 26.9; control: 25.3

Atrial fibrillation (\%): intervention: 33.8; control: 35.5

Hospitalisation for heart failure: not reported

Coronary heart disease (\%): intervention: 68.9; control: 67.6

Stroke (\%): intervention: 0.1 ; control: 0

Diuretic (\%); intervention: 85.8; control: 85.5 
Digoxin (\%): not reported

Beta-blocker (\%): study drug

ACEI (\%): intervention: 81.7 ; control: 82.6

ARB (\%): intervention: 6.2; control: 7.1

MRA (\%): intervention: 28.8; control: 26.4

Interventions

Intervention: nebivolol

"Nebivolol or placebo tablets were provided in identical packaging and tablet appearance. The initial dose was $1.25 \mathrm{mg}$ once daily, and, if tolerated, this was increased to 2.5 and $5 \mathrm{mg}$, respectively, every 12 weeks, reaching a target of $10 \mathrm{mg}$ once daily over a maximum of 16 weeks."

Comparator: placebo

Concomitant medication: exclusion criteria: current use of beta blockers

\begin{tabular}{ll}
\hline Outcomes & Planned: planned in protocol (Shibata 2002): primary: all cause mortality and cardiovascular hospital \\
admissions (time to first event). Secondary: all cause mortality, composite of all cause mortality or all \\
cause hospital admissions, cardiovascular hospital admissions, cardiovascular mortality, functional ca- \\
pacity by NYHA class, functional capacity by 6 min walk test \\
Reported: reported: compliance to treatment, haemodynamics, death or cardiovascular hospital ad- \\
mission, all cause mortality, cardiovascular hospital admissions, total mortality, cardiovascular mortal- \\
ity, all cause hospitalisation
\end{tabular}

\section{Risk of bias}

\begin{tabular}{|c|c|c|}
\hline Bias & Authors' judgement & Support for judgement \\
\hline $\begin{array}{l}\text { Random sequence genera- } \\
\text { tion (selection bias) }\end{array}$ & Low risk & $\begin{array}{l}\text { "Randomization to nebivolol or placebo on a 1:1 basis was carried out by tele- } \\
\text { phone call to a central office (Clinical Data Care, Lund, Sweden)." }\end{array}$ \\
\hline $\begin{array}{l}\text { Allocation concealment } \\
\text { (selection bias) }\end{array}$ & Low risk & $\begin{array}{l}\text { "Patients were allocated a treatment number which corresponded to the ap- } \\
\text { propriate study treatment packs." }\end{array}$ \\
\hline $\begin{array}{l}\text { Blinding of participants } \\
\text { and personnel (perfor- } \\
\text { mance bias) } \\
\text { All outcomes }\end{array}$ & Low risk & "double-blind"; no details \\
\hline $\begin{array}{l}\text { Blinding of outcome as- } \\
\text { sessment (detection bias) } \\
\text { All outcomes }\end{array}$ & Unclear risk & not reported \\
\hline $\begin{array}{l}\text { Incomplete outcome data } \\
\text { (attrition bias) } \\
\text { All outcomes }\end{array}$ & Low risk & ITT used \\
\hline $\begin{array}{l}\text { Selective reporting (re- } \\
\text { porting bias) }\end{array}$ & Low risk & primary outcomes reported as planned \\
\hline
\end{tabular}

Beta-blockers and inhibitors of the renin-angiotensin aldosterone system for chronic heart failure with preserved ejection fraction 


\section{SENIORS (Continued)}

Other bias
Low risk

\begin{abstract}
"Dr. van Veldhuisen has received lecture fees from Menarini and was a member of the steering committee of the SENIORS trial. Dr. Cohen-Solal has received lecture and consultancy fees from Menarini, and was a member of the steering committee for the SENIORS trial and received lecture fees. Dr. Böhm has received speaker fees from Menarini. Dr. Anker has received speaking honoraria from Menarini Ricerche SpA, Roche, Merck, and Tanabe. Dr. Babalis's department has received a grant from Menarini. Dr. Coats has received honoraria from Menarini. Dr. Poole-Wilson has received honoraria from Menarini for speaking about the SENIORS trial. Dr. Flather has received research grant funding to his institution from Menarini and speaker fees from Menarini for lectures at scientific meetings and symposia. The original SENIORS trial was supported by Menarini Ricerche SpA, Italy. Funding for additional statistical analyses for the present study to the Clinical Trials and Evaluation Unit in London were obtained. All members of the Steering Committee of the SENIORS trial have received honoraria for speaking on aspects of heart failure and beta-blockers at meetings funded by companies in the pharmaceutical industry."
\end{abstract}

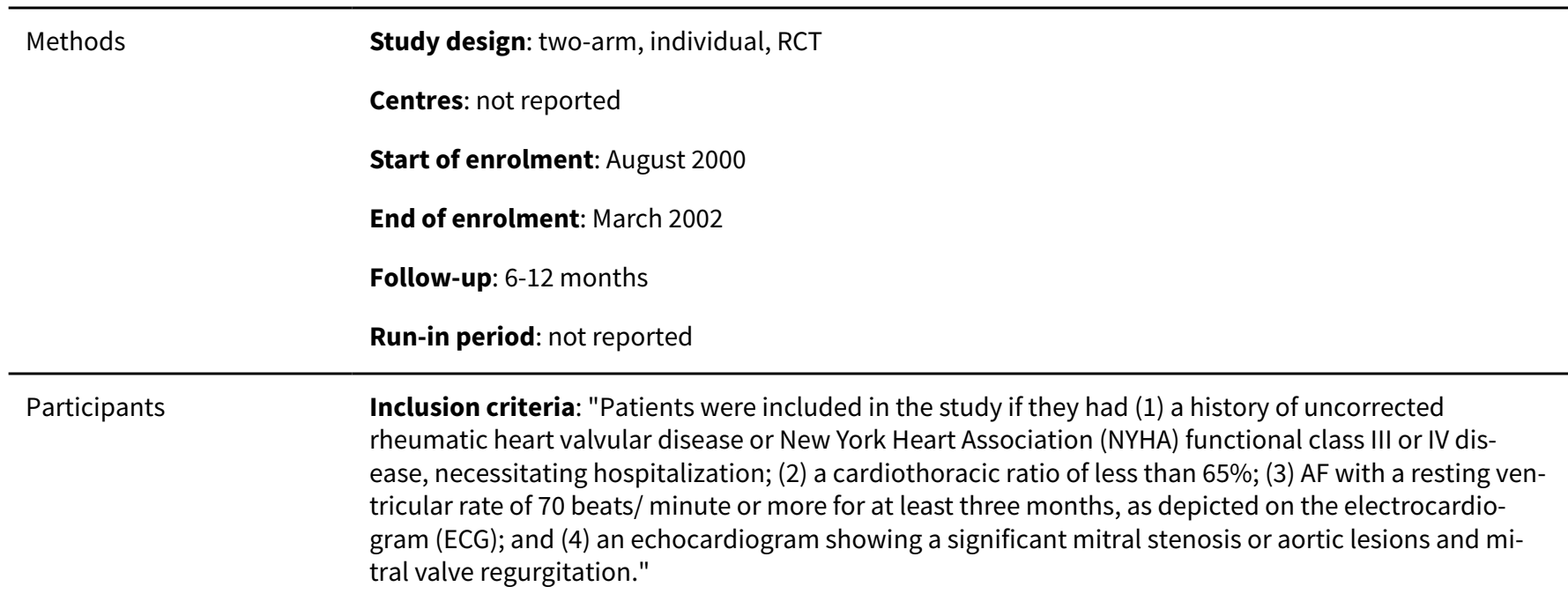

Exclusion criteria: "Patients were excluded from the study if they had uncorrected congenital heart disease, sustained ventricular tachycardia, severe liver and kidney dysfunction, chronic obstructive pulmonary disease, bronchial asthma, obstructive or restrictive cardiomyopathy or myocarditis, myocardial infarction, or unstable angina within the previous three months. Patients were also ineligible for enrollment if they required intensive care or concurrent intravenous therapy or if they were using calcium-channel blockers, class I or III antiarrhythmic drugs, monoamine oxidase (MAO)-inhibitors or beta2-agonists."

Randomised (N): 88 (not reported by treatment arm)

Withdrawn (N): 20 (did not complete the study) intervention: 11 (5 due to suspected adverse drug effects); control: 9

Lost to follow-up (N): 14 (excluded from the evaluation at follow-up - 7 had insufficient quality of echocardiography or difficulties with telephone-connection)

Analysed (N): 67 (intervention: 33; control: 34)

Age (years, mean, SD): intervention: $40.6,6.8$; control: $43.5,7.4$ 
Sex (\% male): intervention: 36; control: 35

Ethnicity not reported

Systolic blood pressure (mmHg, mean, SD): intervention: 115, 12; control: 121, 14

Heart rate not reported

BMI not reported

Serum creatinine not reported

B-type natriuretic peptide not reported

NT pro B-type natriuretic peptide not reported

LVEF not reported

NYHA class not reported

Hypertension not reported

Diabetes not reported

Atrial fibrillation not reported

Hospitalisation for heart failure: not reported

Coronary heart disease not reported

Stroke not reported

Diuretic not reported

Digoxin not reported

Beta-blocker not reported

ACEI not reported

ARB not reported

MRA not reported

Intervention: Bisoprolol, "All patients in the treatment group received bisoprolol at the initial dose of $1.25 \mathrm{mg} /$ day. The recommended maximal dose was $10 \mathrm{mg} /$ day. The dose schedule for titration of the selective beta1 blocker was gradually increased over three to five days, by two to three weeks, to as high as $10 \mathrm{mg} /$ day, with adjustments of diuretics and ACE-inhibitors, as clinically indicated."

Comparator: "control" (unspecified)

Concomitant medication: "At the discretion of the treating physicians, all patients were given concomitant therapy consisting of one of the following:

- diuretics, as required, to control fluid retention

- digoxin, extracted from Digitalis lanata

- ACE-inhibitors (or ARBs when ACE-inhibitors were not tolerated) unless there were specific contraindications

- nitrates, depending on the presence of valvular lesions and on blood pressure readings"

Planned: we did not identify a published protocol or pre-registered clinical trial register record

Notes

\section{Risk of bias}

Beta-blockers and inhibitors of the renin-angiotensin aldosterone system for chronic heart failure with preserved ejection fraction 
Shu 2005 (Continued)

Bias Authors' judgement Support for judgement

\begin{tabular}{|c|c|c|}
\hline $\begin{array}{l}\text { Random sequence genera- } \\
\text { tion (selection bias) }\end{array}$ & High risk & $\begin{array}{l}\text { "On the basis of admission sequence, patients were randomly assigned to a } \\
\text { treatment group or a control group" }\end{array}$ \\
\hline
\end{tabular}

Allocation concealment Unclear risk not reported

(selection bias)

Blinding of participants Unclear risk not reported
and personnel (perfor-
mance bias)
All outcomes

\begin{tabular}{|c|c|c|}
\hline $\begin{array}{l}\text { Blinding of outcome as- } \\
\text { sessment (detection bias) } \\
\text { All outcomes }\end{array}$ & Unclear risk & not reported \\
\hline $\begin{array}{l}\text { Incomplete outcome data } \\
\text { (attrition bias) } \\
\text { All outcomes }\end{array}$ & High risk & unclear reporting of withdrawals/loss-to-follow up \\
\hline $\begin{array}{l}\text { Selective reporting (re- } \\
\text { porting bias) }\end{array}$ & Unclear risk & unable to assess \\
\hline Other bias & Unclear risk & no funding source reported \\
\hline
\end{tabular}

Centres: not reported

Start of enrolment: not reported

End of enrolment: not reported

Follow-up: 3 months

Run-in period: not reported

Participants

Inclusion criteria: "in ambulatory patients (pts) with arterial hypertension and CHF and preserved systolic left ventricular (LV) function" "According including/exclusion criteria pts have had seated systolic $\mathrm{BP}(\mathrm{SBP}) \leq 160 \mathrm{mmHg}$ and diastolic $\mathrm{BP}(\mathrm{DBP}) \leq 95 \mathrm{mmHg}$ at randomization." "with stable symptomatic $\mathrm{CHF}$ (NYHA class II-III) as a result of arterial hypertension (AH) with preserved LV ejection fraction (EF) $\geq$ $50 \% "$

Exclusion criteria: not reported

Randomised (N): 726 (416 intervention, 310 control)

Withdrawn $(\mathrm{N})$ : not reported

Lost to follow-up (N): not reported

Analysed (N): not reported

Age not reported

Sex not reported

Beta-blockers and inhibitors of the renin-angiotensin aldosterone system for chronic heart failure with preserved ejection fraction 


\author{
Ethnicity not reported \\ Systolic blood pressure not reported \\ Heart rate not reported \\ BMI not reported \\ Serum creatinine not reported \\ B-type natriuretic peptide not reported \\ NT pro B-type natriuretic peptide not reported \\ LVEF not reported \\ NYHA class not reported \\ Hypertension not reported \\ Diabetes not reported \\ Atrial fibrillation not reported \\ Hospitalisation for heart failure: not reported \\ Coronary heart disease not reported \\ Stroke not reported \\ Diuretic not reported \\ Digoxin not reported \\ Beta-blocker not reported \\ ACEI not reported \\ ARB not reported \\ MRA not reported
}

Comparator: "conventional treatment, recommended for $\mathrm{CHF}$ [congestive heart failure] and $\mathrm{AH}$ [arterial hypertension] treatment"

Concomitant medication: not reported

\begin{tabular}{|c|c|c|}
\hline Outcomes & \multicolumn{2}{|c|}{$\begin{array}{l}\text { Planned: unclear } \\
\text { Reported: NYHA, 6MWD, clinical status, QoL (MLHFQ), 2D echocardiography, blood pressure }\end{array}$} \\
\hline Notes & \multicolumn{2}{|c|}{$\begin{array}{l}\text { Unable to find contact details to ask investigators for end scores for QoL, full publication of results and } \\
\text { mortality data. }\end{array}$} \\
\hline \multicolumn{3}{|l|}{ Risk of bias } \\
\hline Bias & Authors' judgement & Support for judgement \\
\hline $\begin{array}{l}\text { Random sequence genera- } \\
\text { tion (selection bias) }\end{array}$ & Unclear risk & "were randomly assigned" but no detail \\
\hline
\end{tabular}




\section{SNEGOVIK (Continued)}

Allocation concealment Unclear risk not reported
(selection bias)

Blinding of participants Unclear risk not reported
and personnel (perfor-
mance bias)
All outcomes

\begin{tabular}{lll}
\hline Blinding of outcome as- & Unclear risk & not reported \\
sessment (detection bias) &
\end{tabular}

All outcomes

\begin{tabular}{lll}
\hline $\begin{array}{l}\text { Incomplete outcome data } \\
\text { (attrition bias) } \\
\text { All outcomes }\end{array}$ & Unclear risk & not reported \\
\hline $\begin{array}{l}\text { Selective reporting (re- } \\
\text { porting bias) }\end{array}$ & Unclear risk & not reported \\
\hline Other bias & High risk & published conference abstract only \\
\hline
\end{tabular}

\section{STRUCTURE}

Study design: two-arm, individual,
Centres: Poland, "of each centre" su
Start of enrolment: Novemer 2011
End of enrolment: February 2015
Mean follow-up: 6 months
Run-in period: not reported

Participants

Inclusion criteria: "Patients who presented with signs or symptoms of HF (dyspnea, fatigue, and exercise intolerance) consistent with New York Heart Association functional class II or III, with preserved LV ejection fraction (> 50\%), and with evidence of diastolic dysfunction, were considered suitable for screening."

Exclusion criteria: "Exclusion criteria were: Atrial fibrillation or flutter Resting heart rate > 90 beats/ min Ischemic heart disease (defined by a positive coronary angiogram or inducible ischemia during exercise testing) Moderate or worse valvular heart disease Primary myocardial diseases Established or suspected pulmonary diseases (spirometry results $<80 \%$ of age- and sex-specific reference values) Hemoglobin $\leq 11 \mathrm{~g} / \mathrm{dl}$ Adrenocortical, hepatic, rheumatic, neoplastic, skeletal, thyroid, and renal diseases (including renal insufficiency with serum creatinine $>1.5 \mathrm{mg} / \mathrm{dl}[132 \mathrm{mmol} / \mathrm{l}]$ ) Hyperkalemia $>5.0$ $\mathrm{mmol} / \mathrm{l}$ Known intolerance or treatment with an MRA within the last 3 months Concomitant therapy with a potassium-sparing agent Current lithium use Pregnancy"

Randomised (N): 150 (75 intervention, 75 control)

Withdrawn $(\mathrm{N})$ : for reasons other than death 12 (7 intervention, 5 control)

Lost to follow-up (N): 7 (4 intervention, 3 control)

Analysed (N): 131 (64 intervention, 67 control)

Age (years, mean, SD): intervention: 66.3, 7.7; control: 67.6, 9.1 
Sex (\% men): intervention: 12; control: 19

Ethnicity (\%): not reported

Systolic blood pressure (mmHg, mean, SD): intervention: 131, 15; control: 130, 18

Heart rate (beats/min, mean, SD): intervention: 72, 10; control: 73, 10

BMI (mean, SD): intervention: 30.7, 4.5; control: 29.7, 4.6

Serum creatinine (mg/dL, mean, SD): intervention: 0.99, 0.20; control: 1.03, 0.24

B-type natriuretic peptide (pg/mL, median, IQR): intervention: 40 (26-63); control: 54 (27-99)

NT pro B-type natriuretic peptide $(\mathrm{pg} / \mathrm{mL})$ : not reported

LVEF (\%, median, IQR): intervention: 72.6 (70.4-74.8); control: 71.4 (69.2-73.5)

NYHA class I (\%): 0

NYHA class II (\%): intervention: 78; control: 79

NYHA class III (\%): intervention: 22; control: 21

NYHA class IV (\%): 0

Hypertension (\%): intervention: 92; control: 91

Diabetes (\%): intervention: 39; control: 40

Atrial fibrillation (\%): not reported

Hospitalisation for heart failure (\%): intervention: 17; control: 21

Coronary heart disease (\%): significant CAD excluded

Stroke (\%): not reported

Diuretic (\%); intervention: thiazides 54, loop 13; control: thiazides 46, loop 18

Digoxin (\%): not reported

Beta-blocker (\%): intervention: 78; control: 72

ACEI/ARB (\%): intervention: 97; control: 95

MRA (\%): study drug

Comparator: matching placebo (120 mg/day of microcellulose)

Concomitant medication: "Enrollees continued to receive other prescribed treatments throughout the study period."

\section{Outcomes}

Planned: unclear

Reported: "Coprimary outcomes were change at 6 months in exercise capacity (assessed by peak VO2) and exertional E/e' (reflecting LVFP). The secondary outcomes included change at follow-up in exercise blood pressure (BP) response and post-treatment global longitudinal myocardial deformation (GLS) measured by 2-dimensional strain." 
STRUCTURE (Continued)

Bias Authors' judgement Support for judgement

$\begin{array}{ll}\begin{array}{l}\text { Random sequence genera- } \\ \text { tion (selection bias) }\end{array} & \text { Unclear risk }\end{array} \begin{aligned} & \text { "The study coordinator, who was not involved in study procedures, was re- } \\ & \text { sponsible for drug randomization and dispensing" }\end{aligned}$

Allocation concealment Low risk "sequentially-numbered, opaque, sealed envelopes"

(selection bias)

$\begin{array}{ll}\text { Blinding of participants } \quad \text { Low risk } & \text { "Patients and investigators performing the assessments and data analysis } \\ \text { and personnel (perfor- } & \text { were blinded to group assignment." }\end{array}$

mance bias)

All outcomes

\begin{tabular}{|c|c|c|}
\hline $\begin{array}{l}\text { Blinding of outcome as- } \\
\text { sessment (detection bias) } \\
\text { All outcomes }\end{array}$ & Low risk & $\begin{array}{l}\text { "core laboratory in Hobart, Australia, for independent adjudication of the pri- } \\
\text { mary endpoint" }\end{array}$ \\
\hline $\begin{array}{l}\text { Incomplete outcome data } \\
\text { (attrition bias) } \\
\text { All outcomes }\end{array}$ & Low risk & $\begin{array}{l}\text { ITT not used, withdrawals reported with reasons, lost to follow-up reported, } \\
\text { similar numbers for treatment arms }\end{array}$ \\
\hline $\begin{array}{l}\text { Selective reporting (re- } \\
\text { porting bias) }\end{array}$ & Unclear risk & unclear, clinical trial registration was post-hoc \\
\hline Other bias & Low risk & $\begin{array}{l}\text { "The authors have reported that they have no relationships relevant to the } \\
\text { contents of this paper to disclose" } \\
\text { "This study was funded by grants ST- } 678 \text { from Wroclaw Medical University and } \\
\text { 13-024 from the Royal Hobart Hospital Foundation." }\end{array}$ \\
\hline
\end{tabular}

\section{SUPPORT}

Study design: parallel, individual RCT
Centres: 17, Japan
Start of enrolment: October 2006
End of enrolment: March 2010
Median follow-up: 4.4 years
Run-in period: not reported
Inclusion criteria: The inclusion criteria of the present study were designed to enroll symptomatic CHF
patients with hypertension aged 20 to 79 years who were treated with ACEI or beta-blocker or both.
Inclusion criteria: NYHA Classes II to IV CHF, History of hypertension or treated with anti-hypertensive
medications, Aged 20 or older and, 80 years at the entry, Stable with angiotensin-converting enzyme in-
hibitors and/or b-blockers, Not treated with angiotensin II receptor blockers
Exclusion criteria: The exclusion criteria were designed to exclude patients with substantive con-
founding medical conditions or an inability to meaningfully participate in the SUPPORT trial. Exclu-
sion criteria: Patients who have renal dysfunction (serum creatinine $\geq 3.0$ mg/dL), or those who are un-
der chronic haemodialysis, Drug hypersensitivity to olmesartan, Severe liver dysfunction, History of an-
gioedema, History of malignant tumour or life-threatening illness of poor prognosis, Pregnant or possi-
bly pregnant patients, Cardiovascular surgery within 6 months prior to the date of the entry, Acute my-
ocardial infarction within 6 months prior to the date of the entry, Percutaneous coronary intervention
with or without stent implantation within 6 months prior to the date of the entry.


Randomised (N): 1146 (1 patient excluded prior to this for protocol violation) (578 intervention, 568 control)

Withdrawn (N): for reasons other than death 9 (1 protocol violation, 8 no LVEF data)

Lost to follow-up (N): not reported

Analysed (N): Total 1138 (HFpEF 709, HFrEF 429) (HFpEF 363 intervention, HFpEF 346 control)

Age (years, mean, SD): intervention: 66.5, 10.1; control: 65.9, 9.7

Sex (\% men): intervention: 70.2 ; control: 71.1

Ethnicity (\%): not reported

Systolic blood pressure (mmHg, mean, SD): intervention: 131.5, 17.1; control: 130.1, 17.1

Heart rate (beats/min, mean, SD): intervention: 70.6, 13.2; control: 71.4, 14.9

BMI (mean, SD): intervention: 24.4, 4.2; control: 24.8, 4.2

Serum creatinine (mg/dL, mean, SD): intervention: $0.9,0.3$; control: 0.9, 0.3

B-type natriuretic peptide (pg/mL, median, IQR): intervention: 71.1 (30.2, 148.0); control: 58.7 (27.5, 139.0)

NT pro B-type natriuretic peptide $(\mathrm{pg} / \mathrm{mL})$ : not reported

LVEF (\%, mean, SD): intervention: $63.8,8.8$; control: $63.1,8.6$

NYHA class I (\%): 0

NYHA class II (\%): intervention: 94.2; control: 93.4

NYHA class III (\%): intervention: 5.5; control: 6.4

NYHA class IV (\%): 0

Hypertension (\%): 100

Diabetes (\%): intervention: 46.6; control: 53.9

Atrial fibrillation (\%): not reported

Hospitalisation for heart failure (\%): intervention: 52.2; control: 44.1

Coronary heart disease (\%): intervention: 48.8 ; control: 45.1

Stroke (\%): not reported

Diuretic (\%); intervention: 45.7; control: 48.0

Digoxin (\%): not reported

Beta-blocker (\%): intervention: 63.4; control: 65.4

ACEI (\%): intervention: 79.9; control: 79.0

ARB (\%): study drug

MRA (\%): intervention: 18.5 ; control: 22.0 
Concomitant medication: treated with $\mathrm{ACEI}$ and/or beta-blocker in inclusion criteria, not treated with ARB

\section{Outcomes}

Planned: Clinical trial registry entry at point of enrolment: primary outcomes all-cause death, nonfatal acute myocardial infarction, nonfatal stroke, hospital admission due to congestive heart failure

\section{Reported:}

Primary Endpoint: A composite of the following outcomes: all-cause death, non-fatal acute myocardial infarction, non-fatal stroke, hospital admission due to worsening heart failure Secondary Endpoints: cardiovascular death, death due to heart failure, sudden death, acute myocardial infarction, stroke, hospital admission from any cardiovascular reasons, fatal arrhythmia or appropriate ICD discharge, new-onset diabetes, development of renal dysfunction (equal to or more than twofold increase of serum creatinine level), new-onset atrial fibrillation, a need to modify treatment procedures for heart failure, a decrease in left ventricular ejection fraction (equal to or more than $20 \%$ decrease), an increase in B-type natriuretic peptide levels ( $>2$-fold increase if the baseline level was $>$ $50 \mathrm{pg} / \mathrm{mL}$ and an increase of $>100 \mathrm{pg} / \mathrm{mL}$ if the baseline level was $<50 \mathrm{pg} / \mathrm{mL}$ ), changes in serum markers for metabolic syndrome (high sensitive C-reactive protein, adiponectin, microRNAs)

Notes Emailed investigators to ask for outcome date for participants with LVEF $>40 \%$. No response.

Published (and presented above) are baseline characteristics and results for HFpEF as defined by investigators (LVEF $\geq 50 \%$ ).

\section{Risk of bias}

\begin{tabular}{lll}
\hline Bias & Authors' judgement & Support for judgement \\
\hline $\begin{array}{l}\text { Random sequence genera- } \\
\text { tion (selection bias) }\end{array}$ & Unclear risk & not reported \\
\hline $\begin{array}{l}\text { Allocation concealment } \\
\text { (selection bias) }\end{array}$ & Unclear risk & not reported \\
\hline $\begin{array}{l}\text { Blinding of participants } \\
\text { and personnel (perfor- } \\
\text { mance bias) }\end{array}$ & High risk & open label \\
All outcomes & & \\
\hline
\end{tabular}

Blinding of outcome as- $\quad$ Low risk blinded endpoint study
sessment (detection bias)
All outcomes

\begin{tabular}{|c|c|c|}
\hline $\begin{array}{l}\text { Incomplete outcome data } \\
\text { (attrition bias) } \\
\text { All outcomes }\end{array}$ & Unclear risk & $\begin{array}{l}\text { withdrawals reported with reasons, not detailed by treatment arm } \\
\text { ITT used, but after exclusion of some randomised patients }\end{array}$ \\
\hline $\begin{array}{l}\text { Selective reporting (re- } \\
\text { porting bias) }\end{array}$ & Low risk & primary outcomes reported as planned \\
\hline Other bias & Low risk & $\begin{array}{l}\text { "The Department of Evidence-based Cardiovascular Medicine, Tohoku Univer- } \\
\text { sity Graduate School of Medicine, is supported in part by the unrestricted re- } \\
\text { search grants from Daiichi Sankyo Co, Ltd (Tokyo, Japan), Bayer Yakuhin, Ltd } \\
\text { (Osaka, Japan), Kyowa Hakko Kirin Co, Ltd (Tokyo, Japan), Kowa Pharmaceuti- } \\
\text { cal Co, Ltd (Tokyo, Japan), Novartis Pharma K.K. (Tokyo, Japan), Dainippon Su- } \\
\text { mitomo Pharma, Co, Ltd (Osaka, Japan), and Nippon Boehringer Ingelheim Co, } \\
\text { Ltd (Tokyo, Japan). H.S. has received lecture fees from Bayer Yakuhin, Ltd (Os- } \\
\text { aka, Japan), Daiichi Sankyo Co, Ltd (Tokyo, Japan) and Novartis Pharma K.K. } \\
\text { (Tokyo, Japan)." }\end{array}$ \\
\hline
\end{tabular}


Centres: 12 , Sweden

Start of enrolment: not reported

End of enrolment: not reported

Mean follow-up: not reported

Run-in period: not reported

Participants
Inclusion criteria: "patients with symptoms and/or signs of HF, normal or almost normal systolic function and abnormal DF who did not have a contraindication to receiving therapy with a beta- adrenoceptor blocking agent were included into the study." "Major inclusion criteria were a wall motion index $(\mathrm{WMI}) \leq 1.2$, i.e akinesia of one segment or less or hypokinesia of 2 segments or less, using a 16 segment model with at least 10 segments visible, corresponding to an LVEF $>45 \%$, and evidence of abnormal DF using at least one of the following criteria to assess diastolic dysfunction"

Exclusion criteria: "Major exclusion criteria were restrictive or hypertrophic cardiomyopathies, significant uncorrected obstructive or regurgitant valvular diseases, unstable angina, active myocarditis, uncontrolled symptomatic ventricular arrhythmias, history of sick sinus syndrome, second or third degree AV-block, heart rate less than $60 \mathrm{bpm}$, systolic blood pressure $-85 \mathrm{mmHg}$, uncontrolled hypertension, atrial fibrillation, evidence of obstructive pulmonary disease, unstable diabetes, treatment with beta-2-agonists, MAO-inhibitors, calcium channel blockers or beta-receptor blockers"

Randomised (N): 113

Withdrawn (N): for reasons other than death: "16 patients had echocardiographic data of insufficient quality and were excluded from the evaluation."

Lost to follow-up (N): 2 (reasons not reported)

Analysed (N): 97 (47 intervention, 50 control)

Age (years, median, IQR): intervention: 67 (48 to 81); control: 66 (48 to 84)

Sex (\% men): intervention: 59.6; control: 54.0

Ethnicity (\%): not reported

Systolic blood pressure (mmHg, median, IQR): intervention: 155 (122 to 180); control: 150 (110 to 200)

Heart rate (beats/min, median, IQR): intervention: 74 (60 to 95); control: 73 (60 to 101)

BMI not reported

Serum creatinine not reported

B-type natriuretic peptide (pg/mL): intervention: $67.7,76.1$; control: $67.7,67.7$

NT pro B-type natriuretic peptide $(\mathrm{pg} / \mathrm{mL})$ : not reported

LVEF not reported

NYHA class I (\%): intervention: 40; control: 26 
NYHA class II (\%): intervention: 53; control: 53

NYHA class III (\%): intervention: 7; control: 21

NYHA class IV (\%): 0

Hypertension (\%): intervention: 70.2; control: 62

Diabetes (\%): intervention: 12.8 ; control: 16.0

Atrial fibrillation (\%): 0

Hospitalisation for heart failure: not reported

Coronary heart disease (\%): intervention: 17; control: 6

Stroke (\%): not reported

Diuretic (\%); not reported

Digoxin (\%): not reported

Beta-blocker (\%): study drug

ACEI (\%): not reported

ARB (\%): not reported

MRA (\%): not reported

Intervention: carvedilol. "carvedilol or placebo twice daily in addition to their conventional treatment" "All patients were uptitrated to the maximum tolerated dose or to the target dose $(25 \mathrm{mg}$ b.i.d., or 50 $\mathrm{mg}$ b.i.d. in patients weighing $85 \mathrm{~kg}$ ) of carvedilol or matching placebo. After completion of uptitration they were to continue on double blind medication for a 6 month maintenance period. At study end patients were withdrawn from blinded study medication in a stepwise manner over a 1-3 week period. Optimal therapy for the patient's condition was then reinstated at the investigator's discretion" "Overall, carvedilol was well tolerated, with $81 \%$ of patients receiving the maximum dose at the end of the uptitration phase ( $25 \mathrm{mg}$ b.i.d. or $50 \mathrm{mg}$ b.i.d.) and $82 \%$ at the end of the study"

Comparator: placebo

Concomitant medication: "as an addition to conventional treatment"

Outcomes

Planned: not able to assess as we are unaware of a published protocol or pre-registration in a clinical trial register

Reported: primary: diastolic dysfunction. Secondary: Secondary endpoints were the effects of carvedilol as compared to placebo on combined all cause mortality and cardiovascular hospitalisations, combined all-cause mortality and heart failure hospitalisation, progression of heart failure, individual cardiovascular endpoints and outcome and individual diastolic variables. Additional exploratory analyses on LV dimensions atrial size and WMI were also prespecified."

Notes Emailed investigators for details for RoB assessment, reasons for 2 participants not completing study, start/end of enrolment, duration of follow-up. No response.

\section{Risk of bias}

\begin{tabular}{lll}
\hline Bias & Authors' judgement & Support for judgement \\
\hline $\begin{array}{l}\text { Random sequence genera- } \\
\text { tion (selection bias) }\end{array}$ & Unclear risk & not reported \\
\hline
\end{tabular}




\section{SWEDIC (Continued)}

Allocation concealment Unclear risk not reported
(selection bias)

Blinding of participants Low risk

double-blind but no details, matching placebo

and personnel (perfor-

mance bias)

All outcomes

\section{Blinding of outcome as- Unclear risk}

sessment (detection bias)

All outcomes

"All assessments as to whether the LV diastolic dysfunction had improved, was unchanged, or had worsened were made by two echocardiographers from the core laboratory, who were blinded to the order of the assessment and to the study medication received by the patient."

only partial outcome assessment and for outcomes not relevant to this review

$\begin{array}{lll}\begin{array}{l}\text { Incomplete outcome data } \\ \text { (attrition bias) } \\ \text { All outcomes }\end{array} & \text { Unclear risk } & \text { unable to assess - withdrawals not reported by treatment arm } \\ \text { ITT used }\end{array}$

\section{Takeda 2004}

\begin{tabular}{ll}
\hline Methods & Study design: parallel RCT \\
Centres: 1 , Japan \\
Start of enrolment: April 2000 \\
End of enrolment: March 2001 \\
Mean follow-up: 12 months \\
Run-in period: not reported
\end{tabular}

\section{Participants}

Inclusion criteria: "All patients met Framingham criteria for diagnosis of heart failure. LVEF, as assessed by echocardiography using Simpson's method, was $\geq 45 \%$ in each subject at the screening examination."

Exclusion criteria: "Patients with primary significant valvular disease, cor pulmonale, thyroid dysfunction, diabetes mellitus with hemoglobin $\mathrm{A} 1 \mathrm{C}>8 \%$, alcohol abuse, other systemic diseases, obvious contraindication to carvedilol, or using angiotensin II receptor antagonists or adrenergic blockers were excluded from the initial entry."

Randomised (N): 40 (19 intervention, 21 control)

Withdrawn (N): not reported

Lost to follow-up (N): not reported

Analysed (N): not reported

Age (years, median, IQR): intervention: 69.1, 64.4-73.7; control: 73.1, 69.7-76.4

Sex (\% men): intervention: 68; control: 38

Beta-blockers and inhibitors of the renin-angiotensin aldosterone system for chronic heart failure with preserved ejection fraction 
Ethnicity (\%): not reported

Systolic blood pressure (mmHg, median, IQR): intervention: 129.6, 124.5-134.6; control: 138.0, 130.7145.3

Heart rate (beats/min, median, IQR): intervention: 70.6, 64.3-77.0; control: 68.9, 63.8-74.0

BMI not reported

Serum creatinine not reported

B-type natriuretic peptide (pg/mL, median, IQR): intervention: 172, 135-209; control: 150, 114-186

NT pro B-type natriuretic peptide $(\mathrm{pg} / \mathrm{mL})$ : not reported

LVEF (\%, median, IQR): intervention: 55.8, 51.4-60.3; control: 57.5, 53.4-61.5

NYHA class I (\%): 0

NYHA class II (\%): intervention: 63.3; control: 71

NYHA class III (\%): intervention: 37; control: 29

NYHA class IV (\%): 0

Hypertension not reported

Diabetes not reported

Atrial fibrillation (\%): intervention: 21 ; control: 38

Hospitalisation for heart failure: not reported

Coronary heart disease (\%): intervention: 58 ; control: 48

Stroke not reported

Diuretic not reported

Digoxin not reported

Beta-blocker study drug

ACEI (\%): intervention: 79; control: 86

ARB not reported

MRA not reported

Intervention: carvedilol. "initial daily dosage of $1.25 \mathrm{mg}$ in addition to conventional therapy, and the dose was doubled every week until reaching $>=5 \mathrm{mg} /$ day. The decision to increase carvedilol to $>5$ $\mathrm{mg} /$ day was made by the attending cardiologists on the basis of subjective symptoms, physical findings, and chest roentgenography; the cardiologists were guided to increase carvedilol to $20 \mathrm{mg} /$ day if the patient tolerated it."

Comparator: conventional treatment

Concomitant medication: not reported

Reported: BNP, NYHA, exercise capacity, heart failure hospitalisations, deaths 
Takeda 2004 (Continued)

Risk of bias

\begin{tabular}{lll}
\hline Bias & Authors' judgement & Support for judgement \\
\hline $\begin{array}{l}\text { Random sequence genera- } \\
\text { tion (selection bias) }\end{array}$ & Unclear risk & not reported \\
\hline $\begin{array}{l}\text { Allocation concealment } \\
\text { (selection bias) }\end{array}$ & Unclear risk & not reported \\
\hline $\begin{array}{l}\text { Blinding of participants } \\
\text { and personnel (perfor- } \\
\text { mance bias) }\end{array}$ & Unclear risk & not reported \\
All outcomes & \\
\hline $\begin{array}{l}\text { Blinding of outcome as- } \\
\text { sessment (detection bias) }\end{array}$ & Unclear risk & not reported \\
All outcomes & & \\
\hline $\begin{array}{l}\text { Incomplete outcome data } \\
\text { (attrition bias) }\end{array}$ & Unclear risk & not reported \\
All outcomes & & \\
\hline $\begin{array}{l}\text { Selective reporting (re- } \\
\text { porting bias) }\end{array}$ & Unclear risk & unable to assess \\
\hline \begin{tabular}{l} 
Other bias \\
\hline
\end{tabular} & Unclear risk & funding not reported \\
\hline
\end{tabular}

\section{TOPCAT}

Methods

Study design: parallel RCT

Centres: "233 sites in 6 countries (1151 participants in the United States, 326 in Canada, 167 in Brazil, 123 in Argentina, 1066 in Russia, and 612 in Georgia)"

Start of enrolment: August 2006

End of enrolment: January 2012

Mean follow-up: 3.3 years

Run-in period: no

Participants

Inclusion criteria: " $\geq 50$ years old, "had at least one sign and at least one symptom of heart failure on a prespecified list of clinically defined signs and symptoms, a left ventricular ejection fraction of $45 \%$ or more as measured at the local site by means of echocardiography or radionuclide ventriculography, controlled systolic blood pressure (defined as a target systolic blood pressure of $<140 \mathrm{~mm} \mathrm{Hg}$ or $\leq 160$ $\mathrm{mm} \mathrm{Hg}$ if the patient was taking three or more medications to control blood pressure), and a serum potassium level of less than $5.0 \mathrm{mmol}$ per liter. In addition, eligible patients had a history of hospitalization within the previous 12 months, with management of heart failure a major component of the care provided (not adjudicated by the clinical-events adjudication committee), or an elevated natriuretic peptide level within 60 days before randomization (a brain natriuretic peptide [BNP] level $\geq 100 \mathrm{pg}$ per milliliter or an N-terminal pro-BNP [NTproBNP] level $\geq 360$ pg per milliliter)."

Exclusion criteria: "severe systemic illness with a life expectancy of less than 3 years, severe renal dysfunction (an estimated glomerular filtration rate [GFR] of $<30 \mathrm{ml}$ per minute per $1.73 \mathrm{~m}^{2}$ of body-surface area or a serum creatinine level that was $\geq 2.5 \mathrm{mg}$ per deciliter [ $221 \mu \mathrm{mol}$ per liter]), and specific coexisting conditions, medications, or acute events." 
Randomised (N): 3445 (1722 intervention, 1723 control)

Withdrawn (N): 311 for reasons other than death (160 intervention, 151 control)

Lost to follow-up (N): 132 (67 intervention, 65 control)

Analysed (N): 3445 (1722 intervention, 1723 control)

Age (years, median, IQR): intervention: $68.7,61.0$ to 76.4 ; control: $68.7,60.7$ to 75.5

Sex (\% men): intervention: 48.4 ; control: 48.5

Ethnicity (\%): intervention: white 88.6, control: white 89.2

Systolic blood pressure (mmHg, median, IQR): intervention: 130 ,120-139; control: 130, 120-140

Heart rate (beats/min, median, IQR): intervention: 68, 62-76; control: 68, 62-76

BMI (median, IQR): intervention: 31, 27-36; control: 31, 27-36

Serum creatinine (mg/dL, median, IQR): intervention: 1.0, 0.9-1.2; control: 1.1, 0.9-1.2

B-type natriuretic peptide $(\mathrm{pg} / \mathrm{mL})$ : only in subgroup

NT pro B-type natriuretic peptide $(\mathrm{pg} / \mathrm{mL})$ : only in subgroup

LVEF (\%, median, IQR): intervention: 56, 51-61; control: 56, 51-62

NYHA class I (\%): intervention: 3.3; control: 3.1

NYHA class II (\%): intervention: 63.3; control: 64.1

NYHA class III (\%): intervention: 33.0; control: 32.1

NYHA class IV (\%): intervention: 0.4 ; control: 0.5

Hypertension (\%): intervention: 91; control: 92

Diabetes (\%): intervention: 33; control: 32

Atrial fibrillation (\%): intervention: 35; control: 35

Hospitalisation for heart failure: not reported

Coronary heart disease (\%): intervention: 26; control: 26

Stroke (\%): intervention: 7 ; control: 8

Diuretic (\%); intervention: 81; control: 82

Digoxin not reported

Beta-blocker (\%): intervention: 78; control: 77

ACEI or ARB (\%): intervention: 84; control: 84

MRA (\%): 0

"Study drugs were initially administered at a dose of $15 \mathrm{mg}$ once daily, which was increased to a maximum of $45 \mathrm{mg}$ daily during the first 4 months after randomization. Subsequent dose adjustments were made as required."

Comparator: matching placebo 
Concomitant medication: "Study patients continued to receive other treatments for heart failure and coexisting illnesses throughout the trial."

Outcomes

Planned: From NCT record 21 April 2006: primary outcomes: cardiovascular mortality, aborted cardiac arrest, composite of hospitalisation for the management of heart failure (ie hospitalisation for non-fatal myocardial infarction or non-fatal stroke). Secondary outcomes: all-cause mortality, composite of cardiovascular mortality or cardiovascular related hospitalization (i.e. hospitalization for non-fatal myocardial infarction, non-fatal stroke, or the management of heart failure), hospitalization for the management of heart failure incidence rate, sudden death or aborted cardiac arrest

Reported: "composite of death from cardiovascular causes, aborted cardiac arrest, or hospitalization for the management of heart failure; myocardial infarction; stroke; hospitalisation from any cause; hyperkalemia (potassium level, $\geq 5.5 \mathrm{mmol}$ per liter); hypokalemia (potassium level, $<3.5 \mathrm{mmol}$ per liter); an elevated serum creatinine level ( $\geq 2$ times the baseline value and above the upper limit of the normal range); serum creatinine level of $3.0 \mathrm{mg}$ per deciliter ( $265 \mu \mathrm{mol}$ per liter) or higher; serious adverse events"

Notes

Kao 2017 mentions subgroup analysis by sex for all-cause mortality and hospitalisations but no usable data.

NCT record reports on QoL but no usable data. Hamo 2015 reports baseline QoL data but not by intervention arm.

Solomon 2016 reports data for four LVEF groups for HF hospitalisation, CV death, death (table 2) $40-49 \%, 50-54.99 \%, 55-59.99 \%, 60 \%$ and over.

Data for all-cause mortality, lost to follow up, hyperkalemia differ between Pitt 2014 and NCT results.

Emailed investigators to ask for end scores for QoL KCCQ, clarification on withdrawals due to adverse events and subgroup data for primary outcomes.

\section{Risk of bias}

\begin{tabular}{lll}
\hline Bias & Authors' judgement & Support for judgement \\
\hline $\begin{array}{l}\text { Random sequence genera- } \\
\text { tion (selection bias) }\end{array}$ & Low risk & "Eligible participants were randomly assigned to receive either spironolactone \\
& & or placebo in a 1:1 ratio with the use of permuted blocks." \\
& "the randomization software will return a Treatment Allocation Code corre- \\
& sponding to either spironolactone or placebo"
\end{tabular}

$\begin{array}{ll}\begin{array}{l}\text { Allocation concealment } \\ \text { (selection bias) }\end{array} & \text { "Tow risk nurse coordinator will utilize a master list of Treatment Allocation Codes } \\ \text { to determine which labelled study drug packet to provide to the subject." }\end{array}$

\begin{tabular}{ll}
\hline $\begin{array}{l}\text { Blinding of participants } \\
\text { and personnel (perfor- }\end{array}$ & Low risk \\
mantects and treating physicians will be blinded to whether subjects are re- \\
ceiving spironolactone or placebo"
\end{tabular}

mance bias)

All outcomes

\begin{tabular}{|c|c|c|}
\hline $\begin{array}{l}\text { Blinding of outcome as- } \\
\text { sessment (detection bias) } \\
\text { All outcomes }\end{array}$ & Low risk & $\begin{array}{l}\text { "Data were collected and managed electronically by the New England Re- } \\
\text { search Institutes Clinical Trial Coordinating Center, which also coordinated } \\
\text { site monitoring and analyzed the trial results (with independent verification at } \\
\text { Brigham and Women's Hospital)." }\end{array}$ \\
\hline
\end{tabular}

\begin{tabular}{ll}
\hline Incomplete outcome data & Low risk \\
(attrition bias) & "All randomly assigned participants were included in all analyses according to \\
All outcomes & the intention-to-treat principle."
\end{tabular}

All outcomes

Selective reporting (re- Low risk
porting bias)

Beta-blockers and inhibitors of the renin-angiotensin aldosterone system for chronic heart failure with preserved ejection fraction (Review)

Copyright (c) 2018 The Cochrane Collaboration. Published by John Wiley \& Sons, Ltd. 
TOPCAT (Continued)

$\begin{array}{ll}\text { Other bias } \quad \text { Low risk } & \begin{array}{l}\text { "sponsored by National Heart, Lung and Blood Institute, National Institutes of } \\ \text { Health" }\end{array}\end{array}$
Health"

Start of enrolment: not reported

End of enrolment: not reported

Follow-up: 9 months

Run-in period: not reported

Inclusion criteria: "HFpEF was defined as history, symptoms, and signs of HF, a preserved LVEF of 50\% or greater and no evidence of other medical condition that could mimic HF symptoms"

Exclusion criteria: "Coronary disease was excluded according to history, medical record, electrocardiogram, and rest and exercise echocardiogram" "Exclusions included aldosterone antagonist use within the previous 3 months, a known contraindication, concomitant therapy with a potassium-sparing diuretic or potassium supplementation, baseline serum potassium level greater than $5.0 \mathrm{mEq} / \mathrm{L}$, or serum creatinine level of $2.5 \mathrm{mg} / \mathrm{dL}$ or greater."

Randomised (N): 80 (42 intervention, 38 control)

Withdrawn (N): for reasons other than death 9 (5 intervention (adverse event $\mathrm{N}=1$, patient choice $\mathrm{N}=$ 4), 4 control (patient choice $N=3$, death $N=1$ ))

Lost to follow-up (N): not reported

Analysed (N): 71 (37 intervention, 34 control)

Age (years, mean, SD): intervention: 70.0, 1.1; control: 72.0, 1.2

Sex (\% men): intervention: 19; control: 21

Ethnicity (\%): African American: intervention: 21 , control: 37

Systolic blood pressure (mmHg, mean, SD): intervention: 139, 2.7; control: 143, 3.2

Heart rate not reported

BMI (mean, SD): intervention: 31.5, 0.8; control: 32.4, 1.2

Serum creatinine not reported

B-type natriuretic peptide (unit not reported): intervention: 55, 46; control: 61, 50

NT pro B-type natriuretic peptide $(\mathrm{pg} / \mathrm{mL})$ : not reported

LVEF (\%, mean, SD): intervention: 62.6, 1.1; control: 62.0, 1.1

NYHA class I (\%): 0

NYHA class II (\%): intervention: 29; control: 26

NYHA class III (\%): intervention: 64; control: 63

NYHA class IV (\%): 0 
Hypertension (\%): intervention: 83; control: 92

Diabetes (\%): intervention: 17; control: 29

Atrial fibrillation (\%): not reported

Hospitalisation for heart failure: not reported

Coronary heart disease (\%): 0

Stroke (\%): not reported

Diuretic (\%); intervention: 74; control: 71

Digoxin (\%): intervention: 2; control: 0

Beta-blocker (\%): intervention: 31; control: 32

ACEI (\%): not reported

ARB (\%): not reported

MRA (\%): study drug

Intervention: spironolactone. "The starting dose of spironolactone was $12.5 \mathrm{mg} / \mathrm{d}$ in individuals with baseline creatinine of $2.0 \mathrm{mg} / \mathrm{dL}$ or greater or potassium greater than $4.5 \mathrm{mEq} / \mathrm{L}$; in all other participants, the starting dose was $25 \mathrm{mg} / \mathrm{d}$. In participants who initiated therapy with the $12.5-\mathrm{mg} / \mathrm{d}$ dose, the dose was increased to $25 \mathrm{mg} / \mathrm{d}$ once creatinine fell below $2.5 \mathrm{mg} / \mathrm{dL}$ and potassium fell below 5.0 $\mathrm{mEq} / \mathrm{L}$ and maintained at that dosage as long as those levels were maintained. Spironolactone was discontinued if 1-week creatinine was $2.5 \mathrm{mg} / \mathrm{dL}$ or higher or potassium was $5.0 \mathrm{mEq} / \mathrm{L}$ or higher. " "The mean daily dose of spironolactone was $24.32 .9 \mathrm{mg} / \mathrm{d}$."

Comparator: matching placebo

Concomitant medication: not reported

Outcomes

Planned: July 2005, NCT record: primary outcomes: exercise intolerance, quality of life

Reported: exercise performance, aortic distensibility and LV structure and function, carotid artery stiffness, pulse wave velocity, LV diastolic filling, QoL

Notes

\section{Risk of bias}

\begin{tabular}{|c|c|c|}
\hline Bias & Authors' judgement & Support for judgement \\
\hline $\begin{array}{l}\text { Random sequence genera- } \\
\text { tion (selection bias) }\end{array}$ & Unclear risk & "randomly assigned" \\
\hline $\begin{array}{l}\text { Allocation concealment } \\
\text { (selection bias) }\end{array}$ & Unclear risk & not reported \\
\hline $\begin{array}{l}\text { Blinding of participants } \\
\text { and personnel (perfor- } \\
\text { mance bias) } \\
\text { All outcomes }\end{array}$ & Low risk & $\begin{array}{l}\text { "The research pharmacy prepared and distributed placebo and active drug us- } \\
\text { ing a secure methodology. All investigators, staff, and participants were fully } \\
\text { blinded to treatment group assignment throughout the study period" }\end{array}$ \\
\hline $\begin{array}{l}\text { Blinding of outcome as- } \\
\text { sessment (detection bias) } \\
\text { All outcomes }\end{array}$ & Unclear risk & $\begin{array}{l}\text { "The research pharmacy prepared and distributed placebo and active drug us- } \\
\text { ing a secure methodology. All investigators, staff, and participants were fully } \\
\text { blinded to treatment group assignment throughout the study period" }\end{array}$ \\
\hline
\end{tabular}

Beta-blockers and inhibitors of the renin-angiotensin aldosterone system for chronic heart failure with preserved ejection fraction (Review)

Copyright $\odot 2018$ The Cochrane Collaboration. Published by John Wiley \& Sons, Ltd. 
Upadhya 2017 (Continued)

Incomplete outcome data Unclear risk unable to assess
(attrition bias)

All outcomes

\begin{tabular}{lll}
\hline $\begin{array}{l}\text { Selective reporting (re- } \\
\text { porting bias) }\end{array}$ & Unclear risk & posthoc clinical trial registration \\
\hline Other bias & High risk & $\begin{array}{l}\text { "This study was funded by the National Institutes of Health (NIH; R01AG18915), } \\
\text { the Claude D. Pepper Older Americans Independence Center, Wake Forest Uni- } \\
\text { versity (P30AG21332), the Clinical and Translational Science Institute, Wake } \\
\text { Forest School of Medicine (NIH UL1TR001420), and the Kermit G. Phillips Chair } \\
\text { in Cardiovascular Medicine of Wake Forest School of Medicine" }\end{array}$ \\
& Published as conference abstract only.
\end{tabular}

\section{Wang 2010}

Methods

Study design: parallel, individual, RCT

Centres: 1, Taiwan

Start of enrolment: not reported

End of enrolment: not reported

Follow-up: at least 3 months

Run-in period: not reported

\section{Participants}

Inclusion criteria: "hypertensive pts who had DHF, defined as the presence of HF signs/symptoms, diastolic dysfunction (mitral annular early diastolic velocity $\left(E^{\prime}\right)<8 \mathrm{~cm} / \mathrm{s}$ ), and left ventricular (LV) ejection fraction $(\mathrm{EF})>50 \% "$

Exclusion criteria: not reported

Randomised (N): 36 (19 intervention, 17 control)

Withdrawn (N): not reported

Lost to follow-up (N): not reported

Analysed (N): not reported

Age (years, mean, SD): not reported

Sex (\% men): not reported

Ethnicity (\%): not reported

Systolic blood pressure not reported

Heart rate not reported

BMI not reported

Serum creatinine not reported

B-type natriuretic peptide not reported

NT pro B-type natriuretic peptide not reported

LVEF (\%, mean, SD): intervention: 67, 7; control: 66, 7 
Wang 2010 (Continued)

NYHA class not reported

Hypertension not reported

Diabetes not reported

Atrial fibrillation not reported

Hospitalisation for heart failure: not reported

Coronary heart disease not reported

Stroke not reported

Diuretic not reported

Digoxin not reported

Beta-blocker not reported

ACEI not reported

ARB not reported

MRA study drug

\begin{tabular}{ll}
\hline Interventions & Intervention: spironolactone. $50 \mathrm{mg} / \mathrm{d}$ \\
& Comparator: no treatment control
\end{tabular}

Concomitant medication: not reported

Outcomes

Planned: we are not aware of a published protocol or pre-registered clinical trial registry entry

Reported: echo-parameters, systolic myocardial velocities

\begin{tabular}{|c|c|c|}
\hline Notes & does not contribute ou & come data to this review \\
\hline \multicolumn{3}{|l|}{ Risk of bias } \\
\hline Bias & Authors' judgement & Support for judgement \\
\hline $\begin{array}{l}\text { Random sequence genera- } \\
\text { tion (selection bias) }\end{array}$ & Unclear risk & not reported \\
\hline $\begin{array}{l}\text { Allocation concealment } \\
\text { (selection bias) }\end{array}$ & Unclear risk & not reported \\
\hline $\begin{array}{l}\text { Blinding of participants } \\
\text { and personnel (perfor- } \\
\text { mance bias) } \\
\text { All outcomes }\end{array}$ & Unclear risk & not reported \\
\hline $\begin{array}{l}\text { Blinding of outcome as- } \\
\text { sessment (detection bias) } \\
\text { All outcomes }\end{array}$ & Unclear risk & not reported \\
\hline $\begin{array}{l}\text { Incomplete outcome data } \\
\text { (attrition bias) } \\
\text { All outcomes }\end{array}$ & Unclear risk & not reported \\
\hline
\end{tabular}


Wang 2010 (Continued)

Selective reporting (re- Unclear risk unable to assess
porting bias)

Other bias Unclear risk funding not reported

Yuksek 2012

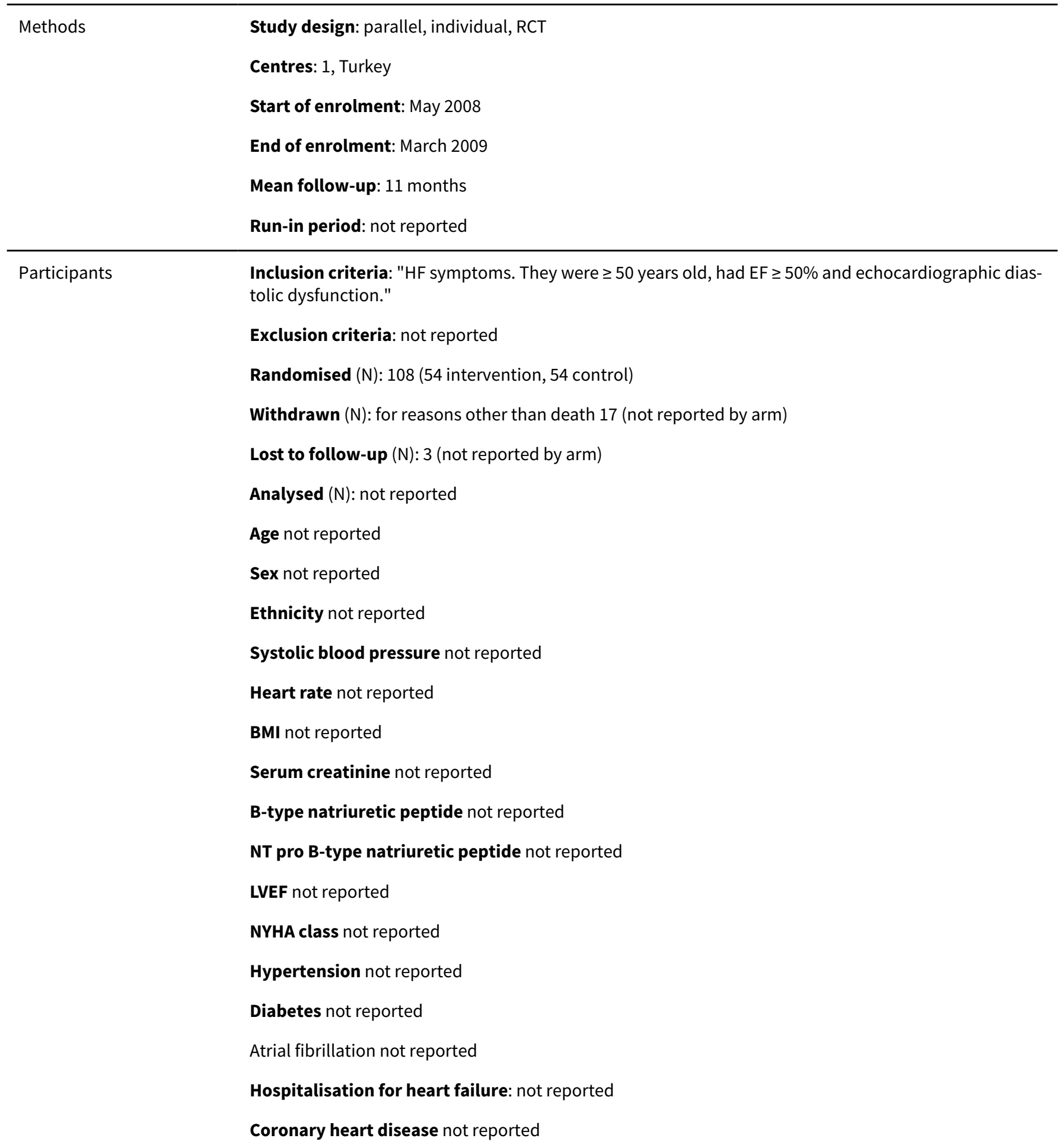


Yuksek 2012 (Continued)

\section{Stroke not reported}

Diuretic not reported

Digoxin not reported

Beta-blocker not reported

ACEI study drug

ARB not reported

MRA not reported

\begin{tabular}{ll}
\hline Interventions & Intervention: perindopril, $10 \mathrm{mg} / \mathrm{d}$ \\
Comparator: "standard DHF treatment" \\
Concomitant medication: not reported
\end{tabular}

Outcomes

Planned: we are not aware of a published protocol or a pre-registration in a clinical trial register

Reported: T-proBNP values and echocardiography

Notes no outcome data of interest

\section{Risk of bias}

\begin{tabular}{lll}
\hline Bias & Authors' judgement & Support for judgement \\
\hline $\begin{array}{l}\text { Random sequence genera- } \\
\text { tion (selection bias) }\end{array}$ & Unclear risk & randomised, but no details \\
\hline
\end{tabular}

\begin{tabular}{lll}
\hline $\begin{array}{l}\text { Allocation concealment } \\
\text { (selection bias) }\end{array}$ & Unclear risk & not reported \\
\hline $\begin{array}{l}\text { Blinding of participants } \\
\text { and personnel (perfor- } \\
\text { mance bias) } \\
\text { All outcomes }\end{array}$ & Unclear risk & not reported \\
\hline $\begin{array}{l}\text { Blinding of outcome as- } \\
\text { sessment (detection bias) }\end{array}$ & Unclear risk & not reported \\
$\begin{array}{l}\text { All outcomes } \\
\text { Incomplete outcome data }\end{array}$ & Unclear risk & \\
$\begin{array}{l}\text { (attrition bias) } \\
\text { All outcomes }\end{array}$ & \\
\hline $\begin{array}{l}\text { Selective reporting (re- } \\
\text { porting bias) }\end{array}$ & Unclear risk & unable to assess \\
\hline Other bias & Unclear risk & funding not reported \\
\hline
\end{tabular}

Methods Study design: parallel, individual, RCT

Centres: 1, Royal Liverpool and Broadgreen University Hospitals 
Zi 2003 (Continued)

\section{Start of enrolment: 1997}

End of enrolment: 1999

Follow-up: 6 months

Run-in period: mentioned but no details

Participants

Inclusion criteria: "aged 65 years or older, with heart failure" "They all had left ventricular ejection fraction (LVEF) on echocardiography or radionuclide ventriculography equal or greater than $40 \%$. Where a left ventricular ejection fraction could not be measured systolic function had to be preserved or only mildly impaired by direct visualisation of the echocardiograms"

Exclusion criteria: "Patients with haemodynamically significant valvular disease, pulmonary hypertension, right ventricular systolic dysfunction, uncontrolled atrial fibrillation or flutter, unstable angina pectoris, hypotension, myocardial infarction within one month, renal failure (serum creatinine $>150$ $\mathrm{mmol} / \mathrm{L}$ ), renal-artery stenosis, severe liver or pulmonary disease were excluded. patients treated with tetracyclines, lithium, benzodiazepines, major tranquillisers, anti-depressants (with the exception of selective serotonin re-uptake inhibitors) or major psychoactive drugs were also excluded."

Randomised (N): 74 (36 intervention, 38 control)

Withdrawn $(\mathrm{N})$ : for reasons other than death 4 (0 intervention, 4 control (worsening heart failure))

Lost to follow-up (N): not reported

Analysed (N): 74 (36 intervention, 38 control)

Age (years, mean, SD): intervention: 77,7 ; control: 78,7

Sex (\% men): intervention: 38.9; control: 31.6

Ethnicity (\%): not reported

Systolic blood pressure not reported

Heart rate not reported

BMI not reported

Serum creatinine not reported

B-type natriuretic peptide not reported

NT pro B-type natriuretic peptide not reported

LVEF not reported

NYHA class I (\%): intervention: 5.5; control: 0

NYHA class II (\%): intervention: 77.8; control: 73.7

NYHA class III (\%): intervention: 16.7; control: 26.3

NYHA class IV (\%): 0

Hypertension (\%): intervention: 27.8; control: 31.6

Diabetes (\%): intervention: 11.1; control: 18.4

Atrial fibrillation (\%): intervention: 38.9 ; control: 31.6

Hospitalisation for heart failure: not reported

Coronary heart disease (\%): intervention: 55.6; control: 57.9

Stroke (\%): not reported

Beta-blockers and inhibitors of the renin-angiotensin aldosterone system for chronic heart failure with preserved ejection fraction (Review)

Copyright @ 2018 The Cochrane Collaboration. Published by John Wiley \& Sons, Ltd. 
Diuretic (\%); intervention: 94.4; control: 97.1

Digoxin (\%): intervention: 38.9; control: 26.3

Beta-blocker (\%): intervention: 19.4; control: 7.9

ACEI (\%): study drug

ARB (\%): not reported

MRA (\%): not reported

Interventions

Intervention: quinapril. "Both drugs were titrated at two-week intervals from $5 \mathrm{mg}$ to $40 \mathrm{mg}$ daily or equivalent within the first six weeks."

Comparator: placebo

Concomitant medication: "All patients continued concomitant treatment with diuretics, nitrates, digitalis glycosides, calcium channel blockers, and beta-blockers as appropriate without change of dose except for diuretics. Therapy with ACE inhibitors for heart failure was withdrawn at least two weeks prior to the run-in period."

Outcomes

Planned: we are not aware of a published protocol or pre-registered clinical trial registry entry

Reported: 6-minutes walking distance, hypotension, worsening heart failure, changes of electrolytes, adverse events, quality of life, deaths, heart failure hospitalisation, hyperkalaemia

\section{Notes}

\section{Risk of bias}

\begin{tabular}{lll}
\hline Bias & Authors' judgement & Support for judgement \\
\hline $\begin{array}{l}\text { Random sequence genera- } \\
\text { tion (selection bias) }\end{array}$ & Unclear risk & randomised, but no further detail \\
\hline $\begin{array}{l}\text { Allocation concealment } \\
\text { (selection bias) }\end{array}$ & Unclear risk & not reported \\
\hline $\begin{array}{l}\text { Blinding of participants } \\
\text { and personnel (perfor- } \\
\text { mance bias) }\end{array}$ & Low risk & double-blind, matching placebo \\
All outcomes & \\
\hline
\end{tabular}

$\begin{array}{ll}\text { Blinding of outcome as- } & \text { Unclear risk }\end{array}$

All outcomes

Incomplete outcome data Low risk withdrawals due to worsening heart failure reported
(attrition bias)

All outcomes

\begin{tabular}{lll}
\hline $\begin{array}{l}\text { Selective reporting (re- } \\
\text { porting bias) }\end{array}$ & Unclear risk & unable to assess \\
\hline Other bias & Low risk & "This study was supported by the grants from Parke Davis \& Co. Ltd., UK." \\
\hline
\end{tabular}

quotes are from the primary reference unless otherwise stated

${ }^{*} \mathrm{mmol} / \mathrm{L}$ converted to $\mathrm{mg} / \mathrm{dL}$ using online converter

ACEl: angiotensin converting enzyme inhibitor

Beta-blockers and inhibitors of the renin-angiotensin aldosterone system for chronic heart failure with preserved ejection fraction 
ARB: angiotensin receptor blocker

BMI: body mass index

CVD: cardiovascular disease

EF: ejection fraction

IQR: interquartile range

ITT: intention-to-treat

LV: left ventricular

LVEF: left ventricular ejection fraction

MRA: mineralocorticoid receptor antagonist

$\mathrm{N}$ : number of people

NCT: clinicaltrials.gov identifier

QoL: quality of life

$\mathrm{RCT}$ : randomised controlled trial

SD: standard deviation

TNF-a: tumour necrosis factor-alpha

Characteristics of excluded studies [ordered by study ID]

\begin{tabular}{ll}
\hline Study & Reason for exclusion \\
\hline ACTRN12610001087044 & $\begin{array}{l}\text { Trial registry entry suggested two parts of a trial of which only the second was of interest to this } \\
\text { review. Contact with trialists confirmed that the part of interest was registered and reported on } \\
\text { separately (ACTRN: } 12614000088640, \text { STRUCTURE study). }\end{array}$ \\
\hline
\end{tabular}

\begin{tabular}{|c|c|}
\hline Adgey 1992 & Wrong patient population \\
\hline Ammon 2001 & Wrong study design \\
\hline Andersson 1996 & Wrong patient population \\
\hline Andersson 1999 & Wrong patient population \\
\hline Andersson 2000 & Wrong patient population \\
\hline Anonymous 1996 & Wrong patient population \\
\hline Anonymous 1999 & Wrong intervention \\
\hline Anonymous 2000 & Wrong patient population \\
\hline Anonymous 2001 & Wrong study design \\
\hline Anonymous 2002 & Wrong study design \\
\hline Anonymous 2003 & Wrong comparator \\
\hline Anonymous 2003a & Wrong study design \\
\hline Anonymous 2003b & Wrong study design \\
\hline Anonymous $2003 c$ & Wrong patient population \\
\hline Anonymous 2005 & Wrong patient population \\
\hline Anonymous 2008 & Wrong study design \\
\hline Anonymous $2008 a$ & Wrong study design \\
\hline
\end{tabular}

Beta-blockers and inhibitors of the renin-angiotensin aldosterone system for chronic heart failure with preserved ejection fraction 


\begin{tabular}{|c|c|}
\hline Study & Reason for exclusion \\
\hline Anonymous 2013 & Wrong study design \\
\hline ANZ HF carvedilol & $\begin{array}{l}\text { Subgroup of participants of interest }(\mathrm{LVEF}=40-44 \%) \text {. We did not receive a response from the trial- } \\
\text { ists to our enquiry for details on the subgroup of interest. }\end{array}$ \\
\hline Aoyama 2007 & Wrong study design \\
\hline Apostolovic 2013 & Wrong comparator \\
\hline Apostolovic 2014a & Wrong comparator \\
\hline Apostolovic 2014b & Wrong comparator \\
\hline Arena 2007 & Wrong study design \\
\hline Armstrong 1999 & Wrong study design \\
\hline Aronow 1991 & Wrong study design \\
\hline Aronow 2001 & Wrong study design \\
\hline Axelsson 2015 & Wrong patient population \\
\hline Balaban 2007 & $\begin{array}{l}\text { Turkish paper. Translated methods and data extraction. Unclear if participants had heart failure. } \\
\text { We did not receive a response from the investigator when we asked for clarification. }\end{array}$ \\
\hline Bao 2005 & Wrong population \\
\hline Barr 1995 & Wrong patient population \\
\hline Barrios 2009 & Wrong patient population \\
\hline Barry 2003 & Wrong study design \\
\hline Bartels 1999 & Wrong patient population \\
\hline Baruch 1999 & $\begin{array}{l}\text { Ineligible participants. Emailed trialists to clarify inclusion criteria. Response received: "Our study } \\
\text { was confined to individuals with a reduced ejection fraction and the data therefore would not be } \\
\text { applicable to your quest." }\end{array}$ \\
\hline Baruch 2004 & Wrong patient population \\
\hline Bauersachs 2004 & Wrong study design \\
\hline Baumhakel 2008 & Wrong study design \\
\hline Bellenger 2004 & Wrong patient population \\
\hline Berry 2001 & Wrong study design \\
\hline Bettencourt 1999 & Wrong study design \\
\hline Beygui 2016 & Wrong patient population \\
\hline Blagodar 2003 & Wrong patient population \\
\hline
\end{tabular}

Beta-blockers and inhibitors of the renin-angiotensin aldosterone system for chronic heart failure with preserved ejection fraction 


\begin{tabular}{|c|c|}
\hline Study & Reason for exclusion \\
\hline Blomer 1990 & Wrong study design \\
\hline Borghi 2011 & Wrong comparator \\
\hline Borgi 1990 & Wrong patient population \\
\hline Borlaug 2014 & Wrong study design \\
\hline Bornkessel 1992 & Wrong patient population \\
\hline Bounhoure 1991 & EF not reported. Could not identify current contact details. \\
\hline Braunwald 2004 & Wrong patient population \\
\hline Brilla 1989 & Wrong study design \\
\hline Brilla 1991 & EF unclear, unclear whether allocation was random, unable to identify current contact details. \\
\hline Bristow 1994 & Wrong patient population \\
\hline Bristow 1996 & Wrong patient population \\
\hline Bussmann 1987 & EF unclear. We did not receive a response to our enquiry for details. \\
\hline Butler 2017 & Wrong patient population \\
\hline Cafaro 2010 & Wrong study design \\
\hline Cardoso 1999 & Wrong study design \\
\hline Castagno 2010 & Wrong patient population \\
\hline Choi 2001 & Wrong patient population \\
\hline Cicoira 2002 & $\begin{array}{l}\text { subgroup of participants of interest; we did not receive a response from the trialist to our enquiry } \\
\text { for details. }\end{array}$ \\
\hline Cleland 1984 & unclear EF. contacted trialists. no response \\
\hline Cleland 1999 & Wrong patient population \\
\hline Cleland 2001 & Wrong patient population \\
\hline Cleland 2003 & Wrong patient population \\
\hline Cleland 2004 & Wrong study design \\
\hline Cleland 2006 & Wrong study design \\
\hline Cleland 2007 & Wrong study design \\
\hline Cleland 2010 & Wrong study design \\
\hline Cleland 2011 & Wrong study design \\
\hline
\end{tabular}




\begin{tabular}{|c|c|}
\hline Study & Reason for exclusion \\
\hline Cleland 2013 & Wrong study design \\
\hline Cohen-Solal 2005 & Wrong patient population \\
\hline Cohn 1993 & Wrong study design \\
\hline Cohn 1996a & Wrong study design \\
\hline Cohn 1996b & Wrong study design \\
\hline Cohn 2007 & Wrong study design \\
\hline Coletta 2008 & Wrong study design \\
\hline Coletta 2009 & Wrong study design \\
\hline Comin-Colet 2002 & Wrong study design \\
\hline CONSENSUS & EF unclear. We did not receive a response from the trialists to our enquiry for details. \\
\hline CONSENSUS II & $\begin{array}{l}\text { Mean EF suggests a subgroup of eligible participants. We did not receive a response from the trial- } \\
\text { ists to our enquiry. }\end{array}$ \\
\hline Conti 2005 & Wrong study design \\
\hline Corder 1993 & EF unclear. Unable to identify current contact details. \\
\hline Crouse 2011 & Wrong study design \\
\hline Dahlstrom 2007 & Wrong study design \\
\hline Davie 2001 & Wrong study design \\
\hline De Melo 2011 & Wrong comparator \\
\hline de Teresa 1995 & Wrong study design \\
\hline DeBock 1994 & EF unclear. Unable to find current contact details for trialists. \\
\hline Dekleva 2012 & Wrong comparator \\
\hline Demers 2001 & Wrong patient population \\
\hline Desai 2013 & Wrong study design \\
\hline Deswal 2010 & $\begin{array}{l}\text { EF unclear. We did not receive a response from trialists to our query on the clarification of inclu- } \\
\text { sion criteria. }\end{array}$ \\
\hline Ding 2008 & Wrong comparator \\
\hline Ditiatkov 1999 & Wrong study design \\
\hline Donal 2008 & Wrong study design \\
\hline Dragana 2015 & Wrong comparator \\
\hline
\end{tabular}

Beta-blockers and inhibitors of the renin-angiotensin aldosterone system for chronic heart failure with preserved ejection fraction 


\begin{tabular}{|c|c|}
\hline Study & Reason for exclusion \\
\hline Edner 2013 & Wrong study design \\
\hline Eichhorn 1994 & subgroup of participants of interest; did not receive a response from trialists to our enquiry. \\
\hline Eichhorn 2003 & Wrong patient population \\
\hline Er 2005 & Wrong study design \\
\hline Ertl 1999 & Wrong study design \\
\hline \multirow[t]{2}{*}{ EudraCT 2004-004169-13 } & $\begin{array}{l}\text { Trial registry record states completed but no contact details given an no published results identi- } \\
\text { fiable. Sponsor: South Manchester University Hospital NHS Trust. Emailed sponsor to ask whether } \\
\text { results are available. }\end{array}$ \\
\hline & $\begin{array}{l}\text { Unclear whether http://www.isrctn.com/ISRCTN77645264 is the same trial. Tried to contact inves } \\
\text { tigator but email was undeliverable. }\end{array}$ \\
\hline Fauchier 2009 & Wrong study design \\
\hline Feola 2003 & Wrong study design \\
\hline Flammer 2013 & Wrong patient population \\
\hline Flather 2016 & Wrong study design \\
\hline Flesch 2006 & Wrong study design \\
\hline Follath 1996 & Wrong study design \\
\hline Fonarow 2004 & Wrong study design \\
\hline Fonarow 2007 & Wrong patient population \\
\hline Fowler 1999 & Wrong study design \\
\hline Franciosa 2002 & Wrong intervention \\
\hline Fukunami 1991 & Wrong study design \\
\hline Galinier 2007 & Wrong study design \\
\hline Galloe 2006 & $\begin{array}{l}\text { Potential eligible subgroup. Did not receive a response from trialists to our enquiry for outcome } \\
\text { data for subgroup. }\end{array}$ \\
\hline Gardner 2003 & Wrong study design \\
\hline Gardner 2004 & Wrong study design \\
\hline Ghali 2002 & Wrong patient population \\
\hline Gheorghiade 2009 & Wrong patient population \\
\hline Good 1994 & Wrong patient population \\
\hline Goodfield 1999 & Wrong patient population \\
\hline
\end{tabular}




\begin{tabular}{|c|c|}
\hline Study & Reason for exclusion \\
\hline Gottlieb 1996 & Wrong patient population \\
\hline Grajek 2008 & Review \\
\hline Greenberg 1996 & Wrong patient population \\
\hline Gremmler 2000 & EF unclear. Unable to identify current contact details. \\
\hline Groenning 2000 & Wrong patient population \\
\hline Groenning 2001 & Wrong study design \\
\hline Groenning 2002 & Wrong patient population \\
\hline Gruner 2007 & Wrong patient population \\
\hline Guazzi 1998 & Wrong patient population \\
\hline Guazzi 1999 & Wrong patient population \\
\hline Gøtzsche 1992 & subgroup with $\mathrm{HF}$ and LVEF $>40 \%$. We did not receive a response from trialists to our enquiry. \\
\hline Hanping 1997 & Wrong study design \\
\hline Hara 2000 & Wrong comparator \\
\hline Hauf 1993 & Wrong study design \\
\hline Hole 2004 & Wrong patient population \\
\hline Holland 2010 & $\begin{array}{l}\text { Limited information in conference abstract. Response to our enquiry for further details received: } \\
\text { "the data you've requested was not collected on this group of patients beyond what has been } \\
\text { published in that abstract". As we could not confirm whether the participants meet our inclusion } \\
\text { criteria, this study was excluded. }\end{array}$ \\
\hline Hong 2003 & Wrong intervention \\
\hline Hoppe 2007 & Wrong study design \\
\hline Hori 2004 & Wrong patient population \\
\hline Hung 2010 & Wrong study design \\
\hline IRIS-HF & $\begin{array}{l}\text { Response from trialists received when asked for outcome data for subgroup of interest: no data } \\
\text { specifically for participants in subgroup of interest (LVEF } 40-45 \%) \text { provided. Confirmed that QoL, } \\
\text { mortality and HF hospitalisation were not formal endpoints. Hyperkalaemia was not shown by } \\
\text { any participants. }\end{array}$ \\
\hline Ito 2012 & Wrong study design \\
\hline Jamieson 1991 & Wrong study design \\
\hline Jellis 2014 & HF/EF unclear. No response to our enquiry for details. \\
\hline Jessup 2003 & Wrong study design \\
\hline
\end{tabular}




\begin{tabular}{|c|c|}
\hline Study & Reason for exclusion \\
\hline Jong 2010 & Wrong study design \\
\hline Kanoupakis 2008 & Wrong patient population \\
\hline Kapel'ko 2011 & Wrong study design \\
\hline Kasama 2007 & Wrong comparator \\
\hline Keren 1992 & Wrong patient population \\
\hline Keren 1994 & Wrong patient population \\
\hline Khalid 2013 & Wrong study design \\
\hline Khand 2015 & Wrong patient population \\
\hline Kikuchi 2016 & Wrong patient population \\
\hline Kimura 2011 & Wrong patient population \\
\hline Kinugawa 2007 & Wrong study design \\
\hline Kjekshus 2007 & Wrong study design \\
\hline Kjøller-Hansen 1998 & Wrong patient population \\
\hline Kleber 1991a & $\begin{array}{l}\text { No participants with heart failure with preserved ejection fraction (confirmed by trialist via email } \\
\text { on } 20 \text { November 2017). }\end{array}$ \\
\hline Kleber 1991b & Heart failure was not an inclusion criteria (confirmed by trialist via email on 15 November 2017). \\
\hline Kongstad-Rasmussen 1998 & EF unclear ("ejection fraction measurement was not part of the protocol") \\
\hline Krum 1996 & Wrong patient population \\
\hline Krum 2015 & Wrong patient population \\
\hline Kulbertus 2003 & wrong study design \\
\hline Kuznar 2003 & Wrong patient population \\
\hline Lang 1995 & cross-over trial \\
\hline Larsen 1996 & EF unclear. Contacted trialists. Response: data are no longer available. \\
\hline Lechat 1993 & LVEF unclear, otherwise eligible. Emailed investigator but did not receive a response. \\
\hline Leonetti 1999 & Wrong patient population \\
\hline Lewis 1988 & EF unclear. Unable to find current contact. \\
\hline Li 2005 & Wrong population \\
\hline Liebson 2004 & Wrong patient population \\
\hline
\end{tabular}




\begin{tabular}{|c|c|}
\hline Study & Reason for exclusion \\
\hline Lindenfeld 2001 & Wrong patient population \\
\hline Lindsay 1999 & Wrong study design \\
\hline Liu 2014 & Wrong patient population \\
\hline Logeart 2006 & Wrong study design \\
\hline Lopez 2000 & Wrong study design \\
\hline Lou 2009 & Wrong study design \\
\hline Luo 2007 & Wrong study design \\
\hline Ma 2005 & Wrong population \\
\hline MacGregor 2009 & Wrong patient population \\
\hline Mak 2008 & EF unclear. unable to find current contact details for trialist. \\
\hline Malnick 2007 & Wrong patient population \\
\hline Maron 2013 & LVEF unclear. Contacted trialists. No response. \\
\hline Mazayev 1998 & LVEF unclear, otherwise eligible. Unable to find current contact details for investigators. \\
\hline McAnulty 2004 & Wrong comparator \\
\hline McCullough 2012 & Wrong patient population \\
\hline Mcllwain 1997 & Wrong study design \\
\hline McKelvie 2012 & Wrong study design \\
\hline McMurray 2000 & Wrong study design \\
\hline McMurray 2004 & Wrong study design \\
\hline Melo 2011 & Wrong comparator \\
\hline Melo 2012 & Wrong comparator \\
\hline Messias 2016 & Wrong study design \\
\hline Meuleman 2007 & wrong participants \\
\hline Mitrovic 2005 & Wrong study design \\
\hline Mochizuki 2004 & retraction \\
\hline Morales 2011 & Wrong patient population \\
\hline Murdoch 2001 & Wrong patient population \\
\hline NCT00293150 & terminated due to lack of eligible participants \\
\hline
\end{tabular}

Beta-blockers and inhibitors of the renin-angiotensin aldosterone system for chronic heart failure with preserved ejection fraction 


\begin{tabular}{|c|c|}
\hline Study & Reason for exclusion \\
\hline NCT00523757 & $\begin{array}{l}\text { Trial did not take place as planned (as per information from trialists: "We abandoned this study as } \\
\text { we could not adequately recruit. No results to present.") }\end{array}$ \\
\hline NCT01691118 & $\begin{array}{l}\text { Completed but no publication with results identified. Emailed trialists to ask for clarification on } \\
\text { comparator (placebo or conventional antihypertensive treatment). No response. }\end{array}$ \\
\hline Nodari 2003 & Wrong comparator \\
\hline Nunez 2016 & Wrong study design \\
\hline O'Callaghan 1995 & Wrong study design \\
\hline O'Keefe 2008 & Wrong patient population \\
\hline O'Keeffe 2015 & Wrong comparator \\
\hline O'Meara 2012 & Wrong patient population \\
\hline Ostergren 2004 & Wrong study design \\
\hline Palazzuoli 2005 & Wrong patient population \\
\hline Paolisso 1992 & Wrong study design \\
\hline Paraskevaidis 2006 & Wrong patient population \\
\hline Park 2016 & Wrong comparator \\
\hline Patten 1997 & Wrong patient population \\
\hline Pennell 2000 & Wrong patient population \\
\hline Pierard 2002 & Wrong patient population \\
\hline Pina 2004 & Wrong study design \\
\hline Pitt 2005 & Wrong patient population \\
\hline Pitt 2008 & Wrong patient population \\
\hline Pitt 2011 & Wrong intervention \\
\hline Pourdjabbar 2015 & Wrong study design \\
\hline Premkumar 2016 & Wrong patient population \\
\hline Quaife 1998 & Wrong patient population \\
\hline Ramaswamy 2003 & Wrong study design \\
\hline Remme 2001 & Wrong patient population \\
\hline Remme 2004 & Wrong patient population \\
\hline Remme 2005 & Wrong patient population \\
\hline
\end{tabular}

Beta-blockers and inhibitors of the renin-angiotensin aldosterone system for chronic heart failure with preserved ejection fraction 


\begin{tabular}{|c|c|}
\hline Study & Reason for exclusion \\
\hline Rimatori 1990 & LVEF unclear, otherwise eligible. Unable to find current contact details for investigators. \\
\hline Roongsritong 2005 & Wrong patient population \\
\hline Rosa 2011 & Wrong intervention \\
\hline Rosenkranz 2003 & Wrong study design \\
\hline Rossignol 2011 & Wrong patient population \\
\hline Sakai 2011 & Wrong intervention \\
\hline Sanderson 1998 & $\begin{array}{l}\text { Subgroup of interest LVEF } 40-45 \% \text {. Investigator responded to our enquiry for data: "the mean EF } \\
\text { was only } 26.9 \% \text { and I doubt any of the patients were in the group of EF } 40 \% \text { to }<45 \% \text {. [...] I do not } \\
\text { have the original data now." }\end{array}$ \\
\hline Sanghera 2011 & Wrong study design \\
\hline Santulli 2015 & Wrong study design \\
\hline Sardu 1991 & $\begin{array}{l}\text { LVEF not specified as an inclusion criteria, mean LVEF at baseline } 35.4,4.7 \% \text {. Could not find cur- } \\
\text { rent contact details for investigator. }\end{array}$ \\
\hline Schindler 2008 & Wrong patient population \\
\hline Schwab 2009 & Wrong study design \\
\hline Segovia 2008 & Wrong study design \\
\hline Shimamoto 2007 & Wrong patient population \\
\hline Sidorenko 2008 & Wrong patient population \\
\hline Silva 2014 & Wrong patient population \\
\hline Smith 2012 & Wrong study design \\
\hline Spoto 2002 & Wrong study design \\
\hline Stecker 2005 & Wrong patient population \\
\hline Stiefelhagen 2006 & Wrong study design \\
\hline Struthers 2004 & Wrong study design \\
\hline Swedberg 1996 & Wrong study design \\
\hline Swedberg 1999 & Wrong study design \\
\hline Szajnbok 1993 & $\begin{array}{l}\text { Portuguese paper. Reported outcomes not of interest but subgroup of participants eligible. } \\
\text { Emailed investigators to ask about measured outcomes for subgroup of interest. Response: data } \\
\text { not available. }\end{array}$ \\
\hline Szymanski 2009 & Wrong study design \\
\hline
\end{tabular}




\begin{tabular}{|c|c|}
\hline Study & Reason for exclusion \\
\hline Taheri 2009 & subgroup of interest LVEF $40-45 \%$. Contacted investigators. No response. \\
\hline Takekoshi 2004 & Wrong study design \\
\hline Tala 2011a & Wrong patient population \\
\hline Tala 2011b & Wrong patient population \\
\hline Tan 2013 & Wrong study design \\
\hline Tatsumi 2006 & Wrong study design \\
\hline Taylor 2003 & Wrong intervention \\
\hline Teerlink 2003 & Wrong patient population \\
\hline Tereshchenko 2005 & Wrong comparator \\
\hline Thornton 2004 & Wrong study design \\
\hline Thune 2008 & Wrong patient population \\
\hline Tinoco 2004 & Wrong study design \\
\hline Tsutamoto 2000 & Wrong study design \\
\hline Tsutamoto 2001 & Subgroup of interest (LVEF 40-45\%). Emailed investigators. No response. \\
\hline Tsutamoto 2005 & Wrong study design \\
\hline Tumasyan 2010 & Wrong comparator \\
\hline Umemoto 2003 & Wrong study design \\
\hline Uusimaa 2001 & Wrong comparator \\
\hline Van den Berg 1993 & Wrong study design \\
\hline Van den Berg 1995 & LVEF unclear; response to our enquiry for details: cannot provide data \\
\hline Vasiuk 2001 & Wrong study design \\
\hline Vincent 2012 & Wrong patient population \\
\hline Vizir 2000 & Wrong patient population \\
\hline Vizzardi 2010 & Wrong patient population \\
\hline Vizzardi 2012 & LVEF unclear. Emailed investigators. No response. \\
\hline Vizzardi 2015a & Wrong study design \\
\hline Vizzardi 2015b & Wrong patient population \\
\hline
\end{tabular}




\begin{tabular}{|c|c|}
\hline Study & Reason for exclusion \\
\hline Volpe 1992 & $\begin{array}{l}\text { Subgroup of interest LVEF } 40-45 \% \text {. We received a response to our enquiry for more details on the } \\
\text { subgroup of interest confirming that the study was conducted in "patients with reduced EF". }\end{array}$ \\
\hline Volpe 2010 & Wrong patient population \\
\hline Voors 2008 & Wrong study design \\
\hline Waagstein 2003 & Wrong patient population \\
\hline Waldo 1995 & Wrong patient population \\
\hline Waldo 1996 & Wrong patient population \\
\hline Warner 1999 & Wrong patient population \\
\hline Weinberg 2001 & Wrong study design \\
\hline Weintraub 2005 & Wrong patient population \\
\hline Weir 2011 & Wrong patient population \\
\hline Wong 2002 & Wrong patient population \\
\hline Wong 2004 & Wrong patient population \\
\hline Woodley 1991 & Wrong patient population \\
\hline Wright 2014 & Wrong patient population \\
\hline Wu 2002 & LVEF unclear, otherwise eligible. Unable to find current contact details for investigators. \\
\hline Xu 2007 & Wrong population \\
\hline Yamamoto 2005 & Wrong study design \\
\hline Yan 2012 & LVEF unclear, otherwise eligible. Unable to find current contact details for investigators. \\
\hline Yoshihiro 2011 & Wrong intervention \\
\hline Young 2004 & Wrong patient population \\
\hline Zeng 2006 & Wrong patient population \\
\hline
\end{tabular}

Characteristics of studies awaiting assessment [ordered by study ID]

Anonymous 2003d

\begin{tabular}{ll}
\hline Methods & No abstract \\
\hline Participants & No abstract \\
\hline Interventions & Eplerenone \\
\hline
\end{tabular}


Anonymous 2003d (Continued)

\begin{tabular}{ll} 
Outcomes & No abstract \\
\hline Notes & Could not yet obtain full text
\end{tabular}

\section{Botoni 2010}

\begin{tabular}{ll}
\hline Methods & Individual, two-arm, RCT \\
\hline Participants & 42 \\
\hline Interventions & Placebo versus carvedilol \\
\hline Outcomes & QoL \\
\hline Notes & Unclear EF/HF status \\
\hline
\end{tabular}

\section{Dielievska 2015}

\begin{tabular}{ll}
\hline Methods & Individual, two-arm, RCT \\
\hline Participants & $\begin{array}{l}\text { 80 participants with EHT and COPD of II-Ill grade of bronchial obstruction (GOLD 2-3) with chronic } \\
\text { heart failure of the II and III NYHA classes and evidence of diastolic dysfunction }\end{array}$ \\
\hline Interventions & Spironolactone versus standard therapy, 3 months \\
\hline Outcomes & Left ventricular diastolic function, impaired relaxation of left ventricle, adverse events \\
\hline Notes & Have not yet obtained full text \\
\hline
\end{tabular}

\section{Gao 2010}

\begin{tabular}{ll}
\hline Methods & Unclear if RCT \\
\hline Participants & 32 elderly people with chronic heart failure \\
\hline Interventions & Control group and metoprolol group, 8 weeks \\
\hline Outcomes & Left ventricular end-diastolic diameter and left ventricular ejection fraction, lymphocyte GRK2 mR- \\
& NA level \\
\hline Notes & Chinese language paper (with translator) \\
\hline
\end{tabular}

Liu 2006

\begin{tabular}{ll}
\hline Methods & No abstract \\
\hline Participants & Elderly hypertensive people with diastolic heart failure \\
\hline
\end{tabular}


Liu 2006 (Continued)

\begin{tabular}{ll} 
Interventions & Spironolactone \\
\hline Outcomes & No abstract \\
\hline Notes & Chinese language paper. Eligibility criteria for trial unclear regarding LVEF. Emailed investigator. \\
\hline
\end{tabular}

Metra 1999

\begin{tabular}{ll}
\hline Methods & No abstract \\
\hline Participants & No abstract \\
\hline Interventions & No abstract \\
\hline Outcomes & No abstract \\
\hline Notes & Could not yet retrieve full text \\
\hline
\end{tabular}

\section{Rapezzi 1999}

\begin{tabular}{ll}
\hline Methods & No abstract \\
\hline Participants & No abstract \\
\hline Interventions & No abstract \\
\hline Outcomes & No abstract \\
\hline Notes & Could not yet retrieve full text \\
\hline
\end{tabular}

\begin{tabular}{ll}
\hline Zheng 2009 & Two-arm, individual, RCT \\
\hline Methods & 76 older people with diastolic heart failure \\
\hline Interventions & Carvediol versus routine treatment \\
\hline Outcomes & Unknown \\
\hline Notes & Chinese language paper. With translator \\
\hline
\end{tabular}

EF: ejection fraction

EHT: essential hypertension

HF: heart failure

$\mathrm{RCT}$ : randomised controlled trial

LVEF: left ventricular ejection fraction

GRK2: G protein-coupled receptor kinase 2

mRNA: messenger RNA

COPD: chronic obstructive pulmonary disease

Beta-blockers and inhibitors of the renin-angiotensin aldosterone system for chronic heart failure with preserved ejection fraction 
NYHA: New York Heart Association functional Classification of heart failure

QoL: quality of life

Characteristics of ongoing studies [ordered by study ID]

EudraCT 2013-000867-10

Trial name or title

Effects of Aldosterone Antagonism in Heart Failure with Preserved Ejection Fraction (HF-PEF): Cardiac MRI, Echocardiography, Exercise Physiology \& Quality of Life Assessment

\begin{tabular}{ll}
\hline Methods & Study design: RCT, open label, parallel 2-arm trial \\
& Follow-up: 6 months \\
\hline
\end{tabular}

Participants Planned inclusion: 60 participants

Inclusion criteria: Diagnosis of heart failure with preserved ejection fraction (HF-PEF), NYHA II-IV heart failure, Compliance with medical treatment, aged 18 years and over

Exclusion criteria: Contra-indication to undergoing full cardiac magnetic resonance study, Contra-indication to aldosterone antagonist therapy, Contra-indication to exercise testing, Unable to give informed consent

\begin{tabular}{ll}
\hline Interventions & Spironolactone versus placebo \\
\hline Outcomes & $\begin{array}{l}\text { Primary: Serial change in ECV, as calculated by T1 map using Cardiac Magnetic Resonance Imaging } \\
\text { following treatment with an aldosterone antagonist. } \\
\text { Secondary: To determine the effect of spironolactone in HF-PEF on: Alternative methods of mea- } \\
\text { suring ECV with CMR, Echocardiographically \& CMR derived measures of cardiac relaxation, Estab- } \\
\text { lish correlation between change in ECV and measures of cardiac relaxation, Exercise tolerance \& } \\
\text { quality of life }\end{array}$ \\
\hline Starting date & Unclear. Date of Ethics Committee Opinion: 13 November 2013 \\
\hline Contact information & Sven Plein, s.plein@leeds.ac.uk \\
\hline Notes & Status 'ongoing' in clinical trial registry entry. Emailed trialist to confirm status of trial. \\
& Response: "The study is complete and the main manuscript being prepared for submission expect- \\
ed in the next weeks." & Emailed trialists to ask for release of results data prior to publication. Response: not possible. \\
\hline
\end{tabular}

\section{IMPRESS-AF}

\begin{tabular}{ll}
\hline Trial name or title & Spironolactone in Atrial Fibrillation (IMPRESS-AF) \\
\hline Methods & Study design: parallel RCT \\
\hline Participants & Inclusion criteria: \\
& Permanent atrial fibrillation \\
& - Left ventricular ejection fraction $>=55 \%$ as established by echocardiography \\
& ity of life questionnaires in English or in their native language.
\end{tabular}

\section{Exclusion criteria:}

Beta-blockers and inhibitors of the renin-angiotensin aldosterone system for chronic heart failure with preserved ejection fraction 
- Severe systemic illness (life expectancy < 2 years)

- Severe chronic obstructive pulmonary disease (e.g. requiring home oxygen or chronic oral steroid therapy)

- Severe mitral/aortal valve stenosis/regurgitation

- Significant renal dysfunction (serum creatinine $220 \mu \mathrm{mol} / \mathrm{L}$ or above), anuria, active renal insufficiency, rapidly progressing or severe impairment of renal function, confirmed or suspected renal insufficiency in diabetic patients/ diabetic nephropathy

- Increase in potassium level to $>5 \mathrm{mmol} / \mathrm{L}$

- Recent coronary artery bypass graft surgery (within 3 months)

- Use of aldosterone antagonist within 14 days before randomisation

- Use of or potassium sparing diuretic within 14 days before randomisation

- Systolic blood pressure $>160 \mathrm{~mm} \mathrm{Hg}$

- Addison's disease

- Hypersensitivity to spironolactone or any of the ingredients in the product

- Any participant characteristic that may interfere with adherence to the trial protocol

\begin{tabular}{ll}
\hline Interventions & Spironolactone versus placebo \\
\hline Outcomes & $\begin{array}{l}\text { Exercise tolerance, QoL, left ventricular diastolic function, exercise tolerance, all-cause hospitalisa- } \\
\text { tions, spontaneous return to sinus rhythm }\end{array}$ \\
\hline Starting date & January 2015 \\
\hline Contact information & Eduard Shantsila: e.shantsila@bham.ac.uk \\
\hline
\end{tabular}

Notes Contacted trialists to ask about status and anticipated completion date, also queried whether heart failure with preserved ejection fraction was an inclusion criteria. No response.

\section{NCT02901184}

Trial name or title

Spironolactone Initiation Registry Randomized Interventional Trial in Heart Failure With Preserved Ejection Fraction, SPIRRIT-HFPEF

Methods

Study design: parallel, open-label, RCT

Anticipated start date: December 2017

Anticipated completion date: June 2022

\section{Participants}

\section{Estimated enrolment: 3500}

\section{Inclusion criteria:}

- Written informed consent

- Age $\geq 50$ years

- Stable heart failure defined by symptoms and signs of heart failure as judged by local Investigator

- Left ventricular ejection fraction (LVEF) $\geq 40 \%$ recorded in last 12 months (stratified to max $2 / 3$ rd in either $40-49 \%$ or $\geq 50 \%$ group)

- NT-proBNP (the N-terminal prohormone of brain natriuretic peptide) $>300 \mathrm{ng} / \mathrm{L}$ in sinus rhythm or $>750 \mathrm{ng} / \mathrm{L}$ in atrial fibrillation as an outpatient or prior to hospital discharge

\section{Exclusion criteria:}

- Previously enrolled in this study

- Known Ejection Fraction < 40\% ever 
- Current absolute indication or contraindication for MRA (mineral receptor antagonist) in judgement of Investigator

- Any condition other than heart failure with a life expectancy $<3$ years

- Known chronic liver disease

- Probable alternative explanations for symptoms:Known primary cardiomyopathy (hypertrophic, constrictive, restrictive, infiltrative, congenital)Primary hemodynamically significant valve diseaseRight-sided HF not due to left-sided HFSignificant chronic pulmonary disease defined by Investigator or by requirement for home $\mathrm{O} 2$ or oral steroids, Hemoglobin $<10 \mathrm{~g} / \mathrm{dL}(100 \mathrm{~g} / \mathrm{L}$ ) BMI (body mass index) > 40Heart rate > 105 bpmAny other condition judged by Investigator to be responsible for symptoms and/or signs

- Heart transplant or LVAD (left ventricular assist device) recipient

- Systolic blood pressure $<90$ or $>160$

- $\mathrm{K}$ (potassium) $>5.0 \mathrm{mmol} / \mathrm{L}$

- eGFR (estimated glomerular filtration rate) by MDRD (Modification of Diet in Renal Disease) $<30$ $\mathrm{mL} / \mathrm{min} / 1.73 \mathrm{~m} 2$ or creatinine $>2.5 \mathrm{mg} / \mathrm{dL}(221 \mu \mathrm{mol} / \mathrm{L})$

- Current lithium use

- Actual or potential for pregnancy

- Participation in another clinical trial where treatment for HF is studied

- Any condition that in the opinion of the Investigator may interfere with adherence to trial protocol

Interventions Spironolactone versus standard care

Outcomes

Primary: Time to death from any cause [Time Frame: Collected at data base lock, five (5) years after study start]

Secondary: Time to first hospitalization for heart failure [Time Frame: Collected at data base lock, five (5) years after study start ]

\begin{tabular}{ll}
\hline Starting date & December 2017 \\
\hline Contact information & Inger Ekman (inger.ekman@ucr.uu.se) \\
\hline Notes & \\
\hline
\end{tabular}

\section{NCT03066804}

Trial name or title

A Randomized, Double-blind Controlled Study Comparing LCZ696 to Medical Therapy for Comorbidities in HFpEF Patients (PARALLAX)

Methods

Study design: parallel RCT, blinding: participant, care provider, investigator, outcomes assessor

Anticipated start date: 29 September 2017

Anticipated completion date: 4 December 2019

Participants

Estimated enrolment: 2200

\section{Inclusion criteria:}

- Left ventricular ejection fraction (LVEF) $\geq 45 \%$ by echo within 6 months prior to study entry or during the screening epoch

- Symptom(s) of heart failure (HF) requiring treatment with diuretics (including loop, or thiazide diuretics, or mineralocorticoid antagonist [MRAs]) for at least 30 days prior to study entry

- NYHA class II-IV

- Structural heart disease (left atrial enlargement or left ventricular hypertrophy) documented by echocardiogram. 
- NT-proBNP $>220 \mathrm{pg} / \mathrm{mL}$ for patients with no atrial fibrillation/atrial flutter or $>600 \mathrm{pg} / \mathrm{mL}$ for patients with atrial fibrillation

- KCCQ clinical summary score $<75$

- Patients on ACEi or ARB therapy must have a history of HTN

\section{Exclusion criteria:}

- Any prior measurement of LVEF $<40 \%$

- Acute coronary syndrome (including myocardial infarction), cardiac surgery, other major CV surgery within 3 months, or urgent percutaneous coronary intervention (PCI) within 3 months or an elective $\mathrm{PCl}$ within 30 days prior to study entry

- Any clinical event within the 6 months prior to Visit 1 that could have reduced the LVEF (eg myocardial infarction, coronary artery bypass graft [CABG]), unless an echo measurement was performed after the event confirming the LVEF to be $\geq 40 \%$ and $E F \geq 45 \%$ by the time of screening

- Current acute decompensated HF requiring therapy.

- Current use of renin inhibitor(s)

- History of hypersensitivity to LCZ696 or its components

- Patients with a known history of angioedema

- Walking distance primarily limited by non-cardiac comorbid conditions

- Alternative reason for shortness of breath such as: significant pulmonary disease or severe COPD, haemoglobin $(\mathrm{Hgb})<10 \mathrm{~g} / \mathrm{dL}$ males and $<9.5 \mathrm{~g} / \mathrm{dL}$ females, or body mass index $(\mathrm{BMI})>40 \mathrm{~kg} / \mathrm{m}^{2}$.

- Systolic blood pressure (SBP) $\geq 180 \mathrm{mmHg}$ at study entry, or SBP $>150 \mathrm{mmHg}$ and $<180 \mathrm{mmHg}$ at study entry unless the patient is receiving 3 or more antihypertensive drugs, or $\mathrm{SBP}<110 \mathrm{mmHg}$ at study entry.

- Patients with $\mathrm{HbA1c}>7.5 \%$ not treated for diabetes

- Patients with prior major organ transplant or intent to transplant (i.e. on transplant list)

- eGFR $<30 \mathrm{~mL} / \mathrm{min} / 1.73 \mathrm{~m}^{2}$ as measured by MDRD at screening

- Serum potassium $>5.2 \mathrm{mmol} / \mathrm{L}$ at study entry

- History or presence of any other disease with a life expectancy of $<3$ years

- Pregnant or nursing women or women of child-bearing potential unless they are using highly effective methods of contraception

Other protocol-defined inclusion/exclusion criteria may apply.

Interventions

All patients who fulfill the inclusion/exclusion criteria will be stratified before randomization based upon prior therapy for comorbidities to one of 3 strata: ACEi, ARB or no RASi. Patients in the ACEi strata will receive LCZ696 or enalapril. Patients in the ARB strata will receive LCZ696 or valsartan. Patients in the no RASi strata will receive LCZ696 or matching placebo.

Outcomes

Primary: Change from baseline in N-terminal pro-brain natriuretic peptide (NT-proBNP) after 12 weeks

\section{Secondary:}

- Mean change from baseline in Kansas City Cardiomyopathy Questionnaire (KCCQ) Clinical Summary Score (CSS) [ Time Frame: baseline, week 24 ]

- Percentage of patients with $\geq 5$-points deterioration in KCCQ CSS at Week 24 [ Time Frame: baseline, week 24 ]

- Percentage of patients with $\geq 5$-points improvement in KCCQ CSS at Week 24 [ Time Frame: baseline, week 24 ]

- Change from baseline in the 6-minute walk test (6MWT) to week 24 [ Time Frame: baseline, week 24]

- Change in NYHA functional class from baseline to week 24 [ Time Frame: baseline, week 24 ]

- Change from baseline in SF-36 physical component summary (PCS) score to week 24 [ Time Frame: baseline, week 24] 
NCT03066804 (Continued)

Contact information_Novartis Pharmaceuticals (novartis.email@novartis.com)

Notes Comparison of interest: LCZ696 or matching placebo

Sponsor: Novartis Pharmaceuticals

Other identifiers: CLCZ696D2302, 2016-003410-28 ( EudraCT Number)

Zhou 2010

\begin{tabular}{ll}
\hline Trial name or title & b-PRESERV \\
\hline Methods & Study design: "multicentre, prospective, randomized, open-label, blinded endpoint trial" \\
\hline Participants & "A total of 1200 patients will be randomized to either b-blocker (metoprolol succinate) or control (n \\
$=600$ per group)." & "The most essential criteria for HFNEF in this trial are: heart failure symptoms, elevated NT-proBNP \\
& $\begin{array}{l}1500 \text { pg/mL, and LVEF 50\%. In addition, age .40 years and a recent hospitalization for heart failure, } \\
\text { but not within } 3 \text { months prior to enrolment, are required." }\end{array}$ \\
\hline Interventions & "The follow-up period is a minimum of 2 years." \\
\hline Outcomes & $\begin{array}{l}\text { "The primary endpoint is a composite of hospitalization for heart failure and cardiovascular death. } \\
\text { The secondary endpoints include cardiovascular death, heart failure mortality or hospitalization, } \\
\text { all-cause mortality, change in New York Heart Association class, change in left ventricular ejection } \\
\text { fraction, increase in NT-proBNP (by 50\% of the value at randomization), b-blocker tolerance, and } \\
\text { premature termination of b-blocker therapy due to adverse events" }\end{array}$ \\
\hline Starting date & $\begin{array}{l}\text { not reported } \\
\text { Contact information }\end{array}$ \\
\hline Notes & $\begin{array}{l}\text { Could not find the entry in the Chinese Clinical Trial Register with ID ChiCTR-TNC-00000144. Con- } \\
\text { tacted investigators to clarify status of study. No response. }\end{array}$ \\
\hline
\end{tabular}

ACEI: angiotensin-converting-enzyme inhibitor

ARB: angiotensin II receptor blockers

CMR: cardiac magnetic resonance

ECV: extra-cellular volume

HTN: hypertension

KCCQ: Kansas City Cardiomyopathy Questionnaire

LVEF: left ventricular ejection fraction

NYHA: New York Heart Association Classification of heart failure

QoL: quality of life

$\mathrm{RCT}$ : randomised controlled trial

\section{DATA AND ANALYSES}


Comparison 1. Beta-blockers versus placebo or no treatment

\begin{tabular}{llllll}
\hline Outcome or subgroup title & $\begin{array}{l}\text { No. of } \\
\text { studies }\end{array}$ & $\begin{array}{l}\text { No. of } \\
\text { partici- } \\
\text { pants }\end{array}$ & Statistical method & Effect size \\
\hline 1 Cardiovascular mortality (RR) & 3 & 1046 & Risk Ratio (M-H, Fixed, 95\% Cl) & $0.78[0.62,0.99]$ \\
\hline 2 Heart failure hospitalisation (RR) & 4 & 449 & Risk Ratio (M-H, Fixed, 95\% Cl) & $0.73[0.47,1.13]$ \\
\hline 2.1 Follow-up <12 months & 1 & 67 & Risk Ratio (M-H, Fixed, 95\% Cl) & $0.31[0.09,1.02]$ \\
\hline 2.2 Follow-up $\geq 12$ months & 2 & 285 & Risk Ratio (M-H, Fixed, 95\% Cl) & $0.79[0.48,1.31]$ \\
\hline 2.3 Follow-up unknown & 1 & 97 & Risk Ratio (M-H, Fixed, 95\% Cl) & $5.31[0.26,107.85]$ \\
\hline 3 All-cause mortality (RR) & 4 & 1105 & Risk Ratio (M-H, Fixed, 95\% Cl) & $0.82[0.67,1.00]$ \\
\hline 4 Quality of life (Minnesota) & 1 & & $\begin{array}{l}\text { Mean Difference (IV, Fixed, 95\% } \\
\text { Cl) }\end{array}$ & Totals not selected \\
\hline 5 Withdrawal due to adverse event & 2 & 338 & Risk Ratio (M-H, Fixed, 95\% Cl) & $18.07[2.45,133.04]$ \\
\hline
\end{tabular}

Analysis 1.1. Comparison 1 Beta-blockers versus placebo or no treatment, Outcome 1 Cardiovascular mortality (RR).

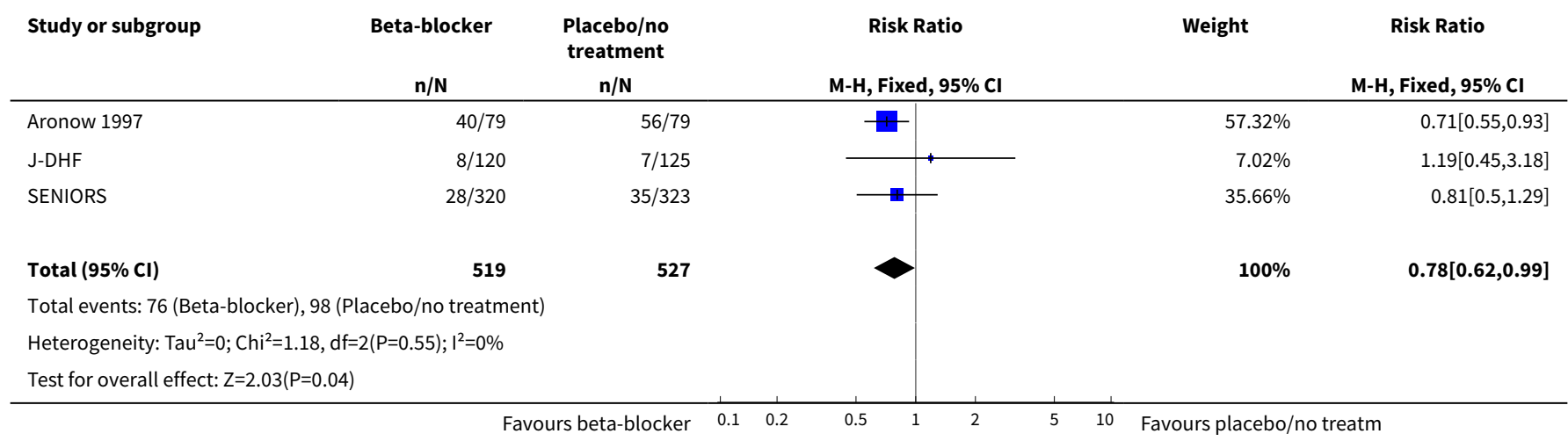

Analysis 1.2. Comparison 1 Beta-blockers versus placebo or no treatment, Outcome 2 Heart failure hospitalisation (RR).

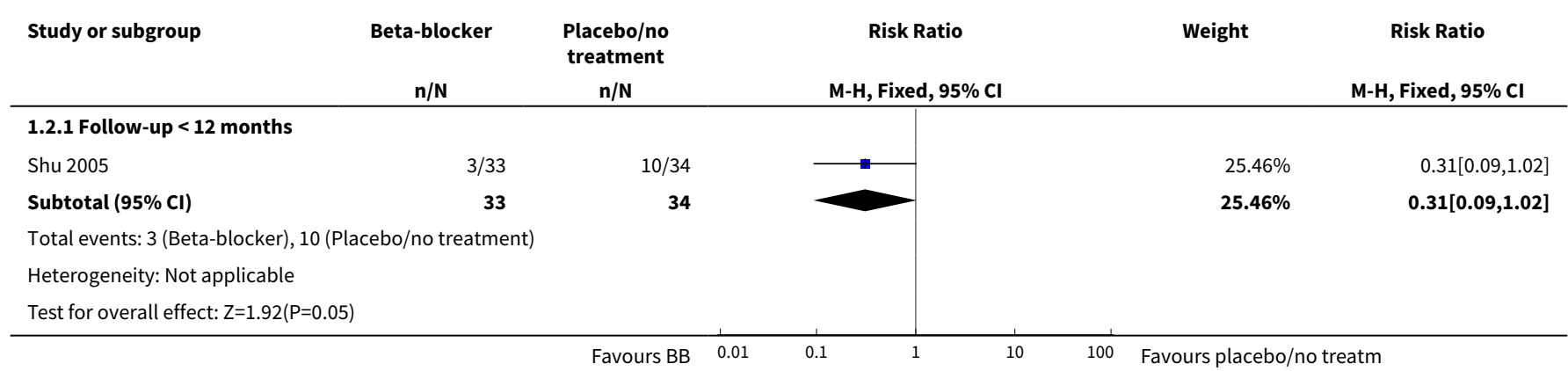

Beta-blockers and inhibitors of the renin-angiotensin aldosterone system for chronic heart failure with preserved ejection fraction 


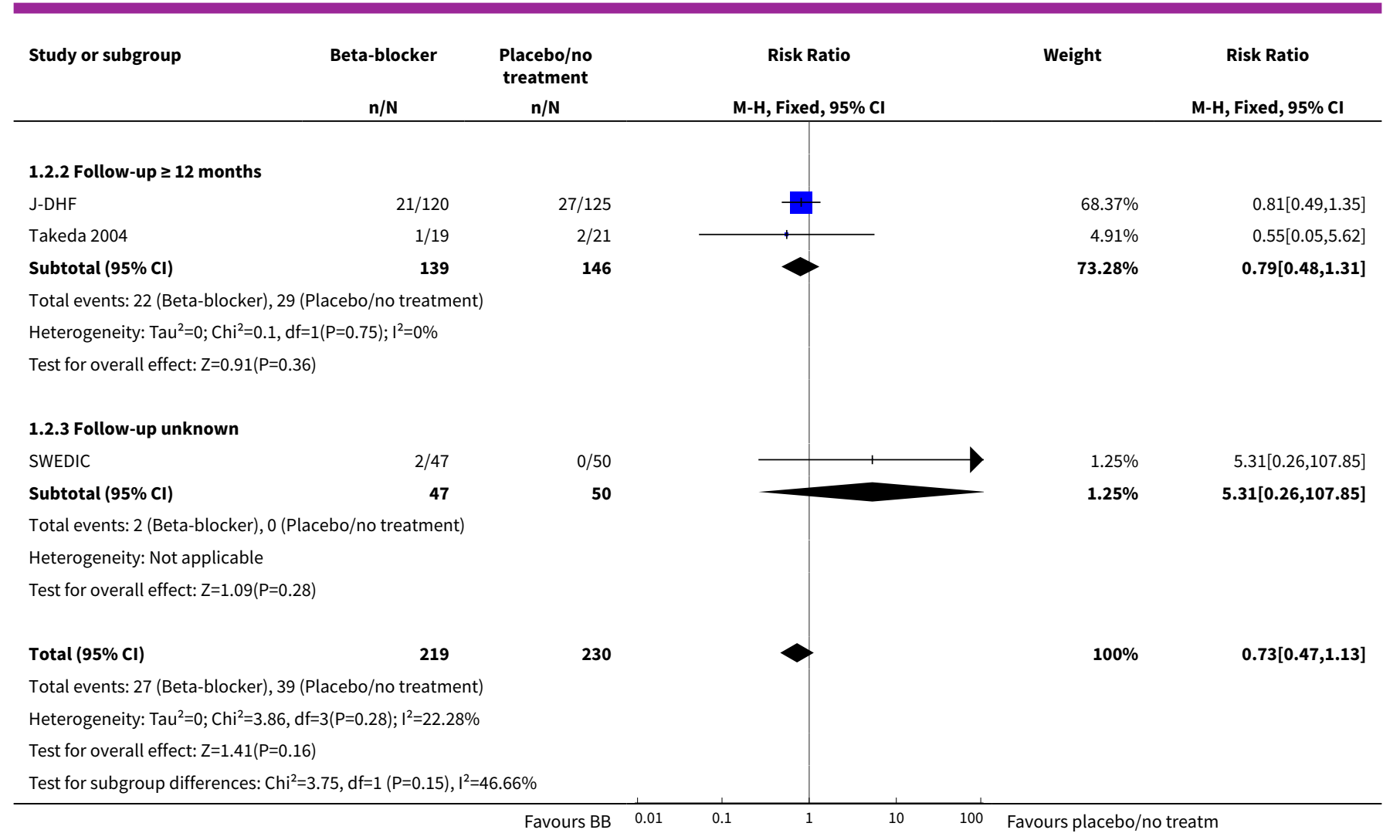

\section{Analysis 1.3. Comparison 1 Beta-blockers versus placebo or no treatment, Outcome 3 All-cause mortality (RR).}

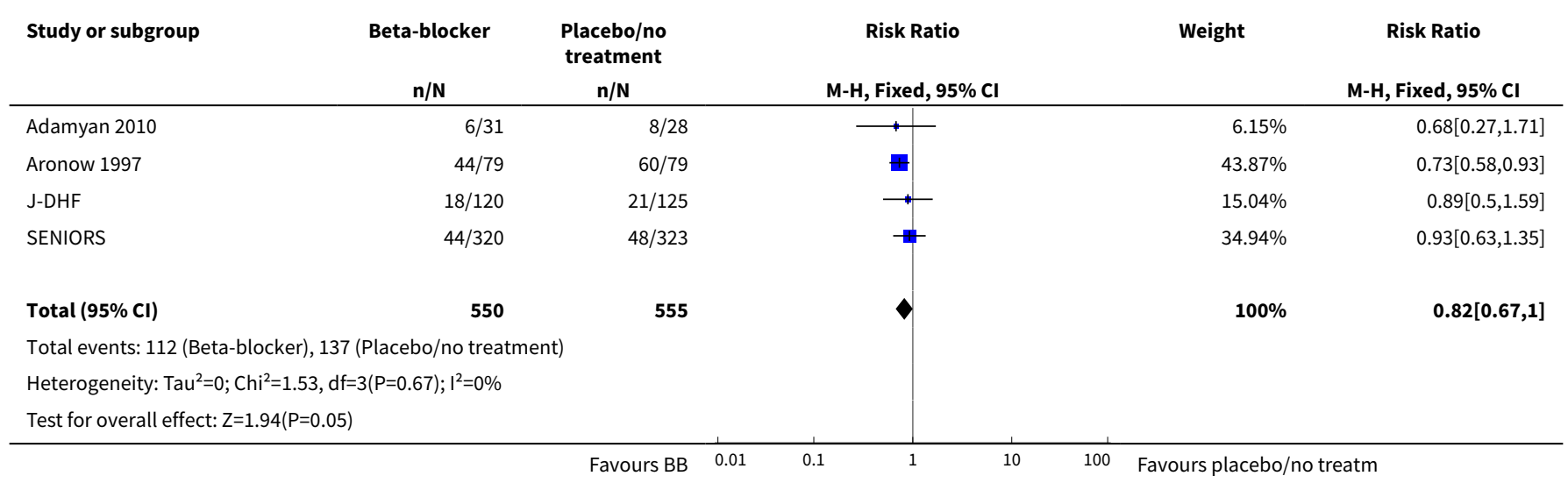

\section{Analysis 1.4. Comparison 1 Beta-blockers versus placebo or no treatment, Outcome 4 Quality of life (Minnesota).}

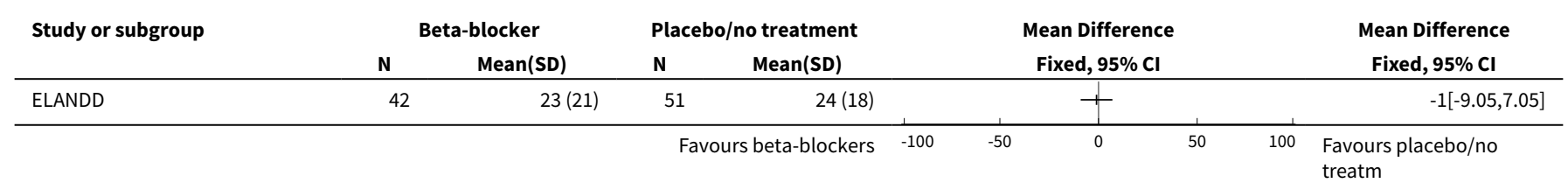




\section{Analysis 1.5. Comparison 1 Beta-blockers versus placebo or} no treatment, Outcome 5 Withdrawal due to adverse event.

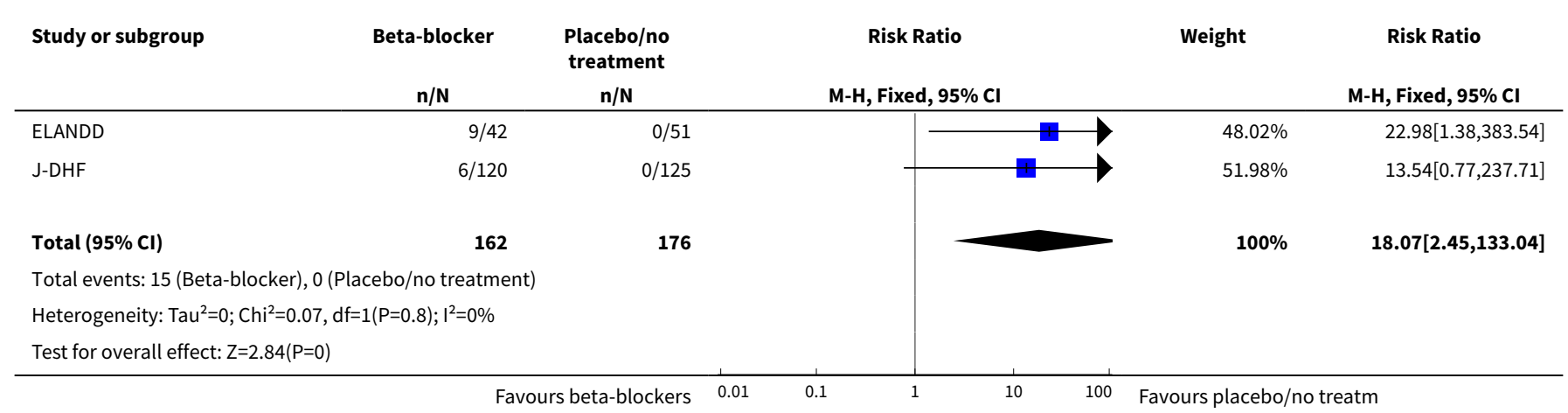

Comparison 2. Mineralocorticoid receptor antagonists versus placebo or no treatment

\begin{tabular}{|c|c|c|c|c|}
\hline Outcome or subgroup title & $\begin{array}{l}\text { No. of } \\
\text { studies }\end{array}$ & $\begin{array}{l}\text { No. of } \\
\text { partici- } \\
\text { pants }\end{array}$ & Statistical method & Effect size \\
\hline 1 Cardiovascular mortality (RR) & 3 & 4070 & Risk Ratio (M-H, Fixed, 95\% Cl) & $0.90[0.74,1.11]$ \\
\hline 2 Heart failure hospitalisation (RR) & 3 & 3714 & Risk Ratio (M-H, Fixed, 95\% Cl) & $0.82[0.69,0.98]$ \\
\hline 2.1 Follow-up $<12$ months & 1 & 44 & Risk Ratio (M-H, Fixed, 95\% Cl) & $0.55[0.05,5.61]$ \\
\hline 2.2 Follow-up $\geq 12$ months & 2 & 3670 & Risk Ratio (M-H, Fixed, 95\% Cl) & $0.82[0.69,0.98]$ \\
\hline 3 Heart failure hospitalisation (HR) & 2 & 3670 & Hazard Ratio (Fixed, 95\% Cl) & $0.82[0.69,0.98]$ \\
\hline 4 Hyperkalaemia & 6 & 4291 & Risk Ratio (M-H, Fixed, 95\% Cl) & $2.11[1.77,2.51]$ \\
\hline 5 All-cause mortality (RR) & 5 & 4207 & Risk Ratio (M-H, Fixed, 95\% Cl) & $0.91[0.78,1.06]$ \\
\hline 6 Quality of life & 5 & 603 & $\begin{array}{l}\text { Std. Mean Difference (IV, Ran- } \\
\text { dom, } 95 \% \mathrm{CI} \text { ) }\end{array}$ & $0.05[-0.23,0.34]$ \\
\hline 7 Quality of life (KCCQ) & 2 & 92 & $\begin{array}{l}\text { Mean Difference (IV, Random, } \\
95 \% \mathrm{CI})\end{array}$ & $-0.78[-28.02,26.46]$ \\
\hline 8 Quality of life (Minnesota) & 3 & 511 & $\begin{array}{l}\text { Mean Difference (IV, Random, } \\
95 \% \mathrm{CI} \text { ) }\end{array}$ & $0.84[-2.30,3.98]$ \\
\hline 9 Withdrawal due to adverse event & 4 & 3986 & Risk Ratio (M-H, Fixed, 95\% Cl) & $1.10[1.00,1.21]$ \\
\hline
\end{tabular}


Analysis 2.1. Comparison 2 Mineralocorticoid receptor antagonists versus placebo or no treatment, Outcome 1 Cardiovascular mortality (RR).

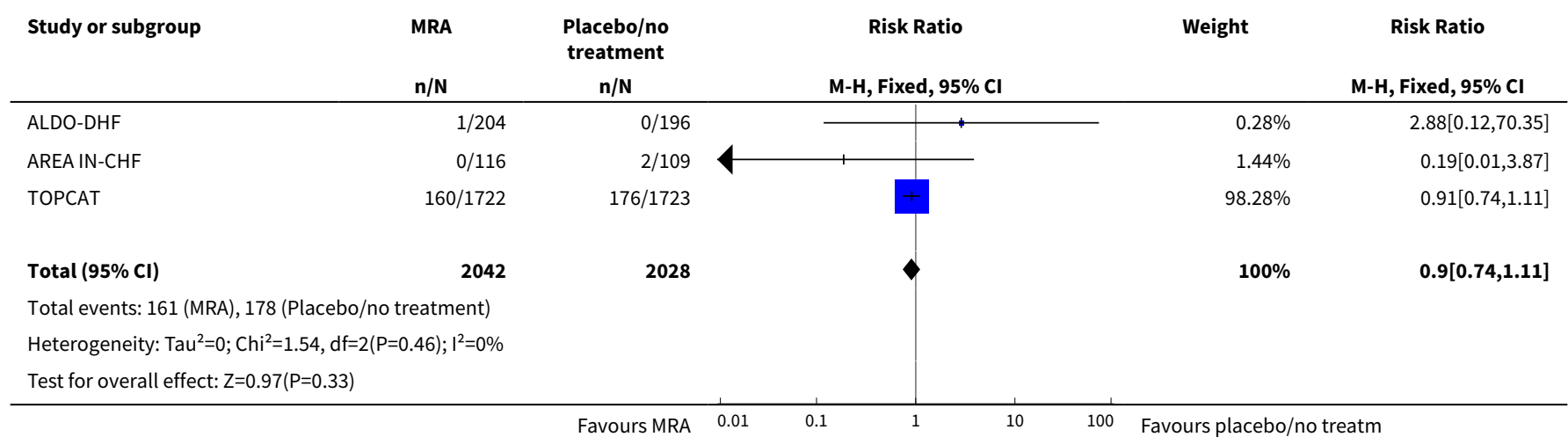

Analysis 2.2. Comparison 2 Mineralocorticoid receptor antagonists versus placebo or no treatment, Outcome $\mathbf{2}$ Heart failure hospitalisation (RR).

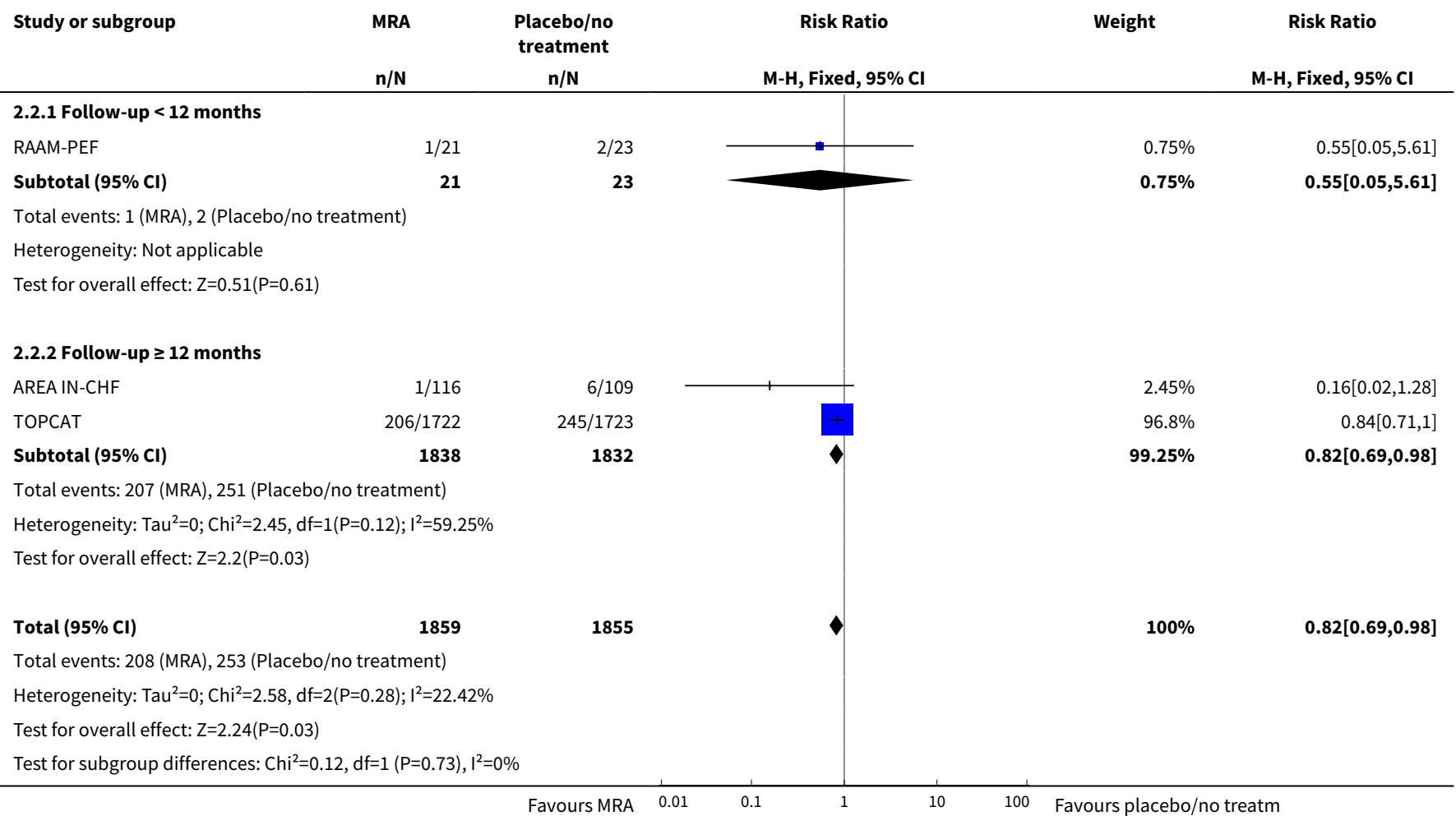


Analysis 2.3. Comparison 2 Mineralocorticoid receptor antagonists versus placebo or no treatment, Outcome 3 Heart failure hospitalisation (HR).

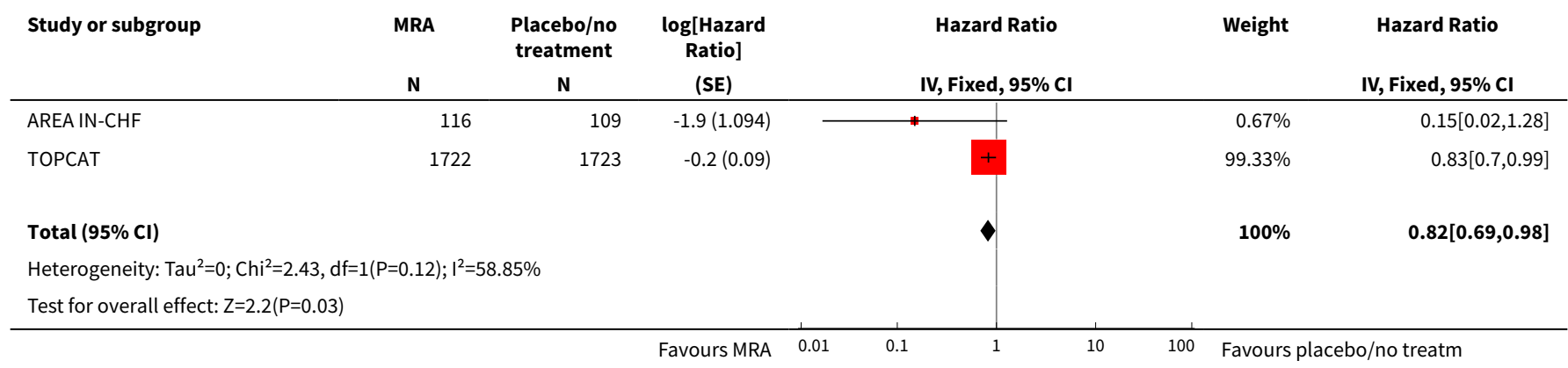

Analysis 2.4. Comparison 2 Mineralocorticoid receptor antagonists versus placebo or no treatment, Outcome 4 Hyperkalaemia.

\begin{tabular}{|c|c|c|c|c|c|}
\hline \multirow[t]{2}{*}{ Study or subgroup } & MRA & $\begin{array}{c}\text { Placebo/no } \\
\text { treatment }\end{array}$ & \multirow{2}{*}{$\begin{array}{c}\text { Risk Ratio } \\
\text { M-H, Fixed, 95\% Cl }\end{array}$} & Weight & \multirow{2}{*}{$\begin{array}{c}\text { Risk Ratio } \\
\text { M-H, Fixed, } 95 \% \mathrm{Cl}\end{array}$} \\
\hline & $\mathrm{n} / \mathrm{N}$ & $\mathrm{n} / \mathrm{N}$ & & & \\
\hline ALDO-DHF & $1 / 203$ & $1 / 195$ & & $0.63 \%$ & $0.96[0.06,15.25]$ \\
\hline AREA IN-CHF & $10 / 116$ & $2 / 109$ & & $1.27 \%$ & $4.7[1.05,20.96]$ \\
\hline Kurrelmeyer 2014 & $4 / 24$ & $1 / 24$ & 4 & $0.62 \%$ & $4[0.48,33.22]$ \\
\hline RAAM-PEF & $3 / 21$ & $1 / 23$ & $\longrightarrow$ & $0.59 \%$ & $3.29[0.37,29.2]$ \\
\hline TOPCAT & $322 / 1722$ & $157 / 1723$ & & $96.6 \%$ & $2.05[1.72,2.45]$ \\
\hline Total $(95 \% \mathrm{Cl})$ & 2150 & 2141 & $\diamond$ & $100 \%$ & $2.11[1.77,2.51]$ \\
\hline \multicolumn{6}{|c|}{ Total events: 342 (MRA), 162 (Placebo/no treatment) } \\
\hline \multicolumn{6}{|c|}{ Heterogeneity: Tau $^{2}=0 ; \mathrm{Chi}^{2}=2.36, \mathrm{df}=5(\mathrm{P}=0.8) ; \mathrm{I}^{2}=0 \%$} \\
\hline Test for overall effect & & & & & \\
\hline
\end{tabular}

Analysis 2.5. Comparison 2 Mineralocorticoid receptor antagonists versus placebo or no treatment, Outcome 5 All-cause mortality (RR).

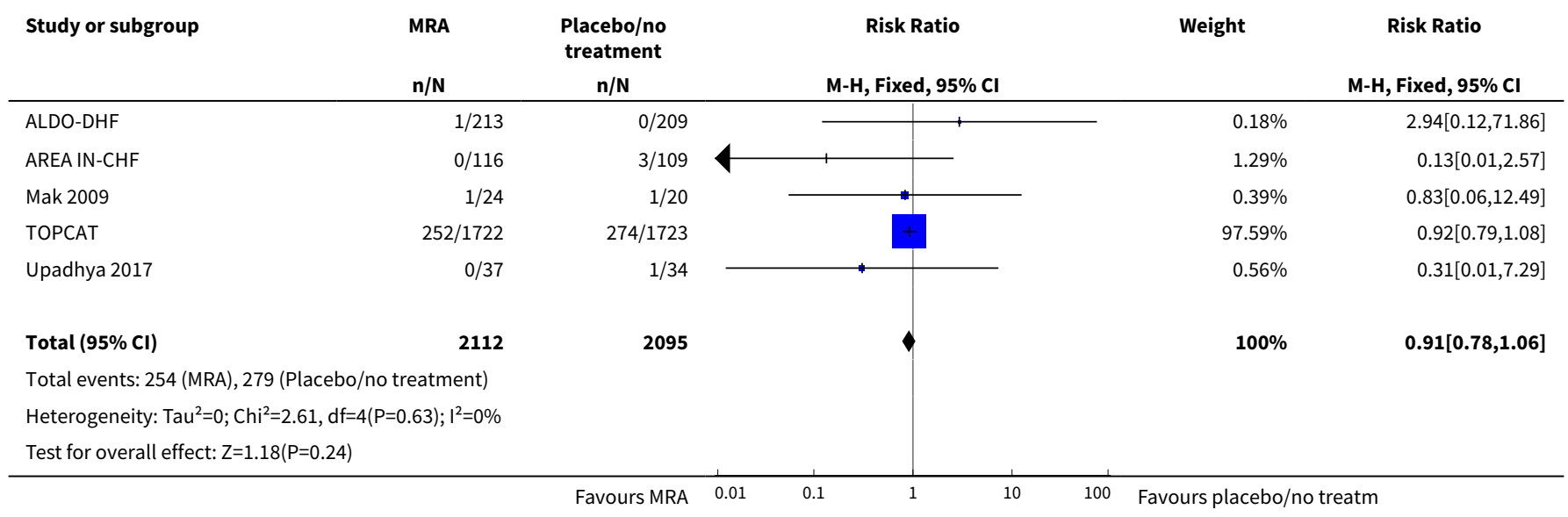

Beta-blockers and inhibitors of the renin-angiotensin aldosterone system for chronic heart failure with preserved ejection fraction 
Analysis 2.6. Comparison 2 Mineralocorticoid receptor antagonists versus placebo or no treatment, Outcome 6 Quality of life.

\begin{tabular}{|c|c|c|c|c|c|c|c|}
\hline \multirow[t]{2}{*}{ Study or subgroup } & \multicolumn{2}{|c|}{ MRA } & \multicolumn{2}{|c|}{$\begin{array}{c}\text { Placebo/no } \\
\text { treatment }\end{array}$} & \multirow{2}{*}{$\begin{array}{l}\text { Std. Mean Difference } \\
\text { Random, } 95 \% \mathrm{Cl} \\
\end{array}$} & \multirow[t]{2}{*}{ Weight } & \multirow{2}{*}{$\begin{array}{l}\text { Std. Mean Difference } \\
\text { Random, } 95 \% \mathrm{Cl}\end{array}$} \\
\hline & $\mathbf{N}$ & Mean(SD) & $\mathbf{N}$ & $\operatorname{Mean}(S D)$ & & & \\
\hline ALDO-DHF & 204 & $21(21.7)$ & 196 & $21(14.2)$ & 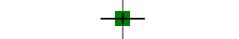 & $35.57 \%$ & $0[-0.2,0.2]$ \\
\hline Kurrelmeyer 2014 & 24 & $-48.5(26.9)$ & 24 & $-61.8(25.5)$ & & $15.72 \%$ & $0.5[-0.08,1.07]$ \\
\hline Mak 2009 & 23 & $23(20)$ & 17 & $20(13)$ & & $14.02 \%$ & $0.17[-0.46,0.8]$ \\
\hline RAAM-PEF & 21 & $-68.7(22.8)$ & 23 & $-54.2(22.8)$ & $\rightarrow$ & $14.67 \%$ & $-0.62[-1.23,-0.02]$ \\
\hline Total $\star \star \star$ & 309 & & 294 & & & $100 \%$ & $0.05[-0.23,0.34]$ \\
\hline \multicolumn{8}{|c|}{ Heterogeneity: $\mathrm{Tau}^{2}=0.05 ; \mathrm{Chi}^{2}=7.93, \mathrm{df}=4(\mathrm{P}=0.09) ; \mathrm{I}^{2}=49.55 \%$} \\
\hline Test for overall effec & & & & & & & \\
\hline
\end{tabular}

Analysis 2.7. Comparison 2 Mineralocorticoid receptor antagonists versus placebo or no treatment, Outcome 7 Quality of life (KCCQ).

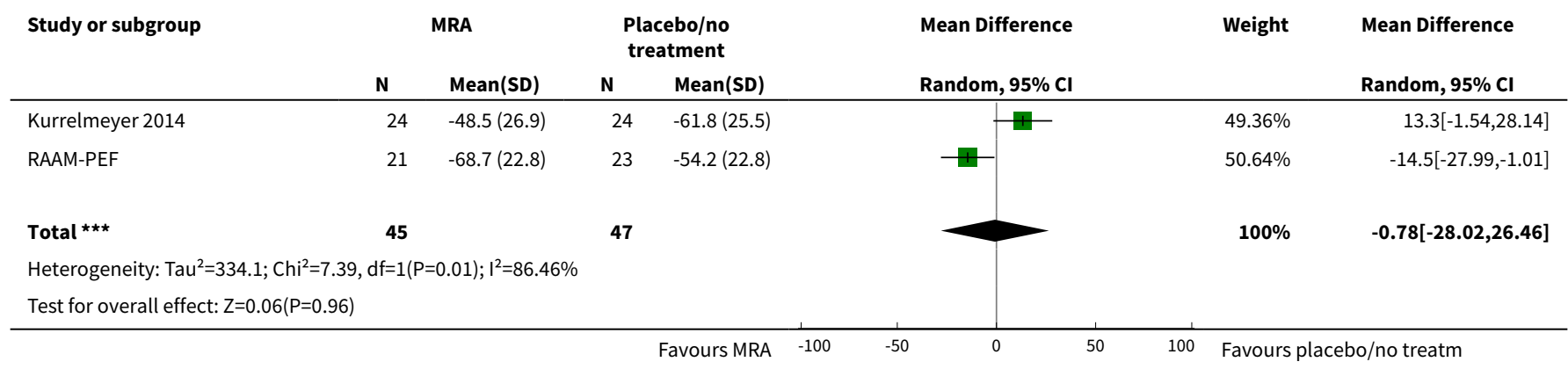

Analysis 2.8. Comparison 2 Mineralocorticoid receptor antagonists versus placebo or no treatment, Outcome 8 Quality of life (Minnesota).

\begin{tabular}{|c|c|c|c|c|c|c|c|}
\hline \multirow[t]{2}{*}{ Study or subgroup } & \multicolumn{2}{|c|}{ MRA } & \multicolumn{2}{|c|}{$\begin{array}{l}\text { Placebo/no } \\
\text { treatment }\end{array}$} & \multirow{2}{*}{$\begin{array}{l}\text { Mean Difference } \\
\text { Random, } 95 \% \mathrm{Cl}\end{array}$} & \multirow[t]{2}{*}{ Weight } & \multirow{2}{*}{$\begin{array}{l}\text { Mean Difference } \\
\text { Random, } 95 \% \mathrm{Cl}\end{array}$} \\
\hline & $\mathbf{N}$ & $\operatorname{Mean}(S D)$ & $\mathbf{N}$ & Mean(SD) & & & \\
\hline ALDO-DHF & 204 & $21(21.7)$ & 196 & $21(14.2)$ & & $76.62 \%$ & $0[-3.58,3.58]$ \\
\hline Mak 2009 & 23 & $23(20)$ & 17 & $20(13)$ & - & $9.37 \%$ & $3[-7.25,13.25]$ \\
\hline Upadhya 2017 & 37 & $29(18)$ & 34 & $25(18)$ & + & $14.01 \%$ & $4[-4.38,12.38]$ \\
\hline \multicolumn{8}{|c|}{ Heterogeneity: $\mathrm{Tau}^{2}=0 ; \mathrm{Chi}^{2}=0.93, \mathrm{df}=2(\mathrm{P}=0.63) ; \mathrm{I}^{2}=0 \%$} \\
\hline \multicolumn{3}{|c|}{ Test for overall effect: $Z=0.53(P=0.6)$} & & & & & \\
\hline
\end{tabular}


Analysis 2.9. Comparison 2 Mineralocorticoid receptor antagonists versus placebo or no treatment, Outcome 9 Withdrawal due to adverse event.

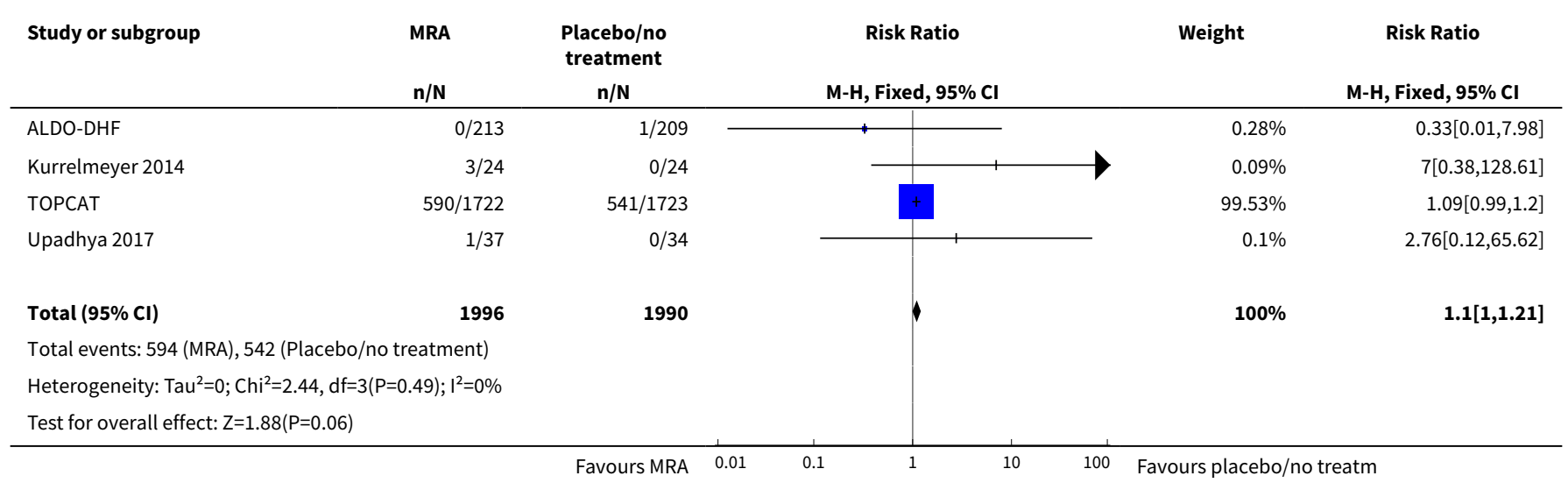

Comparison 3. Angiotensin converting enzyme inhibitors versus placebo or no treatment

\begin{tabular}{llllll}
\hline Outcome or subgroup title & $\begin{array}{l}\text { No. of } \\
\text { studies }\end{array}$ & $\begin{array}{l}\text { No. of } \\
\text { partici- } \\
\text { pants }\end{array}$ & Statistical method & Effect size \\
\hline 1 Cardiovascular mortality (RR) & 2 & 945 & Risk Ratio (M-H, Fixed, 95\% Cl) & $0.93[0.61,1.42]$ \\
\hline 2 Heart failure hospitalisation (RR) & 3 & 1019 & Risk Ratio (M-H, Fixed, 95\% Cl) & $0.86[0.64,1.15]$ \\
\hline 2.1 Follow-up <12 months & 1 & 74 & Risk Ratio (M-H, Fixed, 95\% Cl) & $0.42[0.09,2.04]$ \\
\hline 2.2 Follow-up $\geq 12$ months & 2 & 945 & Risk Ratio (M-H, Fixed, 95\% Cl) & $0.88[0.66,1.19]$ \\
\hline 3 Hyperkalaemia & 1 & Risk Ratio (M-H, Fixed, 95\% Cl) & Totals not selected \\
\hline 4 All-cause mortality (RR) & 4 & 1079 & Risk Ratio (M-H, Fixed, 95\% Cl) & $0.99[0.71,1.38]$ \\
\hline 5 Quality of life (Minnesota) & 2 & 154 & $\begin{array}{l}\text { Mean Difference (IV, Fixed, 95\% } \\
\text { Cl) }\end{array}$ & $-0.09[-3.66,3.48]$ \\
\hline 6 Withdrawal due to adverse event & 3 & 1019 & $\begin{array}{l}\text { Risk Ratio (M-H, Random, 95\% } \\
\text { Cl) }\end{array}$ & $1.53[0.26,9.00]$ \\
\hline
\end{tabular}

Analysis 3.1. Comparison 3 Angiotensin converting enzyme inhibitors versus placebo or no treatment, Outcome 1 Cardiovascular mortality (RR).

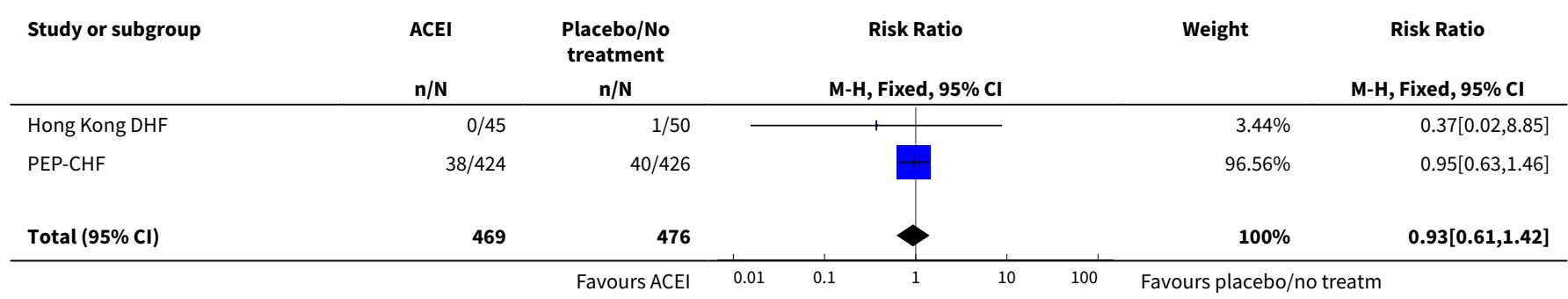




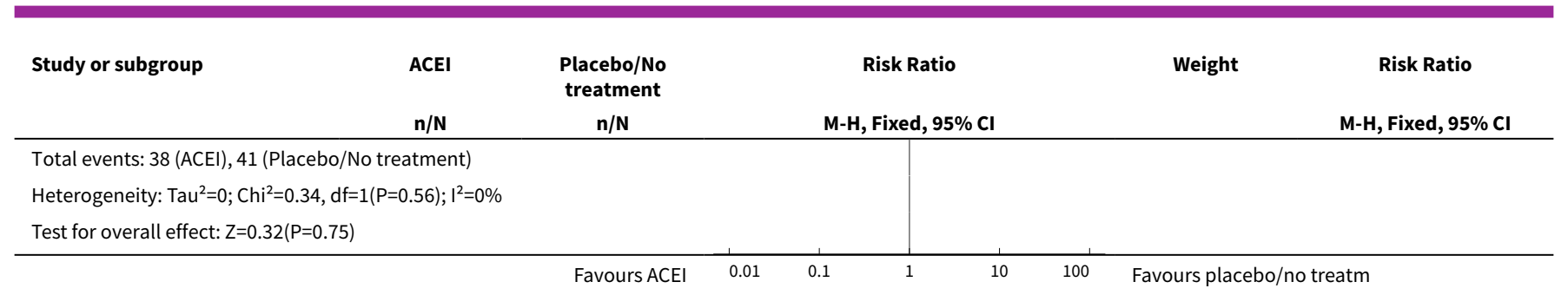

Analysis 3.2. Comparison 3 Angiotensin converting enzyme inhibitors versus
placebo or no treatment, Outcome 2 Heart failure hospitalisation (RR).

Study or subgroup ACEI Placebo/No

Risk Ratio

Weight

Risk Ratio

$\mathrm{n} / \mathrm{N}$ $\mathrm{n} / \mathrm{N}$ M-H, Fixed, $95 \% \mathrm{Cl}$ M-H, Fixed, $95 \% \mathrm{CI}$

3.2.1 Follow-up $<12$ months

Zi 2003

$2 / 36$

Subtotal $(95 \% \mathrm{CI})$

Total events: 2 (ACEI), 5 (Placebo/No treatment) Heterogeneity: Not applicable

Test for overall effect: $\mathrm{Z}=1.07(\mathrm{P}=0.28)$

3.2.2 Follow-up $\geq 12$ months

Hong Kong DHF

PEP-CHF

Total events: 69 (ACEI), 79 (Placebo/No treatment) Heterogeneity: $\mathrm{Tau}^{2}=0 ; \mathrm{Chi}^{2}=0.01, \mathrm{df}=1(\mathrm{P}=0.93) ; \mathrm{I}^{2}=0 \%$ Test for overall effect: $Z=0.81(P=0.42)$

Analysis 3.3. Comparison 3 Angiotensin converting enzyme inhibitors versus placebo or no treatment, Outcome 3 Hyperkalaemia.

\begin{tabular}{|c|c|c|c|c|c|c|c|}
\hline \multirow{2}{*}{$\begin{array}{l}\text { Study or subgroup } \\
\text { Zi } 2003\end{array}$} & $\begin{array}{l}\text { ACEI } \\
\mathrm{n} / \mathrm{N}\end{array}$ & \multicolumn{2}{|l|}{$\begin{array}{c}\text { Placebo/No treatment } \\
n / N\end{array}$} & \multicolumn{2}{|c|}{$\begin{array}{c}\text { Risk Ratio } \\
\text { M-H, Fixed, 95\% Cl } \\
\end{array}$} & & \multirow{2}{*}{$\begin{array}{c}\text { Risk Ratio } \\
\text { M-H, Fixed, 95\% Cl }\end{array}$} \\
\hline & $2 / 36$ & $0 / 38$ & & & & $\rightarrow$ & \\
\hline & & Favours ACEI & 0.01 & 0.1 & 1 & 100 & $\begin{array}{l}\text { Favours placebo/no } \\
\text { treatm }\end{array}$ \\
\hline
\end{tabular}


Analysis 3.4. Comparison 3 Angiotensin converting enzyme inhibitors versus placebo or no treatment, Outcome 4 All-cause mortality (RR).

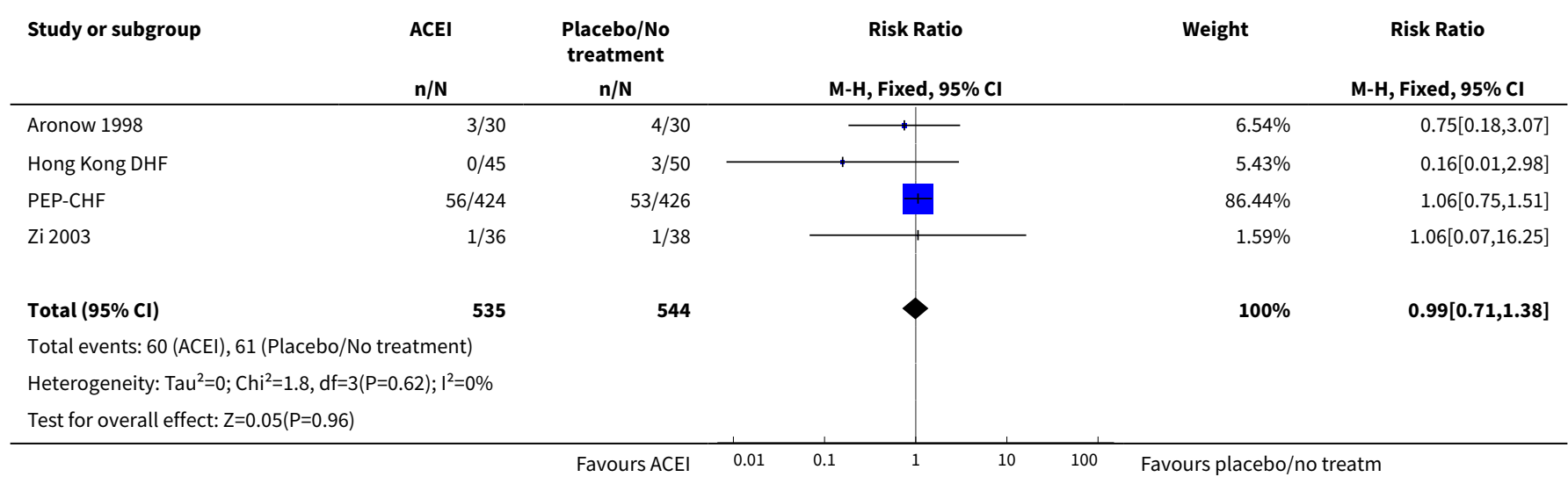

Analysis 3.5. Comparison 3 Angiotensin converting enzyme inhibitors versus placebo or no treatment, Outcome 5 Quality of life (Minnesota).

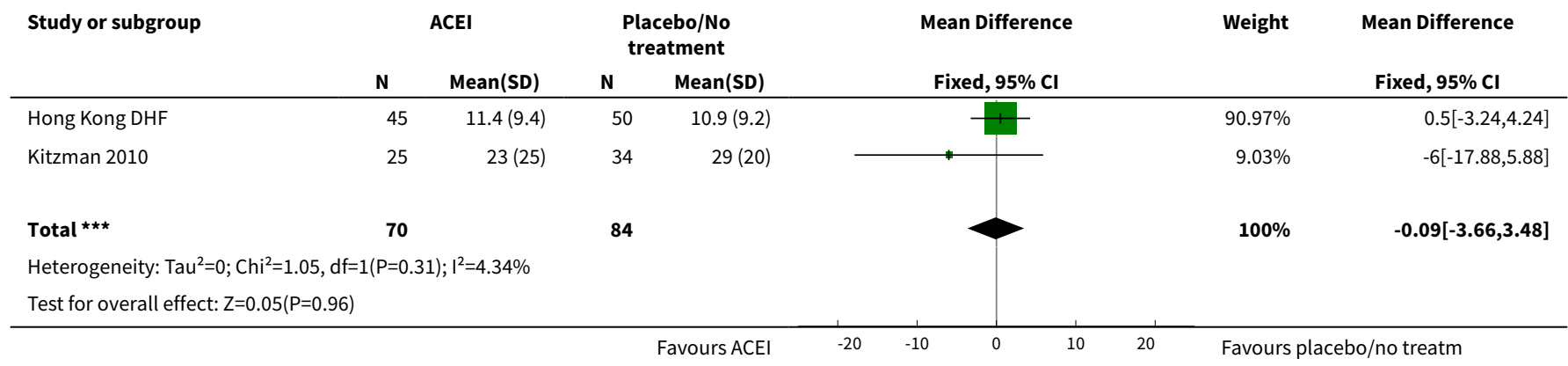

Analysis 3.6. Comparison 3 Angiotensin converting enzyme inhibitors versus placebo or no treatment, Outcome 6 Withdrawal due to adverse event.

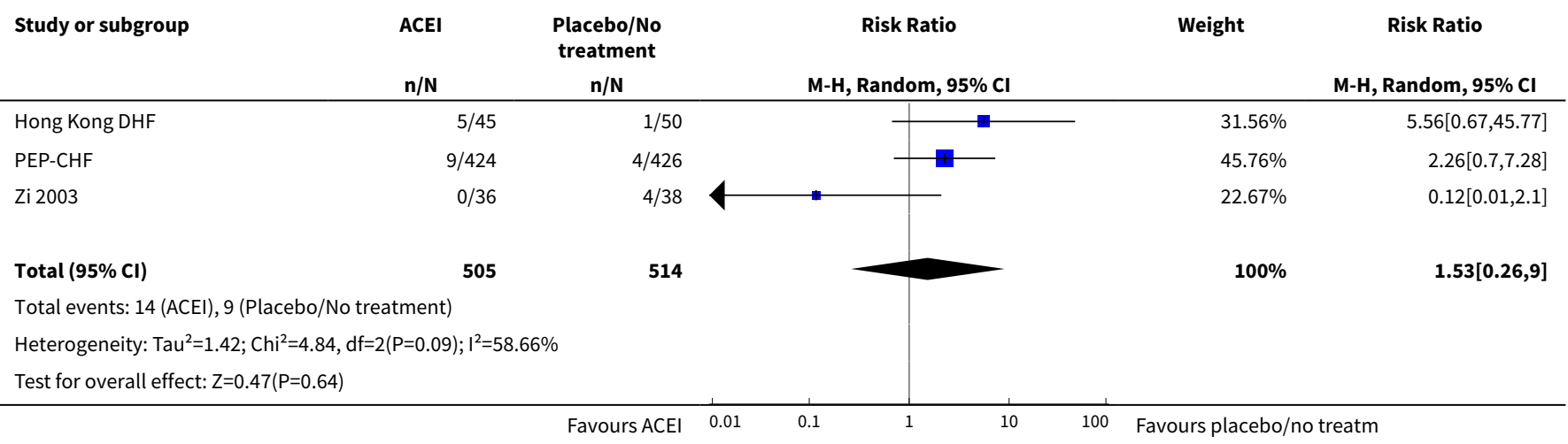


Comparison 4. Angiotensin receptor blockers versus placebo or no treatment

\begin{tabular}{llllll}
\hline Outcome or subgroup title & $\begin{array}{l}\text { No. of } \\
\text { studies }\end{array}$ & $\begin{array}{l}\text { No. of } \\
\text { partici- } \\
\text { pants }\end{array}$ & Statistical method & Effect size \\
\hline 1 Cardiovascular mortality (RR) & 3 & 7254 & Risk Ratio (M-H, Fixed, 95\% Cl) & $1.02[0.90,1.14]$ \\
\hline 2 Cardiovascular mortality (HR) & 2 & 5087 & Hazard Ratio (Fixed, 95\% Cl) & $1.00[0.89,1.13]$ \\
\hline 3 Heart failure hospitalisation (RR) & 3 & 7254 & Risk Ratio (M-H, Fixed, 95\% Cl) & $0.92[0.83,1.02]$ \\
\hline 4 Heart failure hospitalisation (HR) & 2 & 7148 & Hazard Ratio (Fixed, 95\% Cl) & $0.90[0.80,1.01]$ \\
\hline 5 Hyperkalaemia & 2 & 7148 & Risk Ratio (M-H, Fixed, 95\% Cl) & $1.88[1.07,3.33]$ \\
\hline 6 All-cause mortality (RR) & 4 & 7964 & Risk Ratio (M-H, Fixed, 95\% Cl) & $1.01[0.92,1.11]$ \\
\hline 7 All-cause mortality (HR) & 2 & 4838 & Hazard Ratio (Fixed, 95\% Cl) & $0.99[0.88,1.12]$ \\
\hline 8 Quality of life (Minnesota) & 3 & 3117 & $\begin{array}{l}\text { Mean Difference (IV, Fixed, 95\% } \\
\text { Cl) }\end{array}$ & $0.41[-0.86,1.67]$ \\
\hline 9 Withdrawal due to adverse event & 4 & 7406 & Risk Ratio (M-H, Fixed, 95\% Cl) & $1.22[1.09,1.36]$ \\
\hline
\end{tabular}

Analysis 4.1. Comparison 4 Angiotensin receptor blockers versus placebo or no treatment, Outcome 1 Cardiovascular mortality (RR).

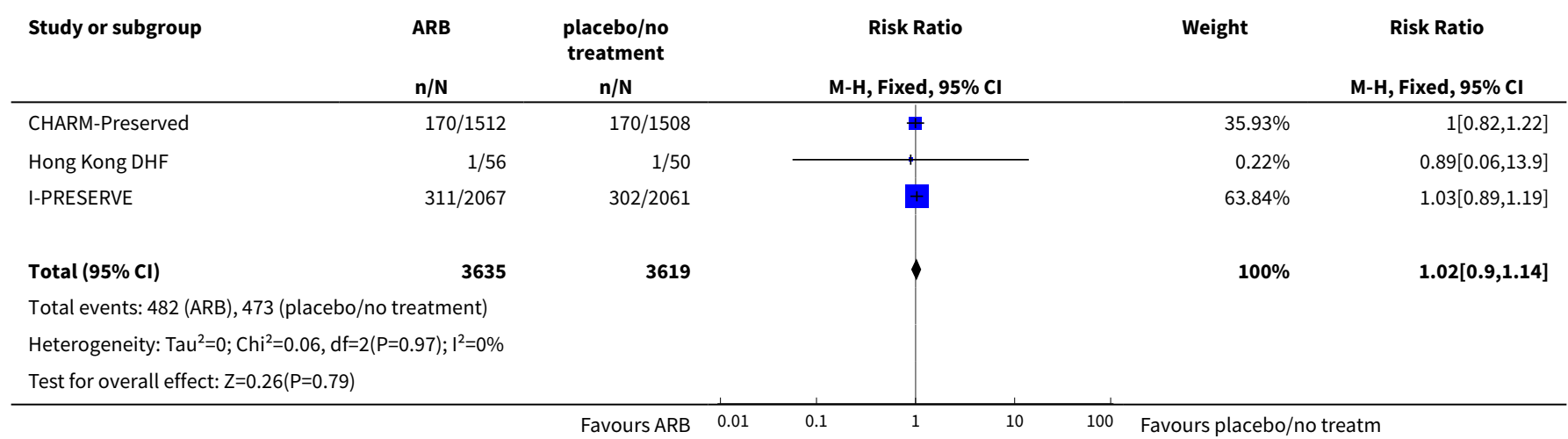

Analysis 4.2. Comparison 4 Angiotensin receptor blockers versus placebo or no treatment, Outcome $\mathbf{2}$ Cardiovascular mortality (HR).

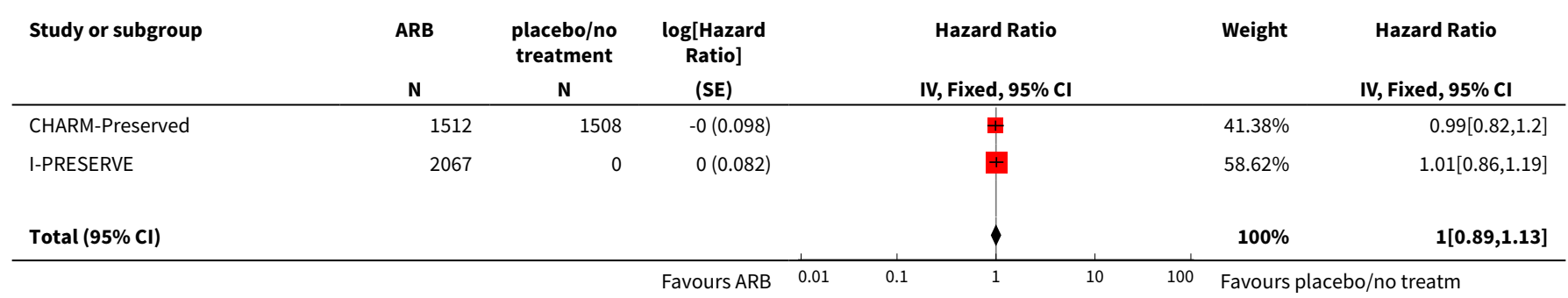




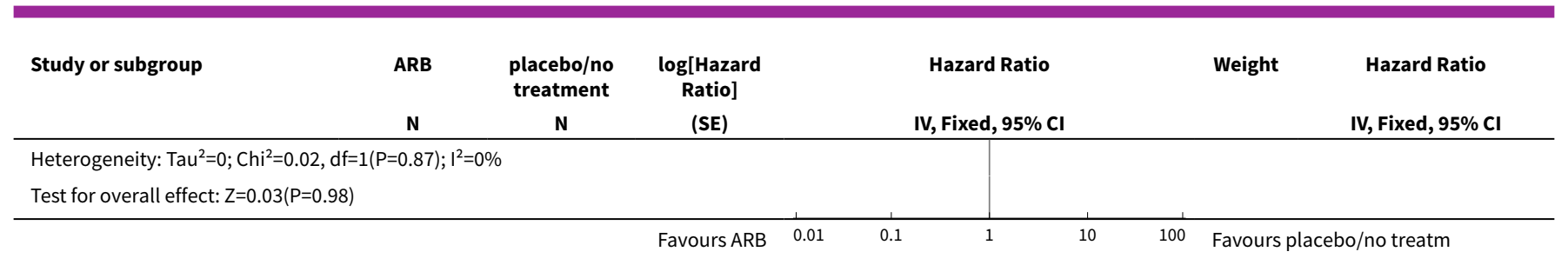

Analysis 4.3. Comparison 4 Angiotensin receptor blockers versus placebo or no treatment, Outcome 3 Heart failure hospitalisation (RR).

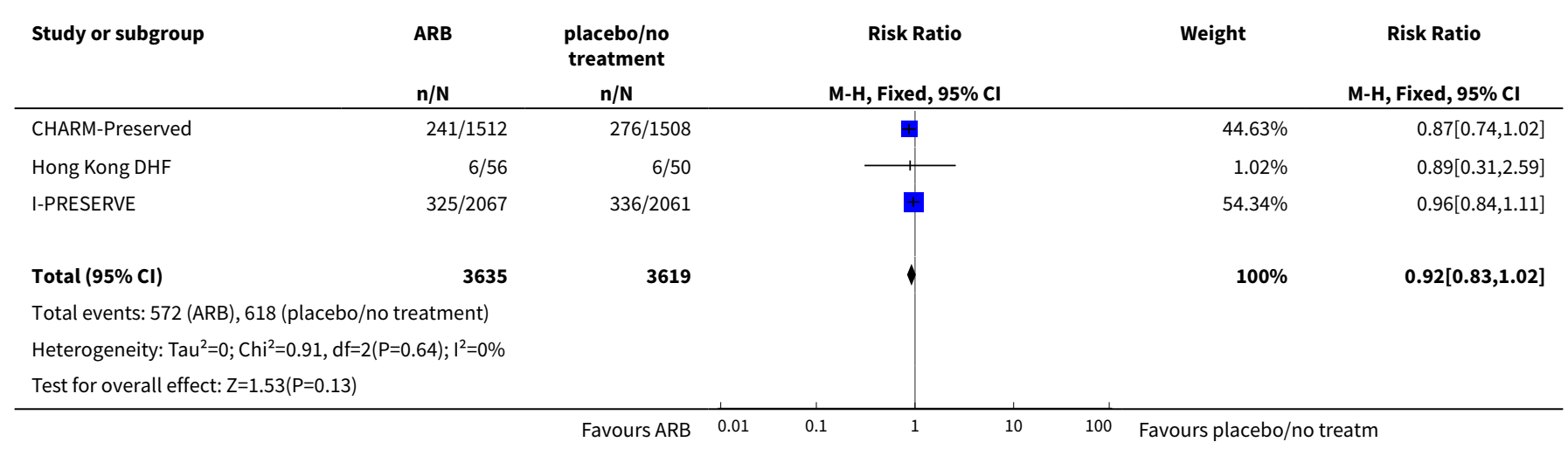

Analysis 4.4. Comparison 4 Angiotensin receptor blockers versus placebo or no treatment, Outcome 4 Heart failure hospitalisation (HR).

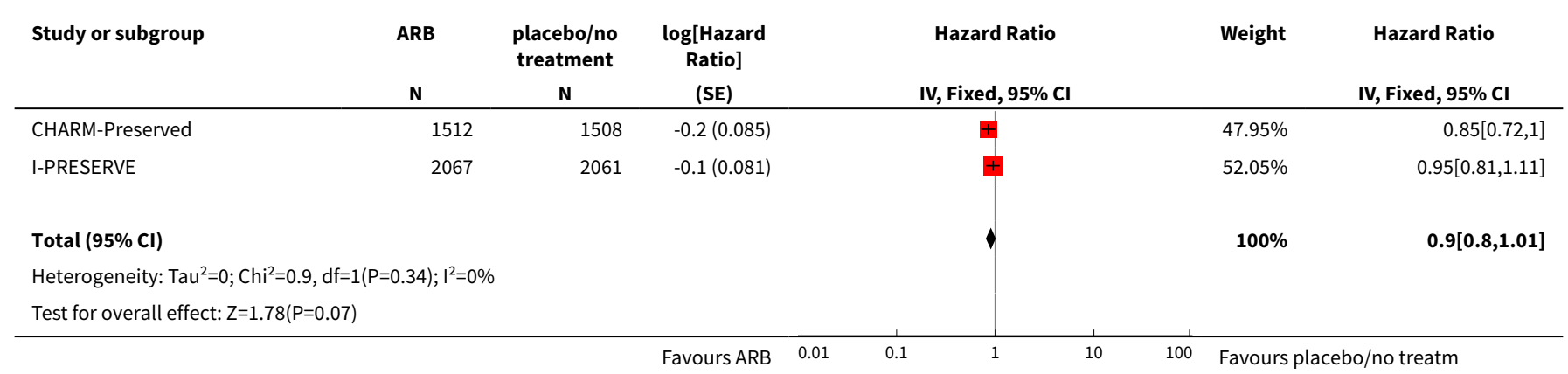

Analysis 4.5. Comparison 4 Angiotensin receptor blockers versus placebo or no treatment, Outcome 5 Hyperkalaemia.

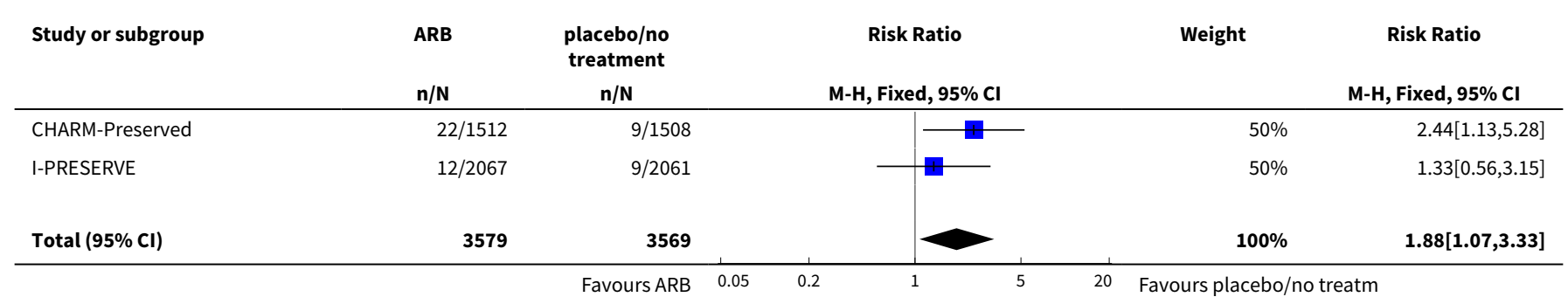




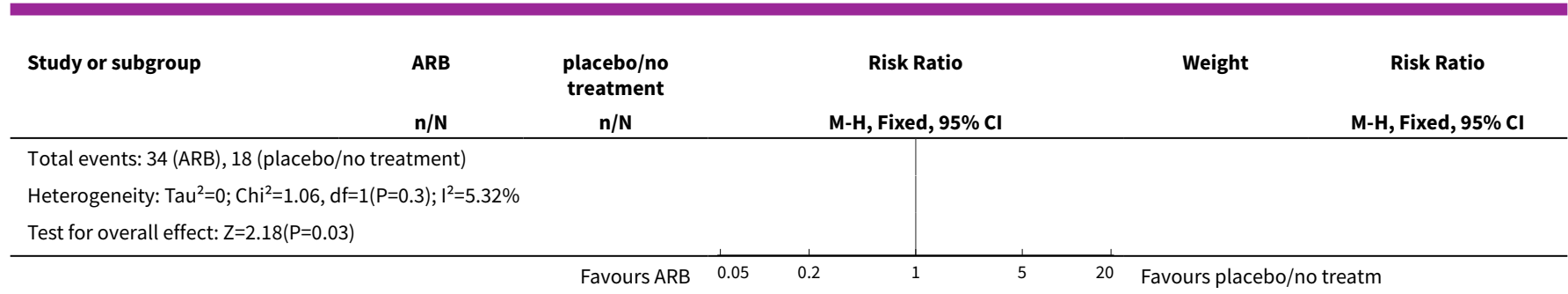

\section{Analysis 4.6. Comparison 4 Angiotensin receptor blockers versus placebo or no treatment, Outcome 6 All-cause mortality (RR).}

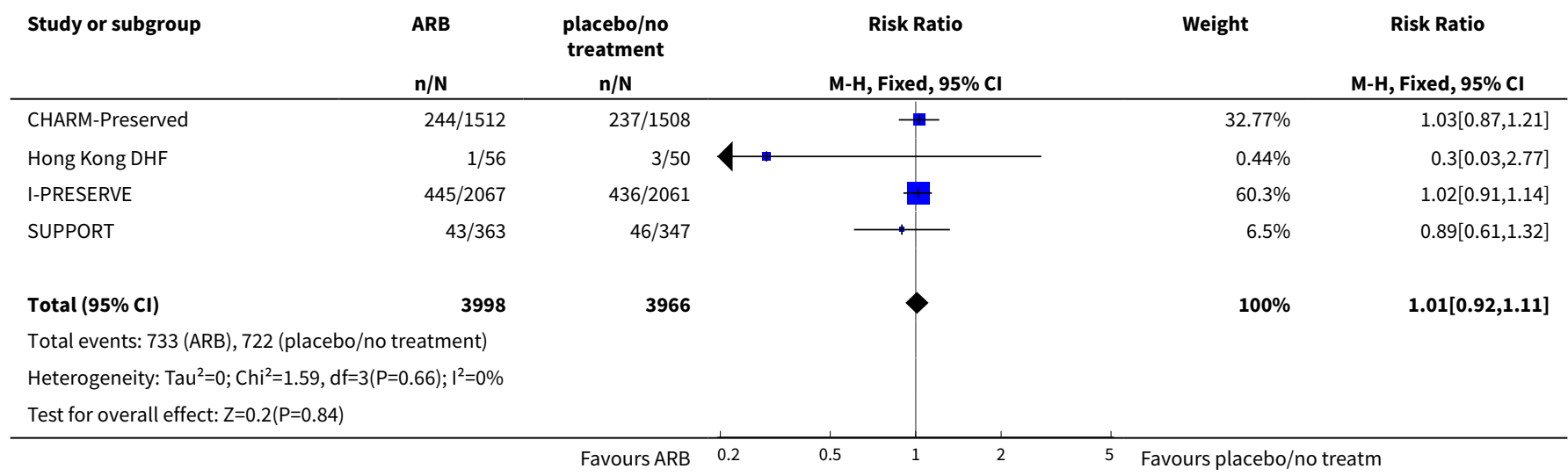

Analysis 4.7. Comparison 4 Angiotensin receptor blockers versus placebo or no treatment, Outcome 7 All-cause mortality (HR).

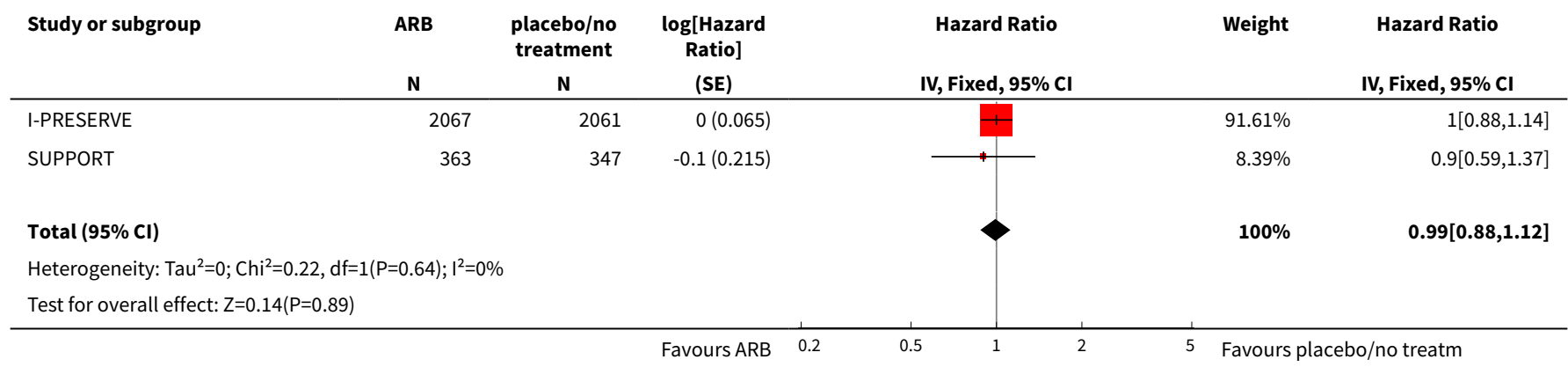

Analysis 4.8. Comparison 4 Angiotensin receptor blockers versus placebo or no treatment, Outcome 8 Quality of life (Minnesota).

\begin{tabular}{|c|c|c|c|c|c|c|c|}
\hline \multirow[t]{2}{*}{ Study or subgroup } & \multicolumn{2}{|c|}{ ARB } & \multicolumn{2}{|c|}{$\begin{array}{c}\text { placebo/no } \\
\text { treatment }\end{array}$} & \multirow{2}{*}{$\begin{array}{c}\text { Mean Difference } \\
\text { Fixed, } 95 \% \mathrm{Cl} \\
\end{array}$} & \multirow[t]{2}{*}{ Weight } & \multirow{2}{*}{$\begin{array}{l}\text { Mean Difference } \\
\text { Fixed, } 95 \% \mathrm{Cl}\end{array}$} \\
\hline & $\mathbf{N}$ & Mean(SD) & $\mathbf{N}$ & Mean(SD) & & & \\
\hline Hong Kong DHF & 56 & $9.4(9.7)$ & 50 & $10.9(9.2)$ & $\longrightarrow$ & $12.32 \%$ & $-1.5[-5.1,2.1]$ \\
\hline I-PRESERVE & 1428 & $32.1(18.9)$ & 1434 & $31.6(18.9)$ & + & $83.27 \%$ & $0.5[-0.89,1.89]$ \\
\hline
\end{tabular}

Beta-blockers and inhibitors of the renin-angiotensin aldosterone system for chronic heart failure with preserved ejection fraction 


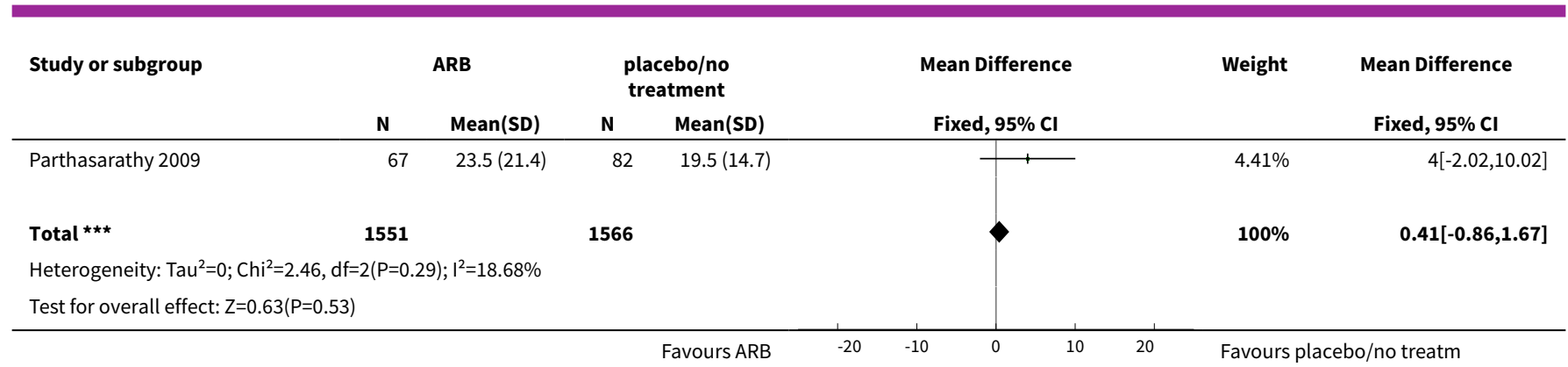

Analysis 4.9. Comparison 4 Angiotensin receptor blockers versus placebo or no treatment, Outcome 9 Withdrawal due to adverse event.

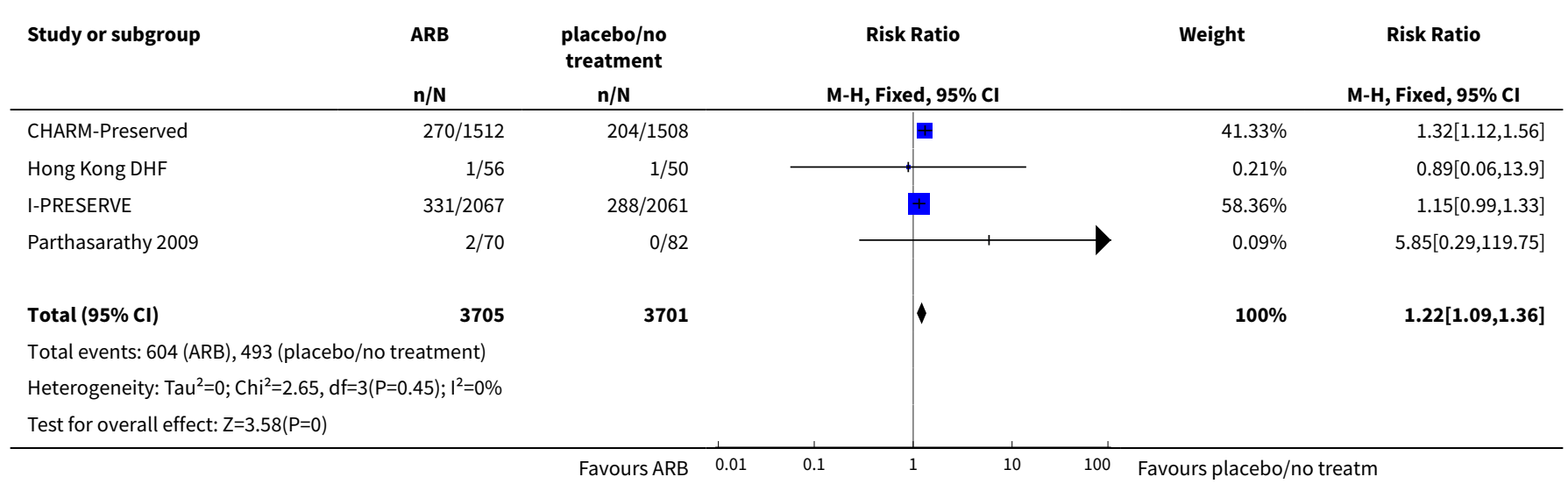

\section{APPENDICES}

\section{Appendix 1. Search strategies}

\section{CENTRAL}

\#1 MeSH descriptor: [Heart Failure] explode all trees

\#2 ((heart or cardia* or myocardial) near/3 (failure or insufficienc ${ }^{*}$ or decompensat $\left.{ }^{\star}\right)$ ):ab,ti,kw

\#3 \#1 or \#2

\#4 MeSH descriptor: [Ventricular Dysfunction] explode all trees

\#5 MeSH descriptor: [Ventricular Function] explode all trees

\#6 ((preserved or normal or greater) near/5 ("ejection fraction" or "EF" or "LVEF")):ab,ti,kw

\#7 ("preserved systolic function" or "normal systolic function" or "HFpEF" or "HF-pEF" or "HFnEF" or "HF-nEF" or "DHF" or diastolic*):ab,ti,kw

\#8 \#4 or \#5 or \#6 or \#7

\#9 \#3 and \#8

\#10 MeSH descriptor: [Adrenergic beta-Antagonists] explode all trees

\#11 (beta near/2 (antagonist* or block ${ }^{\star}$ or receptor $\left.{ }^{\star}\right)$ ):ab,ti,kw

Beta-blockers and inhibitors of the renin-angiotensin aldosterone system for chronic heart failure with preserved ejection fraction 
\#12 (acebutolol or adimolol or afurolol or alprenolol or amosulalol or arotinolol or atenolol or befunolol or betaxolol or bevantolol or bisoprolol or bopindolol or bornaprolol or brefonalol or bucindolol or bucumolol or bufetolol or bufuralol or bunitrolol or bunolol or bupranolol or butofilolol or butoxamine or carazolol or carteolol or carvedilol or celiprolol or cetamolol or chlortalidone or cloranolol or cyanoiodopindolol or cyanopindolol or deacetylmetipranolol or diacetolol or dihydroalprenolol or dilevalol or epanolol or esmolol or exaprolol or falintolol or flestolol or flusoxolol or hydroxybenzylpinodolol or hydroxycarteolol or hydroxy benazepril or indenolol or iodocyanopindolol or iodopindolol or iprocrolol or isoxaprolol or labetalol or landiolol or levobunolol or levomoprolol or medroxalol or mepindolol or methylthiopropranolol or metipranolol or metoprolol or moprolol or nadolol or oxprenolol or penbutolol or pindolol or nadolol or nebivolol or nifenalol or nipradilol or oxprenolol or pafenolol or pamatolol or penbutolol or pindolol or practolol or primidolol or prizidilol or procinolol or pronetalol or propranolol or proxodolol or ridazolol or salcardolol or soquinolol or sotalol or spirendolol or talinolol or tertatolol or tienoxolol or tilisolol or timolol or tolamolol or toliprolol or tribendilol or xibenolol or Betapace or Blocadren or Bystolic or Cartrol or Coreg or Corgard or Inderal or Kerlone or Levatol or Lopressor or Normodyne or Sectral or Tenormin or Toprol or Trandate or Visken or Zebeta):ab,ti,kw

\#13 MeSH descriptor: [Angiotensin-Converting Enzyme Inhibitors] explode all trees

\#14 ((angiotensin ${ }^{\star}$ or dipeptidyl ${ }^{\star}$ or 'kininase ii') near/3 (convert ${ }^{\star}$ or enzyme or inhibit ${ }^{\star}$ or recept ${ }^{\star}$ or block $\left.\left.^{\star}\right)\right): a b, t i, k w$

\#15 (ace near/1 inhibit*):ab,ti,kw

\#16 acei:ab,ti,kw

\#17 (alacepril or altiopril or ancovenin or benazepril* or captopril or ceranapril or ceronapril or cilazapril or deacetylalacepril or delapril or derapril or enalapril* or epicaptopril or fasidotril* or fosinopril or foroxymithine or gemopatrilat or idrapril or ilepatril or imidapril* or indolapril or libenzapril or lisinopril or moexipril ${ }^{\star}$ or omapatrilat or pentopril ${ }^{\star}$ or perindopril ${ }^{\star}$ or pivopril or quinapril* or ramipril* or rentiapril or sampatrilat or saralasin or "s nitrosocaptopril" or spirapril ${ }^{\star}$ or temocapril* or teprotide or trandolapril ${ }^{\star}$ or utibapril* or

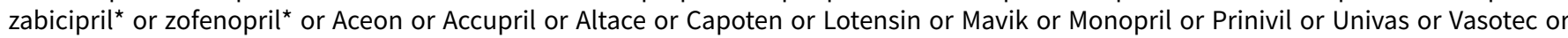
Zestril):ab,ti,kw

\#18 MeSH descriptor: [Angiotensin Receptor Antagonists] explode all trees

\#19 (angiotensin near/3 ('receptor antagonist*' or "receptor block*")):ab,ti,kw

\#20 (arb or arbs):ab,ti,kw

\#21 (abitesartan or azilsartan or candesartan or elisartan or embusartan or eprosartan or fimasartan or fonsartan or forasartan or irbesartan or "KT3-671" or losartan or milfasartan or olmesartan or pomisartan or pratosartan or ripisartan or saprisartan or sparsentan or tasosartan or telmisartan or Losartan or zolasartan or Edarbi or Blopress or Atacand or Amias or Ratacand or Eprozar or Aprovel or Karvea or Avapro or Cozaar or Benicar or Olmecip or Micardis or Diovan):ab,ti,kw

\#22 MeSH descriptor: [Neprilysin] this term only and with qualifier(s): [Antagonists \& inhibitors - Al]

\#23 (neprilysin near/1 (inhibit ${ }^{\star}$ or antagonist $\left.{ }^{\star}\right)$ ):ab,ti,kw

\#24 arni:ab,ti,kw

\#25 (sacubitril or sacubitrilat or lbq657 or "lbq 657" or ahu377 or "ahu 377" or entresto or lcz696 or "lcz 696")

\#26 MeSH descriptor: [Mineralocorticoid Receptor Antagonists] explode all trees

\#27 ((mineralocorticoid or aldosterone) near/3 (antagonist* or block ${ }^{\star}$ or inhibit*)):ab,ti,kw

\#28 ("canrenoic acid" or canrenone or eplerenone or finerenone or "oxprenoate potassium" or spironolactone or aldactone or contaren or inspra or luvion or phanurane or spiroletan):ab,ti,kw

$\# 29\{$ or \#10-\#28\}

\#30 \#9 and \#29

\section{MEDLINE (Ovid)}

1. exp Heart Failure/

2. ((heart or cardia* or myocardial) adj3 (failure or insufficienc ${ }^{\star}$ or decompensat $\left.{ }^{\star}\right)$ ).tw.

3. 1 or 2

4. exp Ventricular Dysfunction/

Beta-blockers and inhibitors of the renin-angiotensin aldosterone system for chronic heart failure with preserved ejection fraction (Review)

Copyright (C) 2018 The Cochrane Collaboration. Published by John Wiley \& Sons, Ltd. 
5. exp Ventricular Function/

6. ((preserved or normal or greater) adj5 (ejection fraction or EF or LVEF)).tw.

7. (preserved systolic function or normal systolic function or HFpEF or HF-pEF or HFnEF or HF-nEF or DHF or diastolic ${ }^{\star}$ ).tw.

8.4 or 5 or 6 or 7

9. 3 and 8

10. exp Adrenergic beta-Antagonists/

11. (beta adj2 (antagonist* or block* or receptor $\left.\left.{ }^{\star}\right)\right) . t w$.

12. (acebutolol or adimolol or afurolol or alprenolol or amosulalol or arotinolol or atenolol or befunolol or betaxolol or bevantolol or bisoprolol or bopindolol or bornaprolol or brefonalol or bucindolol or bucumolol or bufetolol or bufuralol or bunitrolol or bunolol or bupranolol or butofilolol or butoxamine or carazolol or carteolol or carvedilol or celiprolol or cetamolol or chlortalidone or cloranolol or cyanoiodopindolol or cyanopindolol or deacetylmetipranolol or diacetolol or dihydroalprenolol or dilevalol or epanolol or esmolol or exaprolol or falintolol or flestolol or flusoxolol or hydroxybenzylpinodolol or hydroxycarteolol or hydroxymetoprolol or indenolol or iodocyanopindolol or iodopindolol or iprocrolol or isoxaprolol or labetalol or landiolol or levobunolol or levomoprolol or medroxalol or mepindolol or methylthiopropranolol or metipranolol or metoprolol or moprolol or nadolol or oxprenolol or penbutolol or pindolol or nadolol or nebivolol or nifenalol or nipradilol or oxprenolol or pafenolol or pamatolol or penbutolol or pindolol or practolol or primidolol or prizidilol or procinolol or pronetalol or propranolol or proxodolol or ridazolol or salcardolol or soquinolol or sotalol or spirendolol or talinolol or tertatolol or tienoxolol or tilisolol or timolol or tolamolol or toliprolol or tribendilol or xibenolol or Betapace or Blocadren or Bystolic or Cartrol or Coreg or Corgard or Inderal or Kerlone or Levatol or Lopressor or Normodyne or Sectral or Tenormin or Toprol or Trandate or Visken or Zebeta).mp.

13. exp Angiotensin-Converting Enzyme Inhibitors/

14. ((angiotensin ${ }^{\star}$ or dipeptidyl* or kininase ii) adj3 (convert* or enzyme or inhibit* or recept* or block $\left.{ }^{\star}\right)$ ).tw.

15. (ace adj inhibit*).tw.

16. acei.tw.

17. (alacepril or altiopril or ancovenin or benazepril* or captopril or ceranapril or ceronapril or cilazapril or deacetylalacepril or delapril or derapril or enalapril* or epicaptopril or fasidotril* or fosinopril or foroxymithine or gemopatrilat or idrapril or ilepatril or imidapril ${ }^{\star}$ or indolapril or libenzapril or lisinopril or moexipril ${ }^{\star}$ or omapatrilat or pentopril* or perindopril* or pivopril or quinapril* or ramipril ${ }^{\star}$ or rentiapril or sampatrilat or saralasin or s nitrosocaptopril or spirapril* or temocap ril ${ }^{\star}$ or teprotide or trandolapril* or utibapril* or zabicipril* or zofenopril* or Aceon or Accupril or Altace or Capoten or Lotensin or Mavik or Monopril or Prinivil or Univas or Vasotec or Zestril).mp.

\section{8. exp Angiotensin Receptor Antagonists/}

19. (angiotensin adj3 (receptor antagonist* or receptor block $\left.^{\star}\right)$ ).tw.

20. (arb or arbs).tw.

21. (abitesartan or azilsartan or candesartan or elisartan or embusartan or eprosartan or fimasartan or fonsartan or forasartan or irbesartan or KT3-671 or losartan or milfasartan or olmesartan or pomisartan or pratosartan or ripisartan or saprisartan or sparsentan or tasosartan or telmisartan or valsartan or zolasartan or Edarbi or Blopress or Atacand or Amias or Ratacand or Eprozar or Aprovel or Karvea or Avapro or Cozaar or Benicar or Olmecip or Micardis or Diovan).mp.

22. Neprilysin/ai [Antagonists \& Inhibitors]

23. (neprilysin adj (inhibit* or antagonist*)).tw.

24. arni.tw.

25. (Sacubitril or "ahu 377" or ahu377 or Sacubitrilat or lbq657 or "lbq 657" or ahu377 or "ahu 377" or Entresto or lcz696 or "lcz 696 ").mp.

26. exp Mineralocorticoid Receptor Antagonists/

27. ((mineralocorticoid or aldosterone) adj3 (antagonist* or block ${ }^{\star}$ or inhibit $\left.\left.{ }^{\star}\right)\right)$.tw.

28. (canrenoic acid or canrenone or eplerenone or finerenone or oxprenoate potassium or spironolactone or Aldactone or Contaren or Inspra or Luvion or Phanurane or Spiroletan).mp.

Beta-blockers and inhibitors of the renin-angiotensin aldosterone system for chronic heart failure with preserved ejection fraction 
29. or $/ 10-28$

30.9 and 29

31. randomized controlled trial.pt.

32. controlled clinical trial.pt.

33. randomized.ab.

34. placebo.ab.

35. drug therapy.fs.

36. randomly.ab.

37. trial.ab.

38. groups.ab.

39.31 or 32 or 33 or 34 or 35 or 36 or 37 or 38

40. exp animals/ not humans.sh.

41.39 not 40

42. 30 and 41

\section{Embase}

\#33 \#31 AND \#32

\#32 random*:ab,ti OR placebo* OR ((double NEXT/1 blind*):ab,ti)

\#31 \#10 AND \#30

\#30 \#11 OR \#12 OR \#13 OR \#14 OR \#15 OR \#16 OR \#17 OR \#18 OR \#19 OR \#20 OR \#21 OR \#22 OR \#23 OR \#24 OR \#25 OR \#26 OR \#27 OR \#280R \#29

\#29 'canrenoic acid' OR canrenone OR eplerenone OR finerenone OR 'oxprenoate potassium' OR spironolactone OR aldactone OR contaren OR inspra OR luvion OR phanurane OR spiroletan

\#28 ((mineralocorticoid OR aldosterone) NEAR/3 (antagonist* OR block OR inhibit $\left.{ }^{\star}\right)$ ):ab,ti

\#27 'mineralocorticoid antagonist'/exp

\#26 sacubitril OR sacubitrilat OR Ibq657 OR 'Ibq 657' OR 'ahu377' OR 'ahu 377' OR entresto OR Icz696 OR 'Icz 696'

\#25 arni:ab,ti

\#24 (neprilysin NEAR/1 (inhibit* OR antagonist*)):ab,ti

\#23 'enkephalinase inhibitor'/exp

\#22 abitesartan OR azilsartan OR candesartan OR elisartan OR embusartan OR eprosartan OR fimasartan OR fonsartan OR forasartanOR irbesartan OR 'kt3-671' OR losartan OR milfasartan OR olmesartan OR pomisartan OR pratosartan OR ripisartan OR saprisartanOR sparsentan OR tasosartan OR telmisartan OR valsartan OR zolasartan OR edarbi OR blopress OR atacand OR amias OR ratacandOR eprozar OR aprovel OR karvea OR avapro OR cozaar OR benicar OR olmecip OR micardis OR diovan

\#21 arb:ab,ti OR arbs:ab,ti

\#20 (angiotensin NEAR/3 ('receptor antagonist*' OR 'receptor block $\left.{ }^{\star \prime}\right)$ ):ab,ti

\#19 'angiotensin receptor antagonist'/exp

\#18 alacepril OR altiopril OR ancovenin OR benazepril* OR captopril OR ceranapril OR ceronapril OR cilazapril OR deacetylalacepril OR delapril OR derapril OR enalapril* OR epicaptopril OR fasidotril ${ }^{\star}$ OR fosinopril OR foroxymithine OR gemopatrilat OR idrapril OR ilepatril OR imidapril $^{\star}$ OR indolapril OR libenzapril OR lisinopril OR moexipril ${ }^{\star}$ OR omapatrilat OR pentopril ${ }^{\star}$ OR perindopril ${ }^{\star}$ OR pivopril OR quinapril ${ }^{\star}$ OR ramipril* OR rentiapril OR sampatrilat OR saralasin OR 's nitrosocaptopril' OR spirapril* OR temocapril*OR teprotide OR trandolapril ${ }^{\star}$ OR utibapril* OR zabicipril* OR zofenopril* OR aceon OR accupril OR altace OR capoten OR lotensinOR mavik OR monopril OR prinivil OR univas $O R$ vasotec $O R$ zestril

\#17 acei:ab,ti

\#16 (ace NEAR/1 inhibit*):ab,ti

\#15 ((angiotensin* OR dipeptidyl* OR 'kininase ii') NEAR/3 (convert* OR enzyme OR inhibit* OR recept* OR block $\left.\left.{ }^{\star}\right)\right):$ ab,ti

\#14 'dipeptidyl carboxypeptidase inhibitor'/exp

\#13 acebutolol OR adimolol OR afurolol OR alprenolol OR amosulalol OR arotinolol OR atenolol OR befunolol OR betaxolol OR bevantololOR bisoprolol OR bopindolol OR bornaprolol OR brefonalol OR bucindolol OR bucumolol OR bufetolol OR bufuralol OR bunitrolol OR bunolol OR bupranolol OR butofilolol OR butoxamine OR carazolol OR carteolol OR carvedilol OR celiprolol OR cetamolol OR chlortalidone OR cloranolol OR cyanoiodopindolol OR cyanopindolol OR deacetylmetipranolol OR diacetolol OR dihydroalprenololOR dilevalol OR epanolol OR esmolol OR exaprolol OR falintolol OR flestolol OR flusoxolol OR hydroxybenzylpinodolol OR hydroxycarteolol

Beta-blockers and inhibitors of the renin-angiotensin aldosterone system for chronic heart failure with preserved ejection fraction 
OR hydroxymetoprolol OR indenolol OR iodocyanopindolol OR iodopindolol OR iprocrolol OR isoxaprolol OR labetalol OR landiolol OR levobunolol OR levomoprolol OR medroxalol OR mepindolol OR methylthiopropranolol OR metipranololOR metoprolol OR moprolol OR nadolol OR nebivolol OR nifenalol OR nipradilol OR oxprenolol OR pafenolol OR pamatolol OR penbutolol OR pindolol OR practolol OR primidolol OR prizidilol OR procinolol OR pronetalol OR propranolol OR proxodolol OR ridazolol OR salcardolol OR soquinolol OR sotalol OR spirendolol OR talinolol OR tertatolol OR tienoxolol OR tilisolol OR timolol OR tolamolol OR toliprolol OR tribendilol OR xibenolol OR betapace OR blocadren OR bystolic OR cartrol OR coreg OR corgard OR inderal OR kerlone OR levatol OR lopressor OR normodyne OR sectral OR tenormin OR toprol OR trandate OR visken OR zebeta

\#12 (beta NEAR/2 (antagonist* OR block* OR receptor ${ }^{\star}$ )):ab,ti

$\# 11$ 'beta adrenergic receptor blocking agent'/exp

\#10 \#3 AND \#9

\#9 \#4 OR \#5 OR \#6 OR \#7 OR \#8

\#8 'preserved systolic function':ab,ti OR 'normal systolic function':ab,ti OR hfpef:ab,ti OR 'hf-pef':ab,ti OR hfnef:ab,ti OR 'hf-nef':ab,ti OR dhf:ab,ti OR diastolic $:$ ab,ti

\#7 ((preserved OR normal OR greater) NEAR/5 ('ejection fraction' OR ef OR lvef)):ab,ti

\#6 'systolic dysfunction'/exp

\#5 'diastolic dysfunction'/exp

\#4 'heart ventricle function'/de

\#3 \#1 OR \#2

\#2 ((heart OR cardia* OR myocardial) NEAR/3 (failure OR insufficienc* OR decompensat $\left.{ }^{\star}\right)$ ):ab,ti

\#1 'heart failure'/exp

\section{ClinicalTrials.gov}

Advanced Search--Limited to study type: interventional studies

("heart failure" AND ("preserved ejection fraction" OR "normal ejection fraction" OR "preserved systolic function" OR "normal systolic function")) OR "diastolic heart failure" OR "HFpEF" OR "HF-pEF" OR "HFnEF" OR "HF-nEF" OR "DHF"

\section{WHO International Clinical Trials Registry Platform (ICTRP) Search Portal}

Standard Search

heart failure AND preserved ejection fraction OR heart failure AND normal ejection fraction OR

heart failure AND preserved systolic function OR heart failure AND normal systolic function OR

diastolic heart failure OR HFpEF OR HF-pEF OR HFnEF OR HF-nEF OR DHF

\section{CONTRIBUTIONS OF AUTHORS}

NM: selection of studies, data extraction, analysis, GRADE assessment, co-wrote the manuscript.

KM: selection of studies, GRADE assessment.

JT: contributed to review design, approved the final version.

CD: contributed to review design, GRADE assessment, approved the final version.

TL: guarantor of review, designed the review, data extraction, analysis, GRADE assessment, co-wrote the manuscript.

\section{DECLARATIONS OF INTEREST}

NM: none known.

KM: none known.

JT: none known.

CD: has received sponsorship from Servier, Roche and Novartis to attend cardiology conferences, payment from GE Healthcare to give lectures on heart failure, and has served as a paid consultant to Servier and Vifor.

TL: has received research grants from Pfizer and has served as an unpaid consultant to GSK. 


\section{SOURCES OF SUPPORT}

\section{Internal sources}

- R Thomas Lumbers, UK.

NIHR Academic Clinical Lectureship

\section{External sources}

- This project was supported by the National Institute for Health Research via Cochrane Infrastructure and NIHR Incentive funding to Cochrane Heart. The views and opinions expressed therein are those of the authors and do not necessarily reflect those of the Systematic Reviews Programme, NIHR, NHS or the Department of Health, UK.

\section{DIFFERENCES BETWEEN PROTOCOLAND REVIEW}

We originally planned to include participants with LVEF $\geq 40 \%$ but changed this to LVEF $>40 \%$, since this is a more frequently used cutoff in clinical trials.

We originally limited our population to symptomatic heart failure (NYHA class > I) at enrolment; however, this criterion was removed to include people with diagnosis of heart failure in whom symptoms had improved the functional class.

We added a clarification regarding the exclusion of cross-over trials.

We originally planned to include withdrawals due to adverse events in the 'Summary of findings' table. This was changed because this outcome was frequently reported inconsistently, which limits the applicability of a pooled analysis. Instead, we added hyperkalaemia to the 'Summary of findings' table because this adverse event outcome has relevance for clinical decision making. For the same reason, hyperkalaemia was switched from secondary to primary outcomes and withdrawals due to adverse events was switched from primary to secondary outcomes.

We did not pre specify which scale for quality of life we would focus on in the 'Summary of findings' table. To aid comparisons across the 'Summary of findings' tables we chose to include the Minnsota Living with Heart Failure Questionnaire and not the standardised mean difference across two scales which applied only to MRA versus placebo or no treatment comparison.

\section{IN DEX TERMS}

\section{Medical Subject Headings (MeSH)}

*Stroke Volume; Adrenergic beta-Antagonists [*therapeutic use]; Angiotensin Receptor Antagonists [ ${ }^{\star}$ therapeutic use]; AngiotensinConverting Enzyme Inhibitors [ ${ }^{\star}$ therapeutic use]; Chronic Disease; Heart Failure [ ${ }^{\star}$ drug therapy] [mortality]; Hospitalization; Mineralocorticoid Receptor Antagonists [*therapeutic use]; Neprilysin [antagonists \& inhibitors]; Quality of Life; Randomized Controlled Trials as Topic; Renin-Angiotensin System [ ${ }^{\star}$ drug effects]

\section{MeSH check words}

Humans 